\title{
The Use of Concept MappingPattern Matching to Conceptualize the Desired Domain of Student Learning in the First Year of College
}

Jacob B. Sanwidi

Follow this and additional works at: https://researchrepository.wvu.edu/etd

\section{Recommended Citation}

Sanwidi, Jacob B., "The Use of Concept MappingPattern Matching to Conceptualize the Desired Domain of Student Learning in the First Year of College" (2015). Graduate Theses, Dissertations, and Problem Reports. 6568.

https://researchrepository.wvu.edu/etd/6568

This Dissertation is protected by copyright and/or related rights. It has been brought to you by the The Research Repository @ WVU with permission from the rights-holder(s). You are free to use this Dissertation in any way that is permitted by the copyright and related rights legislation that applies to your use. For other uses you must obtain permission from the rights-holder(s) directly, unless additional rights are indicated by a Creative Commons license in the record and/ or on the work itself. This Dissertation has been accepted for inclusion in WVU Graduate Theses, Dissertations, and Problem Reports collection by an authorized administrator of The Research Repository @ WVU.

For more information, please contact researchrepository@mail.wvu.edu. 
The Use of Concept Mapping/Pattern Matching to

Conceptualize the Desired Domain of Student Learning in the First Year of College

Jacob B. Sanwidi

Dissertation submitted to the College of Education and Human Services

at West Virginia University

in partial fulfillment of the requirements

for the degree of

Doctor of Education

in

Higher Education Administration

Elizabeth A. Dooley, Ed.D., Chair

Sebastián R. Díaz, Ph.D., J.D.

Bernadette M.E. Jungblut, Ph.D.

Ann M. Richards, Ph.D.

Nathan M. Sorber, Ph.D.

Department of Curriculum and Instruction/Literacy Studies

Morgantown, West Virginia

2015

Keywords: Assessment, Concept Mapping, First-Year Experience, First-Year Interventions, First-Year Seminar, Foundational Dimensions, Foundations of Excellence, Pattern Matching, Student Learning, Student Outcomes, Student Success, Undecided Students

Copyright 2015 Jacob B. Sanwidi 


\begin{abstract}
The Use of Concept Mapping/Pattern Matching to

Conceptualize the Desired Domain of Student Learning in the First Year of College
\end{abstract}

Jacob B. Sanwidi

This study conceptualized the desired domain of student learning in the first year of college as it pertains to a success program serving first-time, full-time undecided students at a land-grant and high research activity classified university. Trochim's Concept Mapping/Pattern Matching approach, an exploratory mixed methods research methodology, was used to collect and analyze data. The researcher sought the contribution of 23 participants including sixteen students, and seven faculty and staff members involved in the success program. As a group, participants generated 100 statements representing desired learning outcomes. They individually sorted the items into groups and rated them for relative importance and institutional efficacy.

Multidimensional Scaling and Hierarchical Cluster Analysis were conducted to create various concept maps, the final one being a six-cluster concept map, representing the stakeholders' conceptualization of the domain being studied. The findings revealed the highest rated clusters for outcome importance - Independence and Academic Identity — and for institutional efficacyHelp/Resource Seeking and Interdependence. The faculty/staff group rated all clusters higher in terms of importance, compared to students. Both groups agreed on which clusters were the most and the least important. Regarding university efficacy, students rated all clusters higher than the faculty/staff group. The findings were also explored through document analysis and it was determined that they align with nationally established aspirational principles of excellence in the first year. The value of this study is that the findings can be translated into a valuable set of activities, strategies, and intervention areas that can be used to enhance student success. 


\section{Dedication}

I dedicate this dissertation to my loving wife Josephine and my sons Melchior and Yannis for their unwavering support, love, understanding, and patience. You are my inspiration and motivation. Additionally, I dedicate this dissertation to my parents Elisabeth Sawadogo and Alphonse Sanwidi for their love and continued support. I also dedicate this work to my sister Colette and her husband Guillaume Sanou, my bothers Martin and Blaise, as well as my cousins Norbert, Barnabé, and Florence. 


\section{Acknowledgments}

I would like to thank God for being my light and guide and for giving me the strength, motivation, and inspiration to achieve what I have done so far in my life.

I would like to express my deepest gratitude to Dr. Elizabeth A. Dooley, my advisor, for believing in me and for giving me hope when I was about to start my doctoral program. I will always remember how she made me feel the first time I met with her to discuss my educational and personal plans. I am grateful to her for giving me the opportunity to work with her and to gain first-hand experience in higher education administration. I would also like to thank her for her guidance and continued support during my coursework and during the research process that led to this dissertation.

I am deeply grateful to Dr. Sebastián R. Díaz for being my professor and for graciously agreeing to serve on my committee. He is the one who introduced me to the Concept Mapping/Pattern Matching methodology that was utilized in this study. I really appreciate the guidance, effort, and precious time he took away from his work and family to support me in my research endeavor. I would not have been able to do it without his guidance and unwavering support.

I would like to thank Dr. Bernadette M.E. Jungblut, for agreeing to be a member of my committee despite her very busy schedule and, especially, despite the timing of my request for her to serve on the committee. Our insightful discussions at the early stages of my dissertation helped me determine the focus of my research. Her continued support and feedback throughout the research process was very helpful. I enjoy working with her and am very grateful for this opportunity.

I would also like to thank Dr. Ann Richards for serving on my dissertation committee. I really appreciate her timely and helpful feedback. I would also like to thank her for bringing in her expertise as a faculty member as well as an administrator in higher education.

I am grateful to Dr. Nathan Sorber, for also graciously agreeing to serve on my dissertation committee. I would like to thank him for his time, support, constructive comments, and for sharing his expertise as a faculty member and his experience in higher education leadership.

I must also acknowledge the 23 participants who accepted the invitation to participate in the study. It was a lengthy and tedious process and I am so grateful to them for their time and patience. Without them, this study would not have been conducted.

My sincere appreciation is extended to Drs. Paul Chapman and Johan Seynnaeve for temporarily serving on my committee until they had to devote their time to other commitments. Their time, guidance, and feedback have been greatly appreciated. I am grateful to Drs. Ernest Goeres and Elizabeth Jones for accepting me in the doctoral program and for their expertise and guidance during my journey as a student in the College of Education and Human Services. 
I would also like to thank my doctoral cohort colleagues and friends for their friendship and support: Mr. Brad Cox, Drs. Daniel Filer, Aaron Huffman, Jeff Terpstra, and Carrie White.

I would like to acknowledge my colleagues Professor Robin Jones, Mses. Rhonda Black, Joyce Wang, and Ashley Watts, with all of whom I enjoy working, for their continued support during my research process. Special thanks to Ms. Ashley Watts for brilliantly serving as the facilitator for the brainstorming session of the study conducted for this dissertation.

I am deeply grateful to Mrs. Madeleine Viviani for her continued support and guidance throughout the years. Since I started my first job in Ouagadougou in 2002, I have had the pleasure to work with someone who is always there to support me in my personal, professional, and educational endeavors. With her, I am always assured that I will get the most honest and invaluable response to my questions. I thank her for her support to me, my family and friends and especially for serving as an external observer who took the time to read, edit, and provide constructive and extensive feedback regarding my dissertation.

I am also thankful to the following people who supported me when I decided to start this chapter of my life in the United States. I thank Dr. Aralene Callahan for her friendship, guidance, and support. I would not have been able to do it without her support. I am also grateful to Dr. Janice Spleth who graciously guided me in the application process when I was applying to become a student at West Virginia University. I also thank Dr. Victor Wallen (Papa Tano) for his continued support and encouragements since we first met at the Bamako International Airport in 2001.

I am also thankful to my former professors at the University of Ouagadougou, Cheikh Anta Diop University in Dakar, Senghor University in Alexandria, and West Virginia University for contributing to my education. My sincere thanks go to Professors Amadou Bissiri, Mamadou Diallo, Donat Hien, Moses Kambou, Alfred Kiéma, Bakary Konaté, Pierre Kouraogo, Amadou Ouédraogo, Paul Rouamba, Hyacinthe Sanwidi, Samuel Sanwidi, Mahamadou Sawadogo, Lalbila Aristide Yoda, and Jean Zida. Special thanks go to the late Professor Jean-Pierre Guingané with whom I had the pleasure to work for over five years at Espace Culturel Gambidi/Théâtre de la Fraternité in Ouagadougou before coming to West Virginia University.

None of what I have done would have been possible without the love and support of my family and friends. My sincere thanks go to Mr. Moussa Berthe, Mr. Charles Kietega, Mrs. Hortense Kietega Guiatin, Dr. Bagnini Kohoun, Mrs. Edwige Kondombo, Mr. Patoimbasba Nikiema, Mr. Albert Moyenga, Mr. Boukary Albert Moyenga, Mr. Hyacinthe Rouamba, Mrs. Nathalie Rouamba, Dr. Boukary Sawadogo, Mr. Moussa Sawadogo, Mr. Teewende Sandwidi, Mrs. Monique Sandwidi Oubda, Mrs. Lucie Soubeiga, Mr. Augustin Tougma, Mr. Hubert Tougouma, Mr. Benjamin Tougma, Mr. Dominique Tougma and all my friends and classmates from Baskouré.

Finally, I appreciate the doctoral student research support from the College of Education and Human Services that partially funded the research discussed in this study. 
Table of Contents

Table of Contents vi

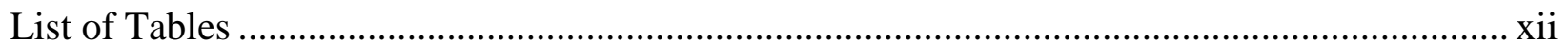

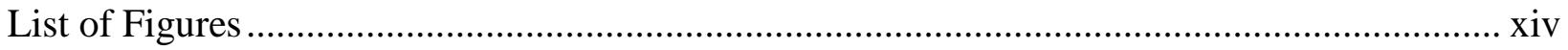

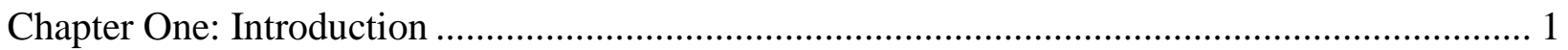

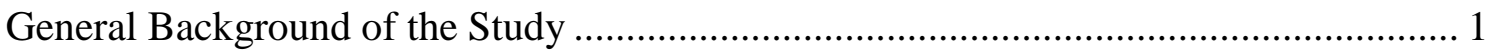

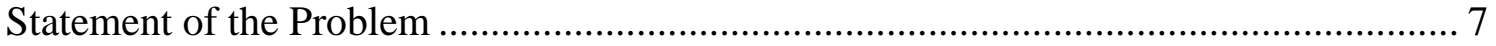

Purpose of the Study and Research Questions ...................................................... 9

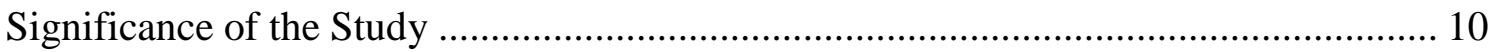

Definition of Key Terms and Concepts.............................................................. 12

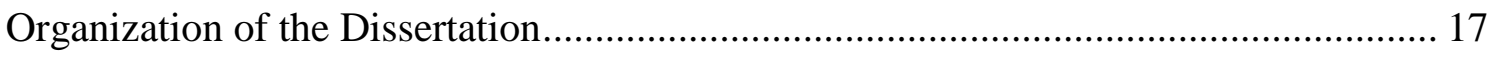

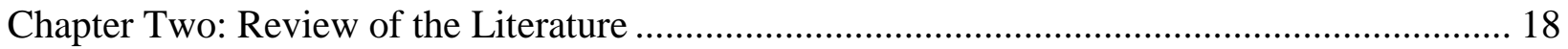

Theoretical Perspectives and Models on College Student Success............................. 18

Astin's Contribution to Theory on College Student Success............................. 19

Tinto's Contribution to Theory on College Student Success............................. 21

Pascarella's General Model for Assessing Change. .......................................... 24

Other Theories on College Student Success.................................................. 25

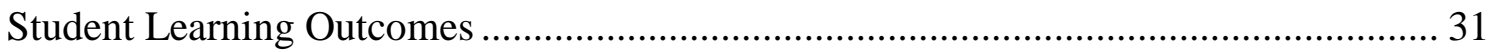

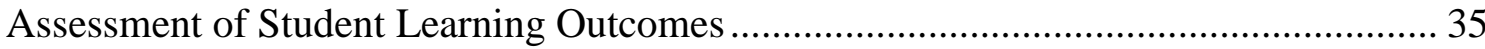

First-Year Intervention Best Practices ................................................................ 36

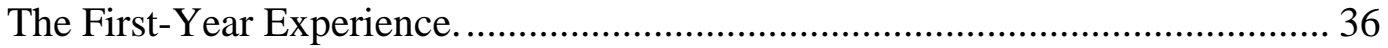

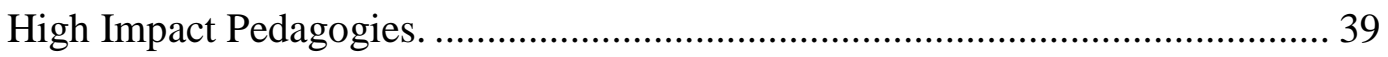

Summer Bridge Programs................................................................... 40

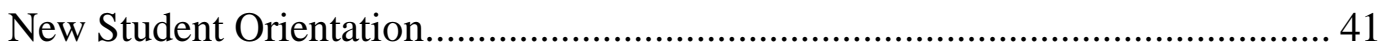


Academic Advising Approaches and Strategies. ........................................... 42

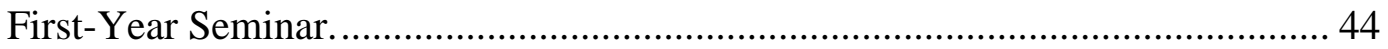

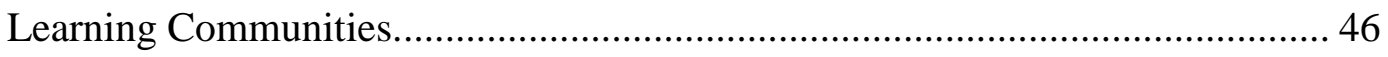

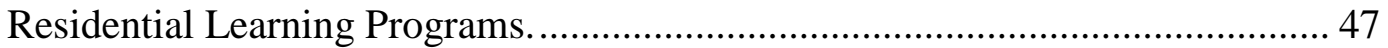

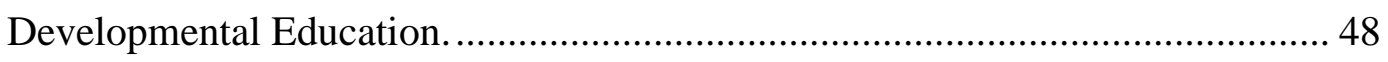

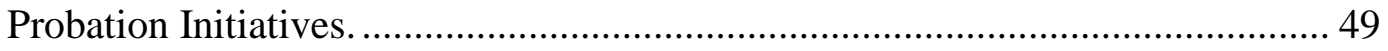

Peer Leadership.................................................................................. 50

Second Year Transitions. ....................................................................... 51

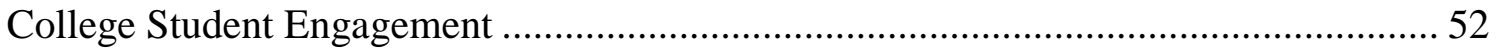

Data Driven Decision Making and Accountability ................................................. 56

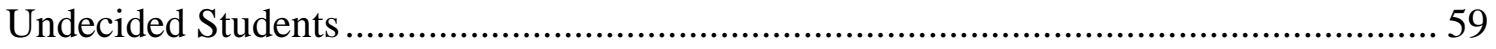

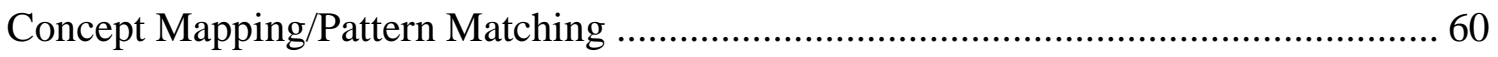

Established Conceptual Framework-Foundational Dimensions .............................. 66

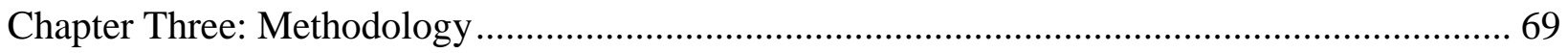

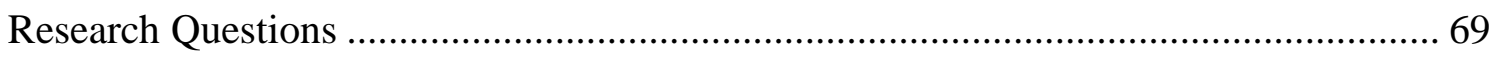

The Concept Mapping/Pattern Matching Methodology …...................................... 70

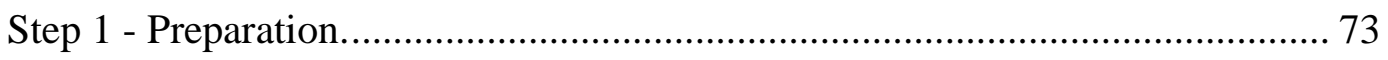

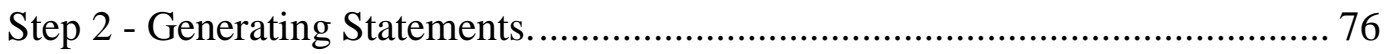

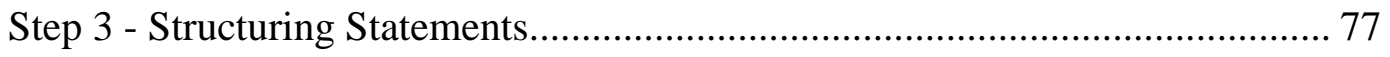

Step 4 - Representation of Statements. ....................................................... 78

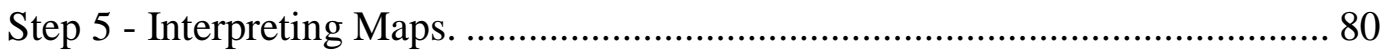

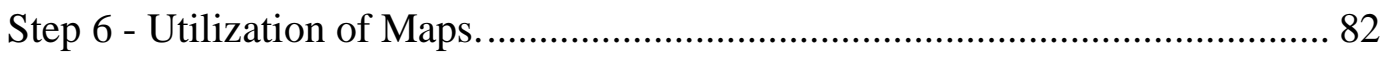

Participants.............................................................. 84 


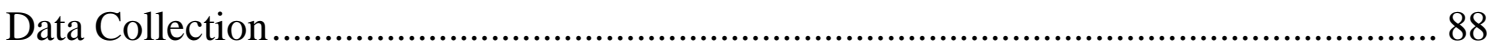

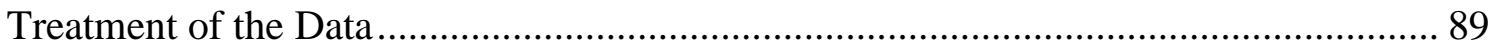

Limitations in the Methodology ……………………............................................... 90

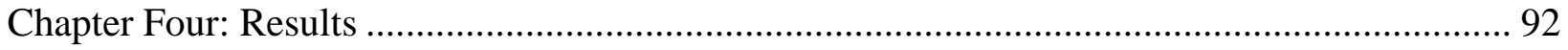

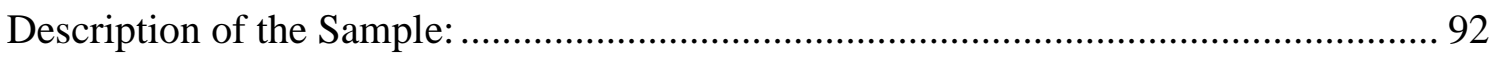

Results of the Concept Mapping/Pattern Matching Process ........................................... 94

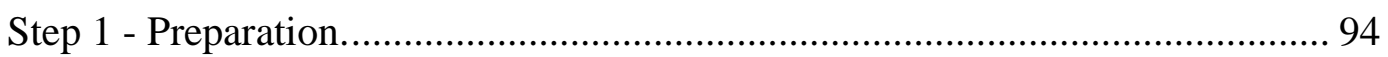

Step 2 - Generating Statements...................................................................... 96

Step 3 - Structuring the Statements...................................................................... 97

Analysis of the Concept Mapping/Pattern Matching Results ......................................... 99

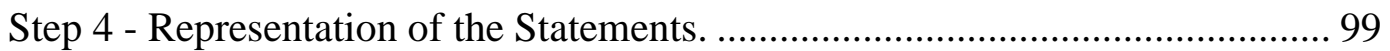

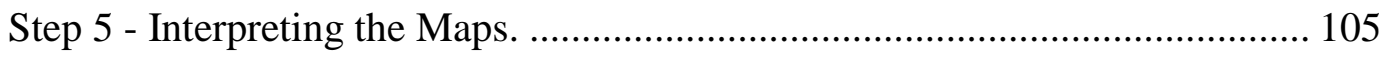

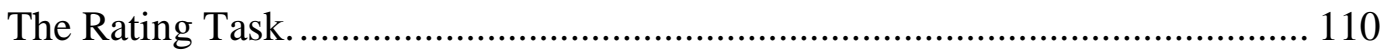

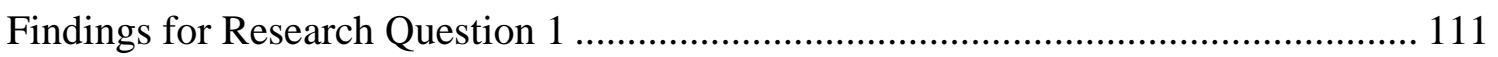

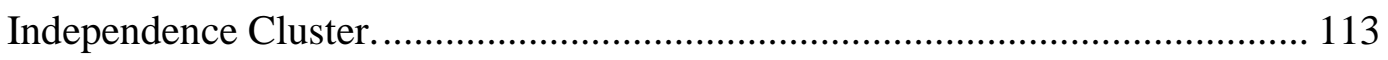

Engaging with the Environment Cluster......................................................... 115

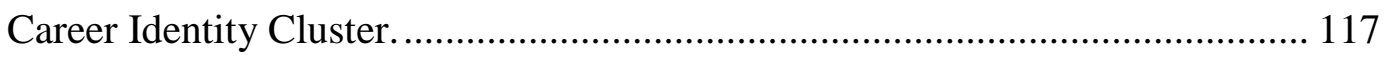

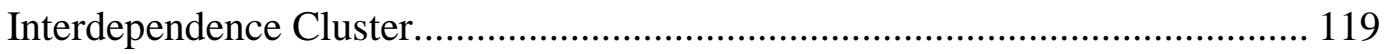

Help/Resource Seeking Cluster. ………....................................................... 120

Academic Identity Cluster. …………………………............................... 122

Findings for Research Question 1.a. ................................................................... 126

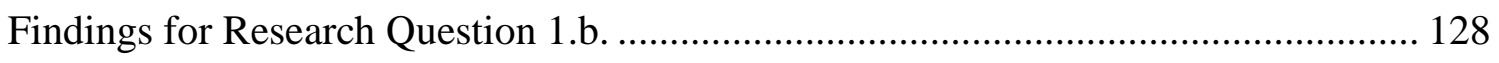

Findings for Research Question 2 ........................................................................ 130 


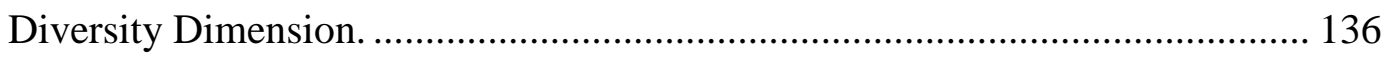

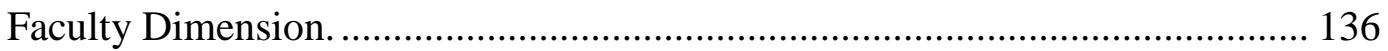

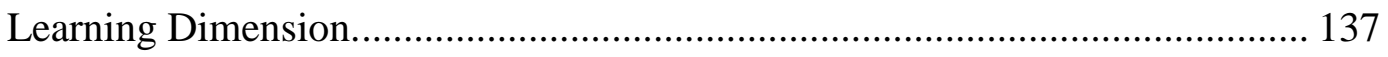

Organization Dimension. .............................................................................. 139

Roles and Purposes. ................................................................................... 140

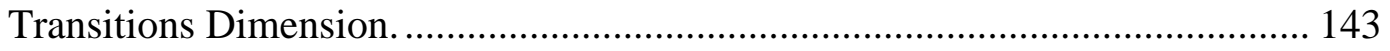

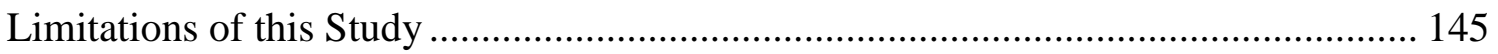

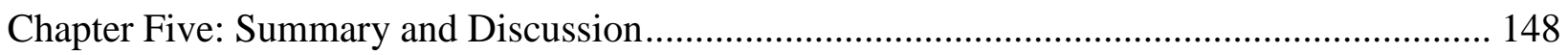

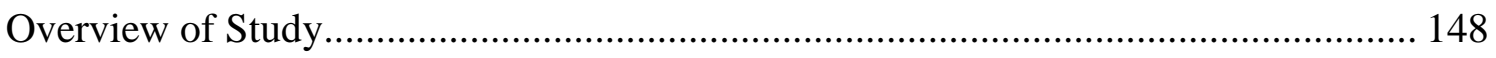

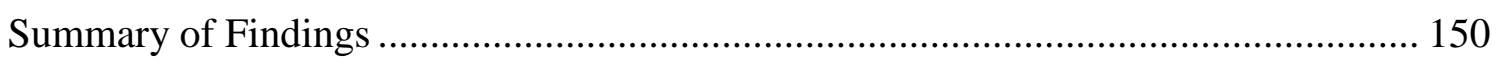

Summary of Findings for Research Question 1............................................. 150

Summary of Findings for Research Question 1.a. ............................................. 153

Summary of Findings for Research Question 1.b........................................... 153

Summary of Findings for Research Question 2............................................. 154

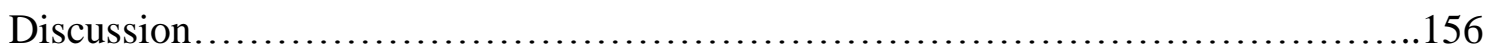

A More Comprehensive Set of Student Learning Outcomes for the First Year. 156

Generated Student Learning Outcomes and Student Needs............................... 159

Generated Student Learning Outcomes and Student Success............................. 160

Generated Student Learning Outcomes and Student Engagement. ..................... 162

Generated Student Learning Outcomes and Student Development.................... 163

Alignment of the Locally Conceptualized Student Learning Outcomes

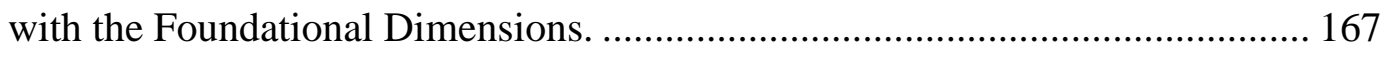

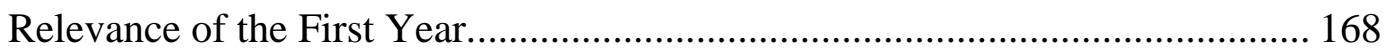




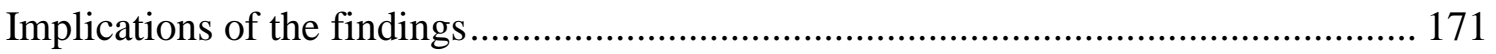

Implication for the First-Year Experience at the Reference University. ............ 171 Implication for First-Year Experience programs at other institutions................ 172 Implications for the Success Program at the Reference University.................... 172 The Use of the Concept Mapping/Pattern Matching Methodology during the Foundation of Excellence Self-Study Process................................................. 173 Implications for postsecondary student success programs. .............................. 174

Recommendations for future research .................................................................... 175

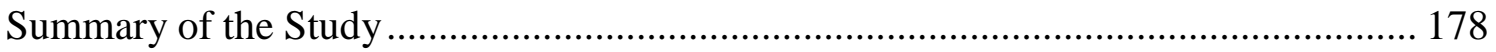

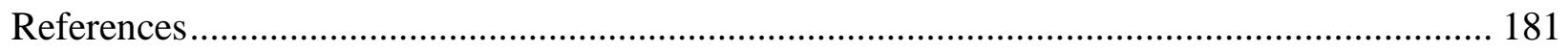

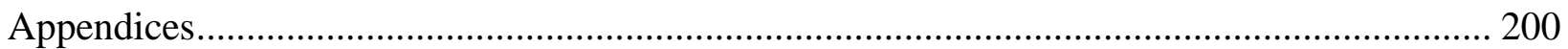

Appendix A: First Year Focus - Foundational Dimensions ${ }^{\circledR}$....................................... 200

Appendix B: IRB Cover Letter .............................................................................. 205

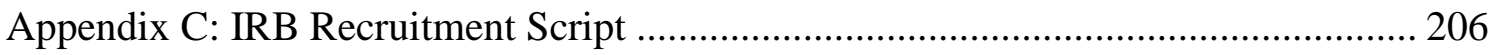

Appendix D: List of Statements Generated by Key Stakeholders at the Reference University Using Concept Mapping/Pattern Matching ............................ 207

Appendix E: List of 100 Outcomes Formatted for the Importance and Efficacy Rating Using Qualtrics ................................................................... 211

Appendix F: Dendrogram or Hierarchical Cluster Tree Derived from the Hierarchical Cluster Analysis Showing Cluster Membership for Each Item ............... 216 Appendix G: List of the 100 Outcomes with Mean Scores for Importance and Efficacy and Cluster Membership …………………….................. 217

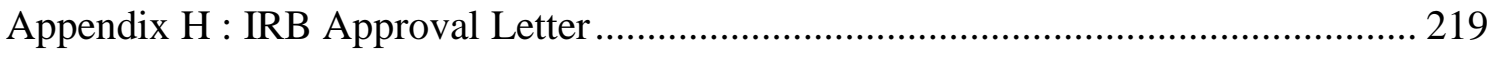


Appendix I: Excel Spreadsheet with Outcomes Distributed Between 3

and 10 Clusters .....

221

Appendix J: Qualtrics Results for Importance of Each Outcome by Number of

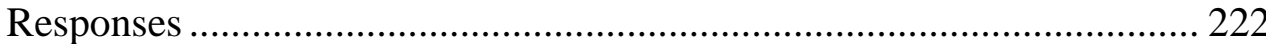

Appendix K: Qualtrics Results for Efficacy of Each Outcome by Number

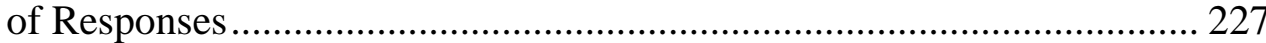




\section{List of Tables}

Table 1: Participants in the Concept Mapping/Pattern Matching Brainstorming

Session, and Statement Sorting and Rating Tasks

Table 2: Illustration of Similarity and Dissimilarity among Statements

Table 3: List of 100 Outcomes Generated by Participants, Organized into

Clusters using Hierarchical Cluster Analysis, and Labeled 106

Table 3 (continued): List of 100 Outcomes Generated by Participants, Organized into Clusters using Hierarchical Cluster Analysis, and Labeled. 107

Table 3 (continued): List of 100 Outcomes Generated by Participants, Organized into Clusters using Hierarchical Cluster Analysis, and Labeled. 108

Table 3 (continued): List of 100 Outcomes Generated by Participants, Organized into Clusters using Hierarchical Cluster Analysis, and Labeled 109

Table 4: List of Six Clusters with Labels and Definitions 112

Table 5: List of Statements in the Independence Cluster and Their Mean Ratings in Terms of Importance and Efficacy. 114

Table 6: List of Statements in the Engaging with the Environment Cluster and Their Mean Ratings in Terms of Importance and Efficacy. 116

Table 7: List of Statements in the Career Identity Cluster and Their Mean Ratings in Terms of Importance and Efficacy...... 118

Table 8: List of Statements in the Interdependence Cluster and Their Mean Ratings in Terms of Importance and Efficacy. 120

Table 9: List of Statements in the Help/Resource Seeking Cluster and Their Mean Ratings in Terms of Importance and Efficacy 121 
Table 10: List of Statements in the Academic Identity Cluster and Their Mean

Ratings in Terms of Importance and Efficacy 123

Table 11: The Importance and Efficacy Mean Scores for Each Cluster.

Table 12: The Importance and Efficacy Mean Scores by Cluster and by Stakeholder Group... 126

Table 13: Comparison of the Foundational Dimensions of the John N. Gardner Institute and the Concept Mapping/Pattern Matching Clusters

Table 14: Concept Mapping/Pattern Matching Outcomes that were Matched with the Diversity Dimension 136

Table 15: Concept Mapping/Pattern Matching Outcomes that were Matched with the Faculty Dimension

Table 16: Concept Mapping/Pattern Matching Outcomes that were Matched with the Learning Dimension 138

Table 17: Concept Mapping/Pattern Matching Outcomes that were Matched with the Organization Dimension

Table 18: Concept Mapping/Pattern Matching Outcomes that were Matched with the Roles and Purposes Dimension. 141

Table 19: Concept Mapping/Pattern Matching Outcomes that were Matched with the Transitions Dimension 


\section{List of Figures}

Figure 1: Point map with each point corresponding to one of the 100 statements................... 101

Figure 2: Numbered point map with each point corresponding to one of the 100 statements ... 102

Figure 3: Cluster map with the six clusters identified ..................................................... 105

Figure 4: Cluster map with the six clusters named........................................................ 110

Figure 5: Laddergraph showing the mean ratings of importance and efficacy

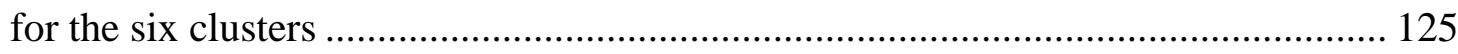

Figure 6: Laddergraph showing the mean group cluster ratings for importance .................... 128

Figure 7: Laddergraph showing the mean group cluster ratings for efficacy......................... 130

Figure 8: Cluster Map Quadrant Analysis .................................................................... 158 


\section{Chapter One: Introduction}

This study conceptualized the desired domain of student learning in the first year of a success program serving first-time, full-time undecided students at a land-grant and high research activity classified university (Carnegie Foundation for the Advancement of Teaching, 2010). The term learning in this study is operationalized via Benjamin Bloom's articulation of learning outcomes — knowledge, skills, and attitudes (Bloom et al., 1956). To collect and analyze the data, the researcher involved students and other stakeholders within the institution and resorted to Concept Mapping/Pattern Matching, a scientific mixed methods approach to consensus building described by Trochim (1989a). In a brainstorming, participants produced 100 learning outcomes and rated their relative importance for ensuring student success as well as the efficacy of their institution in helping students achieve these outcomes. The results were explored to determine to what extent the ratings differed depending on the participants status within the institution, and to what extend the articulated learning outcomes aligned with the Foundational Dimensions (FD), a set of nine aspirational principles of excellence for evaluating and improving the First-Year Experience (John N. Gardner Institute for Excellence in Undergraduate Education, 2005). This chapter provides an overview of the general background of the study, states the problem, the purpose, the research questions, and the significance of the study, defines some key terms and concepts, and finally presents the organization of the study.

\section{General Background of the Study}

Although student success has long been a concern in higher education, the issue has recently gained a stronger sense of urgency due to a variety of factors. Change is imperative, not only at the institutional but also at the student level. Eckel and Kezar (2003) captured a set of factors that higher education as a system faces when they stated that "financial pressure, growth 
in technology, changing faculty roles, public scrutiny, changing demographics, and competition in the world both within and beyond our national borders make change imperative for higher education"(p. ix). In the same vein, the following statement made by the Lumina Foundation (2011) illustrates the regained importance of higher education and the urgency for student success in the knowledge society by stating:

Today's students must prepare for jobs that are rapidly changing, use technologies that are still emerging and work with colleagues from (and often in) all parts of the globe. The challenges that graduates face as citizens during their lives are similarly complex and also are affected by developments around the world. (p. 1).

In a globalized economy, with competition from national and international workers, educational credentials are essential to enter the job market (Evers, Rush, \& Berdrow, 1998; Jamelske, 2009). There is a stronger pressure on educators to ensure that students earn their degrees and skills to enter the workforce and contribute to the economy (McMahon, 2009; Sweetland, 1996). Projections by the Center on Education and the Workforce, Georgetown University, predicted that 63 percent of jobs will require postsecondary credentials by 2018 , underlining the increasing need of the modern economy for more workers with educational credentials (Carnevale, Smith, \& Strohl, 2010). Failure to reach out to and graduate enough students with the right skills will leave the U.S. economy short 3 million qualified workers by 2018, according to the National Governors Association [NGA] (Reindl \& Reyna, 2011).

Another reason why student success is becoming critically important is the clear incentive to go to college when one considers the difference in benefits afforded by educational credentials. Research established a positive relationship between educational attainment and personal income (Becker, 1993; McMahon, 2009; Schultz, 1971; Taylor et al., 2011). Other 
studies (Baum \& Ma, 2007; Baum \& Payea, 2004, 2005, as cited in Tinto, 2012) revealed that the benefit of completing a college degree impacts one's earnings positively, with completers of "a bachelor's degree earn[ing] over one million dollars more during their lifetime than do those who do not go to college" (p. 1). In the same studies, completion was proven to yield more financial benefits since "the gap in lifetime earnings between those who complete at least a college degree and those who start college but do not graduate is more than $\$ 750,000 ”$ (p. 1).

Student success at most colleges and universities around the country, especially in the first year of college, is a prime concern. In a review of the research on the relationships between student persistence and their major and career choices, Cuseo (2005) reported the following concern raised by the "Learning Slope" (1991): "At all types of higher education institutions, including highly selective colleges and universities, the most critical period or stage of vulnerability for student attrition continues to be the first year of college" (Cuseo, 2005, p. 28). The first year is when higher education loses more than one-half of the students who eventually drop out (Consortium for Student Retention Data Exchange 1999, as cited in Cuseo, 2005).

Other researchers suggested that success in the first year helps pave the way for more success in subsequent years (Reason, Terenzini, \& Domingo, 2006; Tinto, 2012). Reason, Terenzini, and Domingo (2006) determined the first year of college to be the critical period during which occurs the "significant gain in learning and cognitive development" (p. 149).

Eckel and Kezar (2003) illustrated well the challenge of meeting students' needs in the $21^{\text {st }}$ century higher education when they predicted that "the new students, who mostly will come from underrepresented populations, call for different and expanded academic programs, enhanced and additional student services, and changes in structures and operating procedures" (p. 15). This is even more important as many students were reported to enter college less 
prepared (Taylor et al., 2011) or with false assumptions about college life (Smith \& Wertlieb, 2005). A majority of surveyed College Presidents acknowledged the declining student quality at their institutions (Taylor et al., 2011). Fifty-eight percent of the respondents believed that students entering college today study less and have a lower level of academic preparation than those who entered college ten years ago. Furthermore, due to the diversity within the entering student body and the complexity of their needs, it takes a comprehensive approach to discern those needs and to provide appropriate responses to meet them. To lay the foundations for student success, institutions should create environments that allow students, based on their personal characteristics, to connect to an institution through academic and social integration (Tinto, 2012).

Retention rates, course completion rates, and success in first-year college courses were among the progress metrics recommended as success and accountability measures for institutions in Complete to Compete: Common College Completion Metrics, a report commissioned by the National Governor Association (Reyna, Reindl, Witham, \& Stanley, 2010). Ewell (1983) considered that "building effective recruitment and retention programs in a period of intense competition for students is [a] compelling motive for collections and assessments" (p. 3) of student outcome data. It is therefore urgent that the actions of leaders in higher education be motivated by a "commitment to the principles of ethical decision making, organizational learning, empowerment, and socially responsible leadership" (Kezar, Carducci, \& ContrerasMcGavin, 2006, p. 98).

Additionally, a sustained retention of students allows for a sustained financial stability for colleges and universities (Jamelske, 2009). Jamelske argued that introducing strategies to retain students reduces the resources that institution would otherwise devote to the recruitment of other 
students to offset loss of revenue. He also highlighted the fact that students who are retained and who eventually graduate from the institution contribute to the development of a loyal alumni base of likely donors, which is another incentive for institutions to promote student success.

Another important factor that makes achieving student success particularly difficult now is the growing demand for higher education. This demand has increased since "the opening of American colleges and universities after World War II to much larger numbers of students...termed the massification of higher education" (Weisbrod, Ballou, \& Asch, 2008, p. 23). For example, about 25 percent of the 18 to 24 -year olds were enrolled in college in the 1960s and 1970s compared to more than 40 percent of the same age group in 2009 (Taylor et al., 2011). With more students aspiring to and enrolling in college, services should be available to prepare students for success, both socially and academically (Smith \& Wertlieb, 2005). Along the same line, Tinto (2012) contended that although "America's public commitment to provide access to any individual who seeks a postsecondary education seems to be working", given the popularity of higher education there is still an achievement gap among various subgroups of students and until the gap is bridged, open "access [to higher education] without support is not opportunity" (p. 117). Although personal effort and motivation are required in order to succeed, "student effort may prove futile in settings that are not conducive to success. In admitting a student, a college enters into a contract — indeed, takes on a moral obligation — to establish those conditions on campus, especially in the classroom, that enhance the likelihood that students who are willing to expend the effort will succeed" (Tinto 2012, p. 120).

Higher education has to also deal with the consequences of increasing attendance costs. Data provided by the College Board showed that higher education attendance costs have increased approximately threefold between the academic years 1980-1981 and 2010-2011 (as 
cited in Taylor et al., 2011). Students and their parents, public policy makers, and educators make considerable efforts to support higher education. Student loan debt has reached unprecedented levels and is near breaking point with its amount representing "about 5 percent of all outstanding debt in the household sector" (Taylor et al., 2011). As a consequence of the decrease in public funding — state appropriations represented 44 percent of four-year public universities' revenue in 1958 and 28 percent in 2004 (Weisbrod, Ballou, \& Asch, 2008) —and recurrent financial crises, most higher education institutions (HEIs) operate with smaller budgets.

In February 2009, aware of the critical role of student success for the leadership of the U.S. in the world, President Barack Obama challenged the nation to achieve this goal during a joint address to the United States congress: "by 2020, America will once again have the highest proportion of college graduates in the world" (Obama, 2009, para. 66). The U.S. Department of Education (2011) estimated that to reach this goal, eight million associate and bachelor degree holders had to be added by 2020, and that the U.S. higher education system would have to reach a nationwide average increase of 50 percent of young adults with college degrees by 2020 .

In a report published in the same year, 50 percent of surveyed college presidents thought that the U.S. higher education is "not too likely" (Taylor et al., 2011, p. 59) to reach the goal set by President Barack Obama, and 38 percent of them believed that "the U.S. higher education system is headed in the wrong direction" (p. 55). In its 2013-2016 Strategic Plan, the Lumina Foundation (2013) has set its 2025 goal to 60 percent of Americans with competitive educational credentials. The Foundation stressed the critical need for more graduates for the nation's success in the modern economy- and knowledge-based society. 
The Lumina Foundation's Strategic Plan also saw higher education as a source of opportunities for the improvement of the human condition. In addition to the economic benefits, the Foundation highlighted the social benefits of higher education:

There is a wealth of evidence that increased attainment improves health, lowers crime rates, and yields citizens who are both globally aware and participate more in civic and democratic processes such as voting and volunteering, all of which have enormous implications for our democracy. (p. 3).

In the same vein, the literature on the human capital theory had already arrived to the conclusion that education is linked to the improvement of personal well-being and to the vitality of the economy (McMahon, 2009; Sweetland, 1996). Human capital was defined as the "knowledge, skills, and attributes acquired by investment in education and health throughout the lifecycle" (McMahon, 2009, p. 41).

Many of the challenges and issues discussed in previous paragraphs of this section are reflected at the university under study which strives to meet the specific needs of entering students, to provide settings and services that are conducive to success, to enhance operating procedures, to raise the retention rate, and to ensure degree completion. The success program examined in this study is one component of this effort. For reasons of privacy and confidentiality, the real name of the success program will not be revealed and the university will henceforth be referred to as the "Reference University".

\section{Statement of the Problem}

The success program examined in this study starts with a one-week bridge program followed by year-long programming to enhance student success. The metrics set to measure the success of the program are: retention rates at the end of the first semester and of the first year; 
probation rates; course completion rates based on credit hours earned as a percentage of credit hours attempted. However, it is not certain that those outcomes, although important, suffice to measure the success of the program or that other essential student learning outcomes are not left out in the process. The stated outcomes reflect mainly an institutional perspective because they are programmatic outcomes (Astin \& Antonio, 2012; Ewell, 1983). Student learning outcomes, even if they are included in the list of outcomes that were stated for the program, are not fully articulated. Under these circumstances, it is unclear if institutional and student goals coincide or if there is a disconnect between program and student expectations and goals. Consequently, the problem is that in the current model for assessing the success program, the key variables might not be fully indicative of actual student learning outcomes.

Even though most U.S. institutions have realized the importance of the first year of college and have introduced related programs to contribute to student success, in some cases "the outcome has been creation of numerous program-level initiatives that operate on the margins of the first year and may have only limited impact on students" (Alexander \& Gardner 2009, p. 18). Alexander and Gardner considered the ineffectiveness of some of those programs to be due to a failure to follow best practice and benchmarks and to a narrow approach, which misses the big picture. Ewell (1983) emphasized the fact that the "missions, programmatic goals, and resource constraints" (p. 21) are usually at the center of the discussions at the expenses of student goals. Astin and Antonio (2012) argued that the student's perspective has not always been taken into account in the process. Additionally, Hunter (2006) argued that "it is far too common for campus officials to spend an inordinate amount of time and energy developing strategies to improve the first college year without ever asking for student involvement” (p. 7). Because of this risk of mismatch between ideal goals and the reality of student aspirations, this study involved students 
and other stakeholders in order to delineate the domain of student learning outcomes for the first year that are more comprehensive than the ones currently listed for the success program.

\section{Purpose of the Study and Research Questions}

The purpose of this study was to conceptualize the desired domain of student learning in the first year of a success program serving first-time, full-time undecided students at a land-grant and high research activity classified university (Carnegie Foundation for the Advancement of Teaching, 2010). To collect and analyze the data, the researcher involved students and other stakeholders within the institution and resorted to Concept Mapping/Pattern Matching, a scientific mixed methods approach to consensus building described by Trochim (1989a). To that end, the researcher sought the contribution of students participating in the success program, on the one hand, and key stakeholders involved in programming and implementing said program, on the other hand. The conceptualization process lead to the development of concept maps representing the desired student learning elements articulated by the study's participants. These results were explored to determine to what extent they align with the Foundational Dimensions, a set of nine aspirational principles of excellence for evaluating and improving the First-Year Experience (FYE) (John N. Gardner Institute for Excellence in Undergraduate Education, 2005).

The learning outcomes conceptualized through this study reflect qualities inherent to first-year students whereas the Foundational Dimensions reflect institutional level goals. Nevertheless, it is the researcher's belief that both levels are connected and should inform each other for improvement, planning, and evaluation purposes. Therefore, it is of great importance for the researcher to determine to which extent the results of the conceptualization process align with the Foundational Dimensions in order to check for relevance of national standards at the local level and to find out if a local program is modeled after and resemble a vetted best-practice 
in post-secondary education. The findings may serve as a framework that will allow practitioners to assess the outcomes of similar success programs for students in the first year of college, and thus to improve existing or develop new programs able to stimulate and support student success. In this endeavor, the following research questions guided this study:

RQ 1: What is the desired domain of student learning of a first-year success program serving first-time, full-time undecided students as conceptualized by stakeholders at a land-grant university, when using the Concept Mapping/Pattern Matching methodology?

a. To what extent do program stakeholder groups differ in their rating of the relative importance of student learning outcomes for ensuring student success?

b. To what extent do program stakeholder groups differ in their evaluation of the overall efficacy of their institution's success program in helping students achieve desired learning outcomes?

RQ 2: To what extent does the conceptualized desired domain of student learning under Research Questions 1 align with the Foundational Dimensions established by the John N. Gardner Institute?

\section{Significance of the Study}

At the Reference University improving retention and graduation rates as well as other student success metrics is a major endeavor. This study might therefore hold some significance in terms of practice, research, and policy for this specific institution and for the field of higher education in general. It is also meant as a contribution to the existing body of literature on the FYE. 
Practice. The study aspires to provide a framework for the evaluation and planning of student success programs and for the assessment of the efficacy of the institution in addressing the heterogeneous and complex needs of first-time full-time undecided students. Using this framework, faculty and staff working directly with such students could gain insightful information about their expectations, find out what is lacking, inadequate or unsatisfactory in the existing support program, identify possible changes and initiatives, and the ways to implement them in order to enhance programs geared toward student success. The framework could also serve in decision making processes regarding future programming for first-year students. It could be used to improve existing programs and services, or to extend successful services to a larger number of students. The expected outcomes of such a program could be modified to encompass a greater variety of relevant factors. Current and future undecided students might use the framework to reflect on their own experiences and consequently be more cognizant and mindful of their own goals, aspirations, and expectations. These various possibilities may help improving first-to-second year retention rates, graduation rates and ultimately, overall student success.

Research. This study may contribute to future research. Similar studies may be conducted with undecided students who do not partake in the success program, for comparison, or with subgroups of students who are already in majors, with the purpose of getting a bigger picture of student expected outcomes and to assess the impact of their exposure to the institution. While the current research focuses on the overall learning outcomes of the FYE, futures studies may investigate separately academic and nonacademic outcomes to check for differences or similarities in order to provide domain-specific services to improve student experiences in the first college year. The results may lead to re-thinking the FYE beyond the First-Year Seminar 
(FYS) course and may lead to a better-coordinated approach to serving first-year students within the institution.

Educational policy. Determining if the results of the study are in alignment with the Foundational Dimensions allows the Reference University to appraise its offering against a nationally renowned benchmark of excellence for first year students. It also allows the Reference University to determine the relevance of its student success standards. The results may lead the institution to re-think and reinvigorate its FYE, its (FYS) and the coordination of all its programs serving first-year students.

Literature. This study aims at adding to the existing body of literature on the FYE and student success. The contribution of this study is to apply the Concept Mapping/Pattern Matching methodology, in light of the literature and research on student success, in order to conceptualize a set of student learning outcomes and to compare them with the Foundational Dimensions, a set of established best practice principles for excellence in the first college year (John N. Gardner Institute for Excellence in Undergraduate Education, 2005). When applied correctly, this approach provides new indications about the skills, knowledge, values, beliefs, and attitudes that are considered to be critical for student success by key stakeholders. The findings can be translated into a valuable set of activities, strategies, and intervention areas that can be used to address local student needs and enhance their success.

\section{Definition of Key Terms and Concepts}

Throughout this study, key terms and concepts that may prove unfamiliar to some readers are discussed. The following section provides definitions for a better understanding of those terms and concepts as they are used in the current study. 
Accountability. In higher education, the concept of accountability has been defined as "a systematic method to assure those inside and outside the higher education system that colleges and universities — and students — are moving toward desired goals" (Leveille, 2005, as cited in Suskie, 2009, p. 61).

Assessment. Angelo (1995) has provided one of the most cited definitions of assessment as it pertains to higher education:

Assessment is an ongoing process aimed at understanding and improving student learning. It involves making our expectations explicit and public; setting appropriate criteria and high standards for learning quality; systematically gathering, analyzing and interpreting evidence to determine how well performance matches those expectations and standards; and using the result in information to document, explain and improve performance. (p. 7).

Attitude. The term attitude belongs to the affective domain of the classification of educational objectives and refers to the behavior that one has "toward some object or process", or "one's feelings and views on a variety of phenomena" (Krathwohl, Bloom, \& Masia, 1964, p. 3-4).

Concept Mapping. Although Concept Mapping can be viewed as "a generic term that describes any process for representing ideas in pictures or maps" (Kane \& Trochim, 2007,p .1), this study relies on a specific mixed methodology resorting to concept maps and other visual representations (Kane \& Trochim 2007, 2009; Trochim, 1989a; Trochim \& Linton, 1986) that is defined as "a structured methodology for organizing the ideas of a group or organization, to bring together diverse groups of stakeholders and help them rapidly form a common framework that can be used for planning, evaluation, or both" (Kane \& Trochim, 2007, p. 1). 
Data-Driven Decision Making. In the area of education, Data-Driven Decision Making was defined as the fact of "systematically collecting and analyzing various types of data, including input, process, outcome and satisfaction data, to guide a range of decisions to help improve the success of students"(Marsh, Pane, \& Hamilton, 2006, p. 1).

First-Year Experience (FYE). The concept of FYE has also been diversely defined based on type and mission of higher education institutions. In this study, the researcher utilized the definition by Hunter (2006):

A comprehensive and intentional approach to the first college year. It comprises both curricular and cocurricular initiatives. It is the sum of all experiences students have in their first year at college. The 'first-year experience' is far more than a single event, program, or course. (p. 6).

First-Year Seminar (FYS). According to Barefoot (1992),

The freshman seminar is a course intended to enhance the academic and/or social integration of first-year students by introducing them (a) to a variety of specific topics which vary by seminar type, (b) to essential skills for college success, and (c) to selected processes, the most common of which is the creation of a peer support group. (As cited in Keup \& Barefoot, 2005, p. 13).

Foundational Dimensions. The Foundations of Excellence (FoE), an institutional selfstudy project of the John N. Gardner Institute for Excellence in Undergraduate Education in collaboration with other educational institutions and partners, established the Foundational Dimensions, a series of "nine standards...developed to serve as a means of measuring a campus's delivery of the first year" (Alexander \& Gardner, 2009, p. 19). 
High impact practices. In the introduction to High-Impact Educational Practices: What They Are, Who Has Access to Them, and Why They Matter, Schneider (2008) defined high impact practices as "effective educational practices... that, according to a growing array of research studies, are correlated with positive educational results for students from widely varying backgrounds" (as cited in Kuh, 2008a, p. 1).

Knowledge. As defined by Bloom et al. (1956) knowledge in the educational context involves intellectual activities such as "remembering; reasoning; problem solving; concept formation; and... creative thinking" (p.15).

Learning Community. Barefoot, Griffin, and Koch (2012) defined Learning communities as "curricular structures in which small cohorts of students... are co-enrolled in two or more courses generally from different disciplines with or without a common residential environment" (p. 20).

Pattern Matching. A technique that "allows for the combination of any two measures (e.g., statement importance ratings either within or between groups) aggregated at the concept map cluster level to examine the degree to which the measures match" (Michalski \& Cousins, 2000, p. 217).

Skill. In the context of educational outcomes, Bloom et al. (1956) argued that a skill is the ability for students to "find appropriate information and techniques in...previous experiences to bring to bear on new problems and situations" (p. 38). They associated skill with the ability of students to apply their knowledge "as the result of participating in some unit of instruction" (p. 12).

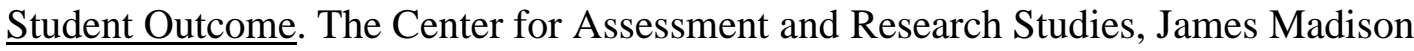
University, defined student outcome in its online Dictionary of Student Outcome Assessment as 
the achieved results or the actual consequences of what a student has demonstrated or accomplished; maybe academic and occupational, as well as the intellectual, personal, civic development, attitudes, values, and beliefs that students attain as a result of postsecondary education. (James Madison University, 2003).

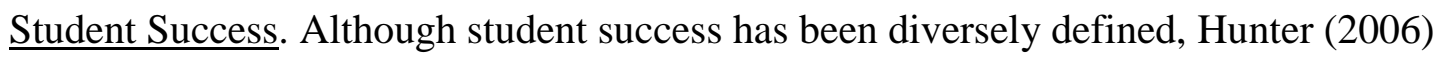
argued that it "goes beyond cognitive or academic success alone" (p. 5). Paraphrasing Upcraft, Barefoot, and Gardner (2005), Hunter (2006) articulated the following definition that she believed to be a comprehensive one. For the purpose of this study, the researcher adopted that same definition:

First-year students succeed when they make progress toward developing academic and intellectual competence, establishing and maintaining interpersonal relationships, exploring identity development, deciding on a career and lifestyle, maintaining personal health and wellness, developing civic responsibility, considering the spiritual dimensions of life, and dealing with diversity. (p. 5).

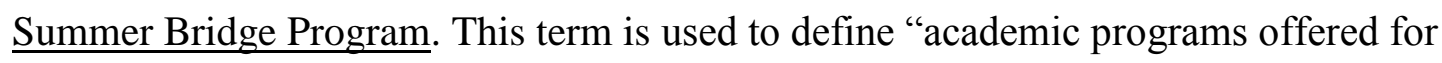
students before the first year of college. Such programs are generally designed to offer students additional academic and/or social support before they begin the first term of the first year" (Barefoot, Griffin, \& Koch, 2012, p. 2).

Undecided/General Studies/Undeclared Major. In this study, these terms are utilized interchangeably to designate "those students who matriculate to colleges and universities without declaring an academic major" (Brown, 2009, p. ii) either by choice or due to being admitted by default in this category for not being able to meet the requirements of a desired academic major. 
The term undecided will be utilized in this study because of the convenience to relate it to previous research studies on similar student populations (Gordon, 1984).

\section{Organization of the Dissertation}

This dissertation consists of five chapters organized as follows. The first chapter introduces the study and entails an overview of its background, the statement of the problem, the purpose of the study and its significance. It also provides definitions of key concepts and terms, and an outline of the general organization of the study. The second chapter consists of a review of the literature pertaining to the topics discussed in the current study. Chapter Three outlines the research methodology, namely the different steps of Concept Mapping/Pattern Matching (Kane \& Trochim, 2007; Trochim, 1989a), and how it was utilized in this study to conceptualize student outcomes of a success program serving first-year undecided students. Chapter Four describes the findings while Chapter Five summarizes the findings, discusses the implications and lists recommendations for practice and future research in the areas of student success and the FYE. 


\section{Chapter Two: Review of the Literature}

This chapter presents a review of the literature pertaining to the topics discussed in this study, namely college student success, student learning outcomes, assessment, intervention strategies to enhance the First-Year Experience, student engagement, data-driven decision making and accountability, undecided students, the use of the Concept Mapping/Pattern Matching methodology, and the Foundational Dimensions.

\section{Theoretical Perspectives and Models on College Student Success.}

The definition of first-year student success derived from FYE research (Upcraft, Barefoot, \& Gardner, 2005) and articulated by Hunter (2006) reveals the complexity of the aspects to take into account to achieve student success:

First-year students succeed when they make progress toward developing academic and intellectual competence, establishing and maintaining interpersonal relationships, exploring identity development, deciding on a career and lifestyle, maintaining personal health and wellness, developing civic responsibility, considering the spiritual dimensions of life, and dealing with diversity. (p. 5).

For colleges and universities to be effective in putting in place the environments and conditions for student success both inside and outside of the classrooms, higher education professionals should know their students and understand how they learn and develop (Upcraft \& Crissman, 1999). Students should be perceived "not only as academic beings, but also as emotional, psychosocial, moral, ethical, developing, and maturing human beings" (Upcraft \& Crissman, 1999, p. 26). Cuseo (2005) argued that support programs designed to enhance students success are "more likely to have significant impact when their delivery is proactive, that is, when 
early and preventive action is taken that addresses students' needs in an anticipatory fashionbefore they eventuate in problems that require reactive interventions" (p. 44).

Examples of theories and models recommending frameworks for the development of optimal conditions for student success are abundant in the literature (e.g., Astin, 1984, 1993; Astin \& Antonio, 2012; Evans, Forney, Guido, Patton, \& Renn, 2010; Greenfield, Keup, \& Gardner, 2013; Pascarella, 1985, 2005; Pascarella \& Terenzini, 1991, 2005 ; Tinto, 1975, 1987, 1993, 2012; Upcraft \& Crissman, 1999). The researcher provides a review of these frameworks in the following sections.

Astin's Contribution to Theory on College Student Success. Astin (1984) developed a theory that rests on five principles of student involvement. He argued that student involvement implies an "investment of physical and psychological" effort, spans on "a continuum", and "can be measured both quantitatively... and qualitatively" (p. 298). Astin also argued that "the amount of student learning and personal development associated with any educational program is directly proportional to the quality and quantity of student involvement in that program", and that "the effectiveness of any educational policy or practice is directly related to the capacity of that policy or practice to increase student involvement" (p. 298). Astin insisted on the importance of student involvement in college experiences as a prime factor for success. Involvement is understood as the energy students invest in their use of campus resources, their active involvement with their academic activities, and their efforts to develop social links by interacting with faculty and peers. The more students engage in such ways with the campus, its resources, and programs, the more they tend to interact with faculty members and peers, and capitalize on their studies. 
Astin (1993) and Astin and Antonio (2012) described also the Inputs-EnvironmentOutputs model as a comprehensive approach to provide institutions with an efficient framework to offer and improve student success programs. The proposed model includes three interrelated variables, Inputs, Environment, and Outputs, which interact to determine the impact of educational programs on the student's overall development.

Inputs consist of college students characteristics at the time they enter college. This includes for example demographic characteristics, pre-college academic competence reflected in test scores, high school grade point average, and other personal information. Environment refers to all aspects of the actual exposure of students to a given institution and how the experience may affect their relationship with that institution or their academic performance and personal development. Examples may include students' living arrangements, their interactions with peers and faculty members the institutional culture and climate. The third element of the model consists of students educational outcomes after their experience within a given institution. This may include for example their academic performance, their persistence and any impact that the college or university may have had on them.

Pascarella and Terenzini $(1991,2005)$ pointed out how earlier versions of Astin’s model presented the student as not playing an active role but rather undergoing changes under the influence of environmental factors. They praised the more active role attributed to the student in later versions of Astin's model where the student became a central player who could benefit from the impact of college by availing him- or herself of the resources available within the environment. Pascarella and Terenzini did not view Astins's contribution as a theory but rather as a model that still needed to prove its capacity of providing a systematic framework for analyzing, interpreting, and predicting the complex relationships among a variety of variables. 
Tinto's Contribution to Theory on College Student Success. As a scholar involved in the research on student retention since the 1970s, Tinto has contributed to practice and theory development in the area of student success. Tinto $(1975,1987,1993)$ contributed to the debate on student persistence by proposing his interactionalist theory, which stipulates that the ultimate factor that influences students' decision to leave an institution of higher learning is their inability to successfully integrate the new community. For Tinto (1987) the notion of integration entails both academic and social aspects. He contended that students need to withdraw from past community links and to transition into the new community. Success in the transition process is key to students deciding to persist. Tinto (1993) argued that student departure occurs mainly due to academic failure, challenges in reconciling personal goals, and failure to integrate socially. This theory compelled institutions to lay the foundations for success, by creating environments that allow for students, based on their personal characteristics, to develop vital relationships with higher institutions through academic and social integration.

In his book Completing College: Rethinking Institutional Action, Tinto (2012) identified four variables that foster student retention and graduation. He argued that "students are more likely to succeed in settings that establish clear and high expectations for success, provide academic and social support, frequently assess and provide feedback about their performance, and actively involve them with others on campus, especially in the classroom" (p. 8).

Expectations: Tinto (2012) urged for the establishment of consistent and clear expectations at the institutional, program, and course levels. These expectations may be set through various venues, formal and informal, such as academic advising, orientations, mentoring, interactions with faculty, staff, and peers, classroom activities. No matter what the venues, Tinto believed that "high expectations are a condition for student success, low 
expectations a recipe for failure" (p. 12). For him, when there is no challenge, when expectations are low, student success will is negatively impacted because "no one rises to low expectations, student success is enhanced when expectations for effort are high and clearly enunciated" (p. 22).

Support: Tinto (2012) also stressed the fact that a diversified support structureacademic, financial, and social—is crucial to student success. Academic support should be offered to compensate for insufficient preparedness for college. Support services such as "basicskills, developmental, or remedial courses; tutoring; study groups; supplemental instruction; and summer bridge programs" (p. 25) may be very beneficial to student with low academic preparedness. Other support programs, such as first-year seminars and study skills, may benefit all students regardless of academic preparedness. Academic support programs should be tailored to meet specific student needs. Financial support programs should also be embedded in the many services that colleges and universities provide to their students. Tinto urged HEIs to "employ work-study programs as part of their aid packages, often with funds from the Federal WorkStudy Program and state work-study programs" (p. 51).

As for social support programs, they can "range from advising, mentoring, residential life, and campus recreation programs to counseling, health services, career services, religious services, and services for particular groups of students including underrepresented students, adults, those from abroad, and those with disabilities" (Tinto, 2012, p. 48). Tinto considered these services as crucial as the other types of support for student success, especially because "retention is also shaped, directly and indirectly, by social forces internal and external to the campus, especially those that influence students' sense of belonging and membership in the social communities of the institution" (p. 27). College is a new life and environment for first year students and it is important that they develop a sense of belonging within the various social 
structures and communities of the institution. Suggested support structures that enhance the First-Year Experience "may take the form of residential settings, extracurricular activities, and in some cases in shared learning programs like learning communities” (p. 29).

Assessment: Tinto (2012) asserted that when effectively utilized, the information obtained from various forms of assessment can contribute to the development and improvement of academic and non-academic programs to enhance the likelihood of students' success in the classroom and ultimately to the completion of their college career. In an environment where assessment is prevalent, "students become more involved in learning activities, and more effective in self-assessment to improve their learning strategies and study habits" (p. 54).

Involvement: the last condition that is critical to student success and that Tinto (2012) mentioned is involvement. Tinto went as far as to posit that student involvement is "perhaps the most important" (p. 64) condition for student success to happen. He emphasized the fact that academic and social engagement, student's involvement inside and outside of the classroom with faculty, peers, and the community contribute to their retention and eventual graduation from the institution. A whole section of this literature review is devoted to student engagement.

After a description of the four conditions for student success, Tinto (2012) urged institutions to take institutional action to provide the setting for student success. He encouraged institutions to invest in assessment and use gathered data to improve efforts geared toward student success; to invest in program development and "provide incentives and rewards to promote program continuation over time" (p. 85). He viewed the classroom as playing a paramount role in student success and predicted that "any long-term strategy to enhance student retention must involve long-term investment in faculty development" (p. 87). He urged institution to deploy a systematic and well-timed institutional action that aligns with all other 
student success and initiatives in the first year and beyond. He underlined that institutional success in developing successful program will be reflected in "the ability of various programs to improve, endure, and scale up over time in ways that are systematic and aligned to the achievement of the same goal: enhanced student retention and graduation" (p. 82). In conclusion Tinto (2012) predicted that

student retention and graduation are most likely to occur when four conditions are met: that students experience high and clear expectations; that they find needed academic and social support; that they are assessed and provided with frequent feedback about their progress; and that they are socially and academically involved in the life of the institution, especially in the classrooms of the campus. (p. 104).

Berger and Braxton (1998) reported that in studies focusing on single institutions, only five out of the 13 original postulates of Tinto's theory (1975) had been empirically documented to support that academic integration is part of a college persistence model. Berger and Braxton suggested the inclusion of characteristics pertaining to "organizational behavior on campus", rather than the structural information "such as size, selectivity, control" (p. 105) traditionally used in the literature. The results of their study provided a strong support to the inclusion of "participation in organizational decision making, fairness in the administration of policies and rules, and communication" as important factors of social integration and as having "indirect effects on student's intent to reenroll" (p. 116). They suggested a revision of Tinto's theory to include organizational attributes.

Pascarella's General Model for Assessing Change. By contrast with Tinto’s theory on student departure $(1975,1987)$, which focused on the effects of the interaction occurring within a given institution, and the role of other players on the student level of integration, Pascarella 
(1985) introduced a model that took into account "both an institution's structural characteristics and its environment providing a conceptual foundation for multi-institutional studies of collegiate impact" (as cited in Pascarella \& Terenzini, 2005, p. 56). The model is organized around five groups of variables. The impact of college on students is achieved through a process involving all these five areas. (1) Institutional characteristics and (2) student characteristics interact to delineate the (3) institutional environment where students evolve. These three areas serve as underlying factors that will determine the (4) interactions of students with the environment. The (5) quality of the effort exerted by students is directly influenced by the students' personal characteristics at entry, the college or university environment, and the role of other players. In this model, the "structural/organizational characteristics of institutions" (p. 57) play an indirect role on college impact on students. Pascarella and Terenzini $(1991,2005)$ believed that this model could serve as a framework to study various student outcomes.

Other Theories on College Student Success. Many other theories summarized in the literature (e.g., Evans et al., 2010; Greenfield, Keup, \& Gardner, 2013; Upcraft \& Crissman, 1999) provided frameworks for analyzing and understanding psychosocial and cognitive development throughout the college years. Presented in this review are only examples of these models and theories.

The seven principles of good practice in undergraduate education (Chickering \& Gamson, 1987, as cited in Greenfield, Keup, \& Gardner, 2013) were developed to foster studentfaculty interactions, peer-to-peer collaboration among students, and "active learning within and outside the class room" (p. 1), to prompt feedback on assessments, to focus on "time on task" (p. 1), and on the establishment of expectations, and to take into account variations in student ability and learning styles. 
The engaging pedagogies (Swing 2002, as cited in Greenfield, Keup, \& Gardner, 2013) advocated for a diversification in teaching approaches, a design of "challenging assignments", efficient "use of class time", student participation and collaboration, as well as "meaningful discussion and homework" (p. 2).

In the vectors of development theory (Chickering \& Reisser, 1993, as cited in Evans et al., 2010) argued that student development is achieved via their evolution through seven different stages called "vectors": "Developing Competence", "Managing Emotions", "Moving Through Autonomy Toward Interdependence”, “Developing Mature Interpersonal Relationships”, "Establishing Identity", "Developing Purpose", and "Developing Integrity" (as cited in Evans et al., 2010, pp 67-69). These vectors are not organized in a hierarchy, rather they are intertwined with each other and students may experience more than one vector at a time. Upcraft and Crissman (1999) reported that Chickering and Reisser considered the first four vectors to pertain mostly to "first-year students, while the other vectors apply to upper-level students" (p. 30).

Perry's (1968, as cited in Evans et al., 2010) theory of intellectual and ethical development was composed of nine stages and their transitional points dispersed on a continuum and ranging from "duality", the lowest stage, to the highest stage, "evolving commitments" (p. 85). The nine stages are categorized in three main stages (duality, multiplicity, and relativism) described by Evans et al. (2010). Duality is the stage where students see the world in a dualistic way, "good-bad, right-wrong, black-white" (p. 86) and authorities are seen as the source of knowledge. Multiplicity is the stage where "diverse views" are considered "when the right answers are not yet known" (p. 86). At this stage, individuals consider that "all opinions are equally valid" (p. 86). At the stage of relativism, individuals develop more independent thinking, contextualize knowledge, and "improve their ability to think analytically" (p. 86). When the 
stage of committed relativism is reached, there is evidence of an ethical development. At this stage individuals are committed to ideas, values and make choices in a contextual world.

Schlossberg's (1984) transition theory examined forms of transitions, their processes and the factors that influence them. She wanted to create a framework to help adults in transition deal with the "ordinary and extraordinary process of living" (Schlossberg, 1984, as cited in Evans et al., 2010, p. 213). Her transition model, also known as the 4 S's (situation, self, support, and strategies), presented "four sets of factors that influence one's abiltiy to cope with a tansition" (p. 216). Goodman et al. (2006) defined transition as "any event, or non-event, that results in changed relationships, routines, assumptions, and roles" (as cited in Evans et al., 2010, p. 215). First-year college student experience transition as they leave their past enrivoments and communities behind to adapt to their new college life and experiences (Tinto, 1973, 1987, 1993).

The theory of moral development (Kohlberg, 1976, as cited in Evans et al., 2010) consisted of three levels (preconventional, conventional, and post-conventional) which have two stages each. It assumed that "each successive stage is more likely developed than the previous one because it incorporates aspects of all earlier stages" (p. 102). At the lower stages, individuals obey rules due to fear of punishment. At the intermediate stages, "individuals identify with rules and expectations of others, especially authorities" (p. 103). At Level 3, "they separate themselves from the rules and expectations of others and base their decisions on self-chosen principles" (p. 103). This last level is a more conscious approach of morality. Individual at this level are supposed to have developed the highest sense of moral obligation.

The faith development theory was introduced by Parks (1986, 2000, as cited in Evans et al., 2010). She defined faith as "the activity of seeking and discovering meaning on the most comprehensive dimensions of our experiences" (Parks, 2000, as cited in Evans et al. 2010, 
p. 202). For her, "during young adulthood, individuals are consumed with questions regarding purpose, vocation, and belonging" (p. 203). She identified four periods in the development process: "adolescence or conventional, young adult, tested adult, and mature adult" (p. 203). She also considered development through the following four perspectives: forms of knowing, forms of dependence, forms of community, and mentoring communities. For the last one, she stated that "the higher education community is a place in which young adults benefit greatly from mentoring relationships" (p. 207).

The learning styles model introduced by Kolb (1984, as cited in Evans et al., 2010) was organized around a cycle of learning including four areas: concrete experience, abstract conceptualization, active experimentation, and reflective observation. From these four areas Kolb derived fours learning styles (converging, diverging, assimilating, and accommodating) that do not entail the notion of hierarchy; they are just different ways of approaching learning tasks and contribute differently to learning. They are stable and consistent but can be influenced by the learning experiences and by the environment. Learning styles also vary depending on individual preferences and characteristics. They do not operate like stages that occur one after the other. Individuals may utilize more than one style depending on the learning task, personal ability or preference. Individuals may be challenged when presented with styles that they do not prefer. Learning structures may be designed to offer more flexibility and allow the combination of several styles. Learners with the converging style "are inclined to be good problem solvers and decision makers" (Evans et al., 2010, p. 139). Those with the diverging style "tend to be imaginative and aware of meaning and values. They can view situations from many perspectives and excel at coming up with alternatives and implications" (p. 139-140). Individuals who learn by assimilating "excel at inductive reasoning and display an ability to create theories by 
integrating disparate ideas" (p. 140). Finally, learners with the accommodating style "are doers. They implement plans, complete tasks, and are open to new experiences" (p. 140).

The notions of marginality and mattering were explored by Schlossberg (1989a, as cited in Evans et al., 2010). Marginality was defined "as a sense of not fitting in" (p. 31) and mattering as "our belief, whether right or wrong, that we matter to someone else" (p. 32). Marginality and mattering are important environmental factors that affect student development. Schlossberg argued that institutions should demonstrate to student that they matter in order to encourage them to get involved in their studies and the other aspects of their college experiences.

The notion of validation was introduced by Rendón (1994) who defined it as “an enabling, confirming and supportive process initiated by in- and out-of-class agents that foster academic and interpersonal development" (as cited in Evans et al., 2010, p. 32). She further stated that "the more students get validated, the richer the academic and interpersonal experience" (p. 32). The individuals that can act as "validating agents" (p. 32) can be peers, staff and faculty members, and many other people in the student's environment. Validation as articulated by Rendón was thought to be very effective when "offered during the early stages of the student's academic experience, preferably during the first few weeks of classes" (p. 32).

Sanford (1966, as cited in Evans et al., 2010) introduced "the idea of student development as a function of person-environment interaction" and provided a three-part framework for analyzing how the interaction between students and their surrounding environment can affect their development. The first condition for student development is readiness which "results either because of the internal processes associated with maturation or beneficial environmental factors" (p. 30). The second and third conditions are challenge and support. According to Sanford, these two interact and balance should be found for student 
development to occur. Support is needed to help students overcome the challenges they face in their lives while attending college. When the appropriate support is not provided students may not develop or may abandon their studies. However, too much challenge can hamper development and too little challenge may not provide any incentive for development to occur.

The reflective judgment model introduced by King and Kitchener (1994, as cited in Evans et al., 2010) is made of seven stages through which students evolve as they approach knowledge and its acquisition. The seven areas can be grouped into three main areas. Stages 1 through 3 are categorized as "prereflective thinking"; stages 4 and 5 as "quasi-reflective thinking"; and stages 6 and 7 as "reflective thinking" (p. 131). Students at the prereflective thinking stage believe that there is "an absolute, correct answer" (p. 131) to every problem. At the quasi-reflective stage, they perceive the uncertainty around knowledge and resort to evidence in seeking knowledge. However, "they have difficulty drawing reasoned conclusions and justifying their beliefs" (p. 131). Students at the reflective thinking stage perceived knowledge as a contextualized and evolving notion that should be achieved by examining evidence and should be subjected to continuous questioning.

The model of epistemological reflection was introduced by Baxter Magolda (1992, 2004a, as cited in Evans et al., 2010). Epistemological reflection was defined as "assumptions about the nature, limits, and certainty of knowledge" (Baxter Magolda, 2004a, as cited in Evans et al., 2010, p. 125). Learners are described as going through four stages of knowing (absolute, transitional, independent, and contextual). The quality of the approach to knowledge improves as learner progress in the hierarchy. For the first three stages, a difference in the approach is observed between women and men. 
The identity development theory introduced by Erikson (1959, as cited in Upcraft \& Crissman, 1999) provided a framework for the analysis of identity development from early ages to adulthood. Erikson argued that identity development is facilitated by external factors as well as other factors internal to the individual. For individuals to go from one of the eight stages to another, they undergo a transitional crisis that is resolved by the interaction between internal and external factors. This theory is relevant to first-year students' experiences as they transition to college and at "a time when youth must redefine themselves" (Upcraft \& Crissman, 1999, p. 30).

\section{Student Learning Outcomes}

Suskie (2009) acknowledged Bloom's taxonomy as the “best-known framework for articulating learning goals” (p. 115). Krathwohl, Bloom, and Masia (1964) classified educational objectives and described educational outcomes as "the actions, feelings, and thoughts students are expected to develop as a result of the instruction process" (p. 4). They expanded this definition by emphasizing that the term outcome entailed

a range of human responses, including knowing about something, solving problems of various kinds, evincing an interest in some types of human experiences, having an attitude toward some object or process, or expressing one's feelings and views on a variety of phenomena. (pp. 3-4).

Synthesizing Bloom's theory with other theories (Costa \& Kallick, 2000; Marzano, Pickering, \& McTighe, 1993), Suskie classified learning goals into three main clusters:

- Knowledge and conceptual understanding

- Thinking and other skills

- Attitudes, values, disposition, and habits of mind. (p. 118) 
This classification led her to the definition of student learning outcomes as "the knowledge, skills, attitudes, and habits of mind that students have and take with them when they successfully complete a course or program" (p. 23). Suskie contended that student learning outcomes should be articulated through a collaborative and consensual process. For her, the process of outcome identification will provide better learning experiences for students when they are asked to participate in the articulation of the "intended goals of their education" (p. 76).

The Council for the Advancement of Standards in Higher Education (CAS) (2009) classified student outcomes into six domains. Along with these domains, several "learning outcome domains" and specific examples were provided to assist institutions of higher education in adapting the information to their specific needs and to allow them to develop appropriate assessments to measure how students are meeting learning and development goals. The following are the six main domains that the CAS listed on its website:

Knowledge acquisition, construction, integration and application Cognitive complexity

Intrapersonal development

Interpersonal competence

Humanitarianism and civic engagement

Practical competence. (Council for the Advancement of Standards in Higher Education, 2009, para. 3).

In his book Information on Student Outcomes: How to Get and How to Use it, Ewell (1983) articulated a definition of student outcome as "any change or consequence occurring as a result of enrollment in a particular educational institution and involvement in its programs" 
(p.11) including "a wide range of phenomena, from short-term cognitive development to longterm changes in behavior" (p. 3).

Ewell (1983) reviewed some typologies of student outcomes as discussed by Astin, Panos, and Creager (1967). As far as outcome types are concerned, cognitive outcomes represent "changes in actual knowledge or learning "and affective outcomes "changes in student attitudes or values". In terms of data types, psychological and behavioral data are used respectively to characterize "outcomes that are observable in overt student behaviors" and outcomes "that must be identified and measured by psychometric and allied techniques" (Ewell, 1983, p. 12). As noted by Ewell (1983) and Astin and Antonio (2012) institutions have a habit of focusing on psychological/cognitive outcomes. However, Astin and Antonio (2012) added that "no program of student outcomes assessments would seem complete without due consideration for assessment of relevant affective outcomes" (p. 47). They argued also that student perspective has not always been taken into account in the process although "students come to college with a wide variety of personal goals and aspirations" and that "no system of outcome assessment is adequate if it fails to incorporate some of this student perspective" (p. 43).

As noted by Ewell (1983), institutions have focused on outcomes that promote "claims of individual institutional success - mainly with respect to retention and graduation rates, placement in advanced-degree programs, and placement in favorable employment situations" (p. 3). Ewell went on to emphasize the way in which institutions are usually presented as having "missions, programmatic goals, and resource constraints" (p. 21). He argued that students should be perceived the same way because they have programs. No matter how less sophisticated student programs are, they have "a well-defined set of goals, a set of behavioral objectives, and a set of strategies to gain these objectives within limits imposed by the resources available" (p. 21) 
to them. Astin and Antonio (2012) added that the definition and assessment of outcomes are based on the value attributed to them and this is achieved through various lenses following the perspectives of academic departments, disciplines, professional boards, employers, states, and students.

Cuseo (2007a) defined student success "as a favorable or desirable student outcome” and linked student success to "positive student outcomes" (p. 2). Cuseo (2007a, 2007b) identified the following areas of college student outcomes: "retention (persistence), learning (academic achievement), and personal development (holistic outcomes)" (Cuseo, 2007b, p. 3). Retention implies continuous enrollment and pursuit of education; academic achievement and educational attainment are reached when students make sustained progress and ultimately achieve their educational goals through graduation; student advancement refers to the ability of students to achieve desired ultimate educational and professional goals; personal development refers to the holistic development of students at the intellectual, emotional, social, ethical, physical and spiritual levels (Cuseo, 2007a, 2007b).

Expanding on the component of holistic personal development, Cuseo (2007b) further argued that academic success and development occur when: (1) students achieve personal validation by feeling valued at their institution; (2) students experience self-efficacy by feeling empowered to become the agents of their own success; (3) students develop a sense of purpose through purposeful an relevant experiences and programs; (4) students experience active involvement by engaging in learning and experiences inside and outside the classroom; (5) students resort to reflective thinking through action and by connecting new to prior knowledge; (6) and students achieve self-awareness by engaging in self-discovery. 


\section{Assessment of Student Learning Outcomes}

The purpose of student learning outcome assessment is "to determine the effect of the experience on the participants, often measured in terms of learning or student growth and development" (Schuh, 2005, p. 148). Effective assessments should lead to findings that are utilized to introduce improvements in the areas of teaching and learning and to inform planning and resource allocation processes (Astin and Antonio, 2012; Schuh, 2005; Suskie, 2009; Tinto, 2012; Walvoord, 2004). Suskie identified various levels where student learning can occur and where assessment can be conducted, including at the course, program, general education, cocurricular, student life programming, cohort, and college or university levels. Walvoord (2004) saw the assessment movement as being mainly motivated by outside pressure of stakeholders who started to question the cost and quality of education. She listed the factors that fostered the emergence of the movement and they included educational reform, competition among higher education institution for students and resources, overall increased public expectations of results and educational information.

Ewell (1983) outlined three approaches to the identification and assessment of student outcomes in higher education. The first process is "a purely academic investigation" (p. 4), which thrives to explain the effect of higher education on students. This approach leads to theory development in the areas of student cognitive development with a focus on student learning and changes in attitude as a result of attending a higher education institution. Another aspect of this approach investigates the social changes that occur as a result of higher education. The second approach identified by Ewell, "the student-personnel perspective" (p. 4), is relating to the assessment of student outcomes involving advising and counseling in an effort to meet the needs of individual students. A focus is placed on student achievement and attitudinal data that are used 
to investigate how specific programs meet students' needs. The managerial perspective is the third approach identified by Ewell which views assessment of student outcomes as a tool for decision making and resources allocation. Astin and Antonio (2012) viewed assessment of student outcomes as a way to guide decision making because assessment results "can provide information about the likely impact of alternative courses of action" (p. 16).

Tinto (2012) viewed assessment as an opportunity to create a setting where feedback is shared with involved constituents for students to excel and succeed. He argued that "to be effective, assessments must be frequent, early and formative as well as summative in character" (p. 54). For him, assessment can take the form of classroom assessment, or assessment of student learning at the institutional level. Among all types of assessment mentioned by Tinto, such as entry-assessment, one-minute papers, learning portfolios, course, program and institutional level assessment, he argues that "the most effective form of assessment is that which monitors actual student performance in the classroom" (p. 63). He encouraged the use of classroom assessments within an early warning system to allow for an early detection of student who struggle and may need help. He argued that "early classroom difficulties, if left unattended, can snowball over time and undermine student learning" (p. 59). He urged also for an effective use of instructional technology to redesign some courses, especially those with high failure and lower performance rates, to provide success opportunities for all students. He encouraged the use of institutional assessment of student experience such as the National Survey of Student Engagement (NSSE) to collect students' perception of their classroom experiences.

\section{First-Year Intervention Best Practices}

The First-Year Experience. As previously mentioned, higher education has become more popular and has been able to attract various groups of students (Eckel \& Kezar, 2003; 
Taylor et al., 2011; Weisbrod, Ballou, \& Asch, 2008). The benefits of achieving a college degree are more and more perceived and valued (McMahon, 2009). Whether they are unprepared to pursue a college career (Taylor et al., 2011) or are not fully aware of the demands and expectations of college and entertain false assumptions about college life (Smith \& Wertlieb, 2005) today's students need an engaging and structured environment that will help them transition successfully into college and its mindset (Tinto, 2012).

Transition has been defined as "any event, or nonevent, that results in changed relationships, routines, assumptions, and roles" (Goodman et al., 2006, as cited in Evans et al., 2010, p. 215). Schlossberg (1984) provided a framework for the analysis of the ways people in situation of transition react to events and nonevents. Schlossberg's theory presented transition as a temporary condition that will end at some point. Transition is further decomposed into subgroups, "anticipated transition", "unanticipated transition", and "nonevent" (Evans et al., 2010, p. 215). Schlossberg identified four factors, i.e. "situation”, “self”, "support” and “strategies" (Evans et al., 2010, p. 217), as influential in one's ability to cope with transition. Personal characteristics and context are important in shaping the preparedness of students to cope with a transition situation. Although transition presents "opportunities for growth and development...positive outcomes for the individual cannot be assumed" (Evans et al., 2010, p. 213). Hence the importance of putting in place robust FYE programs to enhance the likelihood of first-year student success (Greenfield, Keup, \& Gardner, 2013).

Research on the first year of college has indicated that "the vast majority of the explained variance in academic competence is attributed to what happened to students during their first year and not to the characteristic they brought with them to college" (Reason, Terenzini, \& Domingo, 2006, p. 164), and that the first year of college is the critical period during which 
occurs the "significant gain in learning and cognitive development" (p. 149). Pascarella (2005) went as far as to posit that critical thinking skills developed in the first year of college "may represent a substantial part of the total growth in those areas attributable to the entire undergraduate experience" (p. 114).

The definition by Koch and Gardner (2006) explained well how comprehensive FYE programs should be:

The first-year experience is not a single program or initiative, but rather an intentional combination of academic and co-curricular efforts within and across postsecondary institutions... [that represent] a purposeful set of initiatives designed and implemented to strengthen the quality of student learning during and satisfaction with the first year of college - the stage in American higher education during which the largest proportion of university dropout occurs. (As cited in Greenfield, Keup, \& Gardner, 2013, p. xxx). An increased interest in the first year of college has been witnessed since the beginning of the 1980s (Alexander \& Gardner, 2009; Hunter, 2006). The University of South Carolina was one of the pioneer institutions in revitalizing first-year programs (Alexander \& Gardner, 2009). With the introduction in 2003-2004 of the Foundations of Excellence and of the nine aspirational principles known as the Foundational Dimensions, the John N. Gardner Institute has invited institutions to take the lead and conduct self-study based on excellence measures to determine if a new direction is needed in the way their FYE is packaged.

Greenfield and his colleagues (2013) have identified twelve interventions as critical to student success in the first year: high impact pedagogies, summer bridge programs, new student orientation, academic advising approaches and strategies, first-year seminar, learning communities, residential learning programs, developmental education, early alert warning 
systems, probation initiatives, peer leadership, and second-year transitions. These interventions are briefly described in the following pages.

High Impact Pedagogies. Greenfield, Keup, and Gardner (2013) recommended that students be exposed to high impact pedagogies, named after high impact strategies, a set of student-centered structures proposed by the Association of American Colleges and Universities, AACU, (2007, 2011, as cited in Greenfield, Keup, \& Gardner, 2013). Greenfield and his colleagues argued that high impact pedagogies align also with the characteristics of the wellknown Seven Principles for Good Practice in Undergraduate Education (Chickering \& Gamson, 1987, as cited in Greenfield, Keup, \& Gardner, 2013), the "engaging pedagogies" (Swing, 2002, as cited in Greenfield, Keup, \& Gardner, 2013), and other student success models.

Through its high impact strategies, the AACU (2007, 2011, as cited in Greenfield, Keup, \& Gardner, 2013), advocated for the establishment of robust first-year seminars and experiences programs to enhance student success. The AACU, recommended also that HEIs create environments that allow students to engage in shared learning experiences, form communities of learners, conduct undergraduate research, collaborate in learning processes, learn about diversity and global issues, learn through service and engagement with their communities, gain professional experience through internships, and participate in culminating courses and experiences.

Referring to the research by Kuh (2008a), Greenfield, Keup, and Gardner (2013) reported that exposure to high impact practices allow students to invest more of their time and energy into their college experiences, interact with faculty and peers, experience diversity, receive frequent feedback, and reflect on their experiences, in an integrative learning environment with high expectation. 
Summer Bridge Programs. Bridge programs are complex academic and social support structures implemented prior to the beginning of the first semester in college for some subgroups of the freshman class (Greenfield, Keup, \& Gardner, 2013; Tinto, 2012). Participants take part in "various enrichment activities and enroll in a range of college courses to help bridge the gap between high school and college coursework" (Tinto, 2012, p. 32). Greenfield, Keup, and Gardner (2013) recommended summer bridge programs, in order to create the conditions for improved retention, and smoother transition from high school to college, and to enhance academic and study skills, the development by students of strong connections with key staff members, and resources on campus that are critical for their success.

Bridge programs have been widely used to provide support services to a variety of student populations with diverse needs. A commonly encountered example includes cases when bridge programs were offered to help mitigate the impact of roadblocks to college success for underrepresented students (Kezar, 2000; Terenzini et al., 1996, as cited in Greenfield, Keup, \& Gardner, 2013). Characteristics for selecting participants often include the following: lowincome, first-generation, gender, race, academic ability (honor students, gifted students, less academically prepared students), area of study, transfer students (Greenfield, Keup, \& Gardner, 2013).

Summer bridge programs vary in length based on the needs, institution, resources, and program goals (Greenfield, Keup, \& Gardner, 2013; Jamelske 2009; Tinto, 2012). Typical interventions include instruction to reinforce mathematics, reading and writing skills as well as study skills such as note taking, time management, and learning styles identification mentoring (Kezar, 2000, as cited in Greenfield, Keup, \& Gardner, 2013). Tinto (2012) called for long term support beyond the pre-term period when the bridge program is held. He argued that "the long- 
term impact of summer bridge programs is even greater when they are connected to support programs that follow immediately at the beginning of the fall semester" (p. 32)

New Student Orientation. Introduced since the late 1880s, New Student Orientation is now a very common practice in American higher education (Greenfield, Keup, \& Gardner, 2013). Mullendore and Banahan (2005) defined New Student Orientation as "a collaborative institutional effort to enhance student success by assisting students and their families in the transition to the new college environment" (as cited in Greenfield, Keup, \& Gardner, 2013, p. 44). Because a large group of incoming students enter college underprepared for college life and college-level coursework (Taylor et al., 2011), with some clueless about the demands and expectations of college and entertaining false assumptions about college life (Smith \& Wertlieb, 2005), orientation should serve as a "rite of passage" (Greenfield, Keup, \& Gardner, 2013, p. 43) designed to welcome new students into their new environment in higher education.

Jacobs (2010) defined three main goals that have been commonly associated with orientation. New students join and connect with their new community, receive critical information for effective participation in the new community and are introduced to the campus culture (as cited in Greenfield, Keup, \& Gardner, 2013). Orientation may be the first critical contact for students and their families with the institution and it is important that it is effectively designed with the mission of "facilitating the transition of new students into the institution; preparing students for the institution's educational opportunities, and student responsibilities; initiating the integration of new students into the intellectual, cultural, and social climate of the institution; and supporting the parents, partners, guardians, and children of the new student" (The Council for the Advancement of Standards in Higher Education, 2009, as cited in Greenfield, Keup, \& Gardner, 2013, p. 44). 
Academic Advising Approaches and Strategies. Academic advising is one of the strategies that Greenfield, Keup, and Gardner (2013) recommended as a strategy to foster student success, especially in the first year. In the same vein, Frost (1991) viewed advising "not only as a method of selecting courses but also as a means of achieving success for students" (p. 1). Although advising approaches should be modeled based on institutional and student population characteristics (Greenfield, Keup, \& Gardner, 2013), O’Banion (1972) suggested five dimensions to academic advising: "exploration of life goals; exploration of vocational goals; program choice; course choice; and scheduling classes" (as cited in Greenfield, Keup, \& Gardner, 2013, p. 67).

The National Academic Advising Association (NACADA) recommended the following outcomes of academic advising for students:

craft a coherent educational plan based on assessment of abilities, aspirations, interests, and values; use complex information from various sources to set goals, reach decisions, and achieve those goals; assume responsibility for meeting academic program requirements; articulate the meaning of higher education and the intent of the institution's curriculum; cultivate the intellectual habits that lead to a lifetime of learning; [and] behave as citizens who engage in the wider world around them" (NACADA, 2012, as cited in Greenfield, Keup, \& Gardner, 2013, p. 68).

There are four commonly followed advising models. The first approach is prescriptive advising, a practice that highlights the central role of the advisor as a professional in charge of explaining and enforcing compliance to university policies and regulations regarding "the general education program, major declarations, and number of credits needed to progress toward a degree in a timely fashion" (Greenfield, Keup, \& Gardner, 2013, p. 68). The second model is 
developmental advising, a more student-centered model where "the teaching-learning relationships embedded in a holistic approach helps students clarify goals and develop the skills they need to achieve them" (p. 69). Frost (1991) considered that developmental advising “contributes to students' rational processes, environmental and interpersonal interactions, behavioral awareness, and problem solving, decision making, and evaluation skills" (Frost, 1991, p.16). For undecided students, (Gordon, 1984) pointed out the choice of a developmental model of advising that "acknowledges the differing characteristics, needs, and rate of maturation unique to each student" (p. 65).

Molina and Abelman (2000) suggested that intrusive, intentional, or proactive advising, the third model, is at the mid-point between prescriptive and developmental advising and focuses on building relationships in order to create the conditions for student success (as cited in Greenfield, Keup, \& Gardner, 2013).

Finally, for Bloom, Huston, and He (2008), appreciative advising, the fourth model, focuses on developing "a deeper personal relationship between advisors and students through an emphasis on the intrinsic ontological value of each student encountered" (as cited in Greenfield, Keup, \& Gardner, 2013, p. 70).

Whatever the approach selected, Frost (1991) argued that advising should be a studentcentered process where addressing the needs of students is the main focus with academic success as a key goal. He suggested that advising should be tailored to meet student needs based on the following characteristics: demographics, level of academic preparedness, disability status, athletes, and international status. He added that for a successful advising experience for first year and undecided students, advisors should be aware of the adjustment phase that transition to college invokes. He urged advisors to establish early and regular contact with their advisees and 
to encourage them to be responsible students. For undecided students, Frost recommended advisors to provide career and major exploration guidance, reassure students that the exploration phase is not a negative situation, and encourage them to develop positive attitudes about their experiences and themselves. Gordon (1984) recommended the identification of an experienced professional who would be the face of the advising services for undecided students and would coordinate the services provided by a team of experienced advisors.

First-Year Seminar. The FYS is an intervention strategy that is not new to higher education since it was introduced in the 1880s (Gordon, 1989, as cited in Greenfield, Keup, \& Gardner, 2013). After a period of decline, first-year seminars were re-introduced and redesigned in the 1970s to serve a diversifying body of entering college students (Doetkott \& Schnell, 2003; Greenfield, Keup, \& Gardner, 2013). First-Year Seminars serve as an extended orientation to the university and the new environment; they can take a variety of forms depending on the institution or the specific student subgroup needs (Greenfield, Keup, \& Gardner, 2013; Tinto, 2012).

Barefoot (1992) identified this purpose for the First-Year Seminar:

The freshman seminar is a course intended to enhance the academic and/or social integration of first-year students by introducing them (a) to a variety of specific topics, which vary by seminar type, (b) to essential skills for college success, and (c) to selected processes, the most common of which is the creation of a peer support group. (As cited in Greenfield, Keup, \& Gardner, 2013, p. 90).

Research on the First-Year Seminar revealed some common recurrent features including the fact that they are letter graded credit-bearing courses that typically last one academic term, count toward graduation and are taught in small-sized classes (Hunter \& Linder, 2005; Padgett \& 
Keup, 2011; Tobolowsky \& Associates, 2008, as cited in Greenfield, Keup, \& Gardner, 2013). The First-Year Seminar is believed to be "an important vehicle for achieving the learning and developmental objectives of undergraduate education in the United States" (Greenfield, Keup, \& Gardner, 2013, p. 89). Tinto (2012) concurred with the critical nature of the FYS when he asserted that "at no time is academic support more important than in the first year-indeed, in the first semester and first weeks of that semester. Early success - whether in the beginning classes of a course or in the first courses of a program of study-increases the likelihood of future success. Conversely, early failure substantially undermines future success” (p. 26).

In their study of the long-term impact of the first year seminar on student retention, Doetkott \& Schnell (2003) compared 1,853 students over a period of four years. The first group consisted of students who had enrolled in a first year seminar while the second group was composed of students who had declined the offer to enroll in a first year seminar course.

Retention rates for each of the four years were significantly higher for students who took the first year seminar as compared to those in the match group. Jamelske (2009) studied the impact of FYS courses on Grade Point Average and first-to-second year retention. For this purpose, he compared the performance of students enrolled in FYS courses with specific FYE goals with those in another version of the same courses with no compatible FYE goals. The findings revealed no positive impact on retention. However, students in the FYE-goal oriented section had higher GPAs compared to those in the comparison group. Further analysis of the data with a reduced sample including only students in sections with FYE compatible goals revealed a positive effect on retention as well as a higher GPA differential. Research by Swing (2004) revealed an increased impact of the FYS on retention with an increase in the number of contact hours (credit hours), with the involvement of undergraduate students as co-facilitators, and with 
co-registration of students in another course under the auspices of a learning community (as cited in Tinto, 2012).

Learning Communities. Learning communities can be defined as "clusters of courses organized around a curricular theme that students take as a group" (Laufgraben, 2005, as cited in Greenfield, Keup, \& Gardner, 2013, p. 113). They are student-centered first-year intervention programs introduced in the late $19^{\text {th }}$ century with the underlying philosophy to foster collaborative learning and increased peer interactions (Barr \& Tagg, 1995; Henscheid, 2004; Love, 1999; Newton \& Ender, 2010, as cited in Greenfield, Keup, \& Gardner, 2013). For Tinto (2012) the purpose of learning communities is to "construct an interdisciplinary or multidisciplinary learning environment in which students are able to connect what they are learning in one course to what they are learning in another" (p. 71) and provide students with "an effective way of bridging the gap between a student's social and academic engagements" (p. 36).

Learning communities are found under the forms of "paired or clustered courses, student cohorts in larger classes, team-taught programs, and living-learning communities" (p. 116). Clustered courses involve concurrent enrollment in two classes for a small group of students on the basis of "logistical curricular connections and skills areas" (Laufgraben, 2005, as cited in Greenfield, Keup, \& Gardner, 2013, p. 116). Student cohorts are similar to clustered courses and are also known as "freshman interest groups (FIGs)" (Greenfield, Keup, \& Gardner, 2013, p. 116). Student cohorts serve participants that are typically registered for a larger class but also meet in a smaller section, their FIG, "a designated discussion or recitation section" (Greenfield, Keup, \& Gardner, 2013, p. 117) of the larger class. In team-taught programs, students enroll in the same courses facilitated by several faculty members. These programs are formed around a theme that spans across disciplines, offering students the possibility of learning from different 
perspectives (Love \& Tokuno, 1999, as cited in Greenfield, Keup, \& Gardner, 2013). The livinglearning community model involves students taking some classes together and integrates a residential component with social and academic activities occurring in the residential area.

Brower and Dettinger (1998, as cited in Greenfield, Keup, \& Gardner, 2013) have constructed a model for learning communities based on three main assumptions: 1) clear parameters for selecting members to avoid "being exclusive or elitist"; 2) a reasonable group size to reach a "critical mass" while conserving a favorable environment to allow for a real "sense of community" to thrive within an effective "learning space"; 3) an effective balance between academic learning, social integration in the form of interaction between students, faculty, and staff, and the physical setting where learning occurs. These conditions are set to help develop “students' professional, civic, and ethical responsibilities” (p. 115).

Residential Learning Programs. A residential learning program or living-learning program is defined as follows:

a residential education unit in a college or university that is organized on the basis of an academic theme or approach and is intended to integrate academic learning and community living. The unit may or may not be degree granting and may involve collaboration with formal academic departments outside the unit. It provides formal and/or informal, credit and/or noncredit learning opportunities (courses, seminars, tutorials, firesides). (Bowling Green State University, 2013, as cited in Greenfield, Keup, \& Gardner, 2013, p. 136).

Although residential learning programs share some features with learning communities, “coresidence is a critical distinction" (Greenfield, Keup, and Gardner, 2013 p. 136). Learning communities do not necessary involve coresidence. 
The purpose of residential learning programs is 'to bridge students' academic experiences with other aspects of their lives" (Inkelas, Vogt, Longerbeam, Owen, \& Johnson, 2006, as cited in Greenfield, Keup, \& Gardner, 2013, p. 138). The most successful programs share the following features: they foster "strong partnerships between student and academic affairs", have "well conceptualized, academically oriented learning objectives," and take "full advantage of their community setting to promote learning whatever and whenever it occurred" (Brower \& Inkelas, 2010, as cited in Greenfield, Keup, \& Gardner, 2013, p. 138).

Developmental Education. Considering the growing popularity of higher education, the diversification of student population, and the resulting needs, HEIs are urged to transform access into opportunity by providing support to enhance the likelihood of student success (Tinto, 2012). Developmental education and learning assistance are made available to students in order to "enable them to develop college-level skills in reading, writing, and mathematics" (Greenfield, Keup, \& Gardner, 2013, p. 157). Entering students are typically asked to take placement tests and those with score that are deemed insufficient for direct enrollment into college-level coursework in certain subjects are required to enroll in developmental coursework before they are allowed in college-level courses.

Greenfield, Keup, and Gardner (2013) warned about the fact that time spent in development education may impact the time-to-degree as it takes longer to advance into classes that count toward a specific major and graduation. In addition to developmental coursework, they recommended that a battery of services in collaboration with various student support services on campus be made available to foster student success. Arendale (2005) argued that students who need support should not be perceived as deficient and rather proposed that developmental education and learning assistance be made available to all students as most of 
them will need some form of help or assistance while in college (as cited in Greenfield, Keup, \& Gardner, 2013).

Early Alert Warning Systems. An early alert warning system is "a formal, proactive, feedback system through which students and student-support agents are alerted to early manifestations of poor academic performance" (Cuseo, 2003a, as cited in Greenfield, Keup, \& Gardner, 2013, p. 179). They were put in place to enhance student success and to remediate to retention issues in higher education.

For Greenfield, Keup, \& Gardner (2013), early warning systems should be part of the strategies put in place by institutions to enhance student retention. They should be implemented early enough in the semester because "student disengagement is likely to begin during the initial weeks of the academic year, as indicated by habitual lateness, poor attendance, and failure to participate in class activities and complete assignments in a timely fashion" (p. 180). Greenfield and his colleagues argued that although the typical posting of midterm grade for first year students may be helpful, it may come too late for students to change their academic and social habits, change their class schedule by adding and dropping classes, and still maintain full time status and financial aid. They argued that an earlier identification of what causes students to struggle allows for the implementation of an efficient intervention.

Probation Initiatives. Greenfield, Keup, and Gardner, (2013) recommend the use of probation initiatives as another way to enhance student success. They report that HEIs determine the criteria for placing some of their student on what is known as academic probation. Possible conditions may include student earning a required grade point average or earning a certain number of credit hours based on credits attempted. Not meeting these requirements may lead to academic probation with a process that may include suspension from the institution for one term 
or one academic year. Being placed on probation is a sign that a student struggles academically. Data on student performance and retention revealed that 25 percent of students wind up on academic probation while in college, and that 50 percent of students on academic probation leave the institution with an overall 66.5 percent retention rate for first-year students returning for a second year (ACT, 2012; Cohen \& Brawer, 2002; Damashek, 2003, as cited in Greenfield, Keup, \& Gardner, 2013).

Probation initiatives may take a variety of forms depending on student needs and institutional type and should provide an array of campus resources, information, and include meeting some requirements designed to help students get back on track academically (Greenfield, Keup, \& Gardner, 2013). In their review of probation initiatives, Greenfield and his colleagues observed that "programs tend to take a holistic approach that recognizes the impact of nonacademic factors, for example, financial or familial challenges, that may have affected the student's academic performance" (p. 205).

Peer Leadership. Astin (1993) highlighted the important role of peers in higher education when he asserted that "the student's peer group is the single most potent source of influence on growth and development during the undergraduate years" (p. 398). Newton and Ender (2010) defined "peer educators" as "students who have been selected, trained, and designated by a campus authority to offer educational services to their peers...[which]...are intentionally designed to assist in the adjustment, satisfaction, and persistence of students toward attainment of their educational goals" (as cited in Greenfield, Keup, \& Gardner, 2013, p. 224). Summarizing the literature on peer leadership Greenfield and his colleagues identified several names utilized to designate those students who intervene with faculty and staff in the education and development of their peers. Such names include "peer counselor, ambassador, student coach, 
student assistant, peer advisor, student facilitator, instructor, and tutor" (Cuseo, 2010c; Newton \& Ender, 2010; Keup, 2012, as cited in Greenfield, Keup, \& Gardner, 2013, p. 226).

Greenfield, Keup, and Gardner (2013) distinguished three different types of peer leadership programs: peer mentoring, where student leaders acts mainly as role models and provide a variety of support to their peers; peer educator, where student leaders provide mainly academic support in the framework of tutoring or supplemental instruction services; peer leader, where student leaders play a more flexible role, which "aligns with the notion of leadership and engaged citizenry as key outcomes of college" as described by the Association of American Colleges and Universities (2007) and summarized by Greenfield and his colleagues ( 2013, p. 226). Depending on the position they hold and the needs of students, peer leaders assume a variety of roles such as "personal support agent, academic success agent, or learning coach, role model, resources and referral agent, college success agent, and life success coach” (p. 225), all key roles in the success of their peers.

Second Year Transitions. The intervention strategies mentioned so far are devoted to the first year of college. The second year is as important as the first year according to Greenfield, Keup, and Gardner (2013) who suggested initiatives to "ease another challenging transition for students" (p. 249). They have identified some of the services that second year student may still need. They may still need some form of academic support due to increasing academic challenge of second year class. It is a good time for them to strengthen their academic skills because, some students may still be without a declared major and may still have freshman status due to limited number of credits hours completed during the first year. Second year students appear to be as fragile as first year students. The second highest dropout rate is recorded in the second year. (Lipka, 2006, as cited in Greenfield, Keup, \& Gardner, 2013). 


\section{College Student Engagement}

With the numerous issues facing higher education in the $21^{\text {st }}$ century the literature has considered student engagement in college as a key factor of student success. Tinto (2012) argued that student involvement is "perhaps the most important" (p. 64) factor that fosters student retention (Tinto, 2012). HEIs were urged to provide the setting for an increased student engagement with their college experience as a whole. Reason, Terenzini, and Domingo (2006) pointed out that "the more actively students involve themselves in the curricular and cocurricular experiences of college, the more growth they can expect to experience" (p. 154). They reiterated the value-added and benefits of the dimensions of the college student involvement structure (curricular, classroom and out-of-class engagement) that the literature has found to be yielding notable gains in student learning, persistence, and development.

In his study on the relationships between the status of being undecided and persistence, Lewallen (1993) found that student involvement in college along with some precollege characteristics and the institutional environment were "significantly associated with persistence" (p. 110). College involvement was measured through student curricular and classroom engagement (e.g., grades, enrollment in honors or advance courses, participation in research activities with faculty) as well as out-of-class experiences (e.g., leadership position in student organizations). Lewallen concluded that undecided students were not that different from other college students because "they have the ability or inability to persist based on personal characteristics, the college environment, and college involvement, regardless of whether they are undecided" (p. 110).

One of the most popular instruments utilized to measure student involvement in college is the National Survey of Student Engagement (NSSE). It was introduced in 2000 at the Indiana 
University Center for Post-Secondary Research \& Planning to assess how undergraduate (FirstTime Freshmen and Seniors) spend their time and what they gain from their college experiences. NSSE intended also to identify aspects of the undergraduate experience inside and outside the classroom that could be improved through changes in institutional policies-thus leading to improved student learning and success. An updated version of the survey instrument, also known as "The College Student Report", revealed in 2013, entailed 38 items designed to gather information pertaining to the following categories: “(1) participation in dozens of educationally purposeful activities, (2) institutional requirements and the challenging nature of coursework, (3) perceptions of the college environment, (4) estimates of educational and personal growth since starting college, and (5) background and demographic information" (NSSE, 2013). Students provide a self-report of their opinions about their college or university, and their learning and personal development during their college education. In addition to the main survey, institutions have the option of adding available additional modules based on their institutional needs. At the end of the survey cycle, NSSE publishes an extensive general report detailing results at the national level and sends customized institutional results to participating HEIs.

NSSE has also identified five indicators or benchmarks of "Effective Educational Practice" which are measured through the survey. The five benchmarks include "Level of Academic Challenge”, “Active and Collaborative Learning”, "Student-Faculty Interaction”, "Enriching Education Experiences", and "Supportive Campus Environment". Institutions are compared across time and to each other based on their score on certain questions. The nature of the survey allows it to provide "data and information that colleges and universities can use to improve educational practices" (Hayek \& Kuh, 2002, p. 60). On one hand, it allows colleges and universities, through the benchmarking mechanism, to compare their results to those of identified 
peers and to national scores. On the other hand, they can also compare different categories of students within their own institution (Schroeder, 2003). The results highlight their strengths and weaknesses, thus showing the institutions the "places where changes in policies and practices could enhance student engagement" (Gonyea \& Kuh, 2009, p. 2). The benchmarks help create "a common language to talk about these important matters" and create a favorable environment for conversations and actions about learning-centered practices” (Schroeder, 2003, p. 13).

The results of the NSSE instrument may be used to determine the level of student engagement with regards to good educational practices and has been reported as "the best predictor of student success, after controlling for past academic performance and preparation " (Kinzie \& Kuh, 2004, p. 2). Some institutions identified by Bridges et al. (2005) have used their NSSE results to serve the following four main purposes: “(1) determining needs of entering and first-year students, (2) identifying obstacles to student progress toward graduation, (3) strategic planning, and (4) representing the institution to external communities" (p. 37). Ahlfeldt et al. (2005) argued that NSSE results helped reveal not only "the extent to which colleges and universities are participating in educational practices that are strongly associated with high levels of learning and personal development" but also "how students use [institutional] resources for learning" (p. 7).

One area of improvement where institutions are sometimes lacking crucial information is retention. Bridges et al. (2005) found that "students who were less able to engage with their academic program were more likely to leave early, even when controlling for such other factors as low GPAs" (p. 30). Tinto (2012) argued that student engagement may be manifested toward one subgroup of the university community and it is important in engagement research to investigate all aspects of this relationship with the community. Tinto contended that "retention 
requires that a student sees him- or herself as belonging to at least one significant community and finds meaning in the involvements that occur within that community" (p. 67). Student learning is another area where improvement is vital to student experience. NSSE does not assess student learning directly but "the results of the survey point to areas where colleges are performing well, and to aspects of the undergraduate experience that could be improved" (Schroeder, 2003, p. 10).

Kuh, Kinzie, Schuh, and Whitt (2005) saw engagement as involving two main groups of stakeholders, students and institutions.

The first is the amount of time and effort students put into their studies and other activities that lead to the experiences and outcomes that constitute student success. The second is the ways an institution allocates its human and other resources and organizes learning opportunities and services to encourage students to participate in and benefit from such activities. (p. 4)

Kuh et al. (2005) have developed eight guiding principles to foster student engagement and success by examining the experiences of institutions engaging in best practices in that respect. They recommended HEIs to: (1) focus in creating environments where the institutional mission, cultures, and student characteristics are aligned and combined to become the catalysts of effective engagement and success; (2) adopt an approach where a tridimensional structure of engagement (academic, interpersonal, and extracurricular) interplay and contribute to the achievement of an enriched and holistic outcome; (3) engage in continuous institutional learning using information generated through tools such as the NSSE instrument and triangulated with information from other sources to assess student experiences; (4) avoid taking assumptions for granted by testing those assumptions over and over in an effort to have the best possible sense of the real student experience; (5) involve a large number of stakeholders in a collaborative process 
where diverse perspectives are joined to shape a bigger and more accurate picture; (6) create opportunities for stakeholders to exchange with and learn from outsiders and their feedbackthus allowing an influx of fresh and revealing ideas; (7) determine priorities about what is important, what goals to achieve, and focus on a continuous quest for improvement; (8) acknowledge that transformational change is a step-by-step but far-reaching process that does not necessarily happen drastically.

In conclusion, students should get involved in their college experience by investing their time and developing the connections to enrich this experience. Colleges and universities should create favorable settings that will allow successful engagement to happen and trigger student success in all its aspects. Engagement is so complex in nature that colleges and universities should thrive to provide students with experiences that meet their needs, because they will be "more likely to become involved in those forms of activity that are perceived to be relevant or at least meaningfully related to their interests broadly understood" (Tinto, 2012, p. 67).

\section{Data Driven Decision Making and Accountability}

Picciano (2006) defined data-driven decision making as "the use of data analysis to inform when determining courses of action involving policy and procedures" (p. 6). Picciano recommended the use of the systems approach with its components (input, process, and output) as the underlying structure for the application of data-driven decision making. In the field of education, the typology of data that might guide decision making include "input data", e.g., "demographics of the student population"; "process data", e.g., "the quality of instruction"; "outcome data", e.g., "dropout rates"; and "satisfaction data" collected from stakeholders (Marsh, Pane, \& Hamilton, 2006, pp. 2-3). 
Accountability was defined as "a systematic method to assure those inside and outside the higher education system that colleges and universities — and students - are moving toward desired goals" (Leveille 2005, as cited in Suskie, 2009, p. 61). Suskie reported that since the mid-1980s there has been more pressure from the federal government on accrediting agencies to push colleges and universities to demonstrate actual student learning. The argument of the accountability movement is that "since the mission of all colleges and universities includes the education of students, colleges and universities must now provide evidence that students are achieving whatever learning goals the colleges have established" (p. 62). Summarizing the work by Darling-Hammond (2004), Picciano (2006) reported five aspects to the demand for accountability in education including a political aspect—-legislators and educational leaders are expected to be accountable to their constituents; a legal aspect—institutions should abide by laws; a bureaucratic aspect—operations are governed by certain guidelines; a professional aspect —instructors are expected to follow good practice and adhere to professional standards; and a market aspect—institutions may need to compete for students, especially when students and parents have the ability to choose.

Joining the call for more accountability, the National Governors Association introduced outcome and progress metrics to help institutions check the progress made at key stages by students while they work their way toward certificate or degree completion (Reyna, Reindl, Witham, \& Stanley, 2010). The NGA argued that "information on the progress toward, and degree completion of, all students in higher education allows state leaders to gauge whether policies are successful and helps inform future funding decisions” (Reyna et al., 2010, p. 5). A study revealed that 57 percent of Americans believe that "the higher education system in the United States fails to provide good value of the money students and their families spend" (Taylor 
et al., 2011, p. 1). McMahon (2009), considering the fact that stakeholders in higher education have to pay more and more for an education, asked this question: "What do we get for that very considerable investment" (p. 11). He was concerned about how institutions of higher education can achieve both "internal efficiency (related to unit costs) and external efficiency (how well the outcomes relate to social benefits expected by society)" (p. 12). With "increased accountability and its siblings assessment and quality assurance, the need to better fulfill the public service role expected on higher education" (Eckel \& Kezar 2003, p. 16) is more than ever relevant.

Additionally, the push for more accountability in higher education led the Lumina Foundation (2013) to urge educators to "adopt data- and evidence-based policies, partnerships, and practices that close attainment gaps for underserved students and improve overall completion rates" (p.13). Eckel and Kezar (2003) argued that "building new programs or making changes that support the academic success of diverse students requires resources that may not be available" (p.16). That means that educational programs — such as the success program analyzed in this study - will be constantly evaluated for effectiveness in order to continue to benefit from the allocation of scarce resources (Ewell, 1983).

Kezar, Carducci, and Contreras-McGavin (2006) considered data-based decision making to be an accountability practice that leads to organizational learning which in turn introduces organizational change, "a core aspect of the leadership process" (p. 155). They contended that accountability practices such as data-based decision making, assessment, and benchmarking serve as triggers for the implementation of innovation in higher education. Kezar and her colleagues also contended that along with a focus on achieving goals, accountable leaders are concerned about observing ethical standards and building trust in their interactions with stakeholders. Furthermore, accountable leaders focus on the learning process in order to improve 
it. Tinto (2012) called for institutional action and warned that "without institutional commitment, which springs from institutional leadership, to the goal of increasing student success" (p. 113), student success programs are not likely to produce the desired outcomes.

\section{Undecided Students}

Gordon (1984) defined undecided students as those "who are not committed to an educational or career direction" (p. 3). Although some students usually designated as undecided may be unsure about their major and career interests, others may be "shadow majors" because they "are decided on a major, but have not yet been accepted or admitted to the major of their choice" (Cuseo, 2005, p. 31). Those two groups have been also described as "Non-Specific Majors", for those who are completely undecided and exploring their options, and "Specific Majors" for those with a desired major who have not yet been accepted to that major (Gordon, 1998, as cited in Brown, 2009 p. 8).

Gordon (1984) stated three reasons why undecided students should benefit from institutional support: the important number of undecided students, the fact that they are depicted in the literature as "attrition prone" and the scale with which students change majors during their college career. She argued that undecided students constitute a heterogeneous population with various needs and interests and that indecision about their college major may be influenced by economic, sociological, and development factors. She recommended that programs designed to support this population be appropriate to the environment, take into account specific needs and characteristics of students, and assist with career discovery and decision making. She emphasized the importance of an institution wide support structure to deliver a wide range of services to meet the various needs of undecided student and foster their success. 
Cuseo (2005) argued that "if students develop a viable plan for identifying a college major and related career that is compatible with their abilities, interests and values, then their overall level of satisfaction with college should increase" (p. 28). This also increases their likelihood to persist at the institution as empirical finding suggested (Noel \& Levitz, 1995; Noel, Levitz \& Saluri, 1985; as cited in Cuseo, 2005).

Lewallen (1993) insisted on the fact that undecided students do not constitute a homogenous group and that one should make the assumption that they are more at-risk than any other students. He found misleading to make generalizations about undecided students based on "one input variable" (p. 104). In contrast, he found student involvement along with some precollege characteristics and the environment to be "significantly associated with persistence" and concluded that undecided students "have the ability or inability to persist based on personal characteristics, the college environment, and college involvement regardless of whether they are undecided" (p. 110).

\section{Concept Mapping/Pattern Matching}

Concept Mapping as a research methodology has been utilized under various forms for conceptualization, planning, and evaluation processes (Novak \& Gowin, 1984; Rico, 1983 as cited in Trochim, 1989a). Reporting about one of the various usages of concept mapping in the literature (Novak, 1990; Novak and Cañas, 2008), Valdes-Vasquez and Klotz (2013) described how it involved "individuals writ[ing] their ideas in separate boxes by using lines to connect related concepts, often including labels showing the type of connection to build meaning among them" (Valdes-Vasquez \& Klotz, p. 2). What makes the process introduced by Trochim unique is that it leads to "a group aggregate map" (Trochim, 1989a, p. 1) through "a systematic approach 
to collect qualitative data from various experts combined with quantitative analyses to represent the results graphically" (Valdes-Vasquez \& Klotz, 2013, p. 8).

Along with Concept Mapping, Trochim (1989b) recommended the utilization of Pattern Matching, an additional measurement tool that attempts "to link two patterns where one is a theoretical pattern and the other is an observed or operational one" (p. 356). For Michalski and Cousins (2000), "pattern matching allows for the combination of any two measures (e.g., statement importance ratings either within or between groups) aggregated at the concept map cluster level to examine the degree to which the measures match. By examining such combinations of measures, differences between stakeholders can be identified and quantified" ( $p$. 217). The following paragraphs describe a sample of studies in a variety of fields that followed the Concept Mapping/Pattern Matching methodology.

A study by Trochim, Stillman, Clark, and Schmitt (2003) aimed at developing a "map of tactics that the tobacco industry uses to undermine tobacco control efforts" (p. 41). A total of 34 tobacco control experts were involved in an online brainstorming exercise that consisted in responding to the following focus prompt: "one specific activity/tactic the tobacco industry uses to oppose tobacco control is..." (p. 41). From a total list of 226 brainstormed ideas, 88 were included in the final list for sorting and rating. The maps derived from the process were interpreted by 13 experts, a subgroup of the initial participants. The interpretation of the results revealed the following information. The experts divided the cluster map into four sections: top, bottom, left and right. The top section of the map displayed four clusters "thought to describe the messages that the tobacco industry issues or tries to control" (p. 144). The bottom section displayed four other clusters reflecting "industry actions — what the tobacco industry does" (p. 144). The left section was thought to "represent tactics that are more hidden or covert in nature. 
On the right are tactics that tend to be more overt or public in nature" (p. 144). Trochim and his colleagues, recommended the use of the results for program evaluation and planning and as a resource "informing current or future frameworks used to classify and analyze tobacco industry documents" (p. 141).

In another study, the Concept Mapping/Pattern Matching methodology was used to collect ideas in order to help with the conceptualization of accreditation standards for the American Evaluation Association (AEA) (Trochim, 1996a). The focus prompt that guided the study was: "Generate statements (short phrases or sentences) that you believe AEA should include in its Standards for Accreditation of Graduate Programs and Specializations in Evaluation" (p. 54). The brainstorming session was conducted online with an undetermined number of people submitting ideas. Concept maps were developed and sorting and rating were performed by a group of 23 people. These maps were made available online to solicit comments.

The generated items were grouped into clusters. The way the clusters were visually represented allowed for the determination of two subgroups: one that included program-specific clusters: "program philosophy, program context, faculty qualification"; and another that included clusters related to the curriculum: "curriculum philosophy, diversity courses, student competencies, quantitative approaches, field experience/practicum" (p. 55). The results of this participative process allowed for the development of a framework that could be used for the development of accreditation standards and evaluation areas.

There were more and more studies using Concept Mapping/Pattern Matching in the area of training evaluation. For example, examining a training program, McLinden and Trochim (1998a) demonstrated how to determine its value-added or "return on expectation" (p. 22), how to measure the value-added, and what the measurement process to follow was. They contended 
that to determine that a training program is adding value, three conditions have to be met: "consensus, correspondence, and consistency" (p. 21). Consensus can be achieved by involving different groups of stakeholders and ensuring that expectations of all groups are aggregated to achieve a consensual expectation measure. Expectation ratings for each section of the training can be "averaged and visually displayed on a vertical number line" (p. 23). For correspondence to be achieved, "a match pattern" should be observed between the rating of expectation and that of the outcome measurement. Consistency is achieved when similar results are observed over time for the same training. For consistency to be achieved, the educational offering of the training should be the same over time as well as the amount and quality of resources devoted to the training.

Still in the area of training evaluation, the study by Michalski and Cousins (2000) consisted in conceptualizing the perceptions of training outcomes by three groups of stakeholders within the same company. A total of 39 participants were involved including 13 who worked in management, 13 in product development and the remaining 13 in training development. They generated a total of 100 statements representing desired outcomes of a given training. After the sorting phase, they were asked to rate each item in terms of its importance as a training result and as a "training evaluation criterion" (p. 216). Concept maps were developed, and to reveal intra and inter group differences "21 pattern matches performed" (p. 211). The conclusions of the study revealed that there was some agreement on the importance of the items as training results. Conversely, major differences were noted as far their importance with the group of training providers revealing "the strongest contrasting view regarding training evaluation" (p. 222). Concept Mapping/Pattern Matching has been widely used in educational settings. The current research study has been modeled after Messman-Mandicott's (2012) dissertation entitled 
The Use of Concept Mapping/Pattern Matching to Determine the Content Domain for

Information Literacy in Baccalaureate Education. Messman-Mandicott involved 14 stakeholders at a university in the State of Maryland to conceptualize the outcomes of information literacy instruction. Participants were invited for a face-to-face brainstorming session where they developed a set of 80 statements by responding to the following prompt: "What are the student learning outcomes for information literacy that the University should expect of its graduates? (p. 90)". After the sorting of the statements, Messman-Mandicott transformed the list of items into a survey that was sent to the participants for rating the importance of each item for students and the efficacy of the university in ensuring that students achieved that outcome. She checked the findings against the standards of the Association of College and Research Libraries standards for relevancy. She arrived to the conclusions that the standards of the Association of College and Research Libraries aligned with outcomes identified at the local university. She recommended libraries to increase their use of multimedia when sharing information and to include all parties in similar conceptualization processes. She finally noted that stakeholders do not always agree on the value-added of information literacy instruction.

Another recent dissertation by Adu (2011) examined the reasons that push doctoral students to drop out of graduate school before achieving their degree. He involved 38 faculty members and 114 doctoral students in research universities around the United States in a conceptualization process that aimed at uncovering their perceptions of the five domains of doctoral advising revealed by the literature: “(a) advising approach, (b) selection process, (c) roles, responsibilities, and expectations, (d) advisor-advisee relationship, and (e) power relations (p. 16). Adu built a survey made of 40 statements developed based on his review of the literature on the topic. In the survey, participants were asked to first organize the list of statements into 
clusters and then to rate each item based on the difficulty of realizing the item and on the importance of the item in the doctoral degree completion process. The findings revealed that faculty members were more preoccupied by faculty-student interaction and delivery of support to doctoral students. As for students, they valued more receiving "guidance and structure" (p. 138) to help them complete their dissertation.

A final example of use of Concept Mapping/Pattern Matching in an educational setting is the study by McLinden and Trochim (1998b) that attempted to determine the value-added of an education program. The researchers argued that this methodology was more appropriate than "determining the monetary value of an investment in education" because "education involves a series of human transactions that introduce ambiguity" (p. 286). The study was conducted in a school setting where students were asked to generate, sort, and rate training expectations. A total of 66 statements were developed. The rating phase consisted in assessing "the degree of impact each outcome should have in the program" and their "degree of importance with respect to the program" (p. 291). After the generation of concept maps, seven clusters were delineated and pattern matches were performed. The interpretation of the results allowed the researchers to show how important it is to involve all concerned stakeholders. They also determined that the training was effective in achieving expected outcomes even if performance decreased slightly with time. They finally identified topics that were effectively covered versus those that were poorly covered.

Concept mapping as described by Trochim is often compared to the Delphi method, another "expert-based" methodology "useful for soliciting individual judgments, integrating them, and making decision" (Valdes-Vasquez \& Klotz (2013, p. 1). These authors considered that "one of the primary advantages of this method in relation to the Delphi approach is the 
possibility to present the results in graphs (concept maps), creating more meaningful ways to communicate and help analyze the results" (p. 8). They pointed out that Concept Mapping/ Pattern Matching is "suited to developing exploratory studies" whereas the Delphi method is "most appropriate for forecasting" (p. 2). Another major difference is that "concept mapping differs in the way it collects the initial input from the experts, without preconceived answers" (p. 2). The process allows each expert to code "his or her own judgment without being influenced by other experts, which may happen with the Delphi method's multiple structured feedback rounds" (p. 2).

\section{Established Conceptual Framework-Foundational Dimensions}

The results of the current study were explored to determine to what extent they align with the Foundational Dimensions, a conceptual framework established by the John N. Gardner Institute. The Foundational Dimensions are the core principles that underlie the Foundation of Excellence (FoE). "Foundation of Excellence is a comprehensive, externally guided self-study and improvement process" developed to assist HEIs in assessing and improving their first year programs (John N. Gardner Institute for Excellence in Undergraduate Education, 2005). The Foundational Dimensions were designed with two target populations in mind: a version for firstyear students and another one for transfer students. These two versions are further subcategorized according to institutional type: a four-year focus and a two-year focus. The fouryear version with a first-year focus served as a reference for the current study.

The Foundational Dimensions establish a comprehensive model and, as a research framework, provide a suitable instrument to assess and investigate student experiences in the first college year (Reason, Terenzini \& Domingo, 2006, p. 151). The Foundational Dimensions were first developed in Academic Year 2003-2004 in conjunction with over 300 institutions 
nationwide as "a set of mutually agreed-upon standards of excellence" (Alexander \& Gardner, 2009 p. 19). The Dimensions are believed to "underlie the structures, activities, and cultures of institutions that are effective in promoting the success and persistence of their first-year students" (Reason, Terenzini \& Domingo, 2006, p. 151). Four fundamental assumptions underlie the establishment of the Dimensions:

- The academic mission of an institution is preeminent;

- The first college year is central to the achievement of an institution's mission and lays the foundation on which undergraduate education is built;

- Systematic evidence provides validation of the Dimensions;

- Collectively, the Dimensions constitute an ideal for improving not only the first college year, but also the entire undergraduate experience. (John N. Gardner Institute for Excellence in Undergraduate Education, 2005)

The following are the labels of the nine Foundational Dimensions preceded by a brief description as presented on the John N. Gardner's Institute website (refer to Appendix A for a complete description):

Foundations Institutions approach the first year in ways that are intentional and based on a philosophy/rationale of the first year that informs relevant institutional policies and practices... (Philosophy)

Foundations Institutions create organizational structures and policies that provide a comprehensive, integrated, and coordinated approach to the first year... (Organization) Foundations Institutions deliver intentional curricular and co-curricular learning experiences that engage students in order to develop knowledge, skills, attitudes, and 
behaviors consistent with the desired outcomes of higher education and the institution's philosophy and mission...( Learning)

Foundations Institutions make the first college year a high priority for the faculty... (Faculty)

Foundations Institutions facilitate appropriate student transitions through policies and practices that are intentional and aligned with institutional mission... (Transitions) Foundations Institutions serve all first-year students according to their varied needs... (All Students)

Foundations Institutions ensure that all first-year students experience diverse ideas, worldviews, and cultures as a means of enhancing their learning and preparing them to become members of pluralistic communities... (Diversity)

Foundations Institutions promote student understanding of the various roles and purposes of higher education, both for the individual and society... (Roles and Purposes) Foundations Institutions conduct assessment and maintain associations with other institutions and relevant professional organizations in order to achieve ongoing first-year improvement... (Improvement). (John N. Gardner Institute for Excellence in Undergraduate Education, 2005). 


\section{Chapter Three: Methodology}

The research method that guided this study is Concept Mapping/Pattern Matching

(CM/PM). This chapter starts with a restatement of the research questions then discusses some benefits to the use of CM/PM in this study and explains how the six steps of the CM/PM method were carried out. Finally, the researcher provides a description of the participants, the collection and treatment of the data, and the limitations of the methodology.

\section{Research Questions}

By design, this study is seeking to broaden and deepen the knowledge pertaining to the domain of student learning in the first year of college. In this endeavor, the following research questions guided this study:

RQ 1: What is the desired domain of student learning of a first-year success program serving first-time, full-time undecided students as conceptualized by stakeholders at a land-grant university, when using the Concept Mapping/Pattern Matching methodology?

a. To what extent do program stakeholder groups differ in their rating of the relative importance of student learning outcomes for ensuring student success?

b. To what extent do program stakeholder groups differ in their evaluation of the overall efficacy of their institution's success program in helping students achieve desired learning outcomes?

RQ 2: To what extent does the conceptualized desired domain of student learning under Research Questions 1 align with the Foundational Dimensions established by the John N. Gardner Institute? 


\section{The Concept Mapping/Pattern Matching Methodology}

As stated previously, this study aims at enriching the set of outcomes that were defined based on the perspective of the institution and that the researcher believes is lacking student perspective. The researcher believes that one way to achieve the goal of conceptualizing the domain of student learning in the first year of college that encompasses both student and institutional goals is to involve a variety of stakeholders in the process. Conceptualization through $\mathrm{CM} / \mathrm{PM}$ appeared to be a suitable option as it allows for the involvement of various stakeholders playing specific roles within the institution and the success program and more importantly, "with knowledge or experience of relevance to the issue at hand" (Kane \& Trochim, 2009, p. 440). Several techniques of conceptualization through Concept Mapping have been utilized by various fields of study since the 1960s (Kane \& Trochim, 2009; Trochim \& Linton, 1986). For this study, the researcher resorted to the conceptualization process described by Trochim (1989a) that concludes with the development of a concept map, which he defines as a pictorial representation of the group's thinking which displays all of the ideas of the group relative to the topic at hand, shows how these ideas are related to each other and, optionally, shows which ideas are more relevant, important, or appropriate. (p. 2).

As for Pattern Matching, it is a measurement tool that allows to "link two patterns where one is a theoretical pattern and the other is an observed or operational one" (Trochim, 1989b, p. 356). It is often used to enhance the results of a Concept Mapping process.

Kane and Trochim (2009) recommended CM/PM "when the desired outcome of a group's thinking is not well articulated" (p. 441). They considered CM/PM as a process that "generates a conceptual framework for planning and evaluation that has several benefits for 
social scientists and other researchers, compared with less sophisticated conceptualization approaches such as focus groups" (Kane \& Trochim, 2007, p. 1).

Kane and Trochim (2009) argued that Concept Mapping is a valuable tool as it allows for the establishment of a connection between theory and practice. It allows a group of people to express their thinking as it relates to a specific aspiration or issue and their plan to address it. It also provides the stakeholders with tools for decision making, action, or evaluation. The process fosters the application of agreed upon interventions.

The process involves gathering ideas from various stakeholders and from various sources, and leads to the development of a framework of generated ideas that are visually mapped and that can serve for program planning, implementation, evaluation, and feedback delivery (Kane \& Trochim, 2007). This research methodology is a collaborative and participatory process that can be implemented with variable sizes of participant groups and where participants "rather than the facilitator" (p. 2) are at the forefront of the process.

Other reasons for the choice of Concept Mapping as described by Trochim is that it is "a systematic approach to collect qualitative data from various experts combined with quantitative analyses to represent the results graphically" (Valdes-Vasquez \& Klotz, 2013, p. 8). Rosas (2012) also praised the capacity of Concept Mapping to synthesize "qualitative and quantitative data in a complementary and additive manner" (p. 14). Patton (2002) acknowledged the benefit of using $\mathrm{CM} / \mathrm{PM}$ "as a way of visually displaying data to facilitate analytic clarity and depicting relationships in a network or system" (p. 471).

Rosas (2012) emphasized the characteristics of Concept Mapping as a participatory research methodology where, with the involvement of stakeholders in the research process, ultimately "knowledge-generation and the process of learning are linked to concrete action" 
(p. 10). Reviewing the study by Hansen et al. (2005), Rosas (2012) noted that they "characterize concept mapping as part of sequential exploratory designs" (p. 14). Hansen and his colleagues (2005) explained that in sequential exploratory designs, qualitative data are collected and analyzed first, followed by quantitative data...Quantitative data are used primarily to augment qualitative data. Data analysis is usually connected, and integration usually occurs at the data interpretation stage and in the discussion. These designs are useful for exploring relationships when study variables are not known, refining and testing an emerging theory, developing new psychological test/assessment instruments based on an initial qualitative analysis, and generalizing qualitative findings to a specific population. (2005, p. 229).

Kane \& Trochim (2007) identified five player groups in the concept mapping process: the "initiator(s) (p. 29) is an entity or individual introducing and undertaking the process and in charge of its planning and implementation. The "facilitator" is the individual in charge of leading the implementation of the conceptualization process. The "Advisory Group" is composed of representatives of the constituency "with an oversight role for some or all phases of the project". The "Core Participant Group" is made of individuals selected or committed to participate in the six steps of concept mapping. The "Invited Participants Group" (p. 30) is made of representatives of a larger audience concerned by a particular issue.

This study was initiated by the researcher in the framework of a doctoral dissertation. Although no one at the Reference University commissioned this study, the university could be considered as a beneficiary of its results. Concept Mapping/Pattern Matching affords unique opportunities to take into account simultaneously stated, unstated and even yet unidentified student outcomes in the first college year. The steps involved in CM/PM allowed a group of 
selected participants to generate statements, and engage collaboratively and individually in a process that produced a series of concept maps. These maps display a broader view of the domain of student learning in the first year of college and reveal for example what is more or less important, what should be given priority, and what is feasible. The concept maps guided the development of recommendations and may serve as a framework for the planning and evaluation of future programs for first year college students at said institution. As pointed out in the literature (Kane \& Trochim, 2007; Trochim, 1989a), these maps are useful tools in both planning and evaluation of programs.

The six-step process of this methodology, as delineated by Trochim (1989a), "integrates group processes such as brainstorming, unstructured idea sorting, and rating tasks with sophisticated multivariate statistical methods to produce a well-defined, quantitative set of results" (Kane \& Trochim, 2007, p. 1). They are detailed in the following sections.

Step 1 - Preparation. At the preparation step the tasks are to articulate the outcomes of the whole process, enunciate a focus prompt to guide the process, define the focus for the ratings, and identify the participants.

It is at this step that "the facilitator works with the client or sponsor to ensure that desired outcomes of the effort are clearly articulated" (Kane \& Trochim, 2007, p. 8). These outcomes may be "major goals and objectives, needs, resources and capabilities or other dimensions which eventually constitute the elements of a plan" (Trochim, 1989a, p. 1).

Then, the facilitator works with a subgroup of key participants, generally including representatives of the client or the client in person, and a few selected stakeholders. This subgroup is in charge of the planning and implementation of the process. 
Based on the desired outcomes stated by the sponsor, the subgroup drafts a focus prompt, which defines the "focus of the brainstorming session" and "is worded to give the specific instruction intended" (Kane \& Trochim, 2007, p.10). The focus prompt is the reference during the whole conceptualization process. It has therefore to be formulated very precisely, to trigger the generation of statements that mostly share same syntactic features. An accurately formulated focus prompt also prevents confusion during the generation of statements and their rating, It is usually "phrased either as a sentence completion prompt or as a directive... to elicit a wide range of responses that address the conceptual domain of interest” (Kane \& Trochim, 2009, p. 442).

In the current study, participants were asked to generate conceptual student learning outcomes in the first year. The term learning in this study is operationalized via Benjamin Bloom's articulation of educational goals in terms of knowledge, skills, and attitudes (Bloom et al., 1956). According to Bloom and his colleagues, "educational objectives refer to explicit formulations of the ways in which students are expected to be changed by the educative process. That is, the ways in which they will change in their thinking, their feelings, and their actions" (p. 26). They argued that for the educational process to be effective in bringing about the expected changes, the three areas of knowledge, skills, and attitudes need to interact. Pure knowledge per se is rarely considered "as the primary or sole outcome of instruction" (p. 38). There is usually an expectation that students will develop skills that will allow them to "apply the information to new situations and problems" (p .38). Before the application of knowledge, emotional disposition or attitude is important. In order to use their skills, students need to develop "a positive feeling" toward what is expected from them and show a certain level of "involvement" or "commitment” (Krathwohl, Bloom \& Masia, 1964, p. 25). Considering these elements, the focus prompt for the brainstorming session of the present study was formulated as 
follows: What knowledge, skills, and attitudes should students gain as a result of participating in the success program? Each generated outcome was expected to be a "value statement—a verbal description of some future condition or state of affairs that is considered desirable or important" (Astin \& Antonio, 2012, p. 41) for first-year students in the success program.

The subgroup also develops the focus for the ratings that are performed during Step 3, and prepare the focus scheme reflecting it. In the current study, the following two ordinal scale questions served as prompts for the ratings:

1. Please rate the relative importance of each item for ensuring the success of students in the first year of college. Possible answers and their corresponding numeric values are: 1 = Not At All Important; 2 = somewhat important; 3 = Important; 4 = Very Important; 5 = Extremely Important.

2. For each item, please evaluate the overall efficacy of your institution in helping student achieve that desired learning element. Possible answers and their corresponding numeric values are: 1 = Poor; 2 = Fair; 3 = Average; 4 = Good; $5=$ Excellent

The subgroup finally identifies the participants in the brainstorming session. "Concept mapping is most useful when it includes a range of people whose knowledge or experience is relevant to the questions" (Kane \& Trochim, 2007, p. 10). Trochim (1989a) asserted that there is no limit to the number of participants but, for practical reasons, considers that 10 to 20 participants is a typical "workable number" (p. 3). He argued that, although it may be convenient or relevant to work with small groups, "broad heterogeneous participation helps to insure that wide variety of viewpoints will be considered and encourages a broader range of people to 'buy into' the conceptual framework which results" (p. 3). He did not deem necessary the involvement 
of all participants in all activities of the process but pointed out that "concept maps are better understood by people who have participated in all phases of the process than by those who have only taken part in one or two steps" (p. 3). In case sampling was utilized, Trochim recommended "some form of stratified random sampling or purposive sampling for heterogeneity" (p. 3). A full description of the participants is provided in a subsequent section of this chapter.

Step 2 - Generating Statements. The focus prompt articulated in Step 1 serves as a prompt for the generation of statements. The selected and invited participants are gathered in one place, or consulted via internet during a given time framework.

The facilitator informs them about the whole process and states the focus prompt on which they are invited to generate statements. He or she stresses that "there should be no criticism or discussion regarding legitimacy of statements which are generated during the session" (Trochim, 1989a, p. 4) and that participants will be asked to rate the generated statements in a subsequent step. Participants may ask clarification questions if necessary.

As they are generated, in one or more brainstorming sessions, statements are recorded and displayed for all to see. Anonymous statements may be submitted to the facilitator to be included in the final list. Whereas "theoretically, there is no limit to the number of statements that can be processed", Kane and Trochim (2007) recommended to "limit the final set of statements to 100 or fewer" (p. 11).

At the end of the generation stage, participants review the statement to edit as needed, to ensure consistency with the focus prompt, and to make sure that all participants have the same understanding of the statements. Ideally, these statements "will represent the entire conceptual domain for the topic of interest" (Kane \& Trochim, 2007, p. 11). In some cases, a brainstorming session may not be necessary, for example, when "a set of statements can be abstracted from 
existing text documents" or when "the nature of the conceptualization dictates the elements of the conceptual domain" (Trochim, 1989a, p. 5).

Step 3 - Structuring Statements. This step involves the definition of the relationships between the statements made by the participants through sorting and rating of each statement based on a predefined rating scheme. All participants are requested to sort the statements individually, "in a way that makes sense" (p. 12) to them. Typical instructions and restrictions about how the statements should be sorted are summarized as follows: "Participants may not sort all items into one pile, sort every statement as its own pile (although some items may be grouped by themselves), or sort an item into more than one pile (Kane \& Trochim, 2007, p. 12).

At the end of the sorting process, individual results are recorded into a "binary symmetric similarity matrix" (Trochim, 1989a, p. 6) with the same number of columns, rows, and statements. "All of the values of this matrix are either zero or one. The number ' 1 ' indicates that the statement for that row and column were placed by that person in a pile while a ' 0 ' indicates that they were not" (Trochim, 1989a, p. 5). Subsequently, all individual results are recorded in a "combined group similarity matrix" (Trochim, 1989a, p. 6). This matrix has the same number of rows, columns, and statements. Values entered into that matrix represent the number of people who recorded a pair of statements in the same pile. "A high value in this matrix indicates that many of the participants put that pair of statements together in a pile and implies that the statements are conceptually similar in some way" (Trochim, 1989a, p. 7).

The last phase of the structuring process consists of rating the statements "using a Likerttype response scale...to indicate how much importance, priority, effort or expected outcome is associated with each statement" (Trochim, 1989a, p. 7). The purpose of the rating phase is "to enable the researcher to observe value or opinion differences on the specific ideas, from the 
participating stakeholders" (Kane \& Trochim, 2009, p. 445). If demographic information or participants' characteristics are collected and associated with rating information, "rich opportunities to compare the ratings of one subgroup of participants to another" will be available to the researcher (Kane \& Trochim, 2009, p. 445).

For the current study, participants were asked to rate the importance of each learning outcome for first-year students in the success program, as they perceive it, and to rate the efficacy of the Reference University in helping students achieve each outcome, also based on their observation. For this second phase of data collection, the researcher integrated the statements into Qualtrics, an Internet-based data collection instrument. Participants were asked to rate the statements in Qualtrics within a few days following reception.

Step 4 - Representation of Statements. The statements are numbered and recorded as individual points on a map, using multidimensional scaling analysis which "creates a map of points which represent the set of statements which were brainstormed based on the similarity matrix which resulted from the sorting task" (Trochim, 1989a, p.7). Statements that were sorted together are located close to one another on the map and those that were less frequently sorted together are separated by relatively longer distances. Although more dimensions may be considered for this type of analysis, Trochim recommended the use of "a two-dimensional multidimensional scaling analysis to map the brainstormed statements into a two-dimensional plot" (Trochim, 1989a, p. 8).

The point map stemming from multidimensional scaling is transformed into a cluster map through a procedure called "hierarchical cluster analysis" (Trochim, 1989a, p.8). The analysis is performed by stages, with an "algorithm combin[ing] two clusters until, at the end, all of the statements are in a single cluster" (Trochim, 1989a, p. 8). The cluster map shows how the cluster 
analysis grouped the points. Statements more frequently sorted together are grouped into visually observable clusters.

Cluster analysis involves a subjective aspect because the analyst determines how many clusters to retain and can make final adjustments that are consistent with the goals of the conceptualization process. This subjective aspect led Trochim to argue that "the cluster analysis results are less interpretable than the results from multidimensional scaling.

The cluster analysis is viewed as suggestive and, in some cases, one may want to 'visually adjust' the cluster into more sensibly interpretable partitions of the multidimensional space. The key operative rule here would be to maintain the integrity of the multidimensional scaling results, that is, try to achieve a clustering solution which does not allow any overlapping cluster”. (Trochim, 1989a, pp. 8-9).

In a second phase, two subsequent maps can be derived from the concept map analysis. They are "the point rating map which shows the average ratings for each statement on the point map" and "the cluster rating map which shows the average rating for each cluster on the cluster map" (Trochim, 1989a, p. 9).

In a third phase, Trochim (1989a) recommended the utilization of an additional measurement tool, Pattern Matching, where each cluster "can be viewed as a measurement construct and the individual statements can suggest specific operationalizations of measures within constructs" (p. 13). Trochim (1989b) also viewed Pattern Matching as "an attempt to link two patterns where one is a theoretical pattern and the other is an observed or operational one" (p. 356). For Michalski and Cousins (2000), "pattern matching allows for the combination of any two measures (e.g., statement importance ratings either within or between groups) aggregated at the concept map cluster level to examine the degree to which the measures match. By examining 
such combinations of measures, differences between stakeholders can be identified and quantified" (p. 217).

As recommended by Trochim (1989a), Pattern Matching was utilized at this stage as an additional measurement tool to compare the importance ratings of results shown in the concept maps. The Pattern Matching is expected to evidence differences or similarities in perception of importance among the participants. The results were expected to show "a comparison of average cluster ratings between [the] two variables" (Kane \& Trochim, 2007, p. 19), and would be visually displayed on a "ladder graph" (p. 20). The results of a pattern match are represented both graphically (as a ladder graph) and numerically (as a correlation coefficient) between measures. The correlation coefficient which is "known as the Pearson product-moment correlation $(r)$ " can be computed and utilized to estimate "the linear association based on the data for each variable" (Valdes-Vasquez \& Klotz, 2013, p. 7).

Step 5 - Interpreting Maps. The maps generated through this process "are all concept maps", because "they are all related to each other and are simply reflecting different sides of the same underlying conceptual phenomenon", the cluster map being "usually the most directly interpretable map" (Trochim, 1989a, p. 9). In the current study, the researcher examined and named the clusters. It was argued that this interpretation activity can be performed by "the group of participants or the researchers, depending on the research goals" (Valdes-Vasquez \& Klotz, 2013, p. 2). To interpret the conceptual information, Trochim (1989a) proposed the following materials:

1. The Statements List. The original list of brainstormed statements, each of which is shown with an identifying number. 
2. The Cluster List. A listing of the statements as they were grouped into cluster by the cluster analysis.

3. The Point Map. The numbered point map which shows the statements as they were placed by multidimensional scaling.

4. The Cluster Map. The cluster map which shows how statements were grouped by the cluster analysis.

5. The Point Rating Map. The numbered point map with average statement ratings overlayed.

6. The Cluster Rating Map. The cluster map with average cluster ratings overlayed. (Trochim, 1989a, p. 9).

In this step, all participants are presented with the list of brainstormed statements as they appear on the cluster list. They are invited to individually name each cluster with "a short phrase or word" (Trochim, 1989a, p. 9), then to agree on a common name for each cluster.

Participants proceed to review the point map and the cluster map. They are made aware of the reason why certain points or clusters are close to or far from each other and how the whole process is a succession of steps all connected to each other with, for example, the cluster map being derived from the point map. Each cluster is then named by the participants by placing the previously identified cluster names in the proper section. As for the point map, distance between clusters holds a particular meaning because "clusters which are closer together on the same cluster map should be more similar conceptually than clusters which are farther apart" (Trochim, 1989a, p. 11). Participants may review point and cluster ratings to make sure they are consistent with the conceptualization process. They may also identify patterns where clusters seem to form 
groups or regions and name them. "This final named cluster map constitutes the conceptual framework and the basic result of the concept mapping process "(Trochim, 1989a, p. 11).

In addition to the statement and cluster lists as well as the various maps that were derived, interpretation may also rely on pattern matches which allow to "compare and contrast the average cluster ratings between two variables" (Valdes-Vasquez \& Klotz, 2013, p. 3) and across participants subgroups. Interpretation may rely as well on go zones "that show the average rating values of each statement in relation to the other statements in its conceptual cluster" (Kane \& Trochim, 2009, p. 456). The term "go zone" is used to label sections of value plots that allow the identification of the items that one would want to address urgently due to fact that they are rated as important by one or more groups of stakeholders.

Finally, Valdes-Vasquez and Klotz (2013) reported the research by Kruskal \& Wish, (1978) who identified a stress index value, a mechanism utilized "to evaluate the validity of the two-dimensional model in relation to the original aggregate matrix". The value of this index varies from ' 0 ' to ' 1 ', with ' 0 ' representing a "perfect match" and ' 1 ' the highest level of discrepancies "in the distances on the map compared with the input data in the aggregate matrix" (Valdes-Vasquez \& Klotz, 2013, p. 5). Acceptable ranges were determined by Rosas and Kane (2012) to go "from 0.17 to 0.34 , with a median of 0.28 " (as cited in Valdes-Vasquez \& Klotz, 2013, p. 5).

Step 6 - Utilization of Maps. At this stage, participants discuss ways to use the final concept maps. It is important to remind participants of "the original reason for conducting the structured conceptualization" (Trochim, 1989a, p. 12). It is their responsibility to say "how the final concept map might be used to enhance either the planning or evaluation effort" (Trochim, 1989a, p. 12). Their use of the maps as tools for program evaluation is "limited only by the 
creativity of the evaluator and the constraints of the context motivation" (Kane \& Trochim, 2007, p. 158).

The maps derived from the concept mapping process can be utilized as a "conceptual framework that can guide the planning, development, implementation, and evaluation of programs" (p. 172). For example, Kane and Trochim (2007) identified four categories for the use of concept mapping in the area of planning: "(1) for organizing for action or program planning; (2) for organizing needs assessment; (3) for organizing report writing; and (4) for organizing data synthesis and presentation" (p. 155).

For Kane and Trochim (2007), concept maps are equally useful in program evaluation contexts. They described the project life cycle with four main components: "conceptualization, development, implementation, and assessment" (p. 157). The first two steps coincide with the planning phase of any given project and the last two with evaluation. They highlighted the parallelism between the pairs "implementation"/“assessment” and "process"/“outcome evaluation". "Process evaluation" corresponds to the implementation aspect and consists in "the development of process measures and their use in monitoring the program and its immediate outputs" (p. 157). "Assessment is accomplished through outcome evaluation" and consists in "the development of output and outcome measures and their use in estimating the effects of the program or intervention" (p. 157).

As reported by Kane and Trochim $(2009 ; 2007)$, CM/PM was utilized in dozens of dissertations and other studies. For example: local community members and national tobacco experts engaging to define "factors that affect individuals' behaviors related to tobacco, nutrition, and physical activity" (Trochim et al., 2004, as cited in Kane \& Trochim, 2007, p. 2); or stakeholders defining the implication of state level health departments in "addressing epilepsy 
and other low prevalence chronic conditions" (p. 3). More recently, CM/PM was utilized in dissertations to determine undergraduate student learning outcomes in the area of information literacy (Messman-Mandicott, 2012) and to conceptualize the perception of academic advising by doctoral students and their faculty as it relates to successful dissertation completion (Adu, 2011).

Due to the nature of this research project, the results of the study along with recommendations were made available to the stakeholders of the success program, especially to the team in charge of its planning and evaluation. It is their decision to undertake any necessary steps based on the information revealed through this study to assess and improve existing program or to plan new ones.

\section{Participants}

To set the stage for the discussion about the participants and how they were selected, it is important to provide a brief general description of the Reference University and the success program. The Reference University is a land-grant institution member of the Southern Regional Education Board (SREB) and a high research activity classified public institution (Carnegie Foundation for the Advancement of Teaching, 2010). It comprises a main campus and two divisional campuses within the State. The study was conducted at the main campus. Therefore, data and information discussed here pertain to the main campus only. The main campus entails 15 colleges and schools, offers 197 degree programs covering a variety of academic disciplines. As of fall 2013, the Reference University employed 2,507 full-time and 599 part-time faculty members and had a student-faculty ratio of 22:1. The overall enrollment was of 29,466 students, including 22,757 undergraduate, 5,077 graduate, and 1,632 professional students. Students come from all the counties of the State (45 percent), all U.S. States and the District of Columbia, and 
over 100 countries. Racially, the student population is predominantly white, with 85 percent of undergraduate student identifying themselves as white in fall 2012. The average six-year graduation rates were of 56 percent in 2013, 57 percent in 2012, and 59 percent in 2011.

The following is recent information regarding first-year students. The freshmen class size was of 5,022 in fall 2011, 5,135 in 2012, and 4,913 in 2013. Recent data revealed that the average fall-to-fall retention rate of first-time full-time students was below 80 percent: 76.9 percent in 2012, 77 percent in 2011, and 77.7 percent in 2010. In recent years, about 20 percent of students of the freshman class were on academic probation after the first semester. In the last three years, over 46 percent on average of the freshman class were placed in the last two lowest levels of an institutional index for academic preparedness based on pre-college information and historical performance data of college students with the same profile at entry.

In the academic year 2006-2007, the Reference University undertook a self-study in collaboration with Foundations of Excellence, a project of the John N. Gardner Institute for Excellence in Undergraduate Education, in order to improve the First-Year Experience (FYE). The process led to the development of a philosophy statement for the FYE entailing six goals:

- To prepare students for a successful academic experience by fostering the development of teamwork, personal inquiry, and problem solving skills

- To support students' intellectual relationships with faculty through enrichment activities, both inside and outside the classroom

- To promote ethical behavior and personal integrity

- To foster physical and mental well-being through responsible decision making and behavior 
- To encourage civic engagement so students will learn the value of working for the betterment of their communities

- To engage students in social, cultural, and academic experiences as part of a diverse community. (Reference University website, 2006).

These finding of the self-study may have influenced how stakeholder conceptualized desired domain of student learning in the first-year. Following the self-study with Foundations of Excellence, several working groups were established in fall 2010 to reflect on ways to enhance student success in general at the Reference University. They identified first-time full-time undecided college students as one of the primary student groups who needed support to be successful. The success program examined in this study can be seen as a product of both processes. The program started in fall 2012 with 156 participants. A second class was welcomed on campus in fall 2013 with 251 participants. The success program is run by a subsidiary office in charge of student success under the department of academic affairs. The program consists of five intervention mechanisms, which can briefly be described as follows:

New student orientation: Program participants choose core curriculum courses from a structured curriculum developed in conjunction with various colleges and schools on campus. The curriculum was crafted based on a review of performance of previous cohorts with the same student profile in those courses.

One week pre-term bridge program: In August 2012 and 2013, success program scholars moved to campus one week earlier than other students for a pre-teaching and learning experience, namely in the first college-level English course and in the First-Year Seminar. They were also introduced to the university through orientational workshops and meetings with upper class students, faculty, and staff members. 
Living-learning community: The community is located in one of the residence halls on campus. The programming and support provided by the leadership team is available to all participants of the success program, no matter their living arrangement (commuters, students living in the residence hall, students housed elsewhere on-campus).

Academic advising and student success coaching: All scholars participated in a one-onone academic advising (during the whole year) and student success coaching sessions (during the first semester).

Major and career exploration events: In the fall and spring semesters, program participants are encouraged to participate in on- and off-campus events organized by program staff in order to allow students to explore various major and career opportunities open to them.

Participants of the success program are invited from a pool of students in the two lowest levels of an internal institutional rating of entering students based on their predicted academic preparedness - mainly based on their high school grade point averages and SAT/ACT scores. Participation is voluntary and refusal to participate does not affect the admission's status of invited students. Although some of the invited students are categorized as undecided because they are not sure about their major and career interests, others are what Cuseo (2005) called "shadow majors" because they "are decided on a major, but have not yet been accepted or admitted to the major of their choice" (p. 31). In an attempt to categorize general studies majors, Gordon (as cited in Brown, 2009) referred to the first group of undecided students mentioned above as "Non-Specific Majors" and to the second as "Specific Majors" (p. 8).

With the background information on the Reference University and the success program laid out above, the following is a description of the participants in this study and their selection process. 
Trochim (1989a) asserted that there is no limit to the number of participants but, for practical reasons, considered that 10 to 20 is a typical "workable number" (p. 3). Following Trochim's recommendation, the researcher utilized purposive sampling to identify potential participants, all affiliated with the Reference University. They were requested to participate in the study because the researcher deems their opinion insightful for the conceptualization of the domain of student outcomes in the first year of college. Two main groups of participants were invited: (1) students from the success program (including female and male students) who started their college career as undecided students ; (2) stakeholders playing an active role in programming or services designed to boost success of either first-year students in general or students that are in the success program, including representatives from the FYE office, student success coaches, instructors of the First-Year Seminar course, success program staff members, the residence hall leadership, the office in charge of student housing, the student affairs office, academic advisors and instructors of classes serving this success program students.

Patton (2002) acknowledged the benefits of purposeful sampling when he argued that "the logic and power of purposeful sampling lie in selecting information rich cases for study in depth. Information rich cases are those from which one can learn a great deal about issues of central importance to the purpose of the inquiry" (p. 230). For the current study, the focus was not to convene a representative sample but to "engage individuals in the field of inquiry and to incorporate the breadth of content that the knowledge of the individuals represents" (ValdesVasquez \& Klotz, 2013, p. 2).

\section{Data Collection}

For the current study, the researcher followed CM/PM data collection steps as recommended by Trochim (1989a) and previously described in detail in this Chapter. 
Participants were invited to meet in a room on the campus of the Reference University. The researcher and the facilitator worked to instill a pleasant, safe, convenient, and participative working climate. The participants were first informed thoroughly about the rationale for the study, the various steps of the CM/PM process, and the principles of brainstorming. They were presented with the focus prompt for the study.

For the generating of ideas, the researcher planned for one brainstorming session of about two hours followed by another two-hour sorting session. A certain amount of time was to be devoted after the generation of ideas to allow the participants to review the statements, to edit them as needed, to ensure consistency with the focus prompt, and to make sure that all participants have the same understanding of the statements (Kane \& Trochim, 2007, 2009; Trochim, 1989a,).

After completion of the sorting session, the meeting had to be adjourned. The researcher opted to defer the rating stage for a few days following the generation and sorting of ideas. For this second phase of data collection, the researcher integrated the generated statements into Qualtrics, an Internet-based data collection instrument. Participants were asked to rate the statements within a few days following reception.

\section{Treatment of the Data}

Trochim (1989a) has suggested two possible options in terms of computer programs that can be utilized to treat data in the context of studies utilizing CM/PM as a research methodology. The first option consists of the conjoint use of commonly available word processing and statistical packages. Trochim mentioned Microsoft Word, WordPerfect, SAS, and SPSS among others. Resorting to this option involves dealing with complex data treatment processes. 
The second option suggested by Trochim is a computer program called Concept System that he purposefully designed for this particular research methodology and that allows to circumvent the difficulties and complexities involved with the use of generic software packages for Concept Mapping/Pattern Matching studies. Trochim described the Concept System as an interactive tool that is capable of processing information throughout all the steps involved in the conceptualization process, from the entry of brainstormed statements, to the production of the various maps as described in the methodology sections above.

For the current study, the researcher used a combination of generic word processing and statistics programs (Microsoft Excel, Microsoft Word, SAS, SPSS) because of their availability and ability to produce comparable results to those obtained using the Concept System, as pointed out by Trochim (1989a).

\section{Limitations in the Methodology}

Michalski and Cousin (2000) reported limitations generally associated with concept mapping studies that were identified by Kolb and Shepherd (1997):

(1) reliability and stability of concept mapping results over time, (2) lack of a welldeveloped means for comparative research especially due to the relative dearth of available pattern matching studies, (3) relatively non-intuitive nature of the concept mapping process, which can lead to confusion about statement sorting and map interpretation for various participants, and (4) challenges of organizing and coordinating large-scale concept mapping projects in terms of the logistics of implementation. Michalski \& Cousin (2000, p. 223). Michalski \& Cousin (2000) suggested the conduct of further research as a way to circumvent the first two limitations, and the remaining others through strengthening of the 
capacities of the facilitator for the implementation of studies involving concept mapping as a research methodology.

Another limitation highlighted by Valdes-Vasquez and Klotz (2013) is that experts or participants are entrusted with rating statements based on a predetermined scale. The limitation rests on the fact that it is taken for granted that "the experts can and make appropriate judgments when responding to this scale" (p. 3). Valdes-Vasquez and Klotz (2013) suggested that "a pilot study can serve as an important venue for clarifying the instructions and refine the sorting and rating statements to ensure the validity of the data collected" (p. 3).

In addition to these general limitations of the Concept Mapping/Pattern Matching method, other limitations encountered in the implementation of the current study are discussed in Chapter 4. 


\section{Chapter Four: Results}

The purpose of this chapter is to present the findings of the study implemented in the framework of this dissertation. As stated in the introductory chapter, this study examined the conceptualization of the desired domain of student learning outcomes in the first year of college. This study pertains to a success program serving first-time, full-time undecided students at a land-grant and high research activity classified university (Carnegie Foundation for the Advancement of Teaching, 2010). The researcher presents a description of the data analysis and results adhering to the recommendations of the Concept Mapping/Pattern Matching methodology. The information is organized in a way to directly answer the two research questions that were posed in Chapter One.

\section{Description of the Sample:}

The population in this study consisted of undergraduate students as well as faculty and staff members who work with them at land-grant and high research activity classified universities (Carnegie Foundation for the Advancement of Teaching, 2010) in the United States of America. The sample was selected at one such university and included students who had participated or were participating in a first-year success program, and faculty and staff members who worked closely with them.

Following the suggestions of previous CM/PM studies, the researcher planned to recruit between 10 and 20 participants for this study (Trochim, 1989a). Using a cover letter and a recruitment script (see Appendix B and Appendix C) he contacted students from three cohorts who participated in the program starting respectively in the fall semesters 2012, 2013, and 2014. Participants were contacted via phone, email, or in person. Each time, the researcher shared with them the information contained in the recruitment script and the cover letter in order to solicit 
their participation in the study. Some of the students were targeted by going through the list of past participants (2012 and 2013 cohorts). Students in the 2014 cohort were informed of the study during a class meeting and invited to participate.

The invitation to participate in the study was also extended to faculty and staff members who worked directly with students in the success programs and other programs serving first-year students. They were selected because of the active roles they played in programming or services designed to boost success of either first-year students in general or students that are in the success program. This non-student stakeholder group included individuals who served in at least one of the following capacities: success program staff member, administrator/staff member of the First-Year Experience office, student success coach, instructor of the First-Year Seminar course, residence hall leadership personnel, residence hall staff member, academic advisor, and instructor of other classes serving the students in this success program.

At the end of the recruitment efforts, 28 students, faculty and staff members agreed to take part in the study. Out of the 28 volunteers, 23 were able to attend the brainstorming session. For the remaining five, some excused themselves by invoking unforeseen circumstances while others did not provide any justification for not attending. Out of the 23 participants, 22 were able to complete the rating task that followed a few weeks later. Although desirable, it is not necessary for all participants to participate in all phases of a concept mapping study (Trochim, 1989a). The students group included seven female and nine male students, who all started their college career as undecided students. The faculty and staff members group included six females and one male; one of them could not complete the rating task. The sample size was deemed acceptable by the researcher, considering the typical practical number of 10 to 20 participants recommended for this type of research (Trochim, 1989a). According to Kane and Trochim 
(2007) CM/PM does not adhere to traditional null hypothesis testing approaches and thus does not require large sample sizes. The methodology "is used more for conceptual framework development than for testing the implications of such frameworks" (p. 178). The purposive sampling method utilized in this study was meant to convene a group of participants with a meaningful insight about the topic of the study (Patton, 2002; Valdes-Vasquez \& Klotz, 2013). The details of the demographic information of the participants are summarized in Table 1.

Table 1: Participants in the Concept Mapping/Pattern Matching Brainstorming Session, and Statement Sorting and Rating Tasks

\begin{tabular}{|c|c|c|}
\hline \multirow{2}{*}{$\begin{array}{l}\text { Role of Participants } \\
\text { Faculty and Staff Members }\end{array}$} & \multicolumn{2}{|c|}{ Number of Participants } \\
\hline & $\begin{array}{c}\text { Brainstorming } \\
\text { and Sorting } \\
\text { Tasks } \\
\end{array}$ & Rating Task \\
\hline $\begin{array}{l}\text { Capacities in which served: Success program staff member, } \\
\text { academic advisor, First-Year Experience office staff } \\
\text { member/administrator, First-Year Seminar instructor, } \\
\text { residence hall leadership personnel, residence hall staff } \\
\text { member, academic success coach, and instructor of other } \\
\text { classes serving first-year students }\end{array}$ & 7 & 6 \\
\hline \multicolumn{3}{|l|}{ Students } \\
\hline 2012 Success Program Cohort & 3 & 3 \\
\hline 2013 Success Program Cohort & 1 & 1 \\
\hline 2014 Success Program Cohort & 12 & 12 \\
\hline Total & 23 & 22 \\
\hline
\end{tabular}

\section{Results of the Concept Mapping/Pattern Matching Process}

Step 1 - Preparation. This was the first stage of the Concept Mapping/Pattern Matching study and consisted in articulating the outcomes of the process. Using this methodology the researcher sought to achieve the purpose of the study of conceptualizing the desired domain of student learning in the first year of a success program serving first-time, full-time undecided students. 
As recommended by previous research (Kane \& Trochim, 2007; Trochim, 1989a), the following focus prompt was proposed to guide the generation of the statements: "What knowledge, skills, and attitudes should students gain as a result of participating in the success program?" Additionally a rating scheme, described later in this chapter, was proposed for the statement rating task.

A facilitator, an experienced staff member who is familiar with both the success program and other first-year programs at the Reference University, was identified to assist the researcher by leading the generation of statements during the brainstorming session and sorting task.

The next step in the preparation stage was to identify the potential participants. As reported in the description of the sample above, the selection of the participation was based on two main criteria: they were both students who were or had been participants in the success program; and faculty and staff members who either worked directly with this group of students or were familiar with programs serving first-year students. Invitations to participate were disseminated based on a cover letter and a recruitment script (see Appendix B and Appendix C) approved by the Institutional Review Board (IRB). Potential participants were notified via telephone, email, or face-to-face. They were notified of their right to freely participate in the study and to freely cease their participation at any point without any repercussions jeopardizing their status as a student or employee of the university. They were also informed that their identities would not be revealed without prior approval.

Finally, additional action steps in the preparation stage consisted in reserving a room with the appropriate equipment for the brainstorming session, ordering food and refreshments, communicating with participants to set a date and time for the event, and purchasing supplies. 
Step 2 - Generating Statements. After the arrangements were made, it was possible to move on to the next step, the generation of statements. A brainstorming session was designed to generate statements as responses to the focus prompt: "What knowledge, skills, and attitudes should students gain as a result of participating in the success program?" The researcher was hoping to have the participants come up with statements that "ideally should represent the entire conceptual domain for the topic of interest" (Trochim 1989a, p. 4).

The brainstorming session was held on the evening of October 6, 2014 in a classroom on the Reference University campus. The brainstorming session was led by the facilitator. Before the start of the activities, the researcher welcomed the participants, introduced the study and the facilitator, and provided hard copies of the recruitment script which stated the participants' rights as subjects in this study (see Appendix C). It was also mentioned to the participants that they were free to express themselves and that there would be no criticism or censorship for any of their expressed statements. Following the recommendation of previous Concept Mapping/Pattern Matching research (Kane \& Trochim, 2007; Trochim, 1989a), they were asked not to go beyond 100 statements.

The initial plan was to carry out the sorting session the same day right after the generation of items. Both activities were expected to take place between 4:00 p.m. and 7:00 p.m. The generation of statements could not start on time due to the fact that some participants were late. When 23 of the individuals who had agreed to participate were present, the generation of statements started and went on until 7:00 p.m. Since the event started late, a decision was made to ask participants to leave at the end of the generation of the statements and to expect a followup invitation for the sorting task. It is typical for Concept Mapping/Pattern Matching studies to hold generation of statements and the sorting tasks separately (Kane \& Trochim, 2007; Trochim, 
1989a). The initial decision to hold both activities the same day was to guarantee full participation by holding only one event, considering that it was the middle of the semester, the time for midterm examination for most undergraduate students. It could have been challenging to arrange several meetings with 23 participants with such a variety of engagements and responsibilities.

One of the participants was recording all the statements on a computer. The recording was displayed on a screen for everyone to see. All statements voiced were recorded without censorship and with a sequential number assigned to each of them. Statements were recorded verbatim. Some were slightly rephrased after participants asked for clarification. At the end, the statements were reviewed by the group for clarity and comprehension and to avoid any confusion. The process led to the final list of 100 statements (see Appendix D).

This activity was held in a relaxed environment where all participants appeared comfortable. There was no instance of apparent intimidation or discomfort. Only clarification questions were asked and some statements rephrased to make sure that everyone understood their meaning. Food and drinks were available in the back of the room. Participants were invited to help themselves to the food and drinks and to feel comfortable. At the end of the session, participants were thanked and asked to expect an email invitation to schedule an appointment with the researcher to complete the sorting task.

Step 3 - Structuring the Statements. The structuring of the statements consisted of two main activities: sorting and rating of the statements. As noted above, the initial plan was to hold the brainstorming session and the sorting task during the same meeting, and to complete the rating task online at a later time via Qualtrics, an Internet-based data collection instrument. Due to the fact that the brainstorming event started late, it was agreed to postpone the sorting task in 
order not to keep participants beyond the scheduled three-hour time limit. The decision was also made based on the fact that the separation of the two tasks is not uncommon in CM/PM studies (Kane \& Trochim, 2007; Trochim, 1989a).

All statements were printed on a letter-sized sheet divided into four quadrants, each of them containing one statement. The sheets were then cut in four to create a set of 100 statements for each participant. That is, each participant was provided a stack of 100 cards, with each single card containing one of the 100 items generated.

The sorting was carried out as an individual activity. Participants came either individually or in small groups to complete the task, at their best convenience within four weeks. The researcher had reserved a room on campus to make sure each participant had a space where he or she could carry out the sorting independently. Each participant was given a set of 100 statements. Each participant was asked to sort them into groups based on his or her own criteria. The only restrictions were those provide by Kane and Trochim (2007).

- All statements cannot be put into a single pile.

- All statements cannot be put into their own separate piles (although some statements may be grouped by themselves).

- Each statement can be placed in only one pile (i.e., a statement can't be placed in two piles at the same time). (p. 72)

Each pile of statements was placed by participants into a medium-sized manila envelope along with a statement recording sheet listing the item numbers and the topic or title of each pile (Kane \& Trochim, 2007; Trochim, 1989a). Each participant was then requested to place all his or her medium-sized manila envelopes into a bigger envelope and return it to the researcher. They were also asked to write down their names on each medium envelope, each statement recording 
sheet, and the large envelope. All 23 participants who took part in the brainstorming session were able to complete the sorting task between October 8, 2014 and November 3, 2014. At the end of the sorting process, each participant was thanked for their help and reminded to watch for an email with a link to the online rating task.

The second part of the structuration of the statements consisted in rating each statement twice according to the following predetermined rating scheme:

1. Please rate the relative importance of each item for ensuring the success of students in the first year of college: 1=Not At All Important; 2=somewhat important; 3=Important; 4=Very Important; 5=Extremely Important.

2. For each item, please evaluate the overall efficacy of your institution in helping students achieve that desired learning element: 1=Poor; 2=Fair; 3=Average; 4=Good; 5=Excellent. The statements were arranged in survey format in Qualtrics (see Appendix E) and shared with participants via an individual link sent via email. The initial link was sent on November 3, 2014 followed by two reminders on November 10 and 17. Out of the 23 participants who took part in the brainstorming and sorting tasks, 22 completed the rating. The last rating was completed on November 21, 2014.

\section{Analysis of the Concept Mapping/Pattern Matching Results}

Step 4 - Representation of the Statements. Immediately after receiving the sorting packages from the participants, the researcher manually entered the data into a Microsoft Excel 2013 spreadsheet in the following way. For each pile of statements identified by a given participant, the item numbers were entered sequentially on separate cells on the same row. The same process was repeated until the piles of all sorters were entered into the Microsoft Excel spreadsheet. This was a meticulous recording process to ensure that no number was input 
incorrectly, that no item was lost, that no sorting was attributed to the wrong person or entered in the wrong cell. The researcher executed the recording, one pile and one participant at a time.

All precautions were taken to guarantee accuracy. The researcher devised a technique to ensure that selecting all rows containing the sorting information of each participant in Excel, one should reach a total count of 100 items and a sum of all numbers equaling 5050. If one item was incorrectly entered, these results could not be reached. This data set contained 188 rows (the number of piles formed by the 23 participant who completed the sorting); the smallest pile had only one item and the largest 51 items. The data matrix consisted then of 188 rows and 51 columns.

Using SAS (version 9.3) statistical software, a multidimensional scaling (MDS) was computed to create a group similarity matrix. This matrix had the same number of rows (100) and columns (100) as the number of statements in this study (100). Values entered into that matrix represented the number of people who recorded a pair of statements in the same pile: "A high value in this matrix indicates that many of the participants put that pair of statements together in a pile and implies that the statements are conceptually similar in some way" (Trochim, 1989a, p. 7). This resulted in the number 23 being displayed diagonally from top left to bottom right of the matrix. Since each number could only be placed in one single pile, each item was obviously placed with itself by all 23 participants. This reflected the accuracy of the matrix and the data set. Using Multidimensional Scaling also allowed the researcher to determine coordinates indicating where each item would fall on a two dimensional graph. A visual representation of the graph was developed using Microsoft Excel 2013 (see Figure 1). 


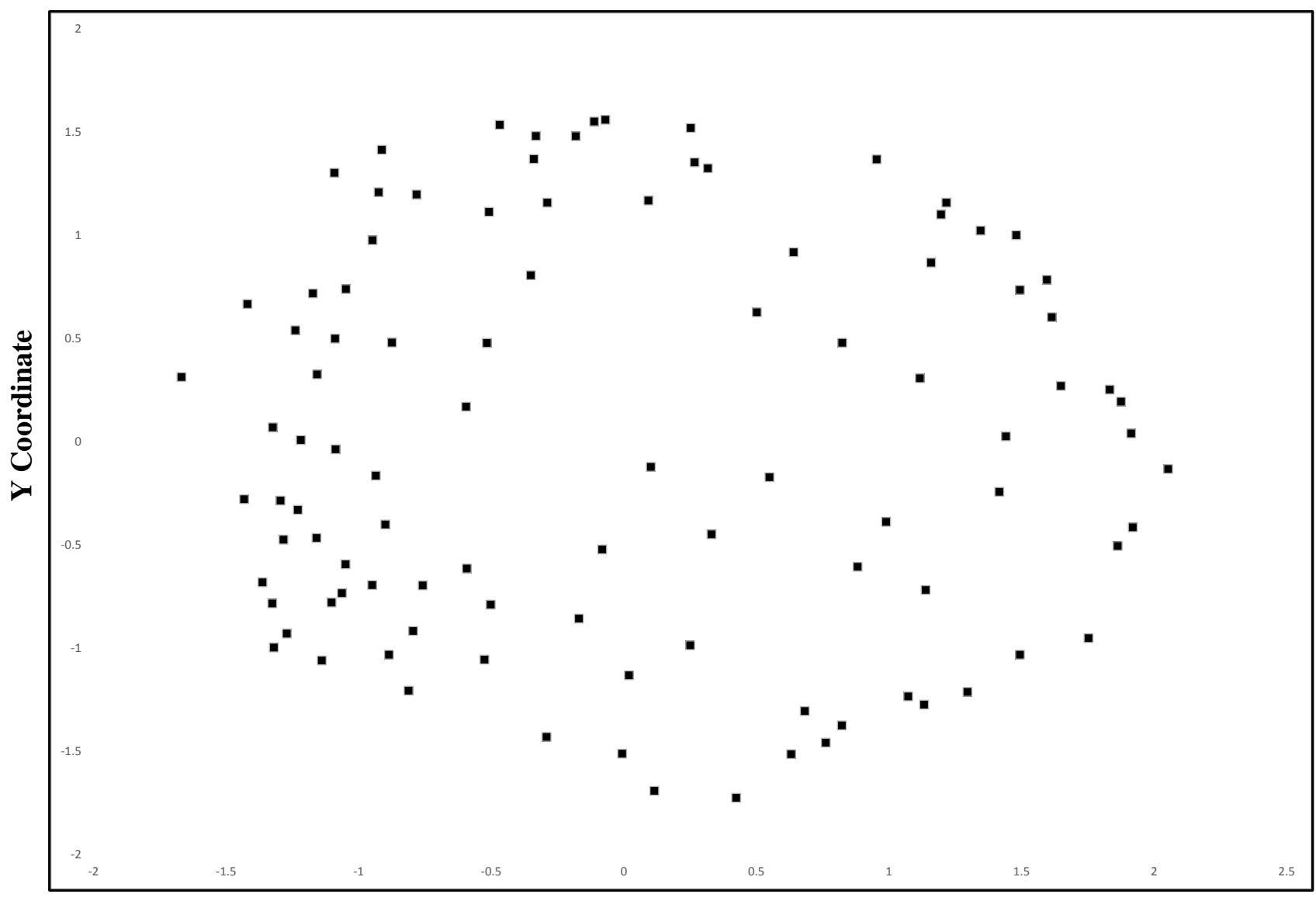

X Coordinate

Figure 1: Point map with each point corresponding to one of the 100 statements

Using the coordinates generated by the Multidimensional Scaling, it was possible to create a visual map of where the different statements fell. This visualization can be first seen on Figure 1 showing the point map and on Figure 2 displaying the item number for each point. Statements that were more frequently sorted together are located close to one another on the map and those that were less frequently sorted together are separated by relatively longer distances. 


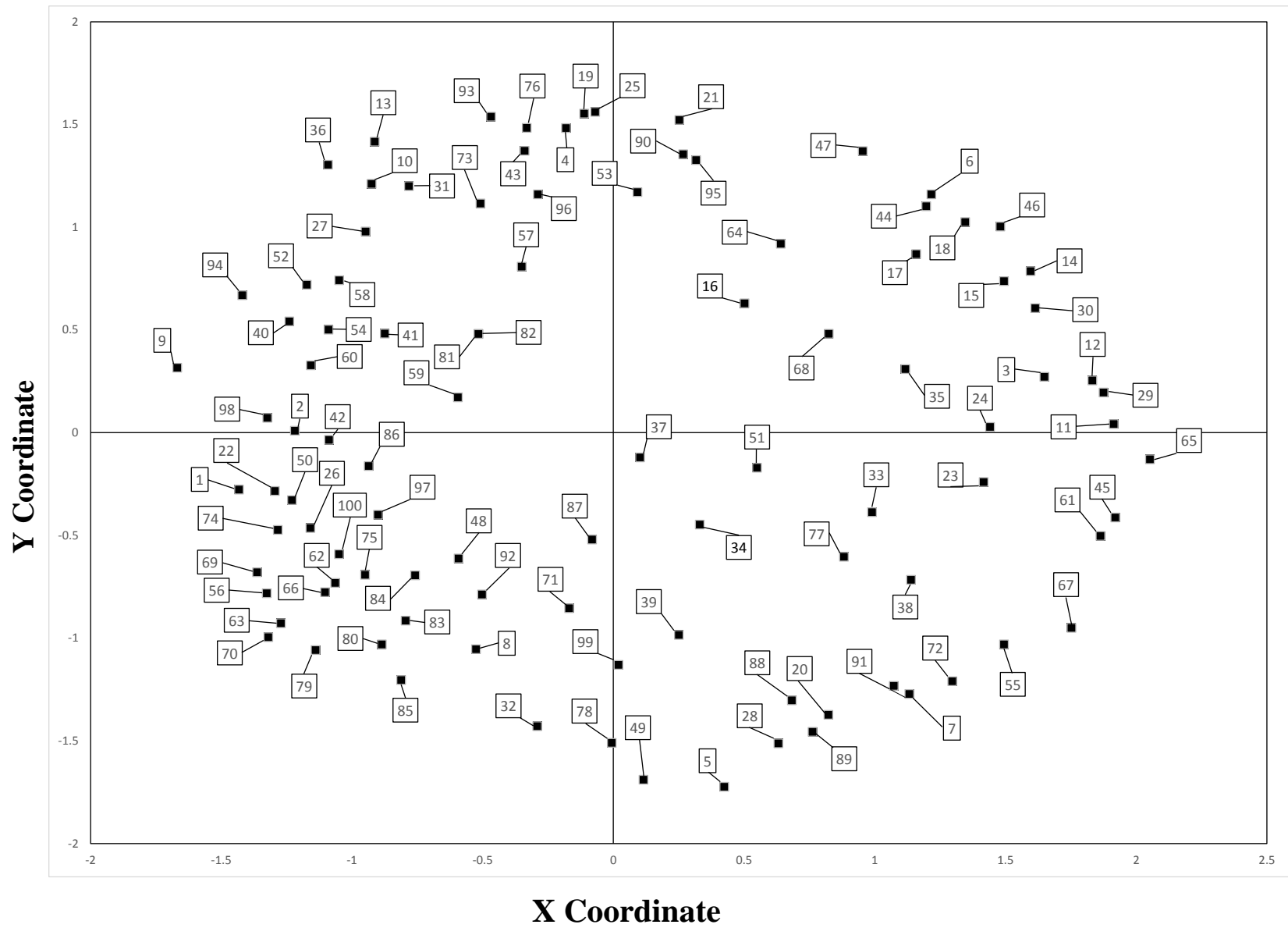

Figure 2: Numbered point map with each point corresponding to one of the 100 statements

An illustration of what led participants to group items based on some criteria can be seen on the case of (\#81) and (\#82) on the upper left quadrant of Figure 2. These two items refer to professional behavior that students are expected to exhibit as an outcome of attending the first year of college. As one can see on Table 2, the statements slightly differ at the end with one referring to proper attire and the other to body language. The sorting results reveal that participants placed those two statements together in such a way that it was visually impossible to dissociate them on the point map. A close look at their coordinates showed how they are practically located on the same position on the two dimensional graph. The group similarity 
matrix shows that all 23 participants sorted these two together. Conversely, a close look at (\#7) and (\#36) allows one to see that their positions are diagonally opposed on the graph, respectively upper left and lower right quadrants. Their coordinates are far different as well. In terms of their meaning, the two statements address separate issues: the opportunity to meet new people for (\#7) and the planning of an alternative major for (\#36). According to the group similarity matrix, none of the participants grouped those two items together. This explains how they are so far apart on the two dimensional graph.

Table 2: Illustration of Similarity and Dissimilarity among Statements

\begin{tabular}{cccl}
\hline $\begin{array}{c}\text { Statement } \\
\text { number }\end{array}$ & X Coordinates & Y Coordinates & \multicolumn{1}{c}{ Statement } \\
\hline 81 & -0.5165 & 0.48043 & $\begin{array}{l}\text { Students should know how to present themselves } \\
\text { professionally, for example, wearing proper attire. }\end{array}$ \\
82 & -0.5165 & 0.48042 & $\begin{array}{l}\text { Students should know how to present themselves } \\
\text { professionally }- \text { for example, using proper body } \\
\text { language. }\end{array}$ \\
7 & 1.13232 & -1.272 & $\begin{array}{l}\text { Students should have an opportunity to meet new } \\
\text { people right off the bat and make new friends. }\end{array}$ \\
36 & -1.092 & $\begin{array}{l}\text { Students should be open to developing a "Plan B." } \\
\text { Meaning that if you are not accepted into your } \\
\text { original major }- \text { or you change your mind, you } \\
\text { have something else to move into. }\end{array}$ \\
\hline
\end{tabular}

The next step in the representation of statements consisted in running an analysis called Hierarchical Cluster Analysis (HCA), a technique that "groups individual statements on the point map into clusters of statements that aggregate to reflect similar concepts" (Kane \& Trochim, 2007, p. 98). The HCA was run using IBM SPSS Statistics (version 22). To achieve this, the X-Y coordinates defined during the Multidimensional Scaling stage were used along with Ward's algorithm as recommended by Kane and Trochim (2007). They recommended Ward's method because it gives "more reasonable and interpretable solutions" and is suitable for "distance-based 
data". To run the HCA, they preferred the X-Y coordinates to the similarity matrix data because that way "statements that were placed in the same cluster would be in contiguous areas of the map" (p. 99). The result of the analysis is called a hierarchical cluster tree or dendrogram (see Appendix F). Starting at the statement level, smaller clusters of statements are formed and then "the algorithm combines two clusters until, at the end, all statements are in a single cluster" (p. 99).

In the process of running the $\mathrm{HCA}$, the researcher had to determine a minimum and a maximum number of clusters to retain. Kane and Trochim (2007) contended that too many or too few clusters can make the results difficult to interpret. While running the HCA for this study, the researcher set the minimum number of clusters to three and the maximum to ten. The HCA distributed the 100 statements between three and ten possible cluster options. In order to leverage $\mathrm{CM} / \mathrm{PM}$ fully to guide evaluation and planning, the researcher must combine subjective decisions with objective statistical reasoning (Kane \& Trochim, 2007). That is why, after relying on robust statistical techniques-Multidimensional Scaling and Hierarchal Clustering — the researcher then reviewed each one of the options, relying this time on his subjective judgment to determine the final number of clusters to keep for this study.

Based on the three-to-ten cluster solution provided by the cluster tree, the researcher, after consulting with an expert of Concept Mapping/Pattern Matching serving on his dissertation committee, decided to keep a 6-cluster solution. This decision was made on the following basis. On the one hand, the researcher reviewed the statements in each of the original ten clusters and concluded that the items in clusters 1,3 , and 5 shared some level of similarity within each cluster, thus providing a justification for each of these groups to be kept as an autonomous cluster. On the other hand, a close look at the items in the remaining cluster $(2,4,6,7,8,9$ and 
10) led the researcher to make some cluster combinations due to conceptual similarities among some of them. For example, items in cluster 4, 9, and 10 were deemed closed enough to justify the researcher's decision to merge them. A similar decision was made for clusters 2 and 6 and finally 7 and 8 . This led to the adoption of the six cluster solution in the cluster tree output as the final number of clusters. Figure 3 displays the six clusters that were retained for this study.

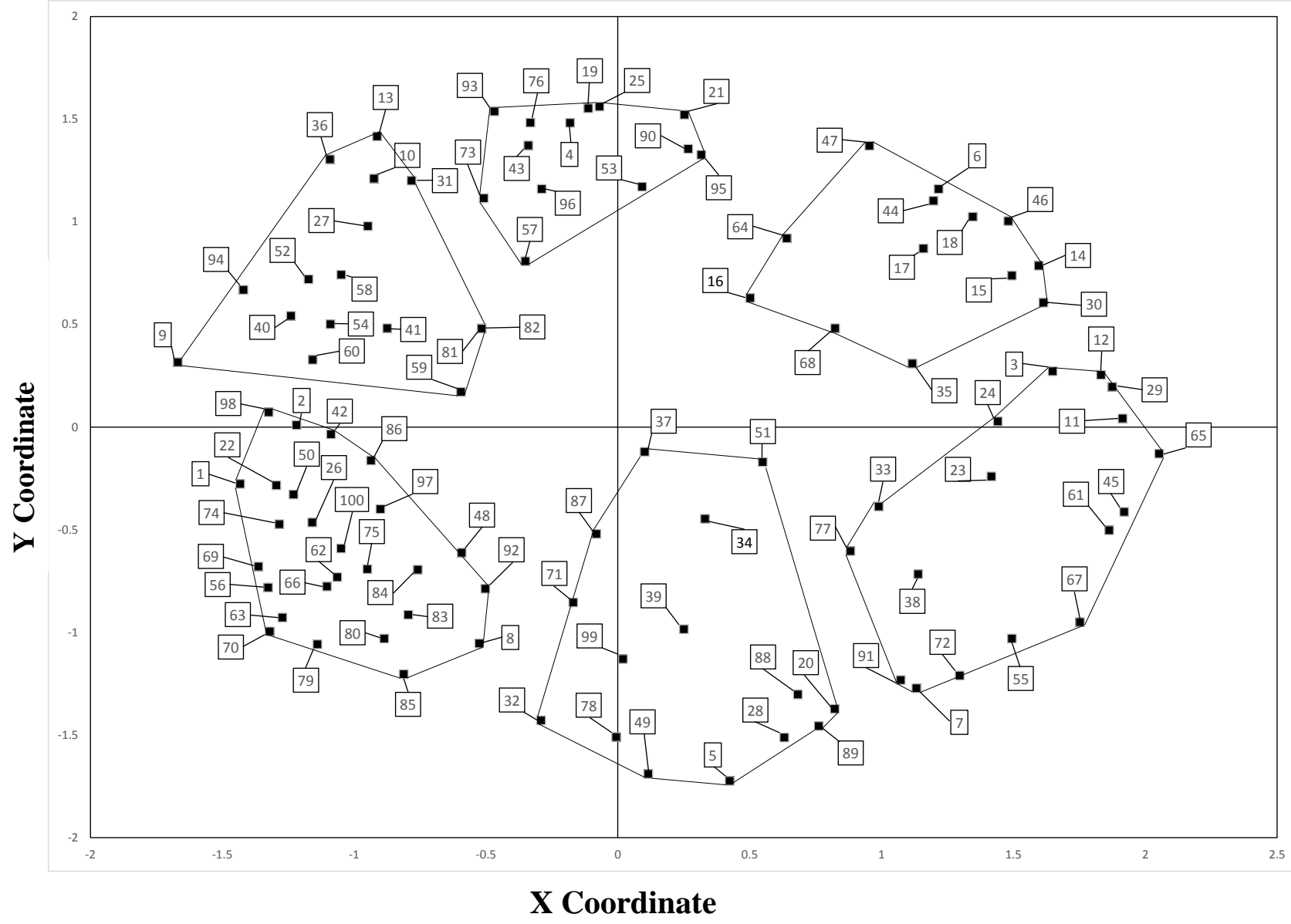

Figure 3: Cluster map with the six clusters identified

Step 5 - Interpreting the Maps. The next step, as recommended by previous research (Trochim, 1989a), is the interpretation of the maps that were produced so far. Trochim contended that all maps developed in the CM/PM process are interrelated and represent the different pieces of the puzzle that underlies the conceptual domain studied. The List of Statements (see Appendix 
D) shows all 100 items generated during the brainstorming session, each with an assigned sequential number. The List of Statements was also modified to show their cluster membership as shown in Table 3.

Table 3: List of 100 Outcomes Generated by Participants, Organized into Clusters using Hierarchical Cluster Analysis, and Labeled

\begin{tabular}{|c|c|c|}
\hline & Outcomes Generated by Participants & Cluster Label \\
\hline 1 & Students should be able to know their priorities. & \multirow{26}{*}{ Independence } \\
\hline 2 & Students should take responsibility for individual learning. & \\
\hline 8 & Students should take opportunities to stand out and be unique. & \\
\hline 22 & $\begin{array}{l}\text { Students should be able to build positive habits to help them become more successful as college } \\
\text { students. }\end{array}$ & \\
\hline 26 & Students should manage their time by prioritizing what they need to accomplish. & \\
\hline 42 & Students should not be scared to take on academic challenges. & \\
\hline 48 & $\begin{array}{l}\text { Students should have confidence by the end of the year in terms of adjusting to college, being } \\
\text { aware of resources, and asking for help. }\end{array}$ & \\
\hline 50 & Students should take responsibility for their actions. & \\
\hline 56 & Students should know how to prioritize better. & \\
\hline 62 & $\begin{array}{l}\text { Students should know what success looks like by the end of their first year because they should } \\
\text { have experienced some form of success by the end of their first year. }\end{array}$ & \\
\hline 63 & Students should learn from their mistakes (academic or personal) and be able to move forward. & \\
\hline 66 & $\begin{array}{l}\text { Students should be more well-rounded in the sense that they have all the tools and skills necessary } \\
\text { to be self-sufficient. }\end{array}$ & \\
\hline 69 & Students should be able to stay positive despite academic setbacks. & \\
\hline 70 & $\begin{array}{l}\text { Students should be prepared for anything that is thrown their way - opportunities and adverse } \\
\text { events. }\end{array}$ & \\
\hline 74 & Students should set their own goals. & \\
\hline 75 & Students should be able to develop from a dependent person to an independent person. & \\
\hline 79 & Students should know how to handle adversity, for example, tough times and challenges. & \\
\hline 80 & $\begin{array}{l}\text { Students should do the best they can based on their own abilities - and not compare themselves to } \\
\text { others. }\end{array}$ & \\
\hline 83 & Students should know how to self-advocate - and not be afraid to ask questions. & \\
\hline 84 & Students should know how to set realistic goals. & \\
\hline 85 & $\begin{array}{l}\text { Students should make decisions to make themselves happy rather than making decisions to make } \\
\text { other people happy. }\end{array}$ & \\
\hline 86 & Students should discover and then build their skills. & \\
\hline 92 & Students should develop strategies to help themselves to de-stress. & \\
\hline 97 & Students should know how to make themselves distinct. & \\
\hline 98 & Students should be able to learn the value of critical thinking. & \\
\hline 100 & Students should learn how to keep themselves healthy. & \\
\hline
\end{tabular}


Table 3 (continued): List of 100 Outcomes Generated by Participants, Organized into Clusters using Hierarchical Cluster Analysis, and Labeled

\begin{tabular}{|c|c|c|}
\hline & Outcomes Generated by Participants & Cluster Label \\
\hline 3 & Students should get to know the different buildings for each college around campus. & \multirow{17}{*}{$\begin{array}{l}\text { Engaging with the } \\
\text { Environment }\end{array}$} \\
\hline 7 & Students should have an opportunity to meet new people right off the bat and make new friends. & \\
\hline 11 & Students should take tours of the campus - to learn about their environment. & \\
\hline 12 & $\begin{array}{l}\text { Students should have enough time during the summer bridge program to figure out their } \\
\text { surroundings. }\end{array}$ & \\
\hline 23 & $\begin{array}{l}\text { Students in the summer bridge program should get to meet more faculty members and become } \\
\text { better friends with faculty than other freshmen are. }\end{array}$ & \\
\hline 24 & $\begin{array}{l}\text { Students should have opportunities to have one-on-one interactions with members of different } \\
\text { colleges (e.g., recruiters and advisors). }\end{array}$ & \\
\hline 29 & $\begin{array}{l}\text { Students should gain familiarity with the campus, all the colleges at the university, and in general, } \\
\text { college life. }\end{array}$ & \\
\hline 33 & $\begin{array}{l}\text { If students are offered an opportunity to participate in a success program, they should take } \\
\text { advantage of it. }\end{array}$ & \\
\hline 38 & $\begin{array}{l}\text { Students should find out about student organizations so they can find others with common } \\
\text { interests. }\end{array}$ & \\
\hline 45 & Students should have a better feel not just for their university but for the whole State as well. & \\
\hline 55 & Students should know how to sing their school song. & \\
\hline 61 & $\begin{array}{l}\text { Students should know their community better - especially their local community - through service } \\
\text { projects. }\end{array}$ & \\
\hline 65 & $\begin{array}{l}\text { Students should have a better understanding of the history of campus buildings and the campus in } \\
\text { general. }\end{array}$ & \\
\hline 67 & Students should want to stay at their institution at the end of their first year. & \\
\hline 72 & Students should try enjoying clubs and/or fraternities or sororities. & \\
\hline 77 & Students should participate in research sessions. & \\
\hline 91 & $\begin{array}{l}\text { Students should know it is important to realize they are not alone - they have friends, professors, } \\
\text { support staff, etc. }\end{array}$ & \\
\hline
\end{tabular}


Table 3 (continued): List of 100 Outcomes Generated by Participants, Organized into Clusters using Hierarchical Cluster Analysis, and Labeled

\begin{tabular}{|c|c|c|}
\hline & Outcomes Generated by Participants & Cluster Label \\
\hline 4 & Student should begin to learn what they are interested in. & \multirow{13}{*}{ Career Identity } \\
\hline 19 & $\begin{array}{l}\text { Students should feel more prepared to decide on a major and not constantly be changing their } \\
\text { minds. }\end{array}$ & \\
\hline 21 & $\begin{array}{l}\text { Students should have opportunities in class early in the semester to find out what their interests } \\
\text { are to help them choose a major. }\end{array}$ & \\
\hline 25 & Students should know what major they want by the end of their first year. & \\
\hline 43 & Students should begin to learn what major they might be interested in. & \\
\hline 53 & Students should know how to contact their academic advisors to make advising appointments. & \\
\hline 57 & Students should know their professors' expectations. & \\
\hline 73 & Students should know they have to find a job after college. & \\
\hline 76 & Students should be aware of the competition to get into some majors. & \\
\hline 90 & $\begin{array}{l}\text { Students should know to take advantage of opportunities (such as internships) related to possible } \\
\text { majors. }\end{array}$ & \\
\hline 93 & Students should follow a four-year plan when preparing for their careers. & \\
\hline 95 & $\begin{array}{l}\text { Students should be exposed to different programs, presentations, and environments to help them } \\
\text { decide on their ultimate major. }\end{array}$ & \\
\hline 96 & Students should know what they have to do to be desirable to employers. & \\
\hline 5 & Students should become more social and be more comfortable talking with people. & \multirow{15}{*}{ Interdependence } \\
\hline 20 & Students should establish a core support group. & \\
\hline 28 & $\begin{array}{l}\text { Students should know how to make and keep relationships (friendships, connections, networking) } \\
\text { with people throughout all of college. }\end{array}$ & \\
\hline 32 & Students should want to reach out to others instead of expecting others to come to them. & \\
\hline 34 & Students should be able to help other students and point them to resources. & \\
\hline 37 & $\begin{array}{l}\text { By the end of the first year, students should feel confident in talking to instructors and people they } \\
\text { look up to or who are in authority. }\end{array}$ & \\
\hline 39 & Students should get involved and take advantage of opportunities provided to them. & \\
\hline 49 & Students should have school pride. & \\
\hline 51 & Students should feel that staff are truly there to help them and are not just "collecting a paycheck." & \\
\hline 71 & Students should show confidence when dealing with people in positions of authority. & \\
\hline 78 & Students should know how to embrace different cultures. & \\
\hline 87 & Students should learn how to negotiate and communicate. & \\
\hline 88 & Students should know it is difficult to go through college alone. & \\
\hline 89 & $\begin{array}{l}\text { Students should know it is important to have friends - a social support system - to help them } \\
\text { through college both in terms of academics and socializing. }\end{array}$ & \\
\hline 99 & Students should try new things to open themselves up to new experiences. & \\
\hline
\end{tabular}


Table 3 (continued): List of 100 Outcomes Generated by Participants, Organized into Clusters using Hierarchical Cluster Analysis, and Labeled

\begin{tabular}{|c|c|c|}
\hline & Outcomes Generated by Participants & Cluster Label \\
\hline 6 & Students should be aware of available resources early in their college career. & \multirow{13}{*}{$\begin{array}{l}\text { Help/Resource } \\
\text { Seeking }\end{array}$} \\
\hline 14 & Students should be able to know where to go for help after their first year. & \\
\hline 15 & Students should have additional support staff to turn to for help. & \\
\hline 16 & Students should know how to use the technology used by the University - e.g., software \& devices. & \\
\hline 17 & Students should have success coaches to help them. & \\
\hline 18 & $\begin{array}{l}\text { Students should have success coaches who can refer them to specific student success } \\
\text { workshops. }\end{array}$ & \\
\hline 30 & Students should know where to go for help so they never feel lost. & \\
\hline 35 & $\begin{array}{l}\text { Students should have a good understanding of the opportunities available to them - such as extra } \\
\text { things like trips. }\end{array}$ & \\
\hline 44 & Students should know where to go if they need academic help. & \\
\hline 46 & Students should know where to go if they need counseling services. & \\
\hline 47 & $\begin{array}{l}\text { Students should know where to go if they need career guidance and career services (e.g., resume } \\
\text { building \& interviewing skill development). }\end{array}$ & \\
\hline 64 & $\begin{array}{l}\text { Students in the summer bridge program should have an idea of what is expected of them before } \\
\text { they start their fall courses. }\end{array}$ & \\
\hline 68 & $\begin{array}{l}\text { Students in the summer bridge program should feel like they have a leg up or a head start } \\
\text { compared to students who start later. }\end{array}$ & \\
\hline 9 & Students should become more confident about their academic abilities. & \multirow{16}{*}{ Academic Identity } \\
\hline 10 & Students should be able to create a success plan for college and career. & \\
\hline 13 & Students should be determined to find the career path they want to follow. & \\
\hline 27 & Students should know how to keep themselves on a schedule to graduate on time. & \\
\hline 31 & $\begin{array}{l}\text { Students should become responsible for themselves completely - particularly in finding their } \\
\text { majors. }\end{array}$ & \\
\hline 36 & $\begin{array}{l}\text { Students should be open to developing a "Plan B." Meaning that if you are not accepted into your } \\
\text { original major - or you change your mind, you have something else to move into. }\end{array}$ & \\
\hline 40 & Students should be able to develop academic maturity. & \\
\hline 41 & Students should know how to write a proper email to higher authority. & \\
\hline 52 & Students should feel prepared to schedule classes. & \\
\hline 54 & Students should be prepared to challenge their professors. & \\
\hline 58 & Students should know how to read the syllabus. & \\
\hline 59 & Students should know to check their email. & \\
\hline 60 & Students should know how to handle themselves in a professional setting. & \\
\hline 81 & $\begin{array}{l}\text { Students should know how to present themselves professionally, for example, wearing proper } \\
\text { attire. }\end{array}$ & \\
\hline 82 & $\begin{array}{l}\text { Students should know how to present themselves professionally - for example, using proper body } \\
\text { language. }\end{array}$ & \\
\hline 94 & $\begin{array}{l}\text { Students should know not to be over-competitive and be able to accept a setback such as } \\
\text { someone else getting a position they wanted. }\end{array}$ & \\
\hline
\end{tabular}


Another item to be considered is the Cluster Map as seen in Figure 4. It displays all 100 items on a two dimensional map and how they were connected to one another to shape the delineation of the six cluster solution that were adopted previously. Each cluster is labelled with a name summarizing the substance of the statements it contains. Trochim (1989a) argued that the Cluster Map is "usually the most directly interpretable map" (p. 9).

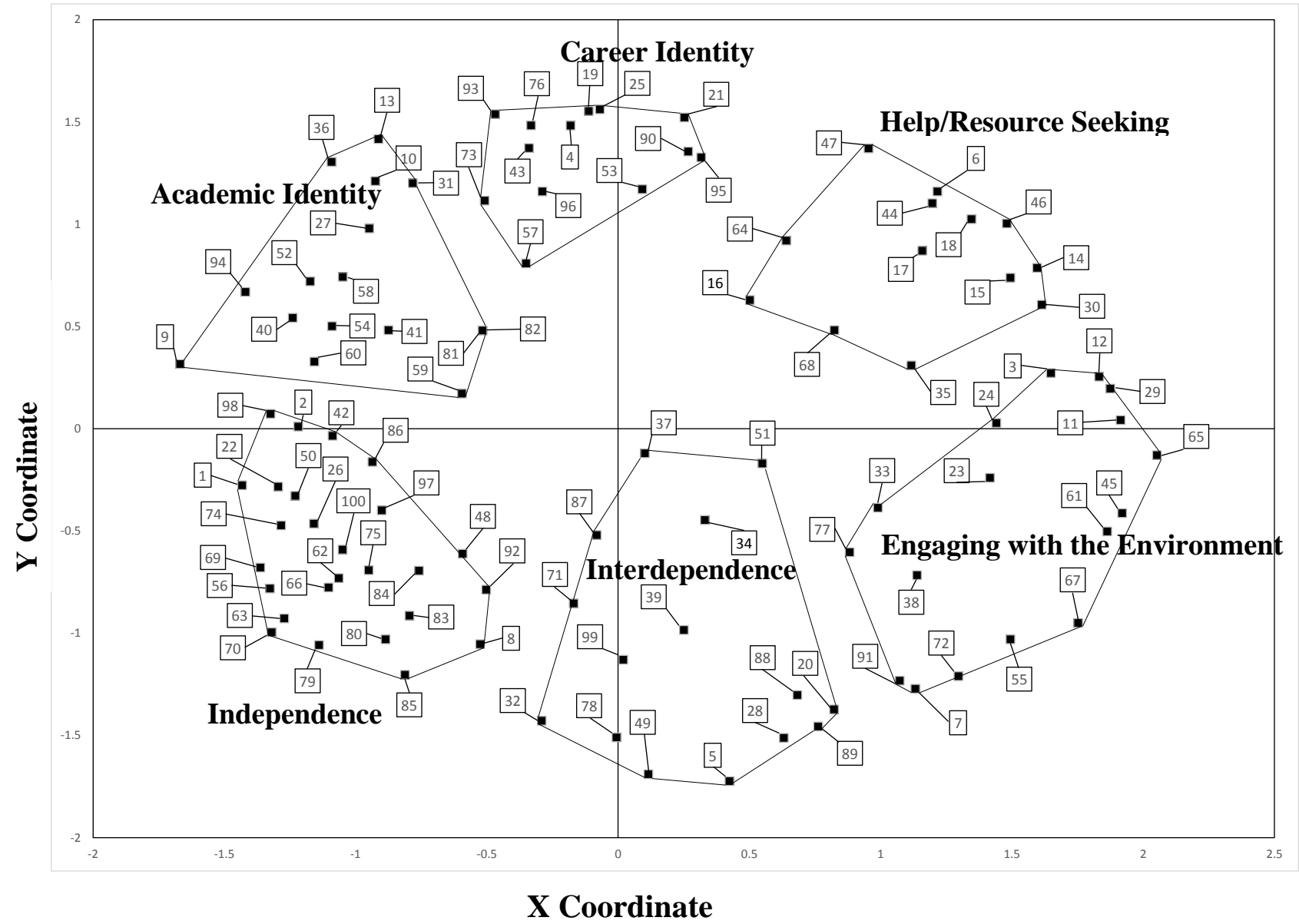

Figure 4: Cluster map with the six clusters named

The Rating Task. As noted previously, 22 out of the 23 participants took part in the rating of the 100 statements following this predetermined five-point rating scale: 
1. Please rate the relative importance of each item for ensuring the success of students in the first year of college: $1=$ Not at all important; $2=$ somewhat important; $3=$ Important; $4=$ Very important; 5 = Extremely important.

2. For each item, please evaluate the overall efficacy of your institution in helping student achieve that desired learning element: 1 = Poor; 2 = Fair; $3=$ Average; 4 = Good; $5=$ Excellent.

The item list was arranged in a survey format in Qualtrics and sent to the participants by email. Once 22 survey submissions were received, the data was transferred into a Microsoft Excel spreadsheet and uploaded to IBM SPSS Statistics (version 20) to compute arithmetic mean scores for each item (see Appendix G) and for each cluster (see Table 11). The rating task was one step further in the researcher's exploration of participants' conceptualization of the domain of study by determining the relative importance of each statement and the participants' perception of the efficacy of the Reference University in helping first year students achieve each articulated outcome.

\section{Findings for Research Question 1}

Research question 1 consisted of a central question and two sub-questions articulated as follows:

RQ 1: What is the desired domain of student learning of a first-year success program serving first-time, full-time undecided students as conceptualized by stakeholders at a land-grant university, when using the Concept Mapping/Pattern Matching methodology?

a. To what extent do program stakeholder groups differ in their rating of the relative importance of student learning outcomes for ensuring student success? 
b. To what extent do program stakeholder groups differ in their evaluation of the overall efficacy of their institution's success program in helping students achieve desired learning outcomes?

The main part of Research Question 1 was addressed through the brainstorming session, and the sorting and rating tasks completed with the help of 23 participants at the Reference University. To solicit their input, they were asked to generate statements representing the conceptual domain of student learning in the first year of college by responding to the following focus prompt: "What knowledge, skills, and attitudes should students gain as a result of participating in the success program?" At the end of the brainstorming session, 100 statements were generated and assigned a sequential number. Following an individual sorting task by participants, statements were grouped into six clusters after a Hierarchical Clustering Analysis and a subjective review by the researcher (see Table 4). Each cluster name is a summary of the statements it contains. Cluster names represent broad areas of the domain student learning in the first year of college as conceptualized by the participants at the Reference University.

Table 4: List of Six Clusters with Labels and Definitions

\begin{tabular}{|c|c|c|}
\hline Cluster & Label & Definition \\
\hline Cluster 1 & Independence & $\begin{array}{l}\text { Ability to function autonomously by devising ways to set goals } \\
\text { and priorities for personal and academic success, take } \\
\text { responsibility, and self-advocate. }\end{array}$ \\
\hline Cluster 2 & $\begin{array}{l}\text { Engaging with the } \\
\text { Environment }\end{array}$ & $\begin{array}{l}\text { Ability to develop, and harness the benefits of, meaningful } \\
\text { relationships with peers, faculty and staff, and other } \\
\text { stakeholders within the university and community } \\
\text { environments }\end{array}$ \\
\hline Cluster 3 & Career Identity & $\begin{array}{l}\text { Ability to plan and embrace a realistic and competitive career } \\
\text { path by taking advantage of existing resources }\end{array}$ \\
\hline Cluster 4 & Interdependence & $\begin{array}{l}\text { Ability to develop a social support system for academic and } \\
\text { personal success through cooperation and communication with } \\
\text { a diverse group of stakeholders }\end{array}$ \\
\hline
\end{tabular}


Cluster 5 Help/Resource Seeking

Cluster 6 Academic Identity
Ability to identify and utilize campus resources and support services to enhance success

Ability to hone academic and professional skills in order to plan for an academic major and a career

In the following sections, each cluster and its statements will be shown in a table along with mean importance and efficacy scores. This will allow for a close examination of the statements in each cluster and how similar or dissimilar they are in meaning. Due to the high number of statements, and the variety of participants in this study, some items may look odd in some clusters and appear to belong better in different clusters. This may be due to the different ways participants understood each statement or the time taken to complete the sorting task. Items in each cluster are sorted in descending order with the high importance mean rating at the top.

Independence Cluster. The Independence Cluster is the largest cluster with 26 statements. It is the only one to have more than 20 statements. This name was given to the cluster based on a close look at the content of the statements it contains. Most of the statements focus on outcomes that will allow students to become autonomous learners who can set goals and priorities, take responsibility for their actions, be unique, care and advocate for themselves. The researcher defined the cluster as follows: "Ability to function autonomously by devising ways to set goals and priorities for personal and academic success, take responsibility, and selfadvocate".

The rating task results revealed participants' perception of the importance of the 26 statements in this cluster. Over half of the statements recorded a mean importance rating of 4.0 or above on a 5-point scale. The participants' perception of the efficacy of the Reference 
University regarding the same statements was less favorable. Only five statements had a mean score of 4.0 or above:

- (\#2) Students should take responsibility for individual learning $(M=4.00)$

- (\#26) Students should manage their time by prioritizing what they need to accomplish $(M=4.05)$

- (\#48) Students should have confidence by the end of the year in terms of adjusting to college, being aware of resources, and asking for help $(M=4.09)$

- (\#66) Students should be more well-rounded in the sense that they have all the tools and skills necessary to be self-sufficient $(M=4.00)$

- (\#79) Students should know how to handle adversity, for example, tough times and challenges $(M=4.00)$.

This reflects the general perception that statements in the Independence Cluster were considered relatively important and the Reference University was not perceived as particularly efficient in helping students achieve those learning outcomes. This cluster being the largest of all — the double of two of the other clusters - the researcher was expecting to encounter statements that would not seem to belong to this group. From the researcher's perspective, all items seemed to fit fairly well to this cluster and its definition stated above.

Table 5: List of Statements in the Independence Cluster and Their Mean Ratings in Terms of Importance and Efficacy

\begin{tabular}{lllc}
\hline $\begin{array}{l}\text { Item } \\
\text { number }\end{array}$ & \multicolumn{1}{c}{ Statement } & \multicolumn{2}{c}{ Rating } \\
\cline { 3 - 4 } & & $\begin{array}{c}\text { Importance } \\
(M=3.99)\end{array}$ & $\begin{array}{c}\text { Efficacy } \\
(M=3.84)\end{array}$ \\
\hline 50 & Students should take responsibility for their actions & 4.41 & 3.82 \\
2 & Students should take responsibility for individual learning & 4.32 & 4.00 \\
1 & Students should be able to know their priorities & 4.23 & 3.77
\end{tabular}




\begin{tabular}{|c|c|c|c|}
\hline 63 & $\begin{array}{l}\text { Students should learn from their mistakes (academic or } \\
\text { personal) and be able to move forward }\end{array}$ & 4.23 & 3.59 \\
\hline 75 & $\begin{array}{l}\text { Students should be able to develop from a dependent person to } \\
\text { an independent person }\end{array}$ & 4.23 & 3.91 \\
\hline 98 & Students should be able to learn the value of critical thinking & 4.18 & 3.91 \\
\hline 79 & $\begin{array}{l}\text { Students should know how to handle adversity, for example, } \\
\text { tough times and challenges }\end{array}$ & 4.14 & 4.00 \\
\hline 22 & $\begin{array}{l}\text { Students should be able to build positive habits to help them } \\
\text { become more successful as college students }\end{array}$ & 4.09 & 3.64 \\
\hline 56 & Students should know how to prioritize better & 4.09 & 3.95 \\
\hline 74 & Students should set their own goals & 4.09 & 3.86 \\
\hline 66 & $\begin{array}{l}\text { Students should be more well-rounded in the sense that they } \\
\text { have all the tools and skills necessary to be self-sufficient }\end{array}$ & 4.05 & 4.00 \\
\hline 70 & $\begin{array}{l}\text { Students should be prepared for anything that is thrown their } \\
\text { way - opportunities and adverse events }\end{array}$ & 4.00 & 3.91 \\
\hline 85 & $\begin{array}{l}\text { Students should make decisions to make themselves happy } \\
\text { rather than making decisions to make other people happy }\end{array}$ & 4.00 & 3.77 \\
\hline 97 & Students should know how to make themselves distinct & 4.00 & 3.59 \\
\hline 100 & Students should learn how to keep themselves healthy & 4.00 & 3.64 \\
\hline 69 & $\begin{array}{l}\text { Students should be able to stay positive despite academic } \\
\text { setbacks }\end{array}$ & 3.95 & 3.82 \\
\hline 84 & Students should know how to set realistic goals & 3.95 & 3.77 \\
\hline 86 & Students should discover and then build their skills & 3.95 & 3.86 \\
\hline 48 & $\begin{array}{l}\text { Students should have confidence by the end of the year in } \\
\text { terms of adjusting to college, being aware of resources, and } \\
\text { asking for help }\end{array}$ & 3.91 & 4.09 \\
\hline 83 & $\begin{array}{l}\text { Students should know how to self-advocate - and not be afraid } \\
\text { to ask questions }\end{array}$ & 3.86 & 3.82 \\
\hline 26 & $\begin{array}{l}\text { Students should manage their time by prioritizing what they } \\
\text { need to accomplish }\end{array}$ & 3.82 & 4.05 \\
\hline 42 & Students should not be scared to take on academic challenges & 3.82 & 3.91 \\
\hline 80 & $\begin{array}{l}\text { Students should do the best they can based on their own } \\
\text { abilities - and not compare themselves to others }\end{array}$ & 3.82 & 3.82 \\
\hline 62 & $\begin{array}{l}\text { Students should know what success looks like because they } \\
\text { should have experienced some form of success by the end of } \\
\text { their first year }\end{array}$ & 3.73 & 3.77 \\
\hline 92 & $\begin{array}{l}\text { Students should develop strategies to help themselves to de- } \\
\text { stress }\end{array}$ & 3.68 & 3.95 \\
\hline 8 & Students should take opportunities to stand out and be unique & 3.18 & 3.50 \\
\hline
\end{tabular}

Engaging with the Environment Cluster. The Engaging with the Environment Cluster is the second largest cluster with 17 statements. They mostly refer to the relationships of students 
with the immediate college environment as well as with off-campus communities and the State in which the university is located. The statements highlight the necessity for students to develop an awareness of their physical surroundings, to build relationships and connections, and to develop a sense of belonging. A review of the items in this cluster led the researcher to define it as "the ability to develop, and harness the benefits of, meaningful relationships with peers, faculty and staff, and other stakeholders within the university and community environments". A close examination of the scores showed that only one item in the cluster, (\#91) Students should know it is important to realize they are not alone - they have friends, professors, support staff, etc. $(M=$ 4.00) recorded a mean importance rating at the 4.0 level. This reveals that participants did not consider items in the particular cluster to be as important as items in other clusters. The lowest mean importance rating in the cluster was recorded by (\#65) Students should have a better understanding of the history of campus buildings and the campus in general $(M=2.77)$.

In terms of efficacy, four statements received a mean rating at or above 4.0 and several others were rated close to that number. Overall, the mean efficacy rating was higher compared to the mean importance rating. This reflects the belief of participants that statements in this cluster were relatively less important and that the Reference University's efficacy in addressing these outcomes was favorably regarded by participants.

Table 6: List of Statements in the Engaging with the Environment Cluster and Their Mean Ratings in Terms of Importance and Efficacy

\begin{tabular}{clcc}
\hline \multirow{2}{*}{$\begin{array}{c}\text { Item } \\
\text { number }\end{array}$} & \multicolumn{1}{c}{ Statement } & \multicolumn{2}{c}{ Rating } \\
\cline { 3 - 4 } 91 & $\begin{array}{l}\text { Students should know it is important to realize they are not alone } \\
- \text { they have friends, professors, support staff, etc. } \\
(M=3.25)\end{array}$ & $\begin{array}{c}\text { Efficacy } \\
(M=3.79)\end{array}$ \\
\hline & $\begin{array}{l}\text { Students should gain familiarity with the campus, all the colleges } \\
\text { at the university, and in general, college life }\end{array}$ & 3.00 & 3.95 \\
\hline
\end{tabular}




\begin{tabular}{|c|c|c|c|}
\hline 38 & $\begin{array}{l}\text { Students should find out about student organizations so they can } \\
\text { find others with common interests }\end{array}$ & 3.45 & 3.64 \\
\hline 7 & $\begin{array}{l}\text { Students should have an opportunity to meet new people right } \\
\text { off the bat and make new friends }\end{array}$ & 3.41 & 4.18 \\
\hline 23 & $\begin{array}{l}\text { Students in the summer bridge program should get to meet more } \\
\text { faculty members and become better friends with faculty than } \\
\text { other freshmen are }\end{array}$ & 3.41 & 3.91 \\
\hline 3 & $\begin{array}{l}\text { Students should get to know the different buildings for each } \\
\text { college around campus }\end{array}$ & 3.36 & 4.00 \\
\hline 33 & $\begin{array}{l}\text { If students are offered an opportunity to participate in a success } \\
\text { program, they should take advantage of it }\end{array}$ & 3.32 & 3.64 \\
\hline 61 & $\begin{array}{l}\text { Students should know their community better - especially their } \\
\text { local community - through service projects }\end{array}$ & 3.27 & 3.36 \\
\hline 24 & $\begin{array}{l}\text { Students should have opportunities to have one-on-one } \\
\text { interactions with members of different colleges (e.g., recruiters } \\
\text { and advisors) }\end{array}$ & 3.23 & 3.82 \\
\hline 77 & Students should participate in research sessions & 3.18 & 3.45 \\
\hline 67 & $\begin{array}{l}\text { Students should want to stay at their institution at the end of their } \\
\text { first year }\end{array}$ & 3.14 & 3.86 \\
\hline 72 & $\begin{array}{l}\text { Students should try enjoying clubs and/or fraternities or } \\
\text { sororities }\end{array}$ & 3.14 & 3.95 \\
\hline 12 & $\begin{array}{l}\text { Students should have enough time during the summer bridge } \\
\text { program to figure out their surroundings }\end{array}$ & 3.09 & 3.82 \\
\hline 45 & $\begin{array}{l}\text { Students should have a better feel not just for their university but } \\
\text { for the whole State as well }\end{array}$ & 3.05 & 3.59 \\
\hline 11 & $\begin{array}{l}\text { Students should take tours of the campus - to learn about their } \\
\text { environment }\end{array}$ & 2.86 & 4.09 \\
\hline 55 & Students should know how to sing their school song & 2.86 & 3.82 \\
\hline 65 & $\begin{array}{l}\text { Students should have a better understanding of the history of } \\
\text { campus buildings and the campus in general }\end{array}$ & 2.77 & 3.27 \\
\hline
\end{tabular}

Career Identity Cluster. With 13 statements, the Career Identity Cluster is one of two clusters with the lowest number of items. Based on its items, this cluster was defined as "the ability to plan and embrace a realistic and competitive career path by taking advantage of existing resources".

Rating results revealed that only two items had a mean importance rating at or above 4.0: (\#90) Students should know to take advantage of opportunities (such as internships) related to possible majors $(M=4.09)$ and $(\# 57)$ Students should know their professors' expectations $(M=$ 
4.05). Perception of item importance in this cluster was relatively lower compared to mean efficacy rating. As a matter of fact, efficacy rating were higher, leading to the conclusion that participants perceived the Reference University to be performing better than they considered these items to be relatively important for first-year students.

One statement, (\#57) Students should know their professors' expectations $(M=4.05)$, seemed not to belong in this cluster. The researcher believes it should have been placed in the Academic Identity Cluster where it seems to fit better. On the Cluster Map, (\#57) is in close proximity of the Academic Identity Cluster and could have been easily assimilated to a number of statements in that cluster. However, the researcher cannot override the results of the Hierarchical Cluster Analysis, which stems from the participants' sorting decisions.

Table 7: List of Statements in the Career Identity Cluster and Their Mean Ratings in Terms of Importance and Efficacy

\begin{tabular}{|c|c|c|c|}
\hline \multirow{2}{*}{$\begin{array}{c}\text { Item } \\
\text { number }\end{array}$} & \multirow[t]{2}{*}{ Statement } & \multicolumn{2}{|c|}{ Rating } \\
\hline & & $\begin{array}{c}\text { Importance } \\
(M=3.67)\end{array}$ & $\begin{array}{l}\text { Efficacy } \\
(M=3.79)\end{array}$ \\
\hline 90 & $\begin{array}{l}\text { Students should know to take advantage of opportunities (such } \\
\text { as internships) related to possible majors }\end{array}$ & 4.09 & 3.82 \\
\hline 57 & Students should know their professors' expectations & 4.05 & 3.86 \\
\hline 53 & $\begin{array}{l}\text { Students should know how to contact their academic advisors } \\
\text { to make advising appointments }\end{array}$ & 3.95 & 4.05 \\
\hline 73 & Students should know they have to find a job after college & 3.95 & 4.05 \\
\hline 96 & $\begin{array}{l}\text { Students should know what they have to do to be desirable to } \\
\text { employers }\end{array}$ & 3.91 & 3.91 \\
\hline 76 & $\begin{array}{l}\text { Students should be aware of the competition to get into some } \\
\text { majors }\end{array}$ & 3.86 & 3.86 \\
\hline 43 & $\begin{array}{l}\text { Students should begin to learn what major they might be } \\
\text { interested in }\end{array}$ & 3.68 & 4.05 \\
\hline 95 & $\begin{array}{l}\text { Students should be exposed to different programs, } \\
\text { presentations, and environments to help them decide on their } \\
\text { ultimate major }\end{array}$ & 3.64 & 3.95 \\
\hline 4 & Student should begin to learn what they are interested in & 3.55 & 3.50 \\
\hline
\end{tabular}


21 Students should have opportunities in class early in the semester to find out what their interests are to help them choose a major

19 Students should feel more prepared to decide on a major and not constantly be changing their minds Students should follow a four-year plan when preparing for their careers

25 Students should know what major they want by the end of their first year

Interdependence Cluster. The Interdependence Cluster has 15 statements that mostly highlight the fact that academic and personal success depend on students reaching out to and working with peers and others stakeholders. Statements in this cluster led to the definition of the goal of this cluster as "the ability to develop a social support system for academic and personal success through cooperation and communication with a diverse group of stakeholders".

Items in this cluster were all rated on average below the threshold of 4.0 for importance. Mean efficacy ratings were in general higher with three statements rated at or above 4.0. This is the third cluster so far where mean efficacy scores are higher than mean importance scores. This reveals again that participants considered the items in the cluster to be relatively less important and the Reference University to perform well in helping students reach the learning outcomes articulated in the cluster. In the researcher's perspective, (\#49) Students should have school pride, seemed to be an outlier in this cluster. Despite its similarity in meaning with items in the Engaging with the Environment Cluster, (\#49) is far away from that cluster. This indicates the participants' decision to allow this distance between (\#49) and the cluster to which it seems to belong. 
Table 8: List of Statements in the Interdependence Cluster and Their Mean Ratings in Terms of

Importance and Efficacy

\begin{tabular}{|c|c|c|c|}
\hline \multirow{2}{*}{$\begin{array}{l}\text { Item } \\
\text { number }\end{array}$} & \multirow[t]{2}{*}{ Statement } & \multicolumn{2}{|c|}{ Rating } \\
\hline & & $\begin{array}{c}\text { Importance } \\
(M=3.76)\end{array}$ & $\begin{array}{l}\text { Efficacy } \\
(M=3.87)\end{array}$ \\
\hline 89 & $\begin{array}{l}\text { Students should know it is important to have friends - a social } \\
\text { support system - to help them through college both in terms of } \\
\text { academics and socializing }\end{array}$ & 3.95 & 3.91 \\
\hline 99 & $\begin{array}{l}\text { Students should try new things to open themselves up to new } \\
\text { experiences }\end{array}$ & 3.95 & 3.95 \\
\hline 32 & $\begin{array}{l}\text { Students should want to reach out to others instead of expecting } \\
\text { others to come to them }\end{array}$ & 3.91 & 3.45 \\
\hline 39 & $\begin{array}{l}\text { Students should get involved and take advantage of } \\
\text { opportunities provided to them }\end{array}$ & 3.91 & 3.95 \\
\hline 37 & $\begin{array}{l}\text { By the end of the first year, students should feel confident in } \\
\text { talking to instructors and people they look up to or who are in } \\
\text { authority }\end{array}$ & 3.86 & 4.00 \\
\hline 5 & $\begin{array}{l}\text { Efficacy - Students should become more social and be more } \\
\text { comfortable talking with people }\end{array}$ & 3.82 & 3.73 \\
\hline 20 & Students should establish a core support group & 3.82 & 3.55 \\
\hline 87 & Students should learn how to negotiate and communicate & 3.82 & 3.95 \\
\hline 28 & $\begin{array}{l}\text { Students should know how to make and keep relationships } \\
\text { (friendships, connections, networking) with people throughout } \\
\text { all of college }\end{array}$ & 3.73 & 3.82 \\
\hline 51 & $\begin{array}{l}\text { Students should feel that staff are truly there to help them and } \\
\text { are not just "collecting a paycheck" }\end{array}$ & 3.73 & 3.73 \\
\hline 71 & $\begin{array}{l}\text { Students should show confidence when dealing with people in } \\
\text { positions of authority }\end{array}$ & 3.73 & 3.91 \\
\hline 78 & Students should know how to embrace different cultures & 3.68 & 4.00 \\
\hline 88 & Students should know it is difficult to go through college alone & 3.59 & 3.95 \\
\hline 34 & $\begin{array}{l}\text { Students should be able to help other students and point them to } \\
\text { resources }\end{array}$ & 3.50 & 3.82 \\
\hline 49 & Students should have school pride & 3.41 & 4.36 \\
\hline
\end{tabular}

Help/Resource Seeking Cluster. With 13 statements, the Help/Resource Seeking

Cluster is one of two clusters with the lowest number of items. Outcomes in this cluster reference resources and services that students need to avail themselves of in the first year of college. The global goal of this cluster focuses on students' "ability to identify and utilize campus resources 
and support services to enhance success". In this cluster, five items recorded a mean importance rating at or above 4.0 :

- (\#30) Students should know where to go for help so they never feel lost $(M=4.50)$;

- (\#6) Students should be aware of available resources early in their college career $(M=$ 4.27);

- (\#14) Students should be able to know where to go for help after their first year $(M=$ 4.18);

- (\#44) Students should know where to go if they need academic help $(M=4.14)$;

- $\quad$ and (\#46) Students should know where to go if they need counseling services $(M=4.00)$.

Three items had mean efficacy ratings at or above 4.0: (\#44) Students should know where to go if they need academic help $(M=4.18)$; (\#15) Students should have additional support staff to turn to for help $(M=4.00)$; and (\#68) Students in the summer bridge program should feel like they have a leg up or a head start compared to students who start later $(M=4.18)$. This is also the fourth cluster in the study with a higher mean efficacy rating compared to the mean importance rating. Participants believed that the Reference University was effective in providing the conditions for students to achieve these learning outcomes. All items in this cluster share common feature and thus fit well in the cluster.

Table 9: List of Statements in the Help/Resource Seeking Cluster and Their Mean Ratings in Terms of Importance and Efficacy

\begin{tabular}{clcc}
\hline \multirow{2}{*}{$\begin{array}{c}\text { Item } \\
\text { number }\end{array}$} & \multicolumn{1}{c}{ Statement } & \multicolumn{2}{c}{ Rating } \\
\cline { 3 - 4 } 30 & $\begin{array}{l}\text { Students should know where to go for help so they never feel } \\
\text { lost } \\
\text { Importance } \\
(M=3.76)\end{array}$ & $\begin{array}{c}\text { Efficacy } \\
(M=3.93)\end{array}$ \\
\hline & $\begin{array}{l}\text { Students should be aware of available resources early in their } \\
\text { college career }\end{array}$ & 4.50 & 3.86 \\
\hline
\end{tabular}




\begin{tabular}{|c|c|c|c|}
\hline 14 & $\begin{array}{l}\text { Students should be able to know where to go for help after their } \\
\text { first year }\end{array}$ & 4.18 & 3.91 \\
\hline 44 & Students should know where to go if they need academic help & 4.14 & 4.18 \\
\hline 46 & $\begin{array}{l}\text { Students should know where to go if they need counseling } \\
\text { services }\end{array}$ & 4.00 & 3.77 \\
\hline 16 & $\begin{array}{l}\text { Students should know how to use the technology used by the } \\
\text { University - e.g., software \& devices }\end{array}$ & 3.68 & 3.77 \\
\hline 47 & $\begin{array}{l}\text { Students should know where to go if they need career guidance } \\
\text { and career services (e.g., resume building \& interviewing skill } \\
\text { development) }\end{array}$ & 3.68 & 3.95 \\
\hline 64 & $\begin{array}{l}\text { Students in the summer bridge program should have an idea of } \\
\text { what is expected of them before they start their fall courses }\end{array}$ & 3.68 & 3.86 \\
\hline 15 & Students should have additional support staff to turn to for help & 3.64 & 4.00 \\
\hline 68 & $\begin{array}{l}\text { Students in the summer bridge program should feel like they } \\
\text { have a leg up or a head start compared to students who start later }\end{array}$ & 3.64 & 4.18 \\
\hline 18 & $\begin{array}{l}\text { Students should have success coaches who can refer them to } \\
\text { specific student success workshops }\end{array}$ & 3.18 & 3.86 \\
\hline 35 & $\begin{array}{l}\text { Students should have a good understanding of the opportunities } \\
\text { available to them - such as extra things like trips }\end{array}$ & 3.18 & 3.95 \\
\hline 17 & Students should have success coaches to help them & 3.05 & 3.86 \\
\hline
\end{tabular}

Academic Identity Cluster. The Academic Identity Cluster counts a total of 16 statements describing the outcomes that relate to student development of academic skills, student professional behavior in academic settings, and career and major planning. This last cluster encompasses students' “ability to hone academic and professional skills in order to plan for an academic major and a career".

During the rating task, five items received a score of 4.0 or above in terms of mean importance rating versus three items with similar ratings for efficacy. In general, importance ratings were higher than efficacy scores. All items fit the cluster and its definition. 
Table 10: List of Statements in the Academic Identity Cluster and Their Mean Ratings in Terms of Importance and Efficacy

\begin{tabular}{|c|c|c|c|}
\hline \multirow{2}{*}{$\begin{array}{c}\text { Item } \\
\text { number }\end{array}$} & \multirow[b]{2}{*}{ Statement } & \multicolumn{2}{|c|}{ Rating } \\
\hline & & $\begin{array}{l}\text { Importance } \\
(M=3.90)\end{array}$ & $\begin{array}{l}\text { Efficacy } \\
(M=3.73)\end{array}$ \\
\hline 59 & Students should know to check their email & 4.45 & 4.05 \\
\hline 41 & $\begin{array}{l}\text { Students should know how to write a proper email to higher } \\
\text { authority }\end{array}$ & 4.36 & 3.91 \\
\hline 58 & Students should know how to read the syllabus & 4.27 & 4.05 \\
\hline 40 & Students should be able to develop academic maturity & 4.23 & 3.77 \\
\hline 60 & $\begin{array}{l}\text { Students should know how to handle themselves in a } \\
\text { professional setting }\end{array}$ & 4.18 & 3.82 \\
\hline 10 & $\begin{array}{l}\text { Students should be able to create a success plan for college and } \\
\text { career }\end{array}$ & 3.95 & 3.55 \\
\hline 81 & $\begin{array}{l}\text { Students should know how to present themselves professionally, } \\
\text { for example, wearing proper attire }\end{array}$ & 3.91 & 3.59 \\
\hline 94 & $\begin{array}{l}\text { Students should know not to be over-competitive and be able to } \\
\text { accept a setback such as someone else getting a position they } \\
\text { wanted }\end{array}$ & 3.91 & 3.59 \\
\hline 27 & $\begin{array}{l}\text { Students should know how to keep themselves on a schedule to } \\
\text { graduate on time }\end{array}$ & 3.86 & 4.00 \\
\hline 36 & $\begin{array}{l}\text { Students should be open to developing a "Plan B." Meaning that } \\
\text { if you are not accepted into your original major - or you change } \\
\text { your mind, you have something else to move into }\end{array}$ & 3.86 & 3.82 \\
\hline 52 & Students should feel prepared to schedule classes & 3.86 & 3.91 \\
\hline 82 & $\begin{array}{l}\text { Students should know how to present themselves professionally } \\
\text { - for example, using proper body language }\end{array}$ & 3.86 & 3.68 \\
\hline 9 & $\begin{array}{l}\text { Students should become more confident about their academic } \\
\text { abilities }\end{array}$ & 3.68 & 3.64 \\
\hline 31 & $\begin{array}{l}\text { Students should become responsible for themselves completely - } \\
\text { particularly in finding their majors }\end{array}$ & 3.68 & 3.41 \\
\hline 13 & $\begin{array}{l}\text { Students should be determined to find the career path they want } \\
\text { to follow }\end{array}$ & 3.45 & 3.59 \\
\hline 54 & Students should be prepared to challenge their professors & 2.95 & 3.45 \\
\hline
\end{tabular}

Mean rating scores were calculated for each of the six clusters retained for this study (see Table 11). Two of the clusters, the Independence Cluster $(M=3.99)$ and Academic Identity Cluster $(M=3.90)$, recorded importance ratings that were higher compared to their respective 
efficacy ratings $(M=3.84 ; M=3.73)$. For the remaining four clusters, efficacy mean ratings were higher compared to their respective mean importance ratings.

The Independence Cluster recorded the highest mean importance rating $(M=3.99)$ while the Engaging with the Environment Cluster recorded the lowest mean importance rating $(M=$ 3.25). The Interdependence and the Help/Resource Seeking both received the same importance rating score from participants $(M=3.76)$. Although none of the clusters was rated at or above a 4.0, they are all above the average rating on a 5-point scale, showing that across the board, participants reached a consensus on the importance of the brainstormed outcomes.

In terms of efficacy, the Help/Resource Seeking Cluster received the highest mean rating $(M=3.93)$ while the lowest rating was received by the Academic Identity Cluster $(M=3.73)$. The Engaging with the Environment and the Career Identity Clusters recorded identical mean ratings $(M=3.79)$. With regards to efficacy, all ratings are also above average on a 5-point scale. Participants acknowledged across the board that the Reference University was performing above average in terms of providing students with the resources to be successful in the first college year.

Table 11: The Importance and Efficacy Mean Scores for Each Cluster

\begin{tabular}{rlrr}
\hline \multirow{2}{*}{ Cluster } & & Label & \multicolumn{2}{c}{ Rating } \\
\cline { 3 - 4 } Cluster 1 & Independence & Importance & Efficacy \\
Cluster 2 & Engaging with the Environment & 3.99 & 3.84 \\
Cluster 3 & Career Identity & 3.25 & 3.79 \\
Cluster 4 & Interdependence & 3.67 & 3.79 \\
Cluster 5 & Help/Resource Seeking & 3.76 & 3.87 \\
Cluster 6 & Academic Identity & 3.76 & 3.93 \\
\hline
\end{tabular}


A visual representation of the pattern matches that were performed at the cluster level for importance and efficacy ratings is shown in Figure 5. A perfect match would be shown by a straight horizontal line linking the value for importance and the value for efficacy for a given cluster. The laddergraph in Figure 5 shows that there are differences in perception of importance of outcomes versus perception of efficacy of the Reference University in helping students achieve those outcomes.

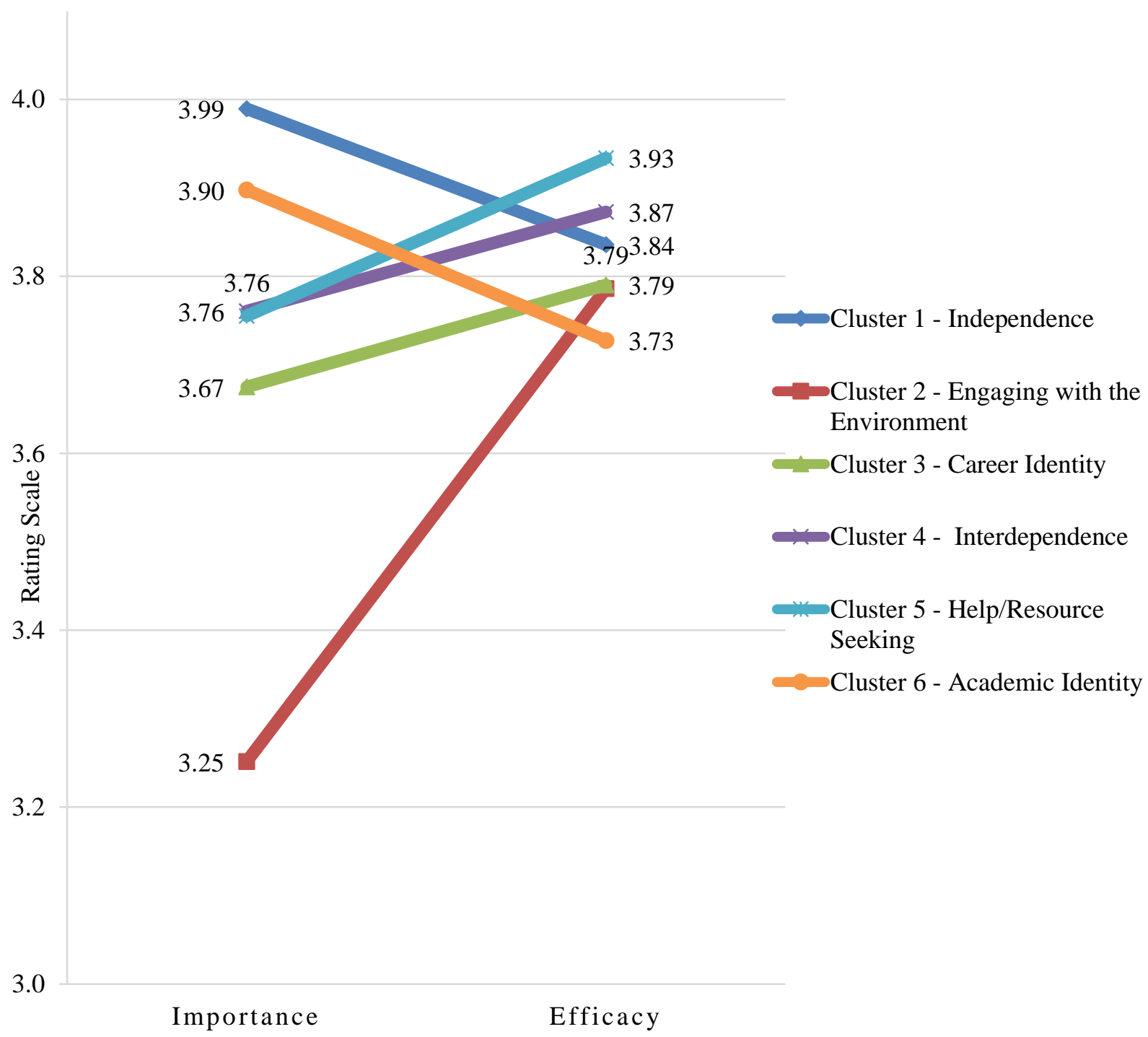

Figure 5: Laddergraph showing the mean ratings of importance and efficacy for the six clusters 
Four clusters, Help/Resource Seeking $(M=3.93)$, Interdependence $(M=3.87)$, Career Identity $(M=3.79)$, and Engaging with the Environment $(M=3.79)$ recorded higher efficacy scores compare to their importance ratings. Two clusters, Independence $(M=3.99)$ and Academic Identity $(M=3.90)$, received higher ratings for importance compared to their efficacy scores. Although the scores are not below the average on a 5-point scale, this chart identified the ability to empower students to be independent learners and to develop an academic identity as potential areas of concerns for the Reference University.

\section{Findings for Research Question 1.a.}

To what extent do program stakeholder groups differ in their rating of the relative importance of student learning outcomes for ensuring student success? Sub-question a) of Research Question 1 was meant to examine the differences between stakeholder groups (students and faculty/staff) in their rating of the relative importance of student learning outcomes for ensuring student success. For that purpose, mean importance scores by each stakeholder group were calculated (see Table 12). Across the board, the faculty/staff group rated all clusters higher than the students group.

Table 12: The Importance and Efficacy Mean Scores by Cluster and by Stakeholder Group.

\begin{tabular}{|c|c|c|c|c|c|}
\hline \multirow{2}{*}{ Cluster } & \multirow[t]{2}{*}{ Label } & \multicolumn{2}{|c|}{ Mean Importance } & \multicolumn{2}{|c|}{ Mean Efficacy } \\
\hline & & Faculty/Staff & Students & Faculty/Staff & Students \\
\hline Cluster 1 & Independence & 4.19 & 3.91 & 3.31 & 4.03 \\
\hline Cluster 2 & $\begin{array}{l}\text { Engaging with the } \\
\text { Environment }\end{array}$ & 3.27 & 3.24 & 3.55 & 3.88 \\
\hline Cluster 3 & Career Identity & 3.71 & 3.66 & 3.46 & 3.91 \\
\hline Cluster 4 & Interdependence & 3.86 & 3.73 & 3.49 & 4.02 \\
\hline Cluster 5 & Help/Resource Seeking & 3.92 & 3.69 & 3.77 & 4.00 \\
\hline Cluster 6 & Academic Identity & 3.97 & 3.87 & 3.18 & 3.93 \\
\hline
\end{tabular}


Engaging with the Environment is the only cluster that faculty/staff rated lower in importance $(M=3.27)$ and higher in efficacy $(M=3.55)$. For them, all other importance scores are consistently higher than the efficacy scores. For students, efficacy scores are consistently higher than importance scores. For them, the lowest importance score was recorded by the Engaging with the Environment Cluster $(M=3.24)$. In terms of efficacy, three clusters had scores at or above 4.0, Independence $(M=4.03)$, Interdependence $(M=4.02)$ and Help/Resource Seeking $(M=4.00)$ (See Table 12).

Group rating differences are expressed on the pattern matches represented on Figure 6 below. They show a mismatch in the degree of perceived importance of the outcomes by the two groups of stakeholders. However, there seems to be some level of agreement. The Independence Cluster was considered by faculty/staff $(M=4.19)$ as well as by students $(M=3.91)$ as the most important one, although the faculty/staff group rated this cluster higher than the students. The consistency in the rating does not end there. The Engaging with the Environment Cluster was identified as the least important by both faculty/staff $(M=3.27)$ and students $(M=3.24)$. Additionally, it is worth noting that the Independence Cluster $(M=4.19)$ is the only cluster to have a mean rating importance score at or above 4.0. 


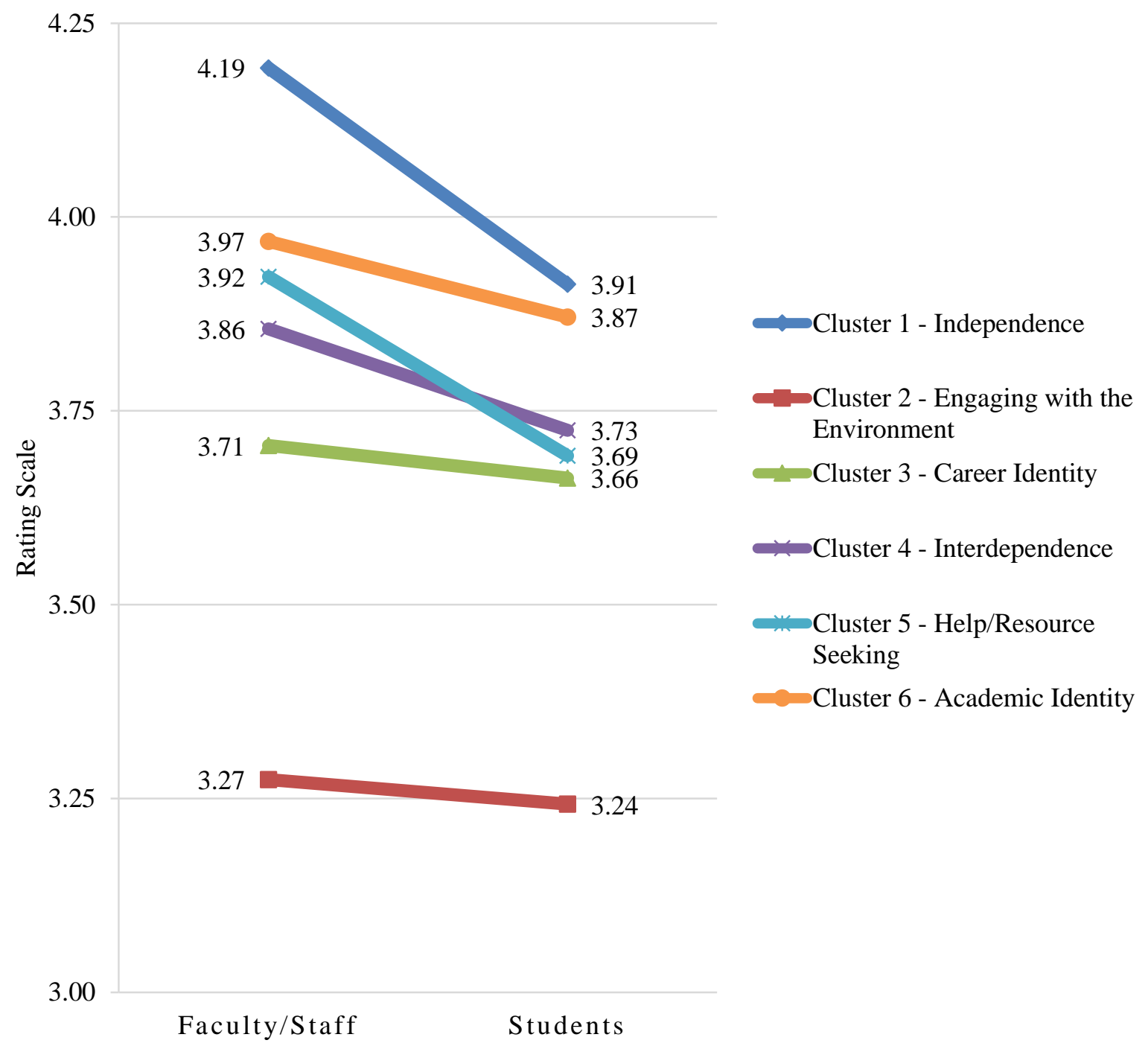

Figure 6: Laddergraph showing the mean group cluster ratings for importance

\section{Findings for Research Question 1.b.}

To what extent do program stakeholder groups differ in their evaluation of the overall efficacy of their institution's success program in helping students achieve desired learning outcomes? As far as sub-question b) of Research Question 1 was concerned, its purpose was to investigate the difference between stakeholder groups (students and faculty/staff) in their rating 
of the overall efficacy of the success program at the Reference University in helping students achieve each of the desired learning outcomes articulated during the brainstorming session.

When comparing the groups' mean efficacy ratings, one realizes that the opposite of what was observed with groups' importance scores can be noted. In each case, students rated all clusters higher in terms of efficacy compared to the faculty/staff. The Independence Cluster was rated highest by students $(M=4.03)$ and the Engaging with the Environment Cluster $(M=3.88)$ was their lowest rated cluster. Faculty/staff rated the Help/Resource Seeking Cluster highest ( $M$ = 3.77) while their lowest was Academic Identity $(M=3.18)$. The pattern matches on Figure 7 allows for a visual comparison of the stakeholder groups. 


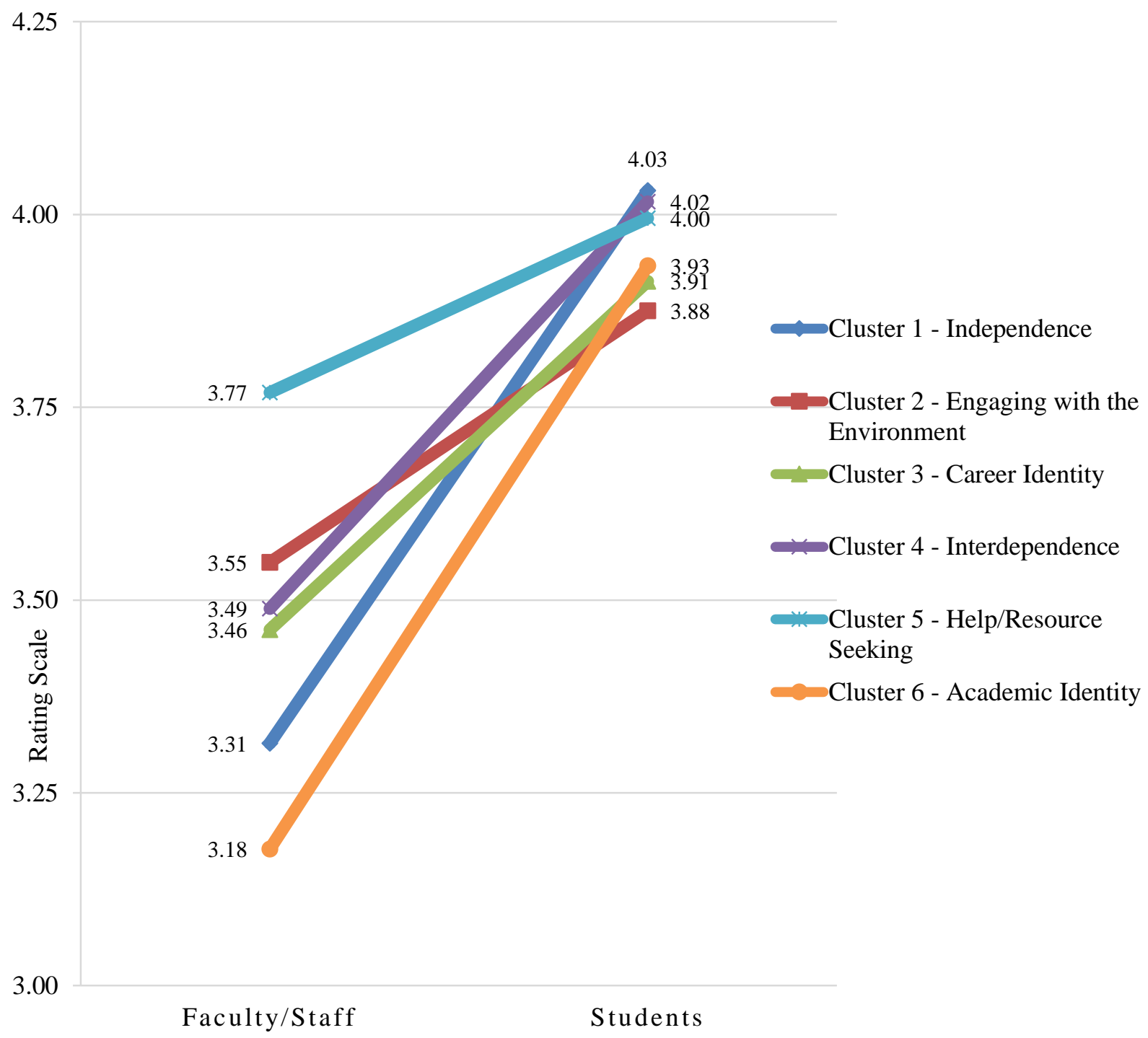

Figure 7: Laddergraph showing the mean group cluster ratings for efficacy

\section{Findings for Research Question 2}

The second Research Question proposed in this study was articulated as follows: "To what extent does the conceptualized desired domain of student learning under Research Questions 1 align with the Foundational Dimensions established by the John N. Gardner Institute?" To respond to this question, the researcher performed a document analysis that consisted of comparing the results revealed by the CM/PM study and the nine Foundational 
Dimensions of the John N. Gardner Institute. It is important to note that the learning outcomes conceptualized through this study reflect aspirational qualities inherent to first-year students whereas the Foundational Dimensions reflect institutional level goals. This research question was included nonetheless because it is the researcher's belief that both levels are connected and should interact for improvement, planning, and evaluation purposes. Therefore, the researcher decided that it was of great importance to determine to what extent the results of the conceptualization process align with the Foundational Dimensions. Another reason for referring to the Foundational Dimensions was to check for relevance of national standards at the local level and to find out if a local program is modeled after and resembles a vetted best-practice in post-secondary education.

As noted previously, the Foundational Dimensions were designed with two target populations in mind: a version for first-year students and another one for transfer students. These two versions are further subcategorized according to institutional type: a four-year focus and a two-year focus. The four-year version with a first-year focus served as reference for the current study.

The Foundational Dimensions establish a comprehensive model and, as a research framework, provide a suitable instrument to assess and investigate student experiences in the first college year (Reason, Terenzini, \& Domingo, 2006, p. 151). The Foundational Dimensions were first developed during the Academic Year 2003-2004 in conjunction with over 300 institutions nationwide as "a set of mutually agreed-upon standards of excellence" (Alexander \& Gardner, 2009, p. 19). The Foundational Dimensions are believed to "underlie the structures, activities, and cultures of institutions that are effective in promoting the success and persistence of their 
first-year students" (Reason, Terenzini, \& Domingo, 2006, p. 151). Four fundamental assumptions underlie the establishment of the Dimensions:

- $\quad$ The academic mission of an institution is preeminent;

- $\quad$ The first college year is central to the achievement of an institution's mission and lays the foundation on which undergraduate education is built;

- $\quad$ Systematic evidence provides validation of the Dimensions;

- $\quad$ Collectively, the Dimensions constitute an ideal for improving not only the first college year, but also the entire undergraduate experience. (John N. Gardner Institute for Excellence in Undergraduate Education, 2005).

The labels of the nine Foundational Dimensions, preceded by a brief description, as presented on the John N. Gardner's Institute website are available on Table 13 (see Appendix A for a complete description).

The comparison between the Foundational Dimensions and the CM/PM results for possible alignment was conducted following a two-step process described in the following sections. In a first step, the researcher juxtaposed the Foundational Dimensions and their descriptions alongside the CM/PM Clusters and their definitions. These items were presented based on the sequential order in which the Foundational Dimensions are listed by the John N. Gardner Institute on its website and based on the sequential order of the CM/PM clusters as determined by the Hierarchical Cluster Analysis conducted in this study (Table 13).

A review of the contents allowed the following conclusion: all CM/PM clusters and their definitions clearly focus on student learning goals as a result of the conceptualization process. As for the Foundational Dimensions, a close look allowed for the identification of two groups. The first one that focuses on institutions of higher learning and how they are encouraged to foster 
student success in the first year of college to serve their students by framing a philosophy, putting in place adequate organizational structures, empowering their faculty, and regularly assessing their programs. Labels of Dimensions in this category are Philosophy, Organization, Faculty, and Improvement. Conversely, a second group of Dimensions focus on a different aspect, which is how higher education institutions could empower all their students, no matter what their needs are, by delivering to all of them quality learning experiences and transitional services, by helping them value and embrace diversity, and understand and value their education. These Dimensions are: Learning, Transitions, All Students, Diversity, and Roles and Purposes. The descriptions of these Dimensions (see Appendix A) provide a brief overview of the key outcomes that could enhance student success.

From the distinction of these two groups of Dimensions, those that are more studentcentered globally align to some extent to the six clusters of student learning outcomes identified in the study. However, due to the difference in their wording, the researcher decided not to attempt matching any particular Dimension with a CM/PM cluster, but rather to undertake a more in-depth analysis by matching each of the 100 individual outcomes of the CM/PM study with the Foundational Dimensions, as described after Table 13.

Table 13: Comparison of the Foundational Dimensions of the John N. Gardner Institute and the Concept Mapping/Pattern Matching Clusters

\begin{tabular}{llll}
\hline $\begin{array}{l}\text { Foundational } \\
\text { Dimension } \\
\text { Label }\end{array}$ & $\begin{array}{l}\text { Foundational Dimension } \\
\text { Description }\end{array}$ & Cluster Definition & Cluster Label \\
\hline & $\begin{array}{l}\text { Foundations Institutions } \\
\text { approach the first year in } \\
\text { ways that are intentional and } \\
\text { based on a } \\
\text { philosophy/rationale of the } \\
\text { first year that informs relevant } \\
\text { institutional policies and } \\
\text { practices. }\end{array}$ & $\begin{array}{l}\text { Ability to function } \\
\text { autonomously by devising } \\
\text { ways to set goals and } \\
\text { priorities for personal and } \\
\text { academic success, take } \\
\text { responsibility, and self- } \\
\text { advocate. }\end{array}$ & Independence \\
& & & \\
& & &
\end{tabular}




\section{Foundations Institutions create organizational structures and policies that Organization provide a comprehensive, integrated, and coordinated approach to the first year. \\ Foundations Institutions deliver intentional curricular and co-curricular learning experiences that engage students in order to develop \\ Learning knowledge, skills, attitudes, and behaviors consistent with the desired outcomes of higher education and the institution's philosophy and mission.}

Foundations Institutions make

Faculty

Transitions

All Students the first college year a high priority for the faculty.

Foundations Institutions facilitate appropriate student transitions through policies and practices that are intentional and aligned with institutional mission.

Foundations Institutions serve all first-year students according to their varied needs.

Foundations Institutions ensure that all first-year students experience diverse Diversity ideas, worldviews, and cultures as a means of enhancing their learning and preparing them to
Ability to develop, and harness the benefits of, meaningful relationships with peers, faculty and staff, and other Engaging with stakeholders within the university and community environments.

the

Environment

Ability to plan and embrace a realistic and competitive career path by taking advantage of

Career Identity existing resources.

Ability to develop a social support system for academic and personal success through cooperation and communication with a diverse group of stakeholders.

Interdependence
Ability to identify and utilize campus resources and support services to enhance success.
Help/Resource Seeking
Ability to hone academic and professional skills in order to plan for an academic major and a Academic Identity career. 


\begin{tabular}{|ll|}
\hline & $\begin{array}{l}\text { become members of } \\
\text { pluralistic communities. }\end{array}$ \\
& $\begin{array}{l}\text { Foundations Institutions } \\
\text { promote student } \\
\text { understanding of the } \\
\text { various roles and purposes } \\
\text { of higher education, both for } \\
\text { Purposes } \\
\text { the individual and society. }\end{array}$ \\
& $\begin{array}{l}\text { Foundations Institutions } \\
\text { conduct assessment and } \\
\text { maintain associations with } \\
\text { other institutions and relevant } \\
\text { professional organizations in } \\
\text { order to achieve ongoing first- } \\
\text { year improvement. }\end{array}$ \\
\hline
\end{tabular}

Adapted from John N. Gardner Institute for Excellence in Undergraduate Education, 2005, First Year Focus - Foundational Dimensions ${ }^{\circledR}$.

For this second step of the document analysis, the researcher reviewed the 100 outcomes generated during the brainstorming session and for each of them, determined in which Foundational Dimensions it would best fit. The decision to categorize a statement as part of any given Dimension was made based on the researcher's subjective perception of the conceptual meaning of each statement and the perceived proximity with a given Dimension. This being said, the researcher is aware that other analysts reviewing the same data could have come up with a different categorization. The decision was also taken to categorize each item in only one Dimension, the one that the researcher felt was conceptually closest. After this categorization task, the statements were matched to the following six Dimensions: Diversity, Faculty, Learning, Organization, Roles and Purposes, and Transitions. After this task was completed, the researcher added the CM/PM cluster membership information allowing one to see where each statement fitted within the Dimensions as well as within the clusters. 
Diversity Dimension. Six statements were paired with the Diversity Dimension (see Table 14). Only one of the statements, (\#7) Students should have an opportunity to meet new people right off the bat and make new friends, belonged to the Engaging with the Environment Cluster. The remaining five statements came from and constituted 33 percent of the Interdependence Cluster. Statements categorized in this dimension describe the necessity for students to meet and interact with new people, reach out to peers and other stakeholders from a diverse background.

Table 14: Concept Mapping/Pattern Matching Outcomes that were Matched with the Diversity

\section{Dimension}

\begin{tabular}{|c|l|l|l|}
\hline $\begin{array}{c}\text { Item } \\
\text { Number }\end{array}$ & \multicolumn{1}{|c|}{ Statement } & $\begin{array}{l}\text { Foundational } \\
\text { Dimensions }\end{array}$ & \multicolumn{1}{|c|}{ Cluster Label } \\
\hline $\mathbf{7}$ & $\begin{array}{l}\text { Students should have an opportunity to meet new } \\
\text { people right off the bat and make new friends. }\end{array}$ & Diversity & $\begin{array}{l}\text { Engaging with the } \\
\text { Environment }\end{array}$ \\
\hline $\mathbf{5}$ & $\begin{array}{l}\text { Students should become more social and be more } \\
\text { comfortable talking with people. }\end{array}$ & Diversity & Interdependence \\
\hline $\mathbf{2 8}$ & $\begin{array}{l}\text { Students should know how to make and keep } \\
\text { relationships (friendships, connections, networking) } \\
\text { with people throughout all of college. }\end{array}$ & Diversity & Interdependence \\
\hline $\mathbf{3 2}$ & $\begin{array}{l}\text { Students should want to reach out to others instead } \\
\text { of expecting others to come to them. }\end{array}$ & Diversity & Interdependence \\
\hline $\mathbf{7 8}$ & $\begin{array}{l}\text { Students should know how to embrace different } \\
\text { cultures. }\end{array}$ & Diversity & Interdependence \\
\hline $\mathbf{9 9}$ & $\begin{array}{l}\text { Students should try new things to open themselves } \\
\text { up to new experiences. }\end{array}$ & Diversity & Interdependence \\
\hline
\end{tabular}

Faculty Dimension. This Dimension was matched with five statements emphasizing that student-faculty interactions contribute to student success (see Table 15). Items in this Dimension came from four different clusters:

- Engaging with the Environment: (\#23) Students in the summer bridge program should get to meet more faculty members and become better friends with faculty than other freshmen are, and (\#77) Students should participate in research sessions; 
- Career Identity: (\#57) Students should know their professors' expectations;

- Interdependence: (\#37) By the end of the first year, students should feel confident in talking to instructors and people they look up to or who are in authority;

- Academic Identity: (\#54) Students should be prepared to challenge their professors.

Table 15: Concept Mapping/Pattern Matching Outcomes that were Matched with the Faculty

Dimension

\begin{tabular}{|c|c|c|c|}
\hline $\begin{array}{c}\text { Item } \\
\text { Number }\end{array}$ & Statement & $\begin{array}{c}\text { Foundational } \\
\text { Dimensions }\end{array}$ & Cluster Label \\
\hline 54 & $\begin{array}{l}\text { Students should be prepared to challenge their } \\
\text { professors. }\end{array}$ & Faculty & Academic Identity \\
\hline 57 & Students should know their professors' expectations. & Faculty & Career Identity \\
\hline 23 & $\begin{array}{l}\text { Students in the summer bridge program should get } \\
\text { to meet more faculty members and become better } \\
\text { friends with faculty than other freshmen are. }\end{array}$ & Faculty & $\begin{array}{l}\text { Engaging with the } \\
\text { Environment }\end{array}$ \\
\hline 77 & Students should participate in research sessions. & Faculty & $\begin{array}{l}\text { Engaging with the } \\
\text { Environment }\end{array}$ \\
\hline 37 & $\begin{array}{l}\text { By the end of the first year, students should feel } \\
\text { confident in talking to instructors and people they } \\
\text { look up to or who are in authority. }\end{array}$ & Faculty & Interdependence \\
\hline
\end{tabular}

Learning Dimension. With 29 matching statements, this is one of the largest

Dimensions with the majority of the statements coming from the Independence and Academic Identity Clusters (see Table 16). The Learning Dimension was matched with 69 percent (18 statements) of the Independence Cluster. The second cluster with substantial representation in the Learning Dimension is Academic Identity which shares 53 percent (8 statements) of its statements with the Dimension. One can note a substantial overlap between the two clusters and the Learning Dimension.

The remaining statements in the Dimension came from Interdependence: (\#71) Students should show confidence when dealing with people in positions of authority, (\#87) Students 
should learn how to negotiate and communicate; Help/Resources Seeking, (\#16) Students should

know how to use the technology used by the University - e.g., software \& devices.

Table 16: Concept Mapping/Pattern Matching Outcomes that were Matched with the Learning

\section{Dimension}

\begin{tabular}{|c|c|c|c|}
\hline $\begin{array}{c}\text { Item } \\
\text { Number }\end{array}$ & Statement & $\begin{array}{c}\text { Foundational } \\
\text { Dimensions }\end{array}$ & Cluster Label \\
\hline 9 & $\begin{array}{l}\text { Students should become more confident about their } \\
\text { academic abilities. }\end{array}$ & Learning & Academic Identity \\
\hline 27 & $\begin{array}{l}\text { Students should know how to keep themselves on a } \\
\text { schedule to graduate on time. }\end{array}$ & Learning & Academic Identity \\
\hline 40 & $\begin{array}{l}\text { Students should be able to develop academic } \\
\text { maturity. }\end{array}$ & Learning & Academic Identity \\
\hline 41 & $\begin{array}{l}\text { Students should know how to write a proper email to } \\
\text { higher authority. }\end{array}$ & Learning & Academic Identity \\
\hline 52 & Students should feel prepared to schedule classes. & Learning & Academic Identity \\
\hline 58 & Students should know how to read the syllabus. & Learning & Academic Identity \\
\hline 59 & Students should know to check their email. & Learning & Academic Identity \\
\hline 60 & $\begin{array}{l}\text { Students should know how to handle themselves in a } \\
\text { professional setting. }\end{array}$ & Learning & Academic Identity \\
\hline 16 & $\begin{array}{l}\text { Students should know how to use the technology } \\
\text { used by the University - e.g., software \& devices. }\end{array}$ & Learning & $\begin{array}{l}\text { Help/Resource } \\
\text { Seeking }\end{array}$ \\
\hline 2 & $\begin{array}{l}\text { Students should take responsibility for individual } \\
\text { learning. }\end{array}$ & Learning & Independence \\
\hline 8 & $\begin{array}{l}\text { Students should take opportunities to stand out and } \\
\text { be unique. }\end{array}$ & Learning & Independence \\
\hline 22 & $\begin{array}{l}\text { Students should be able to build positive habits to } \\
\text { help them become more successful as college } \\
\text { students. }\end{array}$ & Learning & Independence \\
\hline 26 & $\begin{array}{l}\text { Students should manage their time by prioritizing } \\
\text { what they need to accomplish. }\end{array}$ & Learning & Independence \\
\hline 42 & $\begin{array}{l}\text { Students should not be scared to take on academic } \\
\text { challenges. }\end{array}$ & Learning & Independence \\
\hline 56 & Students should know how to prioritize better. & Learning & Independence \\
\hline 62 & $\begin{array}{l}\text { Students should know what success looks like by the } \\
\text { end of their first year because they should have } \\
\text { experienced some form of success by the end of } \\
\text { their first year. }\end{array}$ & Learning & Independence \\
\hline 66 & $\begin{array}{l}\text { Students should be more well-rounded in the sense } \\
\text { that they have all the tools and skills necessary to be } \\
\text { self-sufficient. }\end{array}$ & Learning & Independence \\
\hline 69 & $\begin{array}{l}\text { Students should be able to stay positive despite } \\
\text { academic setbacks. }\end{array}$ & Learning & Independence \\
\hline
\end{tabular}




\begin{tabular}{|l|l|l|l|}
\hline 70 & $\begin{array}{l}\text { Students should be prepared for anything that is } \\
\text { thrown their way - opportunities and adverse events. }\end{array}$ & Learning & Independence \\
\hline 79 & $\begin{array}{l}\text { Students should know how to handle adversity, for } \\
\text { example, tough times and challenges. }\end{array}$ & Learning & Independence \\
\hline 80 & $\begin{array}{l}\text { Students should do the best they can based on their } \\
\text { own abilities - and not compare themselves to } \\
\text { others. }\end{array}$ & Learning & Independence \\
\hline 83 & $\begin{array}{l}\text { Students should know how to self-advocate - and } \\
\text { not be afraid to ask questions. }\end{array}$ & Learning & Independence \\
\hline 86 & $\begin{array}{l}\text { Students should discover and then build their skills. } \\
\text { Students should develop strategies to help }\end{array}$ & Learning & Independence \\
\hline 97 & $\begin{array}{l}\text { Students should know how to make themselves } \\
\text { distinct. }\end{array}$ & Learning & Independence \\
\hline 98 & $\begin{array}{l}\text { Students should be able to learn the value of critical } \\
\text { thinking. }\end{array}$ & Learning & Independence \\
\hline 100 & $\begin{array}{l}\text { Students should learn how to keep themselves } \\
\text { healthy. }\end{array}$ & Learning & Independence \\
\hline 71 & $\begin{array}{l}\text { Students should show confidence when dealing with } \\
\text { people in positions of authority. }\end{array}$ & Learning & Interdependence \\
\hline 87 & $\begin{array}{l}\text { Students should learn how to negotiate and } \\
\text { communicate. }\end{array}$ & Learning & Interdependence \\
\hline
\end{tabular}

Organization Dimension. This Dimension entails 12 statements with the majority of them coming from the Help/Resources Seeking and the Engaging with the Environment Clusters (see Table 17). Five items from and representing 38 percent of the Help/Resources Seeking Cluster aligned with this Dimension. Four statements or 23 percent of the Engaging with the Environment Cluster matched with this Dimension as well.

Another represented cluster was the Career Identity Cluster with two statements, (\#53) Students should know how to contact their academic advisors to make advising appointments, and (\#95) Students should be exposed to different programs, presentations, and environments to help them decide on their ultimate major. The last cluster with a statement in this dimension was the Interdependence Cluster (\#51) Students should feel that staff are truly there to help them and are not just "collecting a paycheck." 
Represented in this Dimension are statements that stress the importance of effective policies, procedures, and organizational structures for student success. Student success in the first year should draw from a coordinated approach and commitment to that cause.

Table 17: Concept Mapping/Pattern Matching Outcomes that were Matched with the Organization Dimension

\begin{tabular}{|c|c|c|c|}
\hline $\begin{array}{c}\text { Item } \\
\text { Number }\end{array}$ & Statement & $\begin{array}{l}\text { Foundational } \\
\text { Dimensions }\end{array}$ & Cluster Label \\
\hline 53 & $\begin{array}{l}\text { Students should know how to contact their academic } \\
\text { advisors to make advising appointments. }\end{array}$ & Organization & Career Identity \\
\hline 95 & $\begin{array}{l}\text { Students should be exposed to different programs, } \\
\text { presentations, and environments to help them decide } \\
\text { on their ultimate major. }\end{array}$ & Organization & Career Identity \\
\hline 24 & $\begin{array}{l}\text { Students should have opportunities to have one-on- } \\
\text { one interactions with members of different colleges } \\
\text { (e.g., recruiters and advisors). }\end{array}$ & Organization & $\begin{array}{l}\text { Engaging with } \\
\text { the Environment }\end{array}$ \\
\hline 29 & $\begin{array}{l}\text { Students should gain familiarity with the campus, all } \\
\text { the colleges at the university, and in general, college } \\
\text { life. }\end{array}$ & Organization & $\begin{array}{l}\text { Engaging with } \\
\text { the Environment }\end{array}$ \\
\hline 45 & $\begin{array}{l}\text { Students should have a better feel for not just for } \\
\text { their university but for the whole State as well. }\end{array}$ & Organization & $\begin{array}{l}\text { Engaging with } \\
\text { the Environment }\end{array}$ \\
\hline 91 & $\begin{array}{l}\text { Students should know it is important to realize they } \\
\text { are not alone - they have friends, professors, support } \\
\text { staff, etc. }\end{array}$ & Organization & $\begin{array}{l}\text { Engaging with } \\
\text { the Environment }\end{array}$ \\
\hline 15 & $\begin{array}{l}\text { Students should have additional support staff to turn } \\
\text { to for help. }\end{array}$ & Organization & $\begin{array}{l}\text { Help/Resource } \\
\text { Seeking }\end{array}$ \\
\hline 17 & Students should have success coaches to help them. & Organization & $\begin{array}{l}\text { Help/Resource } \\
\text { Seeking }\end{array}$ \\
\hline 18 & $\begin{array}{l}\text { Students should have success coaches who can refer } \\
\text { them to specific student success workshops. }\end{array}$ & Organization & $\begin{array}{l}\text { Help/Resource } \\
\text { Seeking }\end{array}$ \\
\hline 46 & $\begin{array}{l}\text { Students should know where to go if they need } \\
\text { counseling services. }\end{array}$ & Organization & $\begin{array}{l}\text { Help/Resource } \\
\text { Seeking }\end{array}$ \\
\hline 47 & $\begin{array}{l}\text { Students should know where to go if they need } \\
\text { career guidance and career services (e.g., resume } \\
\text { building \& interviewing skill development). }\end{array}$ & Organization & $\begin{array}{l}\text { Help/Resource } \\
\text { Seeking }\end{array}$ \\
\hline 51 & $\begin{array}{l}\text { Students should feel that staff are truly there to help } \\
\text { them and are not just "collecting a paycheck." }\end{array}$ & Organization & Interdependence \\
\hline
\end{tabular}

Roles and Purposes. With 30 statements, this is the Dimension with the largest number of items stemming from all CM/PM clusters except one, the Help/Resources Cluster (see Table 18). Statements in the Roles and Purposes Dimension underscore the expectation that first-year 
students will be empowered to explore their interests, grow personally and professionally, situate themselves in higher education and society (John N. Gardner Institute for Excellence in Undergraduate Education, 2005).

Two clusters are heavily represented in this Dimension. The first one is the Career Identity Cluster with nine statements or 69 percent of its items. An example of a statement from the Career Identity Cluster is (\#96), Students should know what they have to do to be desirable to employers. The second most represented cluster is the Academic Identity Cluster with seven statements or 43 percent of its total items. One of the statements is (\#13), Students should be determined to find the career path they want to follow.

Two other clusters have five items each in this Dimension. The Independence Cluster is one of them and includes the following example: (\#85) Students should make decisions to make themselves happy rather than making decisions to make other people happy. The Engaging with the Environment Cluster had five of its items match with the Dimension. One example from this Cluster is (\#61) Students should know their community better - especially their local community - through service projects. The last cluster is the Interdependence Cluster with four statements including this example: (\#34) Students should be able to help other students and point them to resources.

Table 18: Concept Mapping/Pattern Matching Outcomes that were Matched with the Roles and Purposes Dimension

\begin{tabular}{|c|l|l|l|}
\hline $\begin{array}{c}\text { Item } \\
\text { Number }\end{array}$ & \multicolumn{1}{|c|}{ Statement } & $\begin{array}{l}\text { Foundational } \\
\text { Dimensions }\end{array}$ & Cluster Label \\
\hline $\mathbf{1 0}$ & $\begin{array}{l}\text { Students should be able to create a success plan for } \\
\text { college and career. }\end{array}$ & $\begin{array}{l}\text { Roles and } \\
\text { Purposes }\end{array}$ & Academic Identity \\
\hline $\mathbf{1 3}$ & $\begin{array}{l}\text { Students should be determined to find the career } \\
\text { path they want to follow. }\end{array}$ & $\begin{array}{l}\text { Roles and } \\
\text { Purposes }\end{array}$ & Academic Identity \\
\hline $\mathbf{3 1}$ & $\begin{array}{l}\text { Students should become responsible for themselves } \\
\text { completely - particularly in finding their majors. }\end{array}$ & $\begin{array}{l}\text { Roles and } \\
\text { Purposes }\end{array}$ & Academic Identity \\
\hline
\end{tabular}




\begin{tabular}{|c|c|c|c|}
\hline 36 & $\begin{array}{l}\text { Students should be open to developing a "Plan B." } \\
\text { Meaning that if you are not accepted into your } \\
\text { original major - or you change your mind, you have } \\
\text { something else to move into. }\end{array}$ & $\begin{array}{l}\text { Roles and } \\
\text { Purposes }\end{array}$ & Academic Identity \\
\hline 81 & $\begin{array}{l}\text { Students should know how to present themselves } \\
\text { professionally, for example, wearing proper attire. }\end{array}$ & $\begin{array}{l}\text { Roles and } \\
\text { Purposes }\end{array}$ & Academic Identity \\
\hline 82 & $\begin{array}{l}\text { Students should know how to present themselves } \\
\text { professionally - for example, using proper body } \\
\text { language. }\end{array}$ & $\begin{array}{l}\text { Roles and } \\
\text { Purposes }\end{array}$ & Academic Identity \\
\hline 94 & $\begin{array}{l}\text { Students should know not to be over-competitive } \\
\text { and be able to accept a setback such as someone else } \\
\text { getting a position they wanted. }\end{array}$ & $\begin{array}{l}\text { Roles and } \\
\text { Purposes }\end{array}$ & Academic Identity \\
\hline 4 & $\begin{array}{l}\text { Student should begin to learn what they are } \\
\text { interested in. }\end{array}$ & $\begin{array}{l}\text { Roles and } \\
\text { Purposes }\end{array}$ & Career Identity \\
\hline 19 & $\begin{array}{l}\text { Students should feel more prepared to decide on a } \\
\text { major and not constantly be changing their minds. }\end{array}$ & $\begin{array}{l}\text { Roles and } \\
\text { Purposes }\end{array}$ & Career Identity \\
\hline 21 & $\begin{array}{l}\text { Students should have opportunities in class early in } \\
\text { the semester to find out what their interests are to } \\
\text { help them choose a major. }\end{array}$ & $\begin{array}{l}\text { Roles and } \\
\text { Purposes }\end{array}$ & Career Identity \\
\hline 25 & $\begin{array}{l}\text { Students should know what major they want by the } \\
\text { end of their first year. }\end{array}$ & $\begin{array}{l}\text { Roles and } \\
\text { Purposes }\end{array}$ & Career Identity \\
\hline 43 & $\begin{array}{l}\text { Students should begin to learn what major they } \\
\text { might be interested in. }\end{array}$ & $\begin{array}{l}\text { Roles and } \\
\text { Purposes }\end{array}$ & Career Identity \\
\hline 73 & $\begin{array}{l}\text { Students should know they have to find a job after } \\
\text { college. }\end{array}$ & $\begin{array}{l}\text { Roles and } \\
\text { Purposes }\end{array}$ & Career Identity \\
\hline 76 & $\begin{array}{l}\text { Students should be aware of the competition to get } \\
\text { into some majors. }\end{array}$ & $\begin{array}{l}\text { Roles and } \\
\text { Purposes }\end{array}$ & Career Identity \\
\hline 93 & $\begin{array}{l}\text { Students should follow a four-year plan when } \\
\text { preparing for their careers. }\end{array}$ & $\begin{array}{l}\text { Roles and } \\
\text { Purposes }\end{array}$ & Career Identity \\
\hline 96 & $\begin{array}{l}\text { Students should know what they have to do to be } \\
\text { desirable to employers. }\end{array}$ & $\begin{array}{l}\text { Roles and } \\
\text { Purposes }\end{array}$ & Career Identity \\
\hline 38 & $\begin{array}{l}\text { Students should find out about student organizations } \\
\text { so they can find others with common interests. }\end{array}$ & $\begin{array}{l}\text { Roles and } \\
\text { Purposes }\end{array}$ & $\begin{array}{l}\text { Engaging with the } \\
\text { Environment }\end{array}$ \\
\hline 55 & Students should know how to sing their school song. & $\begin{array}{l}\text { Roles and } \\
\text { Purposes } \\
\end{array}$ & $\begin{array}{l}\text { Engaging with the } \\
\text { Environment }\end{array}$ \\
\hline 61 & $\begin{array}{l}\text { Students should know their community better - } \\
\text { especially their local community - through service } \\
\text { projects. }\end{array}$ & $\begin{array}{l}\text { Roles and } \\
\text { Purposes }\end{array}$ & $\begin{array}{l}\text { Engaging with the } \\
\text { Environment }\end{array}$ \\
\hline 67 & $\begin{array}{l}\text { Students should want to stay at their institution at } \\
\text { the end of their first year. }\end{array}$ & $\begin{array}{l}\text { Roles and } \\
\text { Purposes }\end{array}$ & $\begin{array}{l}\text { Engaging with the } \\
\text { Environment }\end{array}$ \\
\hline 72 & $\begin{array}{l}\text { Students should try enjoying clubs and/or } \\
\text { fraternities or sororities. }\end{array}$ & $\begin{array}{l}\text { Roles and } \\
\text { Purposes }\end{array}$ & $\begin{array}{l}\text { Engaging with the } \\
\text { Environment }\end{array}$ \\
\hline 1 & Students should be able to know their priorities. & $\begin{array}{l}\text { Roles and } \\
\text { Purposes }\end{array}$ & Independence \\
\hline 74 & Students should set their own goals. & $\begin{array}{l}\text { Roles and } \\
\text { Purposes }\end{array}$ & Independence \\
\hline 75 & $\begin{array}{l}\text { Students should be able to develop from a dependent } \\
\text { person to an independent person. }\end{array}$ & $\begin{array}{l}\text { Roles and } \\
\text { Purposes }\end{array}$ & Independence \\
\hline 84 & Students should know how to set realistic goals. & $\begin{array}{l}\text { Roles and } \\
\text { Purposes }\end{array}$ & Independence \\
\hline
\end{tabular}




\begin{tabular}{|c|l|l|l|}
$\mathbf{8 5}$ & $\begin{array}{l}\text { Students should make decisions to make themselves } \\
\text { happy rather than making decisions to make other } \\
\text { people happy. }\end{array}$ & $\begin{array}{l}\text { Roles and } \\
\text { Purposes }\end{array}$ & Independence \\
\hline $\mathbf{3 4}$ & $\begin{array}{l}\text { Students should be able to help other students and } \\
\text { point them to resources. }\end{array}$ & $\begin{array}{l}\text { Roles and } \\
\text { Purposes }\end{array}$ & Interdependence \\
\hline $\mathbf{4 9}$ & Students should have school pride. & $\begin{array}{l}\text { Roles and } \\
\text { Purposes }\end{array}$ & Interdependence \\
\hline $\mathbf{8 8}$ & $\begin{array}{l}\text { Students should know it is difficult to go through } \\
\text { college alone. }\end{array}$ & $\begin{array}{l}\text { Roles and } \\
\text { Purposes }\end{array}$ & Interdependence \\
\hline $\mathbf{8 9}$ & $\begin{array}{l}\text { Students should know it is important to have friends } \\
\text { - a social support system - to help them through } \\
\text { college both in terms of academics and socializing. }\end{array}$ & $\begin{array}{l}\text { Roles and } \\
\text { Purposes }\end{array}$ & Interdependence \\
\hline
\end{tabular}

Transitions Dimension. This is the sixth dimension with which statements were matched. It counts a total of 18 statements from five clusters (see Table 19). The Engaging with the Environment and the Help/Resources Seeking Clusters are the most represented with respectively five, or 29 percent, and seven, or 53 percent, of their statements in this Dimension. The Engaging with the Environment Cluster includes (\#12) Students should have enough time during the summer bridge program to figure out their surroundings. The Help/Resources Seeking Cluster includes (\#68) Students in the summer bridge program should feel like they have a leg up or a head start compared to students who start later. The following are examples of statements from each of the three other clusters. The Independence Cluster counts three statements, e.g., (\#48) Students should have confidence by the end of the year in terms of adjusting to college, being aware of resources, and asking for help. One of the two statement from the Interdependence Cluster is (\#39) Students should get involved and take advantage of opportunities provided to them. The only statement from the Career Identity Cluster is (\#90) Students should know to take advantage of opportunities (such as internships) related to possible majors.

The transition Dimension englobes efforts that higher education institution should undertake to foster a successful transition for first-year students. This comprises providing 
resources, setting expectations and collaborating with internal and external stakeholders to

facilitate first-year student transition (John N. Gardner Institute for Excellence in Undergraduate

Education, 2005).

Table 19: Concept Mapping/Pattern Matching Outcomes that were Matched with the Transitions

\section{Dimension}

\begin{tabular}{|c|c|c|c|}
\hline $\begin{array}{c}\text { Item } \\
\text { Number }\end{array}$ & Statement & \begin{tabular}{|c|} 
Foundational \\
Dimensions
\end{tabular} & Cluster Label \\
\hline 90 & $\begin{array}{l}\text { Students should know to take advantage of } \\
\text { opportunities (such as internships) related to } \\
\text { possible majors. }\end{array}$ & Transitions & Career Identity \\
\hline 3 & $\begin{array}{l}\text { Students should get to know the different buildings } \\
\text { for each college around campus. }\end{array}$ & Transitions & $\begin{array}{l}\text { Engaging with the } \\
\text { Environment }\end{array}$ \\
\hline 11 & $\begin{array}{l}\text { Students should take tours of the campus - to learn } \\
\text { about their environment. }\end{array}$ & Transitions & $\begin{array}{l}\text { Engaging with the } \\
\text { Environment }\end{array}$ \\
\hline 12 & $\begin{array}{l}\text { Students should have enough time during the } \\
\text { summer bridge program to figure out their } \\
\text { surroundings. }\end{array}$ & Transitions & $\begin{array}{l}\text { Engaging with the } \\
\text { Environment }\end{array}$ \\
\hline 33 & $\begin{array}{l}\text { If students are offered an opportunity to participate } \\
\text { in a success program, they should take advantage of } \\
\text { it. }\end{array}$ & Transitions & $\begin{array}{l}\text { Engaging with the } \\
\text { Environment }\end{array}$ \\
\hline 65 & $\begin{array}{l}\text { Students should have a better understanding of the } \\
\text { history of campus buildings and the campus in } \\
\text { general. }\end{array}$ & Transitions & $\begin{array}{l}\text { Engaging with the } \\
\text { Environment }\end{array}$ \\
\hline 6 & $\begin{array}{l}\text { Students should be aware of available resources } \\
\text { early in their college career. }\end{array}$ & Transitions & $\begin{array}{l}\text { Help/Resource } \\
\text { Seeking }\end{array}$ \\
\hline 14 & $\begin{array}{l}\text { Students should be able to know where to go for } \\
\text { help after their first year. }\end{array}$ & Transitions & $\begin{array}{l}\text { Help/Resource } \\
\text { Seeking }\end{array}$ \\
\hline 30 & $\begin{array}{l}\text { Students should know where to go for help so they } \\
\text { never feel lost. }\end{array}$ & Transitions & $\begin{array}{l}\text { Help/Resource } \\
\text { Seeking }\end{array}$ \\
\hline 35 & $\begin{array}{l}\text { Students should have a good understanding of the } \\
\text { opportunities available to them - such as extra } \\
\text { things like trips. }\end{array}$ & Transitions & $\begin{array}{l}\text { Help/Resource } \\
\text { Seeking }\end{array}$ \\
\hline 44 & $\begin{array}{l}\text { Students should know where to go if they need } \\
\text { academic help. }\end{array}$ & Transitions & $\begin{array}{l}\text { Help/Resource } \\
\text { Seeking }\end{array}$ \\
\hline 64 & $\begin{array}{l}\text { Students in the summer bridge program should have } \\
\text { an idea of what is expected of them before they start } \\
\text { their fall courses. }\end{array}$ & Transitions & $\begin{array}{l}\text { Help/Resource } \\
\text { Seeking }\end{array}$ \\
\hline 68 & $\begin{array}{l}\text { Students in the summer bridge program should feel } \\
\text { like they have a leg up or a head start compared to } \\
\text { students who start later. }\end{array}$ & Transitions & $\begin{array}{l}\text { Help/Resource } \\
\text { Seeking }\end{array}$ \\
\hline 48 & $\begin{array}{l}\text { Students should have confidence by the end of the } \\
\text { year in terms of adjusting to college, being aware of } \\
\text { resources, and asking for help. }\end{array}$ & Transitions & Independence \\
\hline 50 & Students should take responsibility for their actions. & Transitions & Independence \\
\hline
\end{tabular}




\begin{tabular}{|c|c|c|c|}
\hline 63 & $\begin{array}{l}\text { Students should learn from their mistakes (academic } \\
\text { or personal) and be able to move forward. }\end{array}$ & Transitions & Independence \\
\hline 2 & Students should establish a core support group. & Transitions & Interdependence \\
\hline 39 & $\begin{array}{l}\text { Students should get involved and take advantage of } \\
\text { opportunities provided to them }\end{array}$ & Transitions & Interdependence \\
\hline
\end{tabular}

As noted during the first step of the document analysis, the Philosophy, Organization,

Faculty, and Improvement Dimensions were found to be institution-centered while the Learning, Transitions, All Students, Diversity, and Roles and Purposes Dimensions were considered student-centered based on the basic descriptions that were provided (John N. Gardner Institute for Excellence in Undergraduate Education, 2005).

At the end of the two-step analysis, the researcher can conclude the following. As expected, the Learning, Transitions, Diversity, and Roles and Purposes Dimensions, which were all deemed more student-centered, all matched with outcomes generated during the brainstorming session. In addition, two of the Dimensions, Organization and Faculty, which seemed more institution-centered, matched with student learning outcomes that were brainstormed by the participants of this study. The Philosophy, All Students and Improvement Dimension did not match any of the statements, from the researcher's perspective.

\section{Limitations of this Study}

Several limitations of this study are inherent to concept mapping, as identified by Kolb and Shepherd (1997) and reported by Michalski and Cousin (2000):

(1) reliability and stability of concept mapping results over time, (2) lack of a welldeveloped means for comparative research especially due to the relative dearth of available pattern matching studies, (3) relatively non-intuitive nature of the concept mapping process, which can lead to confusion about statement sorting and map interpretation for various participants, and (4) challenges of organizing and coordinating 
large-scale concept mapping projects in terms of the logistics of implementation.

Michalski \& Cousin (2000, p. 223).

Michalski \& Cousin suggested the conduct of further research as a way to circumvent the first two limitations. To address the other limitations they recommended the strengthening of the capacities of the facilitator for the implementation of studies involving concept mapping as a research methodology.

Another limitation highlighted by Valdes-Vasquez and Klotz (2013) is that experts or participants are entrusted with rating statements based on a predetermined scale. The limitation rests on the fact that it is taken for granted that "the experts can and make appropriate judgments when responding to this scale" (p. 3). Valdes-Vasquez and Klotz (2013) suggested that "a pilot study can serve as an important venue for clarifying the instructions and refine the sorting and rating statements to ensure the validity of the data collected" (p. 3).

In addition to these general limitations of the Concept Mapping/Pattern Matching methodology, the following limitations were identified due to the nature of the current study.

For the purpose of this research, participants were purposely selected from a population of undecided first-time full-time students as well as faculty and staff at the Reference University. This process excluded other undecided students and other stakeholders intervening in the area of the FYE who may express different viewpoints that could lead to a different conceptualization of the outcomes. As pointed out by Kane and Trochim (2007), the visuals produced during the study represent the conceptual domain according to the "point of view of those who participated in the process" (p. 157). For that reason, the results of this study should be considered cautiously.

The conceptualization of the FYE outcomes is that of students and other stakeholders at the Reference University and generalization may not be possible to other peer institutions or 
other types of higher education institutions. Further research in other settings may be conducted in order to reach an acceptable level of generalizability.

In the current study, the brainstorming session was conducted in person as opposed to generating idea via an online instrument such as the Concept System (Kane \& Trochim, 2007, 2009; Trochim 1989a,). Generating ideas in presence of other participants may be an intimidating exercise; that's the reason why Kane and Trochim (2007) viewed a web-based submission of ideas as a way to "minimize bias in the responses from experts and the influence of strong opinions during face-to-face interaction" (Valdes-Vasquez \& Klotz, 2013, p. 3).

The Concept Mapping/Pattern Matching methodology is rooted on robust statistical techniques - multidimensional scaling and hierarchal clustering — used to "augment qualitative data" (Hansen et al., 2005, p. 229). Interpretation of the data followed guidelines provided in the literature (Kane \& Trochim, 2007; Trochim, 1989a) and was made in light of the researcher' professional experience and knowledge of the literature on the First-Year Experience and student success. This process also involved some level of the researcher's subjective judgment and for that reason, the results need to be taken with caution.

Finally, although the number of statements was within the recommended limits (Kane \& Trochim, 2007; Trochim, 1989a), it may have been overwhelming for participants to sort then rate the 100 outcomes twice for importance and efficacy. Participant may have felt overwhelmed by the number of statements and may not have taken the time to review all of them very carefully before completing the sorting and rating tasks. 


\section{Chapter Five: Summary and Discussion}

This final chapter provides an overview of the study, summarizes the findings as they pertained to each Research Question, and discuss the findings and their implications. It also includes recommendations for future research dealing with the conceptualization of first-year student learning outcomes. It concludes with a summary of the study.

\section{Overview of Study}

The success program examined in this study is a first-year experience program serving undecided students at a land grant university. From the researcher's perspective, most stated outcomes used so far to measure success reflected more an institutional perspective (Astin \& Antonio, 2012; Ewell, 1983). Even though most U.S. institutions have realized the importance of the first year of college and have introduced related programs to contribute to student success, in some cases "the outcome has been creation of numerous program-level initiatives that operate on the margins of the first year and may have only limited impact on students" (Alexander \& Gardner 2009, p. 18). Ewell (1983) emphasized the fact that the "missions, programmatic goals, and resource constraints" (p. 21) are usually at the center of the discussions at the expenses of student goals. Astin and Antonio (2012) argued that the student's perspective has not always been taken into account in the process. Additionally, Hunter (2006) argued that "it is far too common for campus officials to spend an inordinate amount of time and energy developing strategies to improve the first college year without ever asking for student involvement" (p. 7).

Alexander and Gardner (2009) considered the ineffectiveness of some of those programs to be due to a failure to follow best practice and benchmarks and to a narrow approach, which misses the big picture. To assist higher education institutions in framing and delivering robust first-year programs, the John N. Gardner Institute for Excellence in Undergraduate Education 
proposed nine Foundational Dimensions, "a set of mutually agreed-upon standards of excellence" (Alexander \& Gardner, 2009 p. 19) for first-year programs adopted at hundreds of higher education institutions nationwide. In a document analysis, the results of the current study were explored to determine to what extent they align with the Foundational Dimensions.

Because of the risk of mismatch between institutional ideal goals and the reality of student aspirations, this study involved students and other stakeholders in order to delineate student learning outcomes for the First-Year Experience (FYE) that are more comprehensive than the ones currently listed for the success program. The research questions that guided this study are the following:

RQ 1: What is the desired domain of student learning of a first-year success program serving first-time, full-time undecided students as conceptualized by stakeholders at a land-grant university, when using the Concept Mapping/Pattern Matching methodology?

a. To what extent do program stakeholder groups differ in their rating of the relative importance of student learning outcomes for ensuring student success?

b. To what extent do program stakeholder groups differ in their evaluation of the overall efficacy of their institution's success program in helping students achieve desired learning outcomes?

RQ 2: To what extent does the conceptualized desired domain of student learning under Research Questions 1 align with the Foundational Dimensions established by the John N. Gardner Institute?

To address these research questions, the researcher prepared and submitted an Institutional Review Board (IRB) protocol that was approved giving way for a study to be 
implemented at the Reference University (see Appendix H). The CM/PM data collection was carried out in a three-step process. First, a brainstorming session during which 23 participants generated 100 statements as responses to the following question: "What knowledge, skills, and attitudes should students gain as a result of participating in the success program?" The 100 statements represented the conceptual domain (Kane \& Trochim, 2007; Trochim, 1989a) of student learning outcome in the first year, from the participants' perspective. Second, a statement sorting task during which each participant was asked, in an individual activity, to categorize all statements into piles based on conceptual similarity. Third, the rating of the statements - online, in the format of a Qualtrics survey_once for their importance for student success, once for the Reference University's efficacy in helping students achieve each of the outcomes.

A total of 23 participants took part in the brainstorming and sorting tasks. Twenty-two of them completed the rating task. Seven of the participants were faculty/staff members including females $(n=6)$ and males $(n=1)$ subjects. A second group of stakeholders included female $(n=$ 7) and male $(n=9)$ undergraduate students who participated in the success program.

\section{Summary of Findings}

Summary of Findings for Research Question 1. What is the desired domain of student learning of a first-year success program serving first-time, full-time undecided students as conceptualized by stakeholders at a land-grant university, when using the Concept Mapping/Pattern Matching methodology? The researcher relied on statistical techniques, multidimensional scale, and hierarchical cluster analysis to treat the data collected from the Concept Mapping/Pattern Matching process.

The hierarchical cluster analysis produced a cluster tree or dendrogram which shows a three to ten-cluster solution output (see spreadsheet with items in Appendix I). Considering this 
output, the researcher decided to retain six clusters for this study. Those six clusters represent the main areas of student learning outcomes in the first year of college that were conceptualized by the participants in this study. The following are the six clusters and their definitions. They comprise a total of 100 statements, respectively $26,17,13,15,13$, and 16 (see Tables 5, 6, 7, 8, $9,10)$

- Independence Cluster (Ability to function autonomously by devising ways to set goals and priorities for personal and academic success, take responsibility, and self-advocate);

- Engaging with the Environment Cluster (Ability to develop, and harness the benefits of, meaningful relationships with peers, faculty and staff, and other stakeholders within the university and community environments);

- Career Identity Cluster (Ability to plan and embrace a realistic and competitive career path by taking advantage of existing resources);

- Interdependence Cluster (Ability to develop a social support system for academic and personal success through cooperation and communication with a diverse group of stakeholders);

- Help/Resource Seeking Cluster (Ability to identify and utilize campus resources and support services to enhance success);

- Academic Identity Cluster (Ability to hone academic and professional skills in order to plan for an academic major and a career).

An examination of the pattern matches performed for this study (see Figure 5) allowed for an overview of the standing of each cluster in terms of ratings. The Independence and Academic Identity Clusters recorded mean importance ratings (respectively, $M=3.99 ; M=3.90$ ) that were higher than their mean efficacy ratings (respectively, $M=3.84 ; M=3.73$ ). The results 
for the Independence $(M=3.99)$ and Academic Identity $(M=3.90)$ Clusters revealed the perception of the participants that these two clusters were the most important for student success. As a group, participants also reached a consensus by identifying those two Clusters with efficacy ratings that are lower than their importance ratings. The remaining four clusters were on average rated higher in efficacy compared to their mean importance scores. For the six clusters, the results demonstrate that participants perceived that the Reference University performed above average in helping students achieve their learning goals. The lowest mean efficacy score is 3.73 on a five-point rating scale.

It is also important to note that both importance and efficacy mean scores are all above 3.0. The lowest mean importance score was recorded by Engaging with the Environment $(M=$ 3.25) and the lowest efficacy mean score was recorded by Academic Identity $(M=3.73)$. This demonstrates that participants considered the majority of items to be important and the Reference University to perform above average for most of the items. This can be observed in the breakdown of how responses were distributed among each of the points of the rating scales.

For importance rating, a count showed how many times the options on the rating scale were selected out of 2200 possible options (100 statements x 22 rating participants): Not At All Important 39 (1.77\%), Somewhat Important 184 (8.36\%), Important 659 (29.95\%), Very Important 735 (33.41\%) and Extremely Important 583 (26.50\%). The number of times statements rated as being at least Important on the rating scale was 1,977 (89.86\%) (see Appendix J).

For efficacy rating, a count showed how many times the following options on the rating scale were selected out of 2200 possible options: Poor 36 (1.64 \%), Fair 146 (6.64 \%), Average 593 (26.95\%), Good 819 (37.23\%) and Excellent 606 (27.55\%). The number of times statements 
were rated as being at least Average on the rating scale was 2018 (91.73\%). Rating scale options Good and Excellent were selected 1,425 times (64.77\%) (see Appendix K).

Summary of Findings for Research Question 1.a. To what extent do program stakeholder groups differ in their rating of the relative importance of student learning outcomes for ensuring student success? When comparing importance ratings of the two stakeholder groups considered for this study, it is important to note that faculty and staff members rated all clusters higher compared to students (see Figure 6). This demonstrates that, there was no consensus among groups in the perception of relative importance of the clusters.

The highest differences between the faculty/staff and students groups were recorded for the Independence (respectively, $M=4.19$ versus $M=3.91$ ) and the Help/Resource Seeking Clusters (respectively $M=3.92$ versus $M=3.69$ ). Career Identity (faculty/staff $M=3.71$, students, $M=3.66$ ) and Engaging with the Environment (faculty/staff $M=3.27$, students, $M=$ 3.24) are two clusters on which both groups were closest to reaching an agreement regarding importance. However, some agreements could be noted. The Independence Cluster was rated the most important by both faculty and staff members $(M=4.19)$ and students $(M=3.91)$. Likewise, the Engaging with the Environment was the lowest for both faculty/staff $(M=3.27)$ and students $(M=3.24)$. This demonstrates that both groups agreed on which clusters are the most and less important (see Table 12).

Summary of Findings for Research Question 1.b. To what extent do program stakeholder groups differ in their evaluation of the overall efficacy of their institution's success program in helping student achieve desired learning outcomes? When the stakeholder groups were compared as to their perception of the Reference University's efficacy in helping students achieve the learning outcomes contained in each cluster, disconnections were noted in all cases 
(see Figure 7). Students rated all clusters higher than faculty and staff members. This indicates that at the group level, there was no consensus with regards to how well the Reference University helped students realize their learning goals.

The clusters with the highest differences between the faculty/staff and students groups were Academic Identity (respectively, $M=3.18$ versus $M=3.93$ ) and Independence Clusters (respectively $M=3.31$ versus $M=4.03$ ). Two other clusters recorded important levels of difference, although the differences between groups were lower: Career Identity (faculty/staff $M$ =3.46, students, $M=3.91$ ) and Interdependence (faculty/staff $M=3.49$, students, $M=4.02$ ). Help/Resource Seeking (faculty/staff $M=3.77$, students, $M=4.00$ ) and Engaging with the Environment (faculty/staff $M=3.55$, students, $M=3.88$ ) are the two clusters on which the two groups were closest to reaching an agreement regarding efficacy (see Table 12).

Contrary to what happened with importance ratings, there was no agreement as to which clusters received the highest and lowest efficacy ratings. The Help/Resources Seeking Cluster was rated by faculty and staff members as having the highest efficacy $(M=3.77)$, while students rated the Independence Cluster highest $(M=4.03)$. The clusters with the lowest efficacy ratings were also different for each group: faculty and staff members rated Academic Identity Cluster ( $M$ $=3.18)$ lowest and students the Engaging with the Environment Cluster $(M=3.88)$.

Finally, differences among groups were more pronounced for efficacy ratings compared to importance ratings. This reveals that, generally, there was more disagreement among groups regarding efficacy of the Reference University and less disagreement regarding the importance of each cluster.

Summary of Findings for Research Question 2. To what extent does the conceptualized desired domain of student learning under Research Questions 1 align with the 
Foundational Dimensions established by the John N. Gardner Institute? The Concept

Mapping/Pattern Matching results were compared with the Foundational Dimensions of the John

N. Gardner's Institute to determine to what extend they align. The review followed a two-steps

process. The researcher first determined that some of the dimensions were more institutioncentered (Philosophy, Organization, Faculty, and Improvement) and others more studentcentered (Learning, Transitions, All Students, Diversity, and Roles and Purposes). Comparing the descriptions of the dimensions and the definition of the clusters, the researcher concluded that the student-centered dimensions shared some conceptual features with the CM/PM clusters (Independence, Engaging with the Environment, Career Identity, Interdependence, Help/Resources Seeking, and Career Identity) (see Table 13). However, at this point, the researcher decided not to attempt any further matching of dimensions and clusters but to proceed to an in-depth analysis. This second stage of the analysis consisted of examining the 100 statements and determining if they fitted in any of the Foundational Dimensions.

This analysis revealed that all statements matched with at least one of the dimensions (see Tables $14,15,16,17,18$, and 19). None of the dimensions matched exclusively with statements from a single cluster. However some substantial overlaps were noted between certain clusters and some of the dimensions. The Diversity Dimension matched substantially with the Interdependence Cluster which had five out of its six statements categorized with that dimension. The Faculty Dimension matched with statements from a variety of clusters. Most of the statements in the Learning Dimension came from Academic Identity (about 28 percent of the dimension) and Independence Clusters (about 62 percent). The Organization Dimension was mostly constituted of statements from the Engaging with the Environment (about 33 percent) and the Help/Resource Seeking (about 41 percent) Clusters. As for the Roles and Purposes 
Dimension, most statements stemmed from the Career Identity (about 23 percent) and Academic Identify (30 percent) Clusters. The Transitions Dimension gathered statements from a variety of clusters with the majority of them being from the Engaging with the Community (about 27 percent) and the Help/Resources Seeking (about 38 percent) Clusters. The only dimensions that could not be matched to any of the statements were the Philosophy, All Students, and Improvement Dimensions. Except for the All Students Dimension they had all been deemed institution-centered during the first stage of the document analysis.

\section{Discussion}

Student success is a major goal for both students and universities. The information and support students get during their first year are decisive in this regard. Based on 100 statements made by students, faculty and staff members, this study proposed to the Reference University a set of student learning outcomes for the first year that was more comprehensive than the progress metrics it was using. These outcomes deal with students' needs, success, engagement, and development. To a certain extent, they align with the Foundational Dimensions.

A More Comprehensive Set of Student Learning Outcomes for the First Year. As explained in Chapter One, the Reference University used a short list of metrics - retention rates at the end of the first semester and of the first year, probation rates, course completion rates based on credit hours earned as a percentage of credit hours attempted - to measure the success of the first-year success program. The findings of this study demonstrated that the short list of outcomes used by the Reference University could grow to include 100 learning outcomes categorized into six clusters by a group of stakeholders. This process allowed for the determination of outcomes to enrich existing metrics set to assess a student success program. It also allowed for the determination of clusters, or broad areas of student learning outcomes in the 
first year. In addition to expanding and categorizing the outcomes, a rating procedure allowed for the determination of which outcomes and clusters were the most important. Participants also reported their perception regarding the efficacy of the Reference University in helping students achieve the outcomes and clusters that were identified. This process allowed to shift from an institutional perspective to a more consensual one, thanks to the involvement of students and other stakeholders from academic and student affairs. The process took into account the fact that students have "well defined set of goals, a set of behavioral objectives, and a set of strategies to gain these objectives within limits imposed by the resources available" to them (Ewell, 1983, p. 21). The collaborative and consensual nature of the process followed guidelines by Suskie (2009) who argued that the process of outcome identification provides better learning experiences for students when they are asked to participate in the articulation of the "intended goals of their education" (p. 76).

A review of the cluster map revealed a notable pattern. The two left quadrants regrouped clusters (Independence, Career Identity, and Academic Identity) and statements that referred to student identity, responsibility, and character. The items in these clusters stressed the importance of a relationship of students with themselves. Examples of items include: (\#2) Students should take responsibility for individual learning; (\#4) Student should begin to learn what they are interested in; (\#9) Students should become more confident about their academic abilities; (\#75) Students should be able to develop from a dependent person to an independent person. Those two left quadrants could be labelled "relationship with self" (see Figure 8).

Conversely, the two right quadrants (Interdependence, Help/Resource Seeking, and Engagement with the Environment) regrouped clusters and statements that place students in situations where they communicate, collaborate, and interact with others and the environment. 
Examples of statements include: (\#15) Students should have additional support staff to turn to for help; (\#45) Students should have a better feel not just for their university but for the whole State as well; (\#78) Students should know how to embrace different cultures; (\#91) Students should know it is important to realize they are not alone - they have friends, professors, support staff, etc. Those two right quadrants could be labeled "relationships with others" (see Figure 8).

A further analysis of the quadrants allowed for another interpretation when the map was

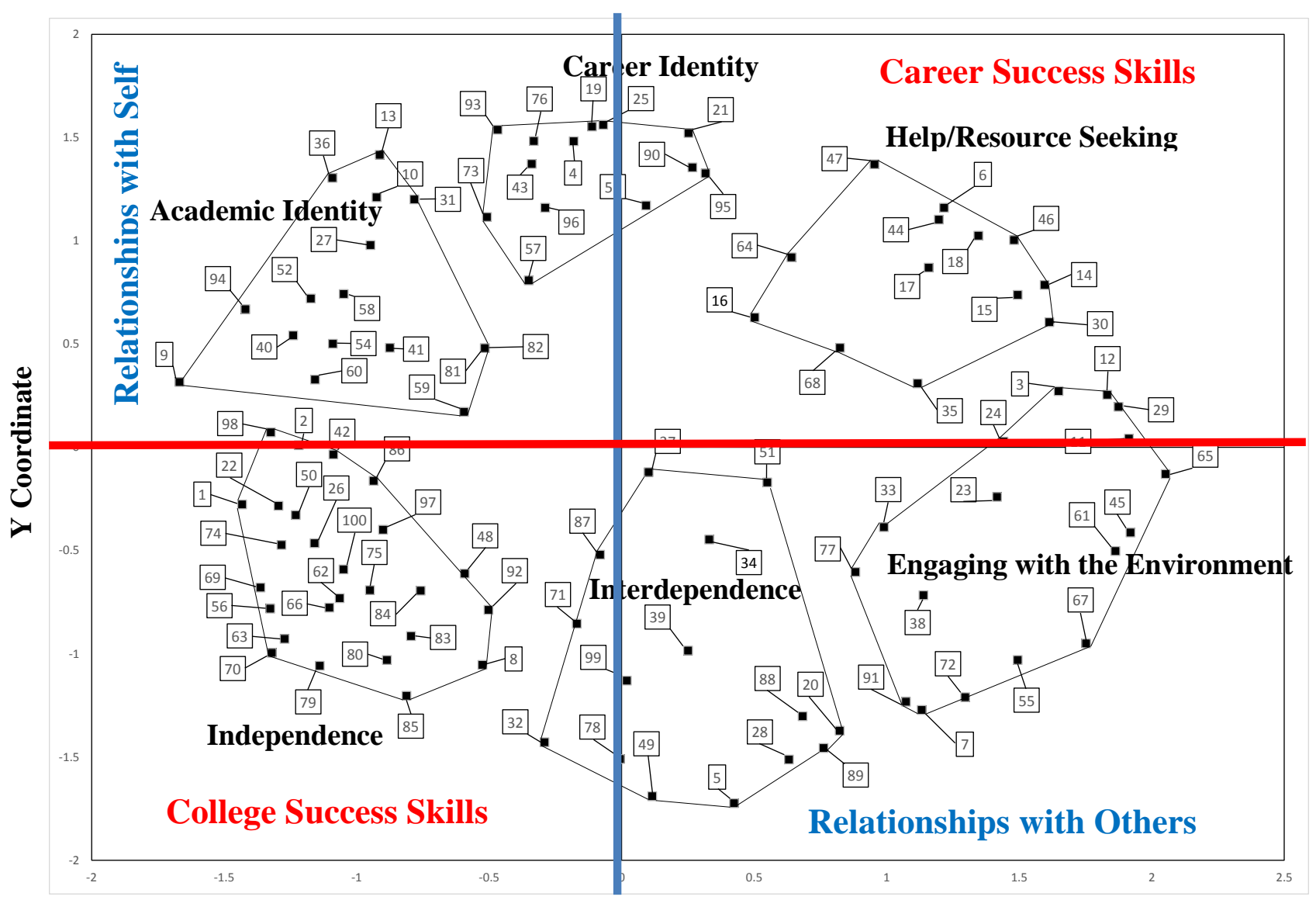

Figure 8: Cluster Map Quadrant Analysis

split horizontally. The top two quadrants consist of the Academic Identity, Career Identity, and Help/Resource Seeking Clusters. A close look at the definitions of the clusters and the items in those clusters leads to this reading: Academic Identity is composed of outcomes relating to the skill set that students need to develop in order to be successful within the academic major that 
they study (e.g., (\#10) Students should be able to create a success plan for college and career). Career Identity refers to the skill set students need to prepare for the job market (e.g., (\#96) Students should know what they have to do to be desirable to employers). The Help/Resource Seeking Cluster is made of all the support they need to be successful in the academic major as well as to prepare for the job market (e.g., (\#47) Students should know where to go if they need career guidance and career services (e.g., resume building \& interviewing skill development). Those top two quadrants can be labelled "Career Success Skills". Students need to identity and pursue an academic major, develop the skills to build a career identity in order to prepare for the job market, and finally avail themselves of resources to be successful (see Figure 8).

Equally, the two bottom quadrants can also be interpreted as a group. Clusters represented are the Independence, Interdependence, and Engaging with the Environment Clusters. For the Independence Cluster, students need to develop the skill necessary to function autonomously and become mature (e.g., (\#22) Students should be able to build positive habits to help them become more successful as college students). For the Interdependence Cluster, student are expected to build relationships with others to enhance their success (e.g., (\#89) Students should know it is important to have friends - a social support system - to help them through college both in terms of academics and socializing). For the Engaging with the Environment Cluster, they should learn how to harness the resources within the college environment (e.g., (\#91) Students should know it is important to realize they are not alone - they have friends, professors, support staff, etc.). The two bottom quadrants can be labelled "College Success Skills", the learning that needs to occur for student success to happen (see Figure 8).

Generated Student Learning Outcomes and Student Needs. Based on Benjamin Bloom's articulation of learning outcomes (Bloom et al., 1956), the focus prompt developed for 
the brainstorming session of this study was: "What knowledge, skills, and attitudes should students gain as a result of participating in the success program?" Building on the work of Bloom, Suskie (2009) defined student learning outcomes as "the knowledge, skills, attitudes, and habits of mind that students have and take with them when they successfully complete a course or program" (p. 23). Outcomes generated in this study represented all key areas of student learning outcomes identified previously (Bloom et al., 1956; Council for the Advancement of Standards in Higher Education, 2009; Cuseo, 2007a, 2007b; Suskie, 2009).

Outcomes generated by participants reflected also the plurality of student needs. In this regard, Upcraft and Crissman (1999) suggested that students should be perceived "not only as academic beings, but also as emotional, psychosocial, moral, ethical, developing, and maturing human beings" (p. 26). The following are examples of outcomes that illustrate the complexity of student needs expressed through this study:

- Academic needs: (\#9) Students should become more confident about their academic abilities; (\#40) Students should be able to develop academic maturity; (\#77) Students should participate in research sessions.

- Emotional needs: (\#69) Students should be able to stay positive despite academic setbacks; (\#92) Students should develop strategies to help themselves to de-stress.

- Ethical needs: (\#50) Students should take responsibility for their actions.

- Psychosocial needs: (\#20) Students should establish a core support group; (\#89) Students should know it is important to have friends - a social support system - to help them through college both in terms of academics and socializing.

Generated Student Learning Outcomes and Student Success. As shown below, the outcomes identified in this study can be tied to the main components of student success as 
defined in the FYE research (Upcraft, Barefoot, \& Gardner, 2005) and articulated by Hunter (2006). The definitions refer to successful first-year student as those who are:

- "developing academic and intellectual competence" (p. 5): e.g., (\#40) Students should be able to develop academic maturity; (\#98) Students should be able to learn the value of critical thinking.

- "establishing and maintaining interpersonal relationships" (p. 5): e.g., (\#28) Students should know how to make and keep relationships (friendships, connections, networking) with people throughout all of college.

- “exploring identity development” (p. 5): e.g., (\#8) Students should take opportunities to stand out and be unique; (\#85) Students should make decisions to make themselves happy rather than making decisions to make other people happy; (\#97) Students should know how to make themselves distinct.

- "deciding on a career and lifestyle" (p. 5): e.g., (\#10) Students should be able to create a success plan for college and career; (\#13) Students should be determined to find the career path they want to follow.

- "maintaining personal health and wellness" (p. 5): e.g., (\#92) Students should develop strategies to help themselves to de-stress; (\#100) Students should learn how to keep themselves healthy.

- "developing civic responsibility" (p. 5): (\#61) Students should know their community better - especially their local community - through service projects.

- “dealing with diversity” (p. 5): (\#78) Students should know how to embrace different cultures; (\#99) Students should try new things to open themselves up to new experiences. 
Generated Student Learning Outcomes and Student Engagement. Kuh, Kinzie,

Schuh, and Whitt (2005) viewed engagement as involving two main groups of stakeholders: students and institutions.

The first is the amount of time and effort students put into their studies and other activities that lead to the experiences and outcomes that constitute student success. The second is the ways an institution allocates its human and other resources and organizes learning opportunities and services to encourage students to participate in and benefit from such activities. (p. 4)

Several other scholars also insisted on the fact that no matter what resources are made available to students, the latter need to exert some effort to reap the benefits of their education. Student involvement is seen as a key to student success. Astin (1984) developed a theory that rests on the principles of student involvement. He argued that student involvement implies an "investment of physical and psychological energy" (p. 298). Tinto (1975, 1987, 1993, 2012) viewed the integration of students to their college environment as a key factor to student persistence and success. Tinto (2012) identified expectation, academic and social support, assessment, and student involvement as key to their success. He emphasized the fact that academic and social engagement, i.e. student involvement inside and outside of the classroom with faculty, peers and the community, contribute to their retention and eventual graduation from the institution. Reason, Terenzini, and Domingo (2006) pointed out that "the more actively students involve themselves in the curricular and co-curricular experiences of college, the more growth they can expect to experience" (p. 154).

The findings of this study align with the principle that student engagement is a condition for student success. Participants agreed with the literature by generating outcomes that stress the 
importance of student engagement. The energy students should invest in their use of campus resources was articulated in the outcomes in the Help/Resource Seeking and Career Identity Clusters. Students' active involvement with intellectual and academic activities was reflected in the outcomes in the Independence and Academic Identity Clusters. The necessity to develop efforts to form social links by interacting with peer students as well as faculty, staff and community members transpired in the Interdependence and Engaging with the Environment Clusters.

Generated Student Learning Outcomes and Student Development. One of the leading theories in student development is the one establishing vectors of development. Chickering and Reisser (1993, as cited in Evans et al., 2010) argued that student development is achieved via their evolution through seven different stages called "vectors": These vectors are not organized in a hierarchy, rather they are intertwined with each other and students may experience more than one vector at a time. Some aspects of the findings of the current $\mathrm{CM} / \mathrm{PM}$ study reflect Chickering's vectors of student development.

- "Developing Competence": In the first stage students develop "intellectual competence, physical and manual skills, and interpersonal competence" (p. 67). This description overlaps, for example, with the description of the Academic Identity, Independence, and Interdependence Clusters. Examples of outcomes that suit this vector include: (\#2) Students should take responsibility for individual learning; (\#9) Students should become more confident about their academic abilities; (\#77) Students should participate in research sessions.

- "Managing Emotions": In the second stage students achieve the "ability to recognize and accept emotions" and "appropriately express and control them" (p. 67). This vector has a 
lot in common with the Independence Cluster. The following are examples of outcomes that could fit the "Managing Emotions" vector : (\#69) Students should be able to stay positive despite academic setbacks; (\#79) Students should know how to handle adversity, for example, tough times and challenges; (\#92) Students should develop strategies to help themselves to de-stress.

- "Moving Through Autonomy Toward Interdependence": In the third stage students gain "increased emotional independence", and become more autonomous through "selfdirection, problem solving ability, and mobility". They also become aware and accept "the importance of interdependence, an awareness of their interconnectedness with others" (p. 68). This vector overlaps most with the Independence and the Interdependence Clusters. Examples of outcomes that match this vector include: (\#75) Students should be able to develop from a dependent person to an independent person; (\#85) Students should make decisions to make themselves happy rather than making decisions to make other people happy; (\#89) Students should know it is important to have friends - a social support system - to help them through college both in terms of academics and socializing.

- "Developing Mature Interpersonal Relationships": In the fourth stage students develop "intercultural and interpersonal tolerance and appreciation of differences, as well as the capacity for healthy and lasting intimate relationships with partners and close friends" (p. 68). This vector has a lot in common with the Interdependence, and the Engaging with the Environment Clusters. Individual outcomes that seem to match the description of this vector include: (\#7) Students should have an opportunity to meet new people right off the bat and make new friends; (\#28) Students should know how to make and keep 
relationships (friendships, connections, networking) with people throughout all of college; (\#78) Students should know how to embrace different cultures.

- "Establishing Identity": In the fifth stage students are able to "acknowledge differences in identity development based on gender, ethnic background, and sexual orientation" (p. 68). The characteristics of the Independence Cluster overlaps with those of the "Establishing Identity" vector. The following individual outcomes seem to fit the identity development process as described in this vector: (\#8) Students should take opportunities to stand out and be unique; (\#97) Students should know how to make themselves distinct.

- "Developing Purpose": In this sixth stage students are "developing clear vocational goals, making meaningful commitments to specific personal interests and activities, and establishing strong interpersonal commitments" (p. 69). The Career identity, Independence, and Interdependence Clusters have descriptions that match this vector. Examples of individual statements sharing features with this vector include: (\#13) Students should be determined to find the career path they want to follow; (\#19) Students should feel more prepared to decide on a major and not constantly be changing their minds; (\#31) Students should become responsible for themselves completely particularly in finding their majors

- "Developing Integrity": In the seventh stage students develop a "more humanized value system in which the interests of others are balanced with their own”, establish a "personalized value system" which allows them to be aware and respectful of the values of others, and their "values and actions become congruent and authentic as self-interest is balanced by a sense of social responsibility" (p. 69). The clusters with most overlapping features with this vector include the Independence, Interdependence, and the Engaging 
with the Environment Clusters. Examples of outcomes that could be paired with this vector include: (\#32) Students should want to reach out to others instead of expecting others to come to them; (\#50) Students should take responsibility for their actions; (\#61) Students should know their community better - especially their local community through service projects.

There are other examples of student development theories that were mirrored in the finding of this study. The notions of marginality and mattering explored by Schlossberg (1989a, as cited in Evans et al., 2010) is also reflected in this study. Schlossberg argued that institutions should demonstrate to student that they matter in order to encourage them to get involved in their studies and the other aspects of their college experiences. The following is an example of outcome that was generated by participants in this study to underscore that : (\#51) Students should feel that staff are truly there to help them and are not just "collecting a paycheck".

Rendón's (1994) validation theory, defined as “an enabling, confirming and supportive process initiated by in- and out-of-class agents that foster academic and interpersonal development" (as cited in Evans et al., 2010, p. 32) is also reflected by outcomes in this study: e.g., (\#20) Students should establish a core support group; (\#88) Students should know it is difficult to go through college alone; (\#34) Students should be able to help other students and point them to resources.

The Help/Resource Seeking Cluster may be related to the theory of challenge and support introduced by Sanford (1966, as cited in Evans et al., 2010). According to Sanford, support is needed to help students overcome the challenges they face in their lives while attending college. When the appropriate support is not provided students may not develop or may abandon their studies. The notion of support is echoed by Tinto (2012) who identified academic and social 
support as part of the key conditions for student success. The Engaging with the Environment Cluster can be assimilated to the theory of campus ecology, the "study of the relationships between the student and the campus environment" (Banning, 1978, p. 4, as cited in Evans et al., 2010.

\section{Alignment of the Locally Conceptualized Student Learning Outcomes with the}

Foundational Dimensions. This study allowed for a conceptualization by local stakeholders of student learning outcomes in the first year of college. These outcomes were then compared to established national principles of excellence for First-Year Experience programs (John N. Gardner Institute for Excellence in Undergraduate Education, 2005). This examination revealed that the locally generated learning outcomes matched with six out of nine of the Foundational Dimensions: Learning, Organization, Transitions, Faculty, Diversity, and Roles and Purposes). Among the nine Dimensions, some were believed by the researcher to be students-centered (Learning, Transitions, All Students, Diversity, and Roles and Purposes). The Dimensions that did not conceptually match with any of the statements were thought by the researcher to be institution-centered (Philosophy, All Students, and Improvement). It is important to note that the Foundational Dimensions were created as guidelines for institutions to improve first year programs, and did not intend to correspond directly to student learning outcomes. It is therefore not surprising that some of them focus more on institutional goals.

The local student learning outcomes were generated by two stakeholder groups: students and faculty/staff members. The students had first-hand experience of the first year of college and had an idea of their desired learning goals. The faculty and staff members had experience working with first-year students. Together, the two stakeholder groups could be considered the experts (Valdes-Vasquez \& Klotz, 2013) in this study. It was therefore important that at the end 
of the analysis, all statements they generated could be categorized along the lines of a nationally recognized framework for Excellence in the first-year of college (John N. Gardner Institute for Excellence in Undergraduate Education, 2005).

Relevance of the First Year. The literature relating to the First-Year Experience revealed some of the growing challenges of higher education. There is a growing demand for higher education (Weisbrod, Ballou, \& Asch, 2008), a diversification of the student body and students' needs and the necessity to provide services to enhance student success (Tinto, 2012). There is also outside pressure due to educational reforms, competition among higher education institutions for students and resources, overall increased public expectations of results and educational information (Walvoord, 2004). There is also the important cost factor that leads stakeholder to ask: "What do we get for that very considerable investment" (McMahon, 2009, p. 11). These are some of the reasons for the increased interest in the first year of college witnessed since the beginning of the 1980s (Alexander \& Gardner, 2009; Hunter, 2006). Although most higher education institutions have realized the importance of the first year, some programs still face challenges and shortcomings, creating the need for adherence to benchmarks and standards of excellence (Alexander \& Gardner, 2009).

This study was intended not only to see how locally generated outcomes would align with national principles, but also to reveal which outcomes would be rated as the most important by students and faculty/staff members. The rating process revealed that 28 percent $(n=28)$ of the statements recorded an importance at or above 4.0 (on a five-point scale), 67 percent $(n=67)$ of the statements were rated at or above 3.0, and 5 percent $(n=5)$ were rated below 3.0. This demonstrates that the majority of the outcomes were rated as being at least important. 
The high importance rating was not surprising. A justification for high importance ratings can be found in the literature. Trochim (1996b) suggested that in Concept Mapping studies, participants are not likely to generate statements that they deem unimportant to the conceptual domain of the study. Trochim assumed that items had to hold some level of importance to be suggested in the first place. For Trochim, the purpose of importance ratings is hence to indicate perceived relative importance of individual items compared to the rest of the items that were deemed to be important in the first place.

An examination of the clusters' mean ratings indicated that two of the clusters, although deemed by participants as the most important, were the only ones with their efficacy ratings being lower than their importance ratings (see Figure 5). The Independence Cluster recorded the highest importance rating $(M=3.99)$ and a rather low efficacy rating $(M=3.84)$. The Academic Identity Cluster had the second highest importance rating $(M=3.90)$ and the lowest efficacy rating $(M=3.73)$. These two clusters, with the highest importance ratings, were the ones for which participants were most concerned in terms of the Reference University's efficacy in helping students achieved the outcomes.

When comparing groups importance ratings, it was not surprising to see that both Independence and Academic Identity Cluster were rated highest by both faculty/staff members $(M=4.19$, resp. $M=3,97)$ and students $(M=3.91$, resp. $M=3,87)$, while they were rated higher by faculty/staff members than students (see Figure 6). This aspect of the importance rating data supports the findings of a previous study. Royal (2010) examined tenure-track faculty members' perception of student learning outcomes at private and public research universities and sought to determine which outcomes were considered the most important. The study involved 7,356 faculty members. Findings revealed that the outcome related to "intellectual growth" (p. 
27 ) of students was the most highly valued outcome compared to other types of outcomes. The item that represented that category of outcomes was entitled "develop ability to think critically" (p. 22). It is quite interesting to note that in the current study, (\#98) students should be able to learn the value of critical thinking, was rated high $(M=4.18)$ on a 5-point scale. Furthermore, (\#98) was in the highest rated cluster, Independence, when importance and efficacy ratings from all participants were compared (see Figure 5). When clusters were compared for importance among the two stakeholder groups, the Independence Cluster was rated highest $(M=4.19)$ (see Figure 6).

Based on the findings of the study conducted by Royal (2010), we know that faculty members value highly outcomes related to intellectual development. One has to wonder why the faculty and staff members' group in this study rated the clusters with most of the items related to intellectual growth (Independence and Academic Identity) as the lowest in terms of efficacy.

The variety of outcomes supports also the suggestion by Koch and Gardner (2006) that student learning does not occur only in the classroom and is not a single event but "an intentional combination of academic and co-curricular efforts" (as cited in Greenfield, Keup \& Gardner, 2013, p. xxx). Additionally, career and major exploration is emphasized in one of the clusters (Career Identity), showing participants' belief that this is an important area of concern for student success, especially for undecided students. This echoes the suggestion by Cuseo (2005) that "if students develop a viable plan for identifying a college major and related career that is compatible with their abilities, interests and values, then their overall level of satisfaction with college should increase" (p. 28). 


\section{Implications of the findings}

The findings of this study hold several implications applicable to first-year programs at the Reference University and other higher education institutions. They are discussed in the following sections.

Implication for the First-Year Experience at the Reference University. This study involved students who started their college career as undecided students as well as faculty and staff members who worked closely with them in a first-year student success program. This led to the articulation of 100 learning outcomes categorized into six clusters. The results were compared to the Foundational Dimensions of the John Gardner Institute to find out if the outcomes aligned with any of the Dimensions. The results of this study may benefit the undecided students enrolling in the success program. The Reference University may also involve a larger and diverse group of students and other stakeholders to generate learning outcomes that would be relevant to all first-year students. Despite the existence of a First-Year Seminar course and a philosophy statement articulated during the Foundation of Excellence self-study process in academic year 2006-2007, there is currently no updated overarching goals specifically determined for the First-Year Experience. Outcomes could be developed for the FYE and all programs serving first-year students inside and outside of the classroom. The findings of such a process may lead the Reference University to re-think and reinvigorate its First-Year Seminar course, and devise a robust FYE and better coordinate all its programs serving first-year students. Coordination of the FYE program should involve a variety of stakeholders including students, community members, faculty, and staff members from academic and student affairs. The learning goals identified could be integrated into academic and other learning experiences to which first-year students are exposed. 
Implication for First-Year Experience programs at other institutions. This study provided a close-up view of a FYE program designed to enhance student success. The process and findings of this study may be used as a framework for planning and evaluation of first-year student success programs. It can also be used to assess the efficacy of higher education institutions' efforts to address the needs of first year students.

The findings of this study reveal the desired learning outcomes of first year students under the form of individual outcomes as well as clusters of outcomes. The results also revealed which outcomes and clusters were deemed the most important. Information regarding participants' perception of the institutional efficacy was also collected. These findings may be used by faculty and staff members working for first-year programs to better respond to student expectations, address program shortcomings and improve institutional offering to enhance student success. Information collected from first-year students may also guide decision making regarding existing and future programs for this and other groups of students.

Implications for the Success Program at the Reference University. Building on the findings of this study, the success program should organize its programming based on a review of the outcomes and the clusters that were identified. Student learning outcomes may be articulated to encompass the six clusters. Each of them may serve as an overarching goal set to measure student success. Assessment of student success may be conducted by measuring how students achieve the learning outcomes articulated in each clusters. Learning could be measured at various levels including at the course, program, general education, co-curricular, student life programming, cohort, and college or university levels (Suskie, 2009). 
Current and future undecided students could be given the opportunity to review the findings of this study in order to encourage them to reflect on their own experiences and consequently be more cognizant of their own goals, aspirations, and expectations.

Similarly, metrics measuring programmatic success could be developed around the clusters. Program success may be measured directly by using student achievement as a proxy or by collecting perception data regarding institutional performance in terms of helping students achieve the learning outcomes.

Program faculty and staff members should be encouraged to pay close attention to two of the clusters (Independence and Academic Identity) which were rated highest in terms of importance but where the only ones with lower efficacy ratings than importance ratings. They should find ways to help students develop a stronger academic identity by empowering them to "hone academic and professional skills in order to plan for an academic major and a career" (description of the Academic Identity Cluster). They should also empower students to become more independent learners by helping them devise "ways to set goals and priorities for personal and academic success, take responsibility, and self-advocate" (definition of the Independence Cluster). Faculty and staff should be made aware of the needs of this group of students and should be empowered to be able to help students succeed.

\section{The Use of the Concept Mapping/Pattern Matching Methodology during the} Foundation of Excellence Self-Study Process. The Foundation of Excellence (FoE) self-study process is based on the principles of the Foundational Dimensions. Since its inception, this selfstudy process has been adopted by hundreds of higher education institutions around the country (Alexander \& Gardner, 2009). It allows institutions to improve their first year programs. The self-study process may benefit from the use of Concept Mapping/Pattern/Matching methodology 
as task force members work to identify strengths and weakness of first-year programs. This methodology has been useful in similar studies in helping stakeholders reach a consensus on various phenomena under study (Kane \& Trochim, 2007; Trochim, 1989a). It may help taskforce members identify common goals and set priorities. Combining the Foundation of Excellence self-study process and the Concept Mapping/Pattern Matching methodology will help optimize the process of applying best practices for the determination of goals, policies, and programs to meet students' needs.

Additionally, when the CM/PM items resulting from the organic research conducted at the Reference University were compared to the Foundational Dimensions, similarities were found but the two perspectives (CM/PM v. FD) categorized the items differently. The participants in the study were largely in agreement with FD regarding what outcomes are necessary for success in the first year, but conceptualized the domain elements differently. Therefore, the Foundation of Excellence may want to do research in order to see if their organization of the skills matches the perceptions of the universities it serves.

Implications for postsecondary student success programs. The findings of this study also holds major implications for postsecondary student success programs, specifically in the following ways: success programs should be created to address the needs of specific subgroups of student populations and not follow a one-size-fits-all approach. To be effective, those programs should be created to address expressed needs identified through research involving key stakeholders. The pursuit of student success in postsecondary education should be a shared endeavor involving a variety of stakeholders including students, faculty, staff members from both academic and student affairs, parents, employers, policymakers as well as other key actors. The quest for strategies to enhance student success should never make do with the status quo. 
Assessment of student learning or success program outcomes should be adequately designed to allow institutions to have a full grasp of all areas of learning and development opportunities to which students have access while attending postsecondary education. Finally, postsecondary student success programs should not simply adopt authority-based initiatives without gathering local data to determine the needs of students. Local issues may need to be solved through locally crafted strategies. By doing so, institutions of higher education will be able to meet more effectively the needs of their students.

\section{Recommendations for future research}

In light of the process and findings of the current study, the researcher suggests additional research be conducted to further explore and refine the conceptualization of first-year student learning outcomes.

1. CM/PM study results reflect the views of its participants (Trochim, 1989a; Kane \& Trochim, 2007). The results of this research can be considered as representing the perception of the 23 participants who took part in the study. That being said, there is no guarantee that if the study was conducted with different participants form the Reference University the same conclusions would be reached. Future research could replicate the study with different participants, including students, faculty, and staff members from the Reference University. The findings of the original and replication studies could be compared and contrasted for differences and similarities.

2. In this study, participants generated 100 outcomes and then sorted them into groups in a way that made sense to them (Kane \& Trochim, 2007). The researcher compared the outcomes and clusters with the Foundational Dimensions of the John N. Gardner Institute to see if there were any alignments between both sets of data. The researcher was able to 
match each outcome with at least one dimension. Determining alignment was made based on the sole subjective opinion of the researcher. Future research could involve participants, individually, in that last process by asking them to sort the items for a second time by determining which outcome matches with which Foundational Dimension. This would allow for a comparison with the researcher's findings on the one hand, and on the other show how participants match the outcomes to the Dimensions.

3. Due to the nature of this study, a doctoral dissertation, the participants were involved in the generating (brainstorming), sorting, and rating of statements. As a group, they were not involved in the subjective part of hierarchical analysis, interpretation, and utilization of maps. Future research could ask participants to participate in those steps of the $\mathrm{CM} / \mathrm{PM}$ process to see if similar or different results would be reached.

4. Future research could also be conducted with undecided students who do not partake in the success program, for comparison, or with subgroups of students who started off college in declared major, with the purpose of getting a bigger picture of student expected outcomes and to assess the impact of their exposure to the institution. This may be beneficial, especially if the Reference University would like to determine learning goals for the First-Year Experience for all students.

5. The current study focused on the conceptualization of overall learning outcomesknowledge, skills, and attitudes (Bloom et al., 1956) — for the FYE. Future research may investigate separately academic and nonacademic outcomes to check for differences or similarities. This would allow the university to provide improved domain-specific services in order to enhance student experiences in the first college year. The results may lead to a better-coordinated approach to serving first-year students within the institution. 
6. Participants in this this CM/PM study were involved in a group activity during which they brainstormed and generated 100 student learning outcomes for the first year of college. Each participant was given a set of the 100 statements and was asked to individually sort them into piles. A total of 188 separate piles were formed across participants. They also rated each outcome for importance and for institutional efficacy. After multidimensional scaling and hierarchical cluster analysis, various concept maps representing the group's thinking were developed. The final concept map included six clusters, representing the broad areas of the group's conceptualization. It is quite possible that in the process of mapping the group's thinking, minority or individual voices were not fully described. Future studies could go beyond the final cluster map and provide additional qualitative analyses to account for some of the information collected that may not be noticeable at the aggregate level. For example, future analyses could help identify and describe patterns regarding how the data was sorted and rated by participants. An emphasis could also be placed on the description of some items or aspects that can be categorized as outliers compared to the consensual representation of the group's conceptualization.

7. Future studies could also include the following three elements in the analysis: the mission, vision, and strategic goals of the higher education institution, the Concept Mapping/Pattern Matching results, and the Foundational Dimensions of the John N. Gardner Institute. This will be a way to check the relevance of national standards at the local level and also to determine whether or not the conceptualization of a group of stakeholders aligns with the mission, vision and goals of their higher education institution. 


\section{Summary of the Study}

Most U.S. colleges and universities acknowledge the importance of the college first year for student success (Alexander \& Gardner, 2009). At a land-grant university, member of the Southern Regional Education Board, a first-year success program was created to enhance the success of first-time full-time undecided students. The success metrics utilized to measure the program's success being too institution-centered, this study was conducted in order to conceptualize a more comprehensive desired domain of student learning using Concept Mapping/Pattern Matching (Kane \& Trochim, 2007; Trochim 1989a).

A group of 23 stakeholders consisting of seven faculty/staff members and 16 students generated 100 outcomes in response to the following focus prompt: "What knowledge, skills, and attitudes should students gain as a result of participating in the success program?" The 23 participants were also asked to individually sort these outcomes into groups. Twenty-two of the stakeholders later rated those 100 outcomes for importance with regards to student success, and with regards to the university' efficacy in helping students achieve each one of the outcomes.

The researcher conducted statistical analyses-Multidimensional Scaling and Hierarchical Cluster Analysis - that allowed for the creation of a Hierarchical Cluster Tree or dendrogram and various concept maps representing the stakeholders' conceptualization of the domain under study. One of the concept maps represented the six clusters retained for this study, which were named as follows: Independence Cluster, Engaging with the Environment Cluster, Career Identity Cluster, Interdependence Cluster, Help/Resource Seeking Cluster, and the Academic Identity Cluster.

Mean ratings for the Independence and Academic Identity Clusters revealed the perception of participants that these two clusters were the most important for student success. 
Participants also gave those two Clusters mean efficacy ratings that were lower compared to their importance ratings. The remaining four clusters were on average rated higher for efficacy than for importance. The lowest mean importance score was recorded by Engaging with the Environment Cluster and the lowest efficacy mean score by the Academic Identity Cluster.

There was no consensus among groups (faculty/staff v. students) in the perception of the relative importance of the clusters. Faculty and staff members rated all clusters higher in terms of importance compared to students. However, the Independence Cluster was rated the most important by both groups. Likewise, the Engaging with the Environment Cluster was rated the less important by both groups. This demonstrates that both groups agreed on which clusters were the most and the least important.

There was no consensus either with regards to the efficacy of the Reference University in helping students realize their learning goals. Students rated all clusters higher than faculty and staff members. Furthermore, there was no agreement as to which clusters received the highest and lowest efficacy ratings. Faculty and staff members gave their highest efficacy rating to the Help/Resource Seeking Cluster and their lowest efficacy rating to the Academic Identity Cluster. For students the highest was the Independence Cluster and the lowest the Engaging with the Environment Cluster. Finally, differences among groups were more pronounced for efficacy ratings compared to importance ratings.

The CM/PM results were compared with the Foundational Dimensions of the John N. Gardner's Institute to determine to what extend they align (John N. Gardner Institute for Excellence in Undergraduate Education, 2005). The researcher determined that some of the dimensions were institution-centered (Philosophy, Organization, Faculty, and Improvement) and others student-centered (Learning, Transitions, All Students, Diversity, and Roles and Purposes). 
Student-centered dimensions shared some conceptual features with the CM/PM clusters.

Furthermore, the 100 statements were examined to determine if they fit in any of the Foundational Dimensions. All statements matched with at least one of the dimensions. None of the dimensions matched exclusively with statements from a single cluster. However some substantial overlaps were noted between certain clusters and some of the dimensions. The dimensions that could not be matched by the researcher to any of the statements were the Philosophy, All Students, and Improvement Dimensions. 


\section{References}

ACT. (2012). National collegiate retention and persistence to degree rates. Retrieved from http://www.act.org/research/policymakers/pdf/retain_2012.pdf

Adu, P. K. (2011). Conceptualizing doctoral advising from professors' and doctoral students' perspectives using concept mapping (Doctoral dissertation). Retrieved from http://hdl.handle.net/10450/12551

Ahlfeldt, S., Mehta, S., \& Sellnow, T. (2005). Measurement and analysis of student engagement in university classes where varying levels of PBL methods of instruction are in use. Higher Education Research \& Development, 24(1), 5-20.

Alexander, J. S., \& Gardner, J. N. (2009). Beyond retention: A comprehensive approach to the first college year. About Campus, 14(2), 18-26.

Angelo, T. A. (1995). Reassessing (and defining) assessment. American Association for Higher Education Bulletin, 48(3), 7-9.

Arendale, D. (2005). Terms of endearment: Words that define and guide developmental education. Journal of College Reading \& Learning, 35(2), 66-82.

Association of American Colleges and Universities. (2007). College learning for the new global century. Washington, DC: Author.

Association of American Colleges and Universities. (2011). The LEAP vision for learning: Outcomes, practices, impact, and employers'views. Washington, DC: Author.

Astin, A. W. (1984). Student involvement: A developmental theory for higher education. Journal of College Student Personnel, 25(4), 297-308.

Astin, A. W. (1993). What matters in college? Four critical years revisited (1st ed.). San Francisco, CA: The Jossey-Bass higher and adult education series. 
Astin, A. W., \& Antonio, A. L. (2012). Assessment for excellence: The philosophy and practice of assessment and evaluation in higher education (2nd ed.). Lanham, MD: Rowman \& Littlefield Publishers.

Astin, A. W., Panos, R. J., \& Creager, J. A. (1967). National norms for entering college freshmen—fall 1966. Washington, D.C.: American Council on Education.

Barefoot, B. O. (1992). Helping first-year college students climb the academic ladder: Report of a national survey of freshman seminar programming in American higher education (Unpublished doctoral dissertation). College of William and Mary, Williamsburg, Virginia.

Barefoot, B. O., Griffin, B. Q. \& Koch, A. K. (2012). Enhancing student success and retention throughout undergraduate education: A national survey. Retrieved from http://www.jngi.org/research-publications/NationalSurvey

Barr, R. B., \& Tagg, J. (1995). From teaching to learning: A new paradigm for undergraduate education. Change, 27(6), 12-25.

Baum, S., \& Ma, J. (2007). Education pays: The benefits of higher education for individuals and society. New York, NY: College Board.

Baum, S., \& Payea, K. (2004). Education pays 2004. New York, NY: College Board.

Baum, S., \& Payea, K. (2005). Education pays update. New York, NY: College Board.

Baxter Magolda, M. B. (1992). Knowing and reasoning in college: Gender-related patterns in students' intellectual development. San Francisco, CA: Jossey-Bass.

Baxter Magolda, M. B. (2004). Evolution of a constructivist conceptualization epistemological reflection. Educationalist Psychologist, 39(1) 31-42.

Becker, G. S. (1993). Human capital: A theoretical and empirical analysis, with special reference to education. Chicago, IL: The University of Chicago Press. 
Berger, J. B., \& Braxton, J. M. (1998). Revising Tinto's interactionalist theory of student departure through theory elaboration: Examining the role of organizational attributes in the persistence process. Research in Higher Education, 39(2), 103-119.

Bloom, J. L., Hutson, B. L., \& He, D. Y. (2008). The appreciative advising revolution. Champaign, IL: Stipes Publishing.

Bloom, B. S., Engelhart, M. D., Furst, E. J., Hill, W. H., \& Krathwohl, D. R. (1956). In Bloom B. S. (Ed.), Taxonomy of educational objectives: The classification of educational goals. Handbook 1: Cognitive domain. New York, NY: David. McKay Co., Inc.

Bowling Green University. (2013). The residential learning communities international clearing house. Retrieved from http://pcc.bgsu.edu/ricch

Bridges, B. K., Cambridge, B., Kuh, G. D., \& Leegwater, L. H. (2005). Student engagement at minority-serving institutions: Emerging lessons from the BEAMS project. New Directions for Institutional Research, 2005(125), 25-43.

Brower, A. M., \& Inkelas, K. K. (2010). Living-learning programs: One high-impact educational practice we now know a lot about. Liberal Education, 96(2), 36-43.

Brower, A. M., \& Dettinger, K. M. (1998). What is a learning community? Toward a comprehensive model. About Campus, 3(5), 15-21.

Brown, K. S. (2009). Factors that predict academic achievement for students who are undecided majors (Doctoral dissertation, Virginia Polytechnic Institute and State University).Retrieved from http://scholar.lib.vt.edu/theses/available/etd-12112009-

131300/unrestricted/Brown_KS_D_2009.pdf

Carnegie Foundation for the Advancement of Teaching. (2010). Carnegie classifications data file. Retrieved from http://classifications.carnegiefoundation.org/resources/ 
Carnevale, A., Smith, N. \& Strohl, J. (2010). Help wanted: Projections of jobs and education requirements through 2018. Georgetown university center on education and the workforce. Retrieved from http://cew.georgetown.edu/jobs2018

Chickering, A. W., \& Gamson, Z. F. (1987). Seven principles for good practice in undergraduate education. American Association for Higher Education Bulletin, 39(7), 3-7.

Chickering, A. W., \& Reisser, L. (1993). Education and identity (2nd ed.). San Francisco, CA: Jossey-Bass.

Cohen, A. M., \& Brawer, F. B. (2002). The American community college (4th ed.). San Francisco, CA: Jossey-Bass.

Consortium for Student Retention Data Exchange. (1999). Executive summary 1998-1999 CSRDE report: The retention and graduation rates in 269 colleges and universities. Norman, OK: Center for Institutional Data Exchange and Analysis, University of Oklahoma.

Costa, A. L., \& Kallick, B. (2000). Discovering and exploring habits of mind. Alexandria, VA: Association for Supervision and Curriculum.

Council for the Advancement of Standards in Higher Education. (2005). The role of academic advising, CAS standards contextual statement. Retrieved from http://standards.cas.edu/getpdf.cfm?PDF=E864D2C4-D655-8F74-2E647CDECD29B7D0

Council for the Advancement of Standards in Higher Education. (2009). CAS learning and development outcomes. Retrieved from http://www.cas.edu/learningoutcomes

Cuseo, J. (2003). Red flags: Behavioral indicators of potential student attrition. Retrieved from http://uwc.edu/sites/default/files/imce-uploads/employees/academicresources/esfy/_files/red_flags-behavioral_indicators_of_potential_student_attrition.pdf 
Cuseo, J. (2005). "Decided", "undecided", and "in transition": Implications for academic advisement, career counseling, and student retention. In R. S. Feldman (Ed.), Improving the first year of college: Research and practice (pp. 27-48). Mahwah, NJ: Laurence Erlbaum Associates, Inc.

Cuseo, J. (2007a). Defining student success: The critical first step in promoting it. E-Source for College Transitions, 4(5), 2-5.

Cuseo, J. (2007b). Seven central principles of student success: Key processes associated with positive student outcomes. E-Source for College Transitions, 4(6), 3-6.

Cuseo, J. (2010). Peer leadership: Definition, description, and classification. E-Source for College Transitions, 7(5), 3-5.

Damashek, R. (2003). Support programs for students on academic probation. Retrieved from http://files.eric.ed.gov/fulltext/ED475734.pdf

Darling-Hammond, L. (2004). Standards, accountability, and school reform. The Teachers College Record, 106(6), 1047-1085.

Eckel, P. D., \& Kezar, A. (2003). Taking the reins: Institutional transformation in higher education (1st ed.). Westport, CT: Greenwood Publishing Group.

Erikson, E. H. (1959). Identity and the life cycle. Psychological Issues Monograph, 1(1), 1-171.

Evans, N. J., Forney, D. S., Guido, F. M., Patton, L. D., \& Renn, K. A. (2010). Student development in college: Theory, research, and practice (2nd ed.). San Francisco, CA: Jossey-Bass.

Evers, F. T., Rush, J. C., \& Berdrow, I. (1998). The bases of competence: Skills for lifelong learning and employability (1st ed.). San Francisco, CA: Jossey-Bass. 
Ewell, P. T. (1983). Information on student outcomes: How to get it and how to use it. Boulder, CO: National Center for Higher Education Management Systems.

Fairris, D. (2012). Using program evaluation to enhance student success. Liberal Education, 98(1), 52-55. Retrieved from http://search.ebscohost.com/login.aspx?direct=true \&db=ehh\&AN=78073105\&site=ehostlive

Frazier, K. G. (2007). First-year experience collaboration among academic affairs and student affairs, (Doctoral dissertation). Available from ProQuest Dissertations and Theses. (UMI No. 304875625)

Frost, S. H. (1991). Academic advising for student success: A system of shared responsibility. Washington, D.C.: School of Education and Human Development, George Washington University.

Gaskins, B. P. (2009). A ten-year study of the conditional effects on student success in the first year of college, (doctoral dissertation). Available from ProQuest Dissertations and Theses. (UMI No. 304847742).

Gonyea, R. M., \& Kuh, G. D. (2009).Using NSSE in institutional research [special issue]. New Directions for Institutional Research, 141

Goodman, J., Schlossberg, N. K., \& Anderson, M. L. (2006). Counseling adults in transition (3rd ed.). New York, NY: Springer.

Gordon, V. P. (1989). Origins and purposes of the freshman seminar. In M. L. Upcraft, J. N. Gardner \& Associates (Eds.), The freshman year experience (pp. 183-197). San Francisco, CA: Jossey-Bass. 
Gordon, V. N. (1984). The undecided college student: An academic and career advising challenge. Springfield, IL: C.C. Thomas.

Greenfield, G. M., Keup, J. R., \& Gardner, J. N. (2013). Developing and sustaining successful first-year programs: A guide for practitioners. San Francisco, CA: John Wiley \& Sons.

Hanson, W. E., Creswell, J. W., Clark, V. L. P., Petska, K. S., \& Creswell, J. D. (2005). Mixed methods research designs in counseling psychology. Journal of Counseling Psychology, 52(2), 224-235.

Hayek, J., \& Kuh, G. (2002). Insights into effective educational practices. Educause Quarterly, 25(1), 60-61.

Henscheid, J. M. (2004). Integrating the first-year experience: The role of first-year seminars in learning communities. Columbia, SC: University of South Carolina, National Resource Center for the First-Year Experience and Students in Transition.

Hunter, M. S. (2006). Fostering student learning and success through first-year programs. Peer Review, 8(3), 4-7.

Hunter, M. S., \& Linder, C. W. (2005). First-year seminars. In M. L. Upcraft, J. N. Gardner, B. O. Barefoot \& Associates (Eds.), (pp. 275-291). San Francisco, CA: Jossey-Bass.

Inkelas, K. K., Vogt, K. E., Longerbeam, S. D., Owen, J., \& Johnson, D. (2006). Measuring outcomes of living-learning programs: Examining college environments and student learning and development. The Journal of General Education, 55(1), 40-76.

Jacobs, B. C. (2010). Making the case for orientation: Is it worth it? In J. A. Ward-Roof (Ed.), Designing successful transitions: A guide for orienting students to college (pp. 29-39). Columbia, SC: University of South Carolina, National Resource Center for the First-Year Experience and Students in Transition. 
Jamelske, E. (2009). Measuring the impact of a university first-year experience program on student GPA and retention. Higher Education, 57(3), 373-391.

James Madison University. (2003). Dictionary of student outcome assessment. Retrieved from http://people.jmu.edu/yangsx/AlphaTerm.asp?FirstLetter=O

John N. Gardner Institute for Excellence in Undergraduate Education. (2005). Retrieved from http://www.jngi.org/foe-program/foundational-dimensions/

Kane, M., \& Trochim, W. M. K. (2007). Concept mapping for planning and evaluation. Thousand Oaks, CA: Sage Publications.

Kane, M., \& Trochim, W. M. K. (2009). Concept mapping for applied social research. In L. Bickman, \& D. J. Rog (Eds.), The SAGE handbook of applied social research methods (2nd ed., pp. 435-474). Los Angeles, CA: Sage.

Keup, J. R. (Ed.) (2012). Peer leadership in higher education: New directions for higher education, 157. Jossey-Bass

Keup, J. R., \& Barefoot, B. O. (2005). Learning how to be a successful student: Exploring the impact of first-year seminars on student outcomes. Journal of the First-Year Experience \& Students in Transition, 17(1), 11-47.

Kezar, A. J., Carducci, R., \& Contreras-McGavin, M. (2006). Rethinking the " $L$ " word in higher education: The revolution in research on leadership. San Francisco, CA: Jossey-Bass.

Kezar, A. J., \& ERIC Clearinghouse on Higher Education. (2000). Summer bridge programs: Supporting all students. (No. EDO-HE-2000-3). Washington, DC: ERIC Clearinghouse on Higher Education, George Washington University. 
King, P. M., \& Kitchener, K. S. (1994). Developing reflective judgment: Understanding and promoting intellectual growth and critical thinking in adolescents and adults. San Francisco, CA: Jossey-Bass.

Kinzie, J., \& Kuh, G. D. (2004). Going deep: Learning from campuses that share responsibility for student success. About Campus, 9(5), 2-8.

Koch, A. K., \& Gardner, J. N. (2006). The history of the first-year experience in the United States: Lessons from the past, practices in the present, and implications for the future. In A. Hamana, \& K. Tatsuo (Eds.), The first-year experience and transition from high school to college: An international study of content and pedagogy. Tokyo, Japan: Maruzen Publishing.

Kohlberg, L. (1976). Moral stages and moralization: The cognitive-developmental approach. In T. Lickona (Ed.), Moral development and behavior: Theory, research, and social issues (pp. 31-53). New York, NY: Holt.

Kolb, D. G., \& Shepherd, D. M. (1997). Concept mapping organizational cultures. Journal of Management Inquiry, 6(4), 282-295.

Kolb, D. A. (1984). Experiential learning: Experience as the source of learning and development. Upper Saddle River, NJ: Prentice Hall.

Krathwohl, D. R., Bloom, B. S., \& Masia, B. B. (1964). Taxonomy of educational objectives: The classification of educational goals. Handbook II: The affective domain. New York, NY: David McKay Co., Inc.

Kruskal, J. B., \& Wish, M. (1978). Multidimensional scaling. Beverly Hills, CA: Sage. 
Kuh, G. D., Kinzie, J., Schuh, J. H., \& Whitt, E. J. (2005). Assessing conditions to enhance educational effectiveness: The inventory for student engagement and success (1st ed.). San Francisco, CA: Jossey-Bass.

Kuh, G. D. (2008a). High-impact educational practices: What they are, who has access to them, and why they matter. Washington, DC: Association of American Colleges and Universities.

Kuh, G. D. (2008b). Why integration and engagement are essential to effective educational practice in the twenty-first century. Peer Review, 10(4), 27-28. Retrieved from http://search.ebscohost.com/login.aspx?direct=true \&db=a2h\&AN=36133892\&site=ehostlive

Kuh, G. D. (2003). The national survey of student engagement: Conceptual framework and overview of psychometric properties. Center for Postsecondary Research, Indiana University, Bloomington. Retrieved from http://nsse.indiana.edu/pdf/conceptual_framework_2003.pdf

Laufgraben, J. L. (2005). Learning communities. In M. L. Upcraft, J. N. Gardner \& B. O. Barefoot (Eds.), Challenging and supporting the first-year student: A handbook for improving the first year of college. (pp. 371-387). San Francisco, CA: Jossey-Bass.

Learning Slope. (1991). Pew Higher Education Research Program Policy perspectives, 4(1), 1A-8A.

Leveille, D. E. (2005). An emerging view on accountability in American higher education. Retrieved from https://escholarship.org/uc/item/89b2b1zt

Lewallen, W. (1993). The impact of being" undecided" on college-student persistence. Journal of College Student Development, 34, 103-112. 
Lipka, S. (2006). After the freshman bubble pops: More colleges try to help their sophomores thrive. Chronicle of Higher Education, A34.

Love, A. G. (1999). What are learning communities? In J. H. Levine (Ed.), Learning communities: New structures, new partnerships for learning (pp. 1-8). Columbia, SC: University of South Carolina, National Resource Center for The First-Year Experience and Students in Transition.

Love, A. G., \& Tokuno, K. A. (1999). Learning community models. In J. H. Levine (Ed.), Learning communities: New structures, new partnerships for learning (pp. 9-18). Columbia, SC: University of South Carolina, National Resource Center for The First-Year Experience and Students in Transition.

Lumina Foundation for Education. (2011). Degree qualifications profile. Retrieved from http://www.luminafoundation.org/publications/The_Degree_Qualifications_Profile.pdf

Lumina Foundation for Education. (2013). Strategic plan 2013 to 2016. Retrieved from http://www.luminafoundation.org/advantage/document/goal_2025/2013Lumina_Strategic_Plan.pdf

Marsh, J. A., Pane, J. F. \& Hamilton, L. S. (2006). Making sense of data-driven decision making in education: Evidence from recent RAND research. Retrieved from http://www.conceptsystems.com/files/all/bibliography_-_evaluation.pdf

Marzano, R. J., Pickering, D., \& McTighe, J. (1993). Assessing student outcomes: Performance assessment using the dimensions of learning model. Alexandria, VA: Association for Supervision and Curriculum Development.

McLinden, D. J., \& Trochim, W. M. K. (1998a). Getting to parallel: Assessing the return on expectations of training. Performance Improvement, 37(8), 21-26. 
McLinden, D. J., \& Trochim, W. M. K. (1998b). From puzzles to problems: Assessing the impact of education in a business context with concept mapping and pattern matching. In J. Phillips (Ed.), Implementing evaluation systems and processes (pp. 285-304). Alexandria, VA: American Society for Training and Development.

McMahon, W. W. (2009). Higher learning, greater good: The private and social benefits of higher education. Baltimore, MD: Johns Hopkins University Press.

Messman-Mandicott, E. M. (2012). The use of concept mapping pattern matching to determine the content domain for information literacy in baccalaureate education (Doctoral dissertation).Retrieved from http://hdl.handle.net/10450/13151

Michalski, G. V., \& Cousins, J. B. (2000). Differences in stakeholder perceptions about training evaluation: A concept mapping/pattern matching investigation. Evaluation and Program Planning, 23(2), 211-230.

Molina, A., \& Abelman, R. (2000). Style over substance in interventions for at-risk students: The impact of intrusiveness. NACADA Journal, 20(2), 5-15.

Mullendore, R. H., \& Banahan, L. A. (2005). Designing orientation programs. In M. L. Upcraft, J. N. Gardner \& B. O. Barefoot (Eds.), Challenging and supporting the first-year student: A handbook for improving the first year of college. (pp. 391-409). San Francisco, CA: JosseyBass.

NACADA. (2012). Concept of academic advising. Retrieved from http://www.nacada.ksu.edu/Resources/Clearinghouse/ViewArticle/Content\%20of\%20Academic\%20Advising-a698.aspx

National Survey of Student Engagement. (2013). The college student report. Retrieved from http://nsse.iub.edu/nsse-update/ 
Newton, F. B., \& Ender, S. C. (2010). Students helping students: A guide for peer educators on college campuses (2nd ed.). San Francisco, CA: Jossey-Bass.

Noel, L., \& Levitz, R. (1995). New strategies for difficult times. Recruitment \& Retention in Higher Education, 9(7), 4-7.

Noel, L., Levitz, R., \& Saluri, D. (1985). In Noel L., Levitz R. and Saluri D. (Eds.), Increasing student retention: New challenges and potential. San Francisco, CA: Jossey-Bass.

Noel-Levitz. (2011). 2011 mid-year student retention indicators report. Retrieved from https://www.noellevitz.com/papers-research-higher-education/2011/2011-mid-year-studentretention-indicators-report

Novak, J. D. (1990). Concept maps and vee diagrams: Two metacognitive tools to facilitate meaningful learning. Instructional Science, 19(1), 29-52.

Novak, J. D., \& Gowin, D. B. (1984). Learning how to learn. Cambridge, England: Cambridge University Press.

Novak, J. D., \& Cañas, A. J. (2008). The theory underlying concept maps and how to construct and use them. Florida Institute for Human and Machine Cognition. Pensacola FL. Retrieved from http://cmap.ihmc.us/docs/theory-of-concept-maps

Obama, B. (2009, February 24). Address to joint session of congress. Retrieved from http://www.whitehouse.gov/the_press_office/Remarks-of-President-Barack-ObamaAddress-to-Joint-Session-of-Congress

O'Banion, T. (1972). An academic advising model. Junior College Journal, 42(6), 62-64, \& 6669. 
Padgett, R., \& Keup, J. (2011). 2009 national survey of first-year seminars: Ongoing efforts to support students in transition. Columbia, SC: University of South Carolina, National Resource Center for The First-Year Experience and Students in Transition.

Parks, S. D. (1986). The critical years: Young adults and the search for meaning, faith, and commitment. New York, NY: HarperCollins.

Parks, S. D. (2000). Big questions, worthy dreams: Mentoring young adults in their search for meaning, purpose, and faith. San Francisco, CA: Jossey-Bass.

Pascarella, E. T. (1985). College environmental influences on learning and cognitive development: A critical review and synthesis. In J. Smart (Ed.), Higher education: Handbook of theory and research. vol. 1 (pp. 1-64). New York, NY: Agathon.

Pascarella, E. T. (2005). Cognitive impacts of the first year of college. In R. S. Feldman (Ed.), Improving the first year of college: Research and practice (pp. 111-140). Mahwah, NJ: Laurence Erlbaum Associates, Inc.

Pascarella, E. T., \& Terenzini, P. T. (1991). How college affects students: Findings and insights from twenty years of research. San Francisco, CA: Jossey-Bass Publishers.

Pascarella, E. T., \& Terenzini, P. T. (2005). How college affects students: A third decade of research. volume 2 Jossey-Bass, An Imprint of Wiley.

Patton, M. Q. (2002). Qualitative research \& evaluation methods (3rd ed.). Thousand Oaks, CA: Sage Publication, Inc.

Perry, W. G., Jr. (1968). Forms of intellectual and ethical development in the college years: A scheme. New York, NY: Holt, Rinehart, \& Winston. 
Picciano, A. G. (2006). Data-driven decision making for effective school leadership. Upper Saddle River, N.J.: Pearson Education. Retrieved from http://www.loc.gov/catdir/toc/ecip0515/2005019466.html

Potts, G., \& Schultz, B. (2008). The freshman seminar and academic success of at-risk students. College Student Journal, 42(2), 647-658. Retrieved from http://search.ebscohost.com/login.aspx?direct=true \&db=s3h\&AN=32544901\&site=ehostlive

Reason, R. D., Terenzini, P. T., \& Domingo, R. J. (2006). First things first: Developing academic competence in the first year of college. Research in Higher Education, 47(2), 149-175.

Reindl, T., \& Reyna, R. (2011). From information to action: Revamping higher education accountability systems. Washington, DC: National Governors Association. Retrieved from http://files.eric.ed.gov/fulltext/ED522081.pdf

Rendon, L. I. (1994). Validating culturally diverse students: Toward a new model of learning and student development. Innovative Higher Education, 19(1), 33-51.

Reyna, R., Reindl, T., Witham, K. \& Stanley, J. (2010). Common college completion metrics technical guide. Washington, DC: National Governors Association. Retrieved from http://files.eric.ed.gov/fulltext/ED516183.pdf

Rico, G. L. (1983). Writing the natural way: Using right-brain techniques to release your expressive powers. Los Angeles, CA: J.P. Tarcher.

Rosas, S. R. (2012). The utility of concept mapping for actualizing participatory research. Cuadernos Hispanoamericanos De Psicologia, 12(2), 7-24.

Rosas, S. R., \& Kane, M. (2012). Quality and rigor of the concept mapping methodology: A pooled study analysis. Evaluation and Program Planning, 35(2), 236-245. 
Royal, K. D. (2010). Evaluating faculty perceptions of student learning outcomes: A Rasch measurement analysis. Journal of MultiDisciplinary Evaluation, 6(14), 18-31

Sanford, N. (1966). Self and society. New York, NY: Atherton Press.

Schlossberg, N. K. (1984). Counseling adults in transition. New York, NY: Springer.

Schlossberg, N. K. (1989). Marginality and mattering: Key issues in building community. In D. C. Roberts (Ed.), Designing campus activities to foster a sense of community (pp. 5-15). New Directions for Student Services, No. 48. San Francisco, CA: Jossey-Bass.

Schneider, C. G. (2008). Introduction. In G.D. Kuh (Ed.), High-impact educational practices: What they are, who has access to them, and why they matter (pp.1-3). Washington, DC: Association of American Colleges and Universities

Schnell, C. A., \& Doetkott, C. D. (2003). First year seminars produce long-term impact. Journal of College Student Retention: Research, Theory and Practice, 4(4), 377-391.

Schroeder, C. (2003). How are we doing at engaging students? Charles Schroeder talks to George Kuh. About Campus, 8(1), 1-32.

Schuh, J. H. (2005). Assessing programs and other student experiences designed to enrich the first-year experience. In R. S. Feldman (Ed.), Improving the first year of college: Research and practice (pp. 141-157). Mahwah, NJ: Laurence Erlbaum Associates, Inc.

Schultz, T. W. (1971). Investment in human capital: The role of education and of research Free Press New York, NY.

Sharma, Y. (2010). Never mind quality as universities expand. OECD Observer, (281), 34-35. Retrieved from http://search.ebscohost.com/login.aspx?direct=true \&db=buh\&AN=60907432\&site=ehostlive 
Smith, J. S., \& Wertlieb, E. C. (2005). Do first-year college students' expectations align with their first-year experiences? Journal of Student Affairs Research and Practice, 42(2), 153174.

Stage, F. K. (1996). College students: The evolving nature of research. Needham Heights, MA: Simon \& Schuster.

Suskie, L. A. (2009). Assessing student learning: A common sense guide (2nd ed.). San Francisco, CA: Jossey-Bass.

Sweetland, S. R. (1996). Human capital theory: Foundations of a field of inquiry. Review of Educational Research, 66(3), 341-359.

Swing, R. L. (2002). Series of essays on the first-year initiative benchmarking study. Retrieved from http://tech.sa.sc.edu/fye/resources/assessment/essays/FYA_Essays_view.php?editid1=41

Swing, R. L. (2004). The improved learning outcomes of linked versus stand-alone first-year seminars. Integrating the first-year experience: The role of first-year seminars in learning communities (pp. 9-17). Columbia, SC: National Resource Center for the First-Year Experience and Students in Transition.

Taylor, P., Parker, K., Fry, R., Cohn, D., Wang, W., Velasco, G. \& Dockterman, D. (2011). Is college worth it? College presidents, public assess value, quality and mission of higher education. Retrieved from http://pewsocialtrends.org/files/2011/05/higher-ed-report.pdf Terenzini, P. T., Rendon, L., Upcraft, M. L., Millar, S., Allison, K., Gregg, P., \& Jalomo, R. (1996). The transition to college: Diverse students, diverse stories. In F. K. Stage, G. Anya, J. Bean, D. Hossler \& G. Kuh (Eds.), College students: The evolving nature of research (pp. 54-79). Needham Heights, MA: Ginn Press. 
Tinto, V. (1975). Dropout from higher education: A theoretical synthesis of recent research. Review of Educational Research, 45(1), 89-125.

Tinto, V. (1987). Leaving college: Rethinking the causes and cures of student attrition. Chicago, IL: University of Chicago Press.

Tinto, V. (1993). Leaving college: Rethinking the causes and cures of student attrition (2nd ed.). Chicago, IL: University of Chicago Press.

Tinto, V. (2012). Completing college: Rethinking institutional action. Chicago, IL: The University of Chicago Press.

Tobolowsky, B. F., \& Associates. (2008). 2006 national survey of first-year seminars: Continuing innovations in the collegiate curriculum. Columbia, SC: University of South Carolina, National Resource Center for The First-Year Experience and Students in Transition.

Trochim, W. M. K. (1985). Pattern matching, validity, and conceptualization in program evaluation. Evaluation Review, 9(5), 575.

Trochim, W. M. K. (1989a). An introduction to concept mapping for planning and evaluation. Evaluation and Program Planning, 12(1), 1-16.

Trochim, W. M. K. (1989b). Concept mapping - soft science or hard art. Evaluation and Program Planning, 12(1), 87-110.

Trochim, W. M. K. (1996a). Criteria for evaluating graduate programs in evaluation. Evaluation News and Comment: The Magazine of the Australasian Evaluation Society, 5(2), 54-57.

Trochim, W. M. K. (1996b). An Internet-Based Concept Mapping of Accreditation Standards for Evaluation. Retrieved from http://www.socialresearchmethods.net/research/AEAaccr/AEAaccr.htm 
Trochim, W. M. K., \& Linton, R. (1986). Conceptualization for planning and evaluation. Evaluation and Program Planning, 9(4), 289-308.

Trochim, W. M. K., Stillman, F. A., Clark, P. I., \& Schmitt, C. L. (2003). Development of a model of the tobacco industry's interference with tobacco control programmes. Tobacco Control, (12), 140-147.

U.S. Department of Education. (2011, March 18). Meeting the nation's 2020 goal: State targets for increasing the number and percentage of college graduates with degrees. Retrieved from http://www2.ed.gov/policy/highered/guid/secletter/110323insert.pdf

Upcraft, M. L., Gardner, J. N., \& Barefoot, B. O. (Eds.). (2005). Challenging and supporting the first-year student: A handbook for improving the first year of college. San Francisco, CA: Jossey-Bass.

Upcraft, M. L., \& Crissman, J. L. (1999). What we know about students and how they learn. In M. S. Hunter, \& T. L. Skipper (Eds.), Solid foundations: Building success for first-year seminars through instructor training and development [Monograph No. 29]) (pp. 25-37). Columbia, SC: University of South Carolina, National Resource Center for the First-Year Experience and Students in Transition.

Valdes-Vasquez, R., \& Klotz, L. (2013). Using the concept-mapping method for empirical studies in construction research. Journal of Construction Engineering and Management, 139(10),

Walvoord, B. E. (2004). Assessment clear and simple: A practical guide for institutions, departments, and general education (1st ed.). San Francisco, CA: Jossey-Bass.

Weisbrod, B. A., Ballou, J. P., \& Asch, E. D. (2008). Mission and money: Understanding the university. New York, NY: Cambridge University Press. 


\section{Appendices}

\section{Appendix A: First Year Focus - Foundational Dimensions ${ }^{\circledR}$}

(Four-Year College Version)

Foundational Dimensions statements constitute a model that provides institutions with a means to evaluate and improve the first year of college. As an evaluation tool, the model enables institutions both to confirm their strengths and to recognize the need for improvement. As an aspirational model, the Dimensions provide general guidelines for an intentional design of the first year. The Dimensions rest on four assumptions:

- The academic mission of an institution is preeminent;

- The first college year is central to the achievement of an institution's mission and lays the foundation on which undergraduate education is built;

- Systematic evidence provides validation of the Dimensions;

- Collectively, the Dimensions constitute an ideal for improving not only the first college year, but also the entire undergraduate experience.

Foundations Institutions approach the first year in ways that are intentional and based on a philosophy/rationale of the first year that informs relevant institutional policies and practices. The philosophy/rationale is explicit, clear and easily understood, consistent with the institutional mission, widely disseminated, and, as appropriate, reflects a consensus of campus constituencies. The philosophy/rationale is also the basis for first-year organizational policies, practices, structures, leadership, department/unit philosophies, and resource allocation.

(Philosophy)

Foundations Institutions create organizational structures and policies that provide a comprehensive, integrated, and coordinated approach to the first year. These structures and 
policies provide oversight and alignment of all first-year efforts. A coherent first-year experience is realized and maintained through effective partnerships among academic affairs, student affairs, and other administrative units and is enhanced by ongoing faculty and staff development activities and appropriate budgetary arrangements. (Organization)

Foundations Institutions deliver intentional curricular and co-curricular learning experiences that engage students in order to develop knowledge, skills, attitudes, and behaviors consistent with the desired outcomes of higher education and the institution's philosophy and mission. Whether in or out of the classroom, learning also promotes increased competence in critical thinking, ethical development, and the lifelong pursuit of knowledge.

\section{(Learning)}

Foundations Institutions make the first college year a high priority for the faculty. These institutions are characterized by a culture of faculty responsibility for the first year that is realized through high-quality instruction in first-year classes and substantial interaction between faculty and first-year students both inside and outside the classroom. This culture of responsibility is nurtured by chief academic officers, deans, and department chairs and supported by the institutions' reward systems. (Faculty)

Foundations Institutions facilitate appropriate student transitions through policies and practices that are intentional and aligned with institutional mission. Beginning with recruitment and admissions and continuing through the first year, institutions communicate clear curricular and co- curricular expectations and provide appropriate support for educational success. They are forthright about their responsibilities to students as well as students' responsibilities to themselves and the institution. They create and maintain curricular alignments 
with secondary schools and linkages with secondary school personnel, families, and other sources of support, as appropriate. (Transitions)

Foundations Institutions serve all first-year students according to their varied needs. The process of anticipating, diagnosing, and addressing needs is ongoing and is subject to assessment and adjustment throughout the first year. Institutions provide services with respect for the students' abilities, backgrounds, interests, and experiences. Institutions also ensure a campus environment that is inclusive and safe for all students. (All Students)

Foundations Institutions ensure that all first-year students experience diverse ideas, worldviews, and cultures as a means of enhancing their learning and preparing them to become members of pluralistic communities. Whatever their demographic composition, institutions structure experiences in which students interact in an open and civil community with people from backgrounds and cultures different from their own, reflect on ideas and values different from those they currently hold, and explore their own cultures and the cultures of others. (Diversity)

Foundations Institutions promote student understanding of the various roles and purposes of higher education, both for the individual and society. These roles and purposes include knowledge acquisition for personal growth, learning to prepare for future employment, learning to become engaged citizens, and learning to serve the public good. Institutions encourage firstyear students to examine systematically their motivation and goals with regard to higher education in general and to their own college/university. Students are exposed to the value of general education as well as to the value of more focused, in-depth study of a field or fields of knowledge (i.e., the major). (Roles and Purposes) 


\section{Foundations Institutions conduct assessment and maintain associations with other} institutions and relevant professional organizations in order to achieve ongoing first-year improvement. This assessment is specific to the first year as a unit of analysis - a distinct time period and set of experiences, academic and otherwise, in the lives of students. It is also linked systemically to the institutions' overall assessment. Assessment results are an integral part of institutional planning, resource allocation, decision making, and ongoing improvement of programs and policies as they affect first-year students. As part of the enhancement process and as a way to achieve ongoing improvement, institutions are familiar with current practices at other institutions as well as with research and scholarship on the first college year. (Improvement)

The Foundational Dimensions were developed by John N. Gardner, Betsy O. Barefoot, Stephen W. Schwartz, Michael J. Siegel, and Randy L. Swing of the Gardner Institute in collaboration with Robert R. Reason, Patrick T. Terenzini, Edward Zlotkowski, and 235 colleges and universities. The following campuses provided national leadership in the inaugural use of the Dimensions: Augsburg College, Aurora University, CUNY - Brooklyn College, CUNY - Medgar Evers College, Chadron State College, Columbia College, Endicott College, Franklin Pierce College, Georgia Southwestern State University, Illinois State University, Indiana UniversityPurdue University Indianapolis, Indiana Wesleyan University, Kennesaw State University, Madonna University, Maryville College, Marywood University, Missouri Western State University, Nazareth College of Rochester, Plymouth State University, Saint Edward's University, SUNY - Brockport, Texas A\&M University - Corpus Christi, University of Charleston, and University of Wisconsin-Parkside.

(C2005 John N. Gardner Institute for Excellence in Undergraduate Education 


\section{Terms \& Conditions}

General Use of the Foundational Dimensions ${ }^{\circledR}$ and Foundations of Excellence ${ }^{\circledR}$ Self Study

\section{Programs}

The Foundational Dimensions were originally developed by the Policy Center on the First Year of College (now Gardner Institute) in collaboration with its research partners and over 300 public and private four-year and two-year institutions. The Dimensions are the trademarked intellectual property of the Gardner Institute. Together the Dimensions constitute an aspirational and measurement model for the first-year and transfer-student experience. We hope that institutions will find them useful as they consider the design of an educationally purposeful experience for first-year and/or transfer students. To that end, campuses are encouraged to copy the Dimensions for internal use. This copyright permission does not extend to other kinds of copying, such as copying for general distribution, for advertising or promotional purposes, for creating new publications, or for resale.

Please note that a public claim to conducting a Foundations of Excellence self study can only be made by campuses that have obtained a license to use the various templates, reporting documents, and processes that are designed to facilitate use of the Foundational Dimensions as an aspirational and measurement model.

If you have questions about these terms and conditions, contact the Gardner Institute at $\underline{\text { info@jngi.org or (828) 233-5874. }}$ 


\title{
Appendix B: IRB Cover Letter
}

\section{West VirginiaUniversity \\ College of Education and Human Services}

\begin{abstract}
September 15, 2014
Dear Participant:

This letter is a request that you participate in a research project which aims to conceptualize the desired domain of student learning outcomes in the first year of college. The study will be conducted by Jacob $B$. Sanwidi, MA, a doctoral candidate in the Higher Education Administration program at WVU, under the direction of Dr. Elizabeth A. Dooley, Ed.D., a Professor of Special Education and Curriculum \& Instruction in the College of Education and Human Services at WVU.
\end{abstract}

You will be asked to join other stakeholders of a first-year student success program and complete these tasks: generate and compile a common list of statements during a brainstorming session, individually sort the statements into labelled piles, and subsequently rate the statements online via Qualtrics. The brainstorming and sorting session will take approximately three hours. Given the anticipated length of the session, snacks and refreshments will be offered.

To generate the statements, you will be asked to respond to the following focus prompt: What knowledge, skills, and attitudes should students gain as a result of participating in the success program? The rating of statements will follow this scheme: 1) Please rate the relative importance of each item for ensuring the success of students in the first year of college. (Extremely important; Very important; Important; Somewhat Important; Not at all important). 2) For each item, please evaluate the overall efficacy of your institution in helping students achieve that desired learning element. (Excellent; Good; Average; Fair; Poor).

The process will lead to the development of concept maps representing the desired student learning elements articulated by participants. The findings may serve as a framework to assess and improve similar programs as well as develop new ones to enhance student success. The results will also be explored to determine the extent to which they align with the Foundational Dimensions, a set of nine aspirational principles of excellence for evaluating and improving the First-Year Experience.

Your involvement in this project will be kept as confidential as legally possible. As the researcher, I will guarantee confidentiality on my part, but I cannot guarantee that confidentiality will be maintained by participants after the session. In any publications that result from this research, neither your name nor any information from which you might be identified will be published without your consent. Participation in this study is voluntary. You are free to withdraw your consent to participate in this study at any time. Refusal to participate or withdrawal will not affect your class standing, grades, or employment status. You must be 18 years of age or older to participate.

Any questions or concerns should be directed to Dr. Elizabeth A. Dooley, at (304) 293-2641, Elizabeth.Dooley@mail.wvu.edu or Jacob B. Sanwidi at (304) 293-5939, Jacob.Sanwidi@mail.wvu.edu .

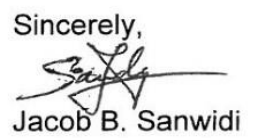

Jacob B. Sanwidi

DEPARTMENT OF CURRICULUM \& INSTRUCTION/LITERACY STUDIES SOCIAL AND CULTURAL FOUNDATIONS

P. O. Box 6122

Morgantown, WV 26506-6122

304-293-3441 Fax (304) 293-3802 


\title{
Appendix C: IRB Recruitment Script
}

\author{
West VirginiaUniversity \\ College of Education and Human Services
}

Dear Participant:

My name is Jacob B. Sanwidi, a Program Coordinator / Academic Intervention Specialist in the University College at West Virginia University. For my doctoral dissertation research, I work under the direction of Dr. Elizabeth A. Dooley in the Department of Curriculum and Instruction/Literacy Studies in the College of Education and Human Services at West Virginia University. The purpose of my research study is to conceptualize the desired domain of student learning in the first year of college using the Concept Mapping/Pattern Matching research methodology.

I am recruiting subjects to participate in a brainstorming session during which, they will be asked to join other stakeholders of a first-year student success program to complete a series of tasks: generate and compile a common list of statements by responding to a focus prompt, individually sort the statements into labelled piles, and subsequently rate the statements online via Qualtrics. The brainstorming and sorting session will take approximately three hours to complete. Given the anticipated length of the session, snacks and refreshments will be offered.

You are invited to participate in this study, either because of your past experience as a first-year college student, or because of your experience as a faculty or staff member working with this student population.

Participation in this study is voluntary. You are free to withdraw your consent to participate in this study at any time. Refusal to participate or withdrawal will not affect your class standing, grades, or employment status. You must be 18 years of age or older to participate. The results of the research may be published, but your name will not be revealed.

Any questions or concerns should be directed to Dr. Elizabeth A. Dooley, at (304) 293-2641, Elizabeth.Dooley@mail.wvu.edu or Jacob B. Sanwidi at (304) 293-5939, Jacob.Sanwidi@mail.wvu.edu.WVU's IRB approval of this study is on file.

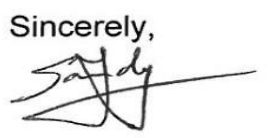

Jacob B. Sanwidi

DEPARTMENT OF CURRICULUM \& INSTRUCTION/LITERACY STUDIES SOCIAL AND CULTURAL FOUNDATIONS

P. O. Box 6122

Morgantown, WV 26506-6122

304-293-3441 Fax (304) 293-3802 


\section{Appendix D: List of Statements Generated by Key Stakeholders at the Reference University Using Concept Mapping/Pattern Matching}

1. Students should be able to know their priorities.

2. Students should take responsibility for individual learning.

3. Students should get to know the different buildings for each college around campus.

4. Student should begin to learn what they are interested in.

5. Students should become more social and be more comfortable talking with people.

6. Students should be aware of available resources early in their college career.

7. Students should have an opportunity to meet new people right off the bat and make new friends.

8. Students should take opportunities to stand out and be unique.

9. Students should become more confident about their academic abilities.

10. Students should be able to create a success plan for college and career.

11. Students should take tours of the campus - to learn about their environment.

12. Students should have enough time during the summer bridge program to figure out their surroundings.

13. Students should be determined to find the career path they want to follow.

14. Students should be able to know where to go for help after their first year.

15. Students should have additional support staff to turn to for help.

16. Students should know how to use the technology used by the University - e.g., software \& devices.

17. Students should have success coaches to help them.

18. Students should have success coaches who can refer them to specific student success workshops.

19. Students should feel more prepared to decide on a major and not constantly be changing their minds.

20. Students should establish a core support group.

21. Students should have opportunities in class early in the semester to find out what their interests are to help them choose a major.

22. Students should be able to build positive habits to help them become more successful as college students.

23. Students in the summer bridge program should get to meet more faculty members and become better friends with faculty than other freshmen are.

24. Students should have opportunities to have one-on-one interactions with members of different colleges (e.g., recruiters and advisors).

25. Students should know what major they want by the end of their first year.

26. Students should manage their time by prioritizing what they need to accomplish.

27. Students should know how to keep themselves on a schedule to graduate on time.

28. Students should know how to make and keep relationships (friendships, connections, networking) with people throughout all of college.

29. Students should gain familiarity with the campus, all the colleges at the university, and in general, college life.

30. Students should know where to go for help so they never feel lost.

31. Students should become responsible for themselves completely - particularly in finding their majors. 
32. Students should want to reach out to others instead of expecting others to come to them.

33. If students are offered an opportunity to participate in a success program, they should take advantage of it.

34. Students should be able to help other students and point them to resources.

35. Students should have a good understanding of the opportunities available to them - such as extra things like trips.

36. Students should be open to developing a "Plan B." Meaning that if you are not accepted into your original major - or you change your mind, you have something else to move into.

37. By the end of the first year, students should feel confident in talking to instructors and people they look up to or who are in authority.

38. Students should find out about student organizations so they can find others with common interests.

39. Students should get involved and take advantage of opportunities provided to them.

40. Students should be able to develop academic maturity.

41. Students should know how to write a proper email to higher authority.

42. Students should not be scared to take on academic challenges.

43. Students should begin to learn what major they might be interested in.

44. Students should know where to go if they need academic help.

45. Students should have a better feel for not just for their university but for the whole state as well.

46. Students should know where to go if they need counseling services.

47. Students should know where to go if they need career guidance and career services (e.g., resume building \& interviewing skill development).

48. Students should have confidence by the end of the year in terms of adjusting to college, being aware of resources, and asking for help.

49. Students should have school pride.

50. Students should take responsibility for their actions.

51. Students should feel that staff are truly there to help them and are not just "collecting a paycheck."

52. Students should feel prepared to schedule classes.

53. Students should know how to contact their academic advisors to make advising appointments.

54. Students should be prepared to challenge their professors.

55. Students should know how to sing their school song.

56. Students should know how to prioritize better.

57. Students should know their professors' expectations.

58. Students should know how to read the syllabus.

59. Students should know to check their email.

60. Students should know how to handle themselves in a professional setting.

61. Students should know their community better - especially their local community - through service projects.

62. Students should know what success looks like by the end of their first year because they should have experienced some form of success by the end of their first year.

63. Students should learn from their mistakes (academic or personal) and be able to move forward. 
64. Students in the summer bridge program should have an idea of what is expected of them before they start their fall courses.

65. Students should have a better understanding of the history of campus buildings and the campus in general.

66. Students should be more well-rounded in the sense that they have all the tools and skills necessary to be self-sufficient.

67. Students should want to stay at their institution at the end of their first year.

68. Students in the summer bridge program should feel like they have a leg up or a head start compared to students who start later.

69. Students should be able to stay positive despite academic setbacks.

70. Students should be prepared for anything that is thrown their way - opportunities and adverse events.

71. Students should show confidence when dealing with people in positions of authority.

72. Students should try enjoying clubs and/or fraternities or sororities.

73. Students should know they have to find a job after college.

74. Students should set their own goals.

75. Students should be able to develop from a dependent person to an independent person.

76. Students should be aware of the competition to get into some majors.

77. Students should participate in research sessions.

78. Students should know how to embrace different cultures.

79. Students should know how to handle adversity, for example, tough times and challenges.

80. Students should do the best they can based on their own abilities - and not compare themselves to others.

81. Students should know how to present themselves professionally, for example, wearing proper attire.

82. Students should know how to present themselves professionally - for example, using proper body language.

83. Students should know how to self-advocate - and not be afraid to ask questions.

84. Students should know how to set realistic goals.

85. Students should make decisions to make themselves happy rather than making decisions to make other people happy.

86. Students should discover and then build their skills.

87. Students should learn how to negotiate and communicate.

88. Students should know it is difficult to go through college alone.

89. Students should know it is important to have friends - a social support system - to help them through college both in terms of academics and socializing.

90. Students should know to take advantage of opportunities (such as internships) related to possible majors.

91. Students should know it is important to realize they are not alone - they have friends, professors, support staff, etc.

92. Students should develop strategies to help themselves to de-stress.

93. Students should follow a four-year plan when preparing for their careers.

94. Students should know not to be over-competitive and be able to accept a setback such as someone else getting a position they wanted.

95. Students should be exposed to different programs, presentations, and environments to help them decide on their ultimate major. 
96. Students should know what they have to do to be desirable to employers.

97. Students should know how to make themselves distinct.

98. Students should be able to learn the value of critical thinking.

99. Students should try new things to open themselves up to new experiences.

100. Students should learn how to keep themselves healthy. 


\section{Appendix E: List of 100 Outcomes Formatted for the Importance and Efficacy Rating Using Qualtrics}

Importance Rating

Q1.

Four weeks ago, you took part in a brainstorming session during which you met with a group of other stakeholders at your institution and generated 100 statements in response to the following focus prompt: "What knowledge, skills, and attitudes should students gain as a result of participating in the success program?"

Within the last four weeks, you individually sorted the statements into several groups based on your own criteria.

The final step in the data collection process consists in rating the statements. Please follow the steps provided thereafter to indicate your ratings of each item.

Q2. Please rate the relative importance of each item for ensuring the success of students in the first year of college

llot at all Somewhat Very Extremely

Students should be able to know their priorities

Students should take responsibility for individual learning

Students should get to know the different buildings for each college around campus

Student should begin to learn what they are interested in

Students should become more social and be more comfortable talking with people

Students should be aware of available resources early in their college career

Students should have an opportunity to meet new people right off the bat and make new friends

Students should take opportunities to stand out and be unique

Students should become more confident about their academic abilities

Students should be able to create a success plan for college and career

Students should take tours of the campus - to learn about their environment

Students should have enough time during the summer bridge program to figure out their surroundings Students should be determined to find the career path they want to follow Students should be able to know where to go for help after their first year Students should have additional support staff to turn to for help

Students should know how to use the technology used by the University - e.g., software \& devices

Students should have success coaches to help them

Students should have success coaches who can refer them to specific student success workshops Students should feel more prepared to decide on a major and not constantly be changing their minds

Students should establish a core support group

Students should have opportunities in class early in the semester to find out what their interests are to help them choose a major

Students should be able to build positive habits to help them become more successful as college students

Students in the summer bridge program should get to meet more faculty members and become bette friends with faculty than other freshmen are

Students should have opportunities to have one-on-one interactions with members of different colleges (e.g., recruiters and advisors)

Students should know what major they want by the end of their first year

Students should manage their time by prioritizing what they need to accomplish

Students should know how to keep themselves on a schedule to graduate on time

Students should know how to make and keep relationships (friendships, connections, networking) with people throughout all of college

Students should gain familiarity with the campus, all the colleges at the university, and in general, college life

Students should know where to go for help so they never feel lost

Important Important Important Important Important


Students should become responsible for themselves completely - particularly in finding their majors

Students should want to reach out to others instead of expecting others to come to them

If students are offered an opportunity to participate in a success program, they should take advantage of it

Students should be able to help other students and point them to resources

Students should have a good understanding of the opportunities available to them - such as extra things like trips

Students should be open to developing a "Plan B." Meaning that if you are not accepted into your original major - or you change your mind, you have something else to move into

By the end of the first year, students should feel confident in talking to instructors and people they look up to or who are in authority

Students should find out about student organizations so they can find others with common interests

Students should get involved and take advantage of opportunities provided to them

Students should be able to develop academic maturity

Students should know how to write a proper email to higher authority

Students should not be scared to take on academic challenges

Students should begin to learn what major they might be interested in

Students should know where to go if they need academic help

Students should have a better feel for not just for their university but for the whole state as well

Students should know where to go if they need counseling services

Students should know where to go if they need career guidance and career services (e.g., resume building \& interviewing skill development)

Students should have confidence by the end of the year in terms of adjusting to college, being aware of resources, and asking for help

Students should have school pride

Students should take responsibility for their actions

Students should feel that staff are truly there to help them and are not just "collecting a paycheck"

Students should feel prepared to schedule classes

Students should know how to contact their academic advisors to make advising appointments

Students should be prepared to challenge their professors

Students should know how to sing their school song

Students should know how to prioritize better

Students should know their professors' expectations

Students should know how to read the syllabus

Students should know to check their email

Students should know how to handle themselves in a professional setting

Students should know their community better - especially their local community - through service projects Students should know what success looks like because they should have experienced some form of success by the end of their first year

Students should learn from their mistakes (academic or personal) and be able to move forward

Students in the summer bridge program should have an idea of what is expected of them before they start their fall courses

Students should have a better understanding of the history of campus buildings and the campus in general

Students should be more well-rounded in the sense that they have all the tools and skills necessary to be self-sufficient

Students should want to stay at their institution at the end of their first year

Students in the summer bridge program should feel like they have a leg up or a head start compared to students who start later

Students should be able to stay positive despite academic setbacks

Students should be prepared for anything that is thrown their way - opportunities and adverse events

Students should show confidence when dealing with people in positions of authority

Students should try enjoying clubs and/or fraternities or sororities

Students should know they have to find a job after college

Students should set their own goals

Students should be able to develop from a dependent person to an independent person

\begin{tabular}{|c|c|c|c|c|}
\hline 0 & 0 & 0 & $\bigcirc$ & 0 \\
\hline 0 & 0 & 0 & 0 & 0 \\
\hline 0 & 0 & 0 & 0 & 0 \\
\hline 0 & 0 & 0 & 0 & 0 \\
\hline 0 & 0 & 0 & 0 & 0 \\
\hline 0 & 0 & 0 & 0 & 0 \\
\hline 0 & 0 & 0 & 0 & $\bigcirc$ \\
\hline 0 & 0 & 0 & 0 & 0 \\
\hline 0 & 0 & 0 & 0 & 0 \\
\hline 0 & 0 & 0 & 0 & 0 \\
\hline $\begin{array}{l}\text { Ilot at all } \\
\text { Important }\end{array}$ & $\begin{array}{l}\text { Somewhat } \\
\text { Important }\end{array}$ & Important & $\begin{array}{c}\text { Very } \\
\text { Important }\end{array}$ & $\begin{array}{l}\text { Extremely } \\
\text { Important }\end{array}$ \\
\hline 0 & 0 & 0 & 0 & 0 \\
\hline 0 & 0 & 0 & 0 & 0 \\
\hline 0 & 0 & 0 & 0 & 0 \\
\hline 0 & 0 & 0 & 0 & 0 \\
\hline 0 & 0 & 0 & 0 & 0 \\
\hline 0 & 0 & 0 & 0 & 0 \\
\hline 0 & 0 & $\bigcirc$ & $\bigcirc$ & 0 \\
\hline$\bigcirc$ & 0 & 0 & 0 & 0 \\
\hline 0 & 0 & 0 & $\bigcirc$ & 0 \\
\hline 0 & 0 & 0 & 0 & 0 \\
\hline $\begin{array}{l}\text { Not at all } \\
\text { Important }\end{array}$ & $\begin{array}{l}\text { Somewhat } \\
\text { Important }\end{array}$ & Important & $\begin{array}{c}\text { Very } \\
\text { Important }\end{array}$ & $\begin{array}{l}\text { Extremely } \\
\text { Important }\end{array}$ \\
\hline 0 & 0 & 0 & 0 & 0 \\
\hline 0 & 0 & 0 & 0 & 0 \\
\hline 0 & 0 & 0 & 0 & 0 \\
\hline 0 & 0 & 0 & $\bigcirc$ & 0 \\
\hline 0 & 0 & 0 & $\bigcirc$ & 0 \\
\hline 0 & 0 & 0 & 0 & 0 \\
\hline 0 & 0 & 0 & 0 & 0 \\
\hline 0 & 0 & 0 & $\bigcirc$ & 0 \\
\hline 0 & 0 & 0 & $\bigcirc$ & 0 \\
\hline 0 & 0 & $\bigcirc$ & 0 & 0 \\
\hline $\begin{array}{l}\text { Not at all } \\
\text { Important }\end{array}$ & $\begin{array}{l}\text { Somewhat } \\
\text { Important }\end{array}$ & Important & $\begin{array}{c}\text { Very } \\
\text { Important }\end{array}$ & $\begin{array}{l}\text { Extremely } \\
\text { Important }\end{array}$ \\
\hline 0 & 0 & 0 & 0 & $\bigcirc$ \\
\hline 0 & 0 & 0 & 0 & 0 \\
\hline 0 & 0 & 0 & 0 & 0 \\
\hline 0 & 0 & 0 & 0 & 0 \\
\hline 0 & 0 & $\bigcirc$ & $\bigcirc$ & 0 \\
\hline 0 & 0 & 0 & 0 & 0 \\
\hline$\bigcirc$ & 0 & 0 & $\bigcirc$ & 0 \\
\hline$\bigcirc$ & $\bigcirc$ & 0 & 0 & 0 \\
\hline$\bigcirc$ & 0 & 0 & 0 & 0 \\
\hline 0 & $\bigcirc$ & 0 & 0 & 0 \\
\hline $\begin{array}{l}\text { Not at all } \\
\text { Important }\end{array}$ & $\begin{array}{l}\text { Somewhat } \\
\text { Important }\end{array}$ & Important & $\begin{array}{c}\text { Very } \\
\text { Important }\end{array}$ & $\begin{array}{l}\text { Extremely } \\
\text { Important }\end{array}$ \\
\hline 0 & 0 & 0 & 0 & 0 \\
\hline 0 & 0 & 0 & $\bigcirc$ & 0 \\
\hline 0 & 0 & 0 & $\bigcirc$ & 0 \\
\hline 0 & 0 & 0 & 0 & 0 \\
\hline 0 & 0 & 0 & 0 & 0 \\
\hline
\end{tabular}


Students should be aware of the competition to get into some majors

Students should participate in research sessions

Students should know how to embrace different cultures

Students should know how to handle adversity, for example, tough times and challenges

Students should do the best they can based on their own abilities - and not compare themselves to others

Students should know how to present themselves professionally, for example, wearing proper attire Students should know how to present themselves professionally - for example, using proper body language Students should know how to self-advocate - and not be afraid to ask questions

Students should know how to set realistic goals

Students should make decisions to make themselves happy rather than making decisions to make other people happy

Students should discover and then build their skills

Students should learn how to negotiate and communicate

Students should know it is difficult to go through college alone

Students should know it is important to have friends - a social support system - to help them through college both in terms of academics and socializing

Students should know to take advantage of opportunities (such as internships) related to possible majors

Students should know it is important to realize they are not alone - they have friends, professors, support staff, etc.

Students should develop strategies to help themselves to de-stress

Students should follow a four-year plan when preparing for their careers

Students should know not to be over-competitive and be able to accept a setback such as someone else getting a position they wanted

Students should be exposed to different programs, presentations, and environments to help them decide on their ultimate major

Students should know what they have to do to be desirable to employers

Students should know how to make themselves distinct

Students should be able to learn the value of critical thinking

Students should try new things to open themselves up to new experiences

Students should learn how to keep themselves healthy

Ilot at all Somewhat

\section{Efficacy Rating}

Q3. In the first part of this rating task, you were asked to rate the relative importance of each item as it relates to student success in the first year of college. In this last part of the rating task, you are asked to evaluate the overall efficacy of your institution in helping students achieve each of the generated items.

Q4. For each item, please evaluate the overall efficacy of your institution in helping students achieve that desired learning element

Students should be able to know their priorities

Students should take responsibility for individual learning

Students should get to know the different buildings for each college around campus

Student should begin to learn what they are interested in

Students should become more social and be more comfortable talking with people

Students should be aware of available resources early in their college career

Students should have an opportunity to meet new people right off the bat and make new friends

Students should take opportunities to stand out and be unique

Students should become more confident about their academic abilities

Students should be able to create a success plan for college and career 
Students should take tours of the campus - to learn about their environment

Students should have enough time during the summer bridge program to figure out their surroundings

Students should be determined to find the career path they want to follow

Students should be able to know where to go for help after their first year

Students should have additional support staff to turn to for help

Students should know how to use the technology used by the University - e.g., software \& devices

Students should have success coaches to help them

Students should have success coaches who can refer them to specific student success workshops

Students should feel more prepared to decide on a major and not constantly be changing their minds

Students should establish a core support group

Students should have opportunities in class early in the semester to find out what their interests are to help them choose a major

Students should be able to build positive habits to help them become more successful as college students

Students in the summer bridge program should get to meet more faculty members and become better friends with faculty than other freshmen are

Students should have opportunities to have one-on-one interactions with members of different colleges (e.g., recruiters and advisors)

Students should know what major they want by the end of their first year

Students should manage their time by prioritizing what they need to accomplish

Students should know how to keep themselves on a schedule to graduate on time

Students should know how to make and keep relationships (friendships, connections, networking) with people throughout all of college

Students should gain familiarity with the campus, all the colleges at the university, and in general, college life

Students should know where to go for help so they never feel lost

Students should become responsible for themselves completely - particularly in finding their majors

Students should want to reach out to others instead of expecting others to come to them

If students are offered an opportunity to participate in a success program, they should take advantage of it Students should be able to help other students and point them to resources

Students should have a good understanding of the opportunities available to them - such as extra things like trips

Students should be open to developing a "Plan B." Meaning that if you are not accepted into your original major - or you change your mind, you have something else to move into

By the end of the first year, students should feel confident in talking to instructors and people they look up to or who are in authority

Students should find out about student organizations so they can find others with common interests

Students should get involved and take advantage of opportunities provided to them

Students should be able to develop academic maturity

Students should know how to write a proper email to higher authority

Students should not be scared to take on academic challenges

Students should begin to learn what major they might be interested in

Students should know where to go if they need academic help

Students should have a better feel for not just for their university but for the whole state as well

Students should know where to go if they need counseling services

Students should know where to go if they need career guidance and career services (e.g., resume building \& interviewing skill development)

Students should have confidence by the end of the year in terms of adjusting to college, being aware of resources, and asking for help

Students should have school pride

Students should take responsibility for their actions

Students should feel that staff are truly there to help them and are not just "collecting a paycheck"

Students should feel prepared to schedule classes

Students should know how to contact their academic advisors to make advising appointments

Students should be prepared to challenge their professors

Students should know how to sing their school song 
Students should know how to prioritize better

Students should know their professors' expectations

Students should know how to read the syllabus

Students should know to check their email

Students should know how to handle themselves in a professional setting

Students should know their community better - especially their local community - through service projects Students should know what success looks like because they should have experienced some form of success by the end of their first year

Students should learn from their mistakes (academic or personal) and be able to move forward

Students in the summer bridge program should have an idea of what is expected of them before they start their fall courses

Students should have a better understanding of the history of campus buildings and the campus in general Students should be more well-rounded in the sense that they have all the tools and skills necessary to be self-sufficient

Students should want to stay at their institution at the end of their first year

Students in the summer bridge program should feel like they have a leg up or a head start compared to students who start later

Students should be able to stay positive despite academic setbacks

Students should be prepared for anything that is thrown their way - opportunities and adverse events

Students should show confidence when dealing with people in positions of authority

Students should try enjoying clubs and/or fraternities or sororities

Students should know they have to find a job after college

Students should set their own goals

Students should be able to develop from a dependent person to an independent person

Students should be aware of the competition to get into some majors

Students should participate in research sessions

Students should know how to embrace different cultures

Students should know how to handle adversity, for example, tough times and challenges

Students should do the best they can based on their own abilities - and not compare themselves to others

Students should know how to present themselves professionally, for example, wearing proper attire Students should know how to present themselves professionally - for example, using proper body language Students should know how to self-advocate - and not be afraid to ask questions

Students should know how to set realistic goals

Students should make decisions to make themselves happy rather than making decisions to make other people happy

Students should discover and then build their skills

Students should learn how to negotiate and communicate

Students should know it is difficult to go through college alone

Students should know it is important to have friends - a social support system - to help them through college both in terms of academics and socializing

Students should know to take advantage of opportunities (such as internships) related to possible majors

Students should know it is important to realize they are not alone - they have friends, professors, support staff, etc.

Students should develop strategies to help themselves to de-stress

Students should follow a four-year plan when preparing for their careers

Students should know not to be over-competitive and be able to accept a setback such as someone else getting a position they wanted

Students should be exposed to different programs, presentations, and environments to help them decide on their ultimate major

Students should know what they have to do to be desirable to employers

Students should know how to make themselves distinct

Students should be able to learn the value of critical thinking

Students should try new things to open themselves up to new experiences

Students should learn how to keep themselves healthy 


\section{Appendix F: Dendrogram or Hierarchical Cluster Tree Derived from the Hierarchical Cluster Analysis Showing Cluster Membership for Each Item}

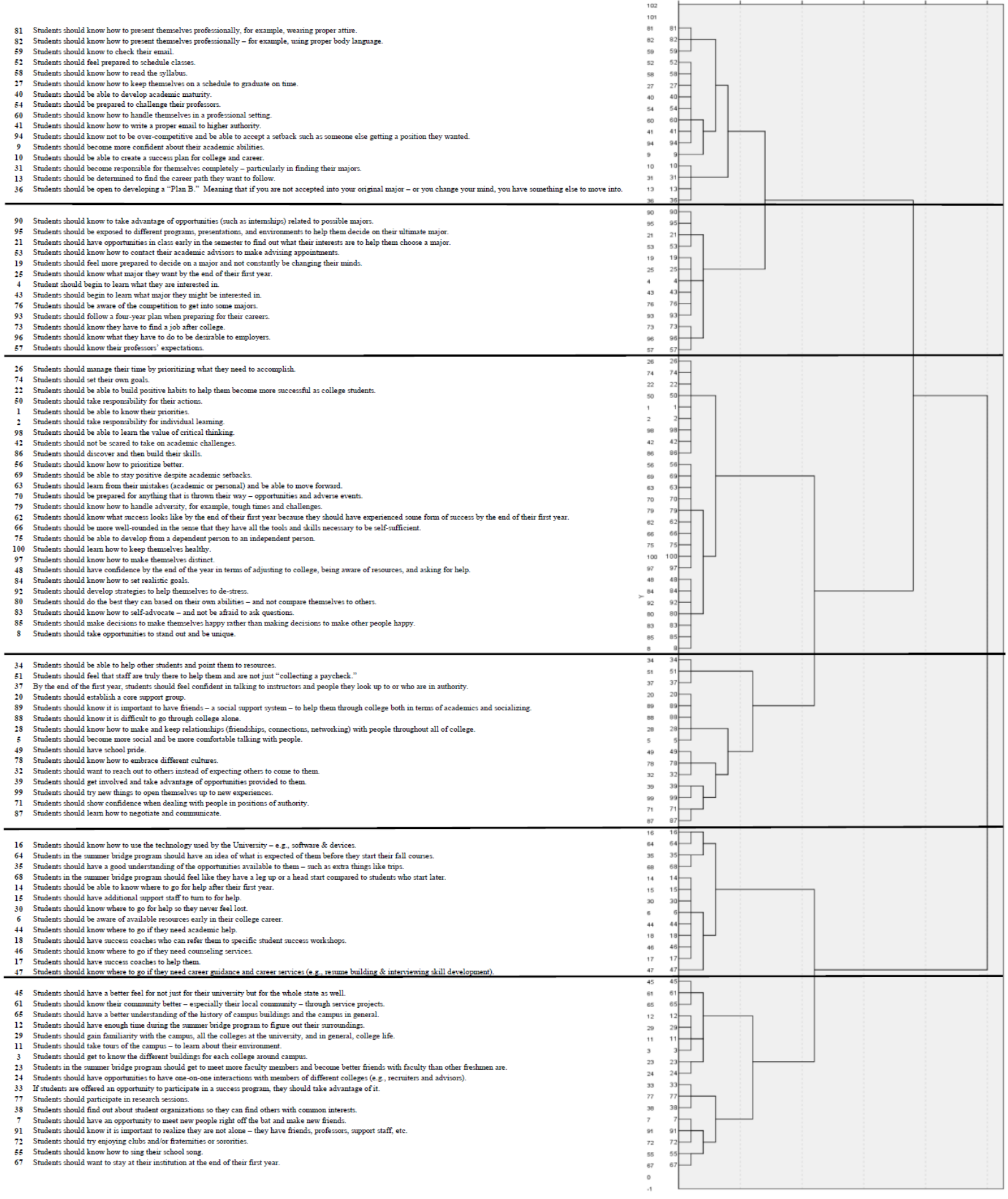




\section{Appendix G: List of the 100 Outcomes with Mean Scores for Importance and Efficacy and Cluster Membership}

\begin{tabular}{|c|c|c|c|c|c|c|}
\hline Order & X Coordinate & Y Coordinate & Outcome & Cluster Membership & Importance & Efficacy \\
\hline 1 & -1.43225 & -0.27696 & 1. Students should be able to know their priorities & 1 & 4.23 & 3.77 \\
\hline 2 & -1.21839 & 0.00984 & 2. Students should take responsibility for individual learning & 1 & 4.32 & 4.00 \\
\hline 3 & 1.64878 & 0.27194 & 3. Students should get to know the different buildings for each college around campus & 3 & 3.36 & 4.00 \\
\hline 4 & -0.18107 & 1.48242 & 4. Student should begin to learn what they are interested in & 5 & 3.55 & 3.50 \\
\hline 5 & 0.42376 & -1.7238 & 5. Students should become more social and be more comfortable talking with people & 2 & 3.82 & 3.73 \\
\hline 6 & 1.21653 & 1.16009 & 6. Students should be aware of available resources early in their college career & 4 & 4.27 & 3.95 \\
\hline 7 & 1.13232 & -1.27195 & 7. Students should have an opportunity to meet new people right off the bat and make new friends & 3 & 3.41 & 4.18 \\
\hline 8 & -0.52566 & -1.05366 & 8. Students should take opportunities to stand out and be unique & 1 & 3.18 & 3.50 \\
\hline 9 & -1.66849 & 0.31574 & 9. Students should become more confident about their academic abilities & 6 & 3.68 & 3.64 \\
\hline 10 & -0.9248 & 1.21092 & 10. Students should be able to create a success plan for college and career & 6 & 3.95 & 3.55 \\
\hline 11 & 1.91396 & 0.0423 & 11. Students should take tours of the campus - to learn about their environment & 3 & 2.86 & 4.09 \\
\hline 12 & 1.83258 & 0.25441 & 12. Students should have enough time during the summer bridge program to figure out their surroundings & 3 & 3.09 & 3.82 \\
\hline 13 & -0.91308 & 1.41605 & 13. Students should be determined to find the career path they want to follow & 6 & 3.45 & 3.59 \\
\hline 14 & 1.59589 & 0.7865 & 14. Students should be able to know where to go for help after their first year & 4 & 4.18 & 3.91 \\
\hline 15 & 1.49436 & 0.73761 & 15. Students should have additional support staff to turn to for help & 4 & 3.64 & 4.00 \\
\hline 16 & 0.50183 & 0.62923 & 16. Students should know how to use the technology used by the University - e.g., software \& devices & 4 & 3.68 & 3.77 \\
\hline 17 & 1.15879 & 0.86953 & 17. Students should have success coaches to help them & 4 & 3.05 & 3.86 \\
\hline 18 & 1.34608 & 1.02508 & 18. Students should have success coaches who can refer them to specific student success workshops & 4 & 3.18 & 3.86 \\
\hline 19 & -0.1121 & 1.55311 & 19. Students should feel more prepared to decide on a major and not constantly be changing their minds & 5 & 3.36 & 3.59 \\
\hline 20 & 0.82243 & -1.37297 & 20. Students should establish a core support group & 2 & 3.82 & 3.55 \\
\hline 21 & 0.25251 & 1.52232 & 21. Students should have opportunities in class early in the semester to find out what their interests are to help them choose a major & 5 & 3.41 & 3.64 \\
\hline 22 & -1.29503 & -0.28356 & 22. Students should be able to build positive habits to help them become more successful as college students & 1 & 4.09 & 3.64 \\
\hline 23 & 1.41648 & -0.24069 & 23. Students in the summer bridge program should get to meet more faculty members and become better friends with faculty than other freshmen are & 3 & 3.41 & 3.91 \\
\hline 24 & 1.4412 & 0.02751 & 24. Students should have opportunities to have one-on-one interactions with members of different colleges (e.g., recruiters and advisors) & 3 & 3.23 & 3.82 \\
\hline 25 & -0.06948 & 1.56166 & 25. Students should know what major they want by the end of their first year & 5 & 2.95 & 3.41 \\
\hline 26 & -1.15911 & -0.46441 & 26. Students should manage their time by prioritizing what they need to accomplish & 1 & 3.82 & 4.05 \\
\hline 27 & -0.94814 & 0.97867 & 27. Students should know how to keep themselves on a schedule to graduate on time & 6 & 3.86 & 4.00 \\
\hline 28 & 0.63123 & -1.51202 & 28. Students should know how to make and keep relationships (friendships, connections, networking) with people throughout all of college & 2 & 3.73 & 3.82 \\
\hline 29 & 1.87538 & 0.19576 & 29. Students should gain familiarity with the campus, all the colleges at the university, and in general, college life & 3 & 3.73 & 4.00 \\
\hline 30 & 1.61403 & 0.6057 & 30. Students should know where to go for help so they never feel lost & 4 & 4.50 & 3.86 \\
\hline 31 & -0.78192 & 1.20022 & 31. Students should become responsible for themselves completely - particularly in finding their majors & 6 & 3.68 & 3.41 \\
\hline 32 & -0.29134 & -1.42837 & 32. Students should want to reach out to others instead of expecting others to come to them & 2 & 3.91 & 3.45 \\
\hline 33 & 0.98941 & -0.38678 & 33. If students are offered an opportunity to participate in a success program, they should take advantage of it & 3 & 3.32 & 3.64 \\
\hline 34 & 0.3306 & -0.44693 & 34. Students should be able to help other students and point them to resources & 2 & 3.50 & 3.82 \\
\hline 35 & 1.11701 & 0.30908 & 35. Students should have a good understanding of the opportunities available to them - such as extra things like trips & 4 & 3.18 & 3.95 \\
\hline 36 & -1.092 & 1.30445 & 36. Students should be open to developing a "Plan B." Meaning that if you are not accepted into your original major - or you change your mind, you & 6 & 3.86 & 3.82 \\
\hline 37 & 0.10198 & -0.12045 & 37. By the end of the first year, students should feel confident in talking to instructors and people they look up to or who are in authority & 2 & 3.86 & 4.00 \\
\hline 38 & 1.13869 & -0.71634 & 38. Students should find out about student organizations so they can find others with common interests & 3 & 3.45 & 3.64 \\
\hline 39 & 0.25024 & -0.98427 & 39. Students should get involved and take advantage of opportunities provided to them & 2 & 3.91 & 3.95 \\
\hline 40 & -1.23929 & 0.54191 & 40. Students should be able to develop academic maturity & 6 & 4.23 & 3.77 \\
\hline 41 & -0.87447 & 0.48193 & 41. Students should know how to write a proper email to higher authority & 6 & 4.36 & 3.91 \\
\hline 42 & -1.08757 & -0.03484 & 42. Students should not be scared to take on academic challenges & 1 & 3.82 & 3.91 \\
\hline 43 & -0.3396 & 1.37185 & 43. Students should begin to learn what major they might be interested in & 5 & 3.68 & 4.05 \\
\hline 44 & 1.19695 & 1.10252 & 44. Students should know where to go if they need academic help & 4 & 4.14 & 4.18 \\
\hline 45 & 1.91987 & -0.4131 & 45. Students should have a better feel for not just for their university but for the whole state as well & 3 & 3.05 & 3.59 \\
\hline 46 & 1.48029 & 1.00313 & 46. Students should know where to go if they need counseling services & 4 & 4.00 & 3.77 \\
\hline 47 & 0.95374 & 1.37019 & 47. Students should know where to go if they need career guidance and career services (e.g., resume building \& interviewing skill development) & 4 & 3.68 & 3.95 \\
\hline 48 & -0.59213 & -0.61206 & 48. Students should have confidence by the end of the year in terms of adjusting to college, being aware of resources, and asking for help & 1 & 3.91 & 4.09 \\
\hline 49 & 0.11508 & -1.68949 & 49. Students should have school pride & 2 & 3.41 & 4.36 \\
\hline 50 & -1.22949 & -0.32859 & 50. Students should take responsibility for their actions & 1 & 4.41 & 3.82 \\
\hline
\end{tabular}




\begin{tabular}{|c|c|c|c|c|c|c|}
\hline Order & $\mathrm{x}$ Coordinate & Y Coordinate & Outcome & Cluster Membership & Importance & Efficacy \\
\hline 51 & 0.54914 & -0.17043 & 51. Students should feel that staff are truly there to help them and are not just "collecting a paycheck" & 2 & 3.73 & 3.73 \\
\hline 52 & -1.17312 & 0.72028 & 52. Students should feel prepared to schedule classes & 6 & 3.86 & 3.91 \\
\hline 53 & 0.0923 & 1.17061 & 53. Students should know how to contact their academic advisors to make advising appointments & 5 & 3.95 & 4.05 \\
\hline 54 & -1.08953 & 0.5016 & 54. Students should be prepared to challenge their professors & 6 & 2.95 & 3.45 \\
\hline 55 & 1.4942 & -1.03025 & 55. Students should know how to sing their school song & 3 & 2.86 & 3.82 \\
\hline 56 & -1.32617 & -0.78146 & 56. Students should know how to prioritize better & 1 & 4.09 & 3.95 \\
\hline 57 & -0.35065 & 0.8083 & 57. Students should know their professors' expectations & 5 & 4.05 & 3.86 \\
\hline 58 & -1.04852 & 0.74199 & 58. Students should know how to read the syllabus & 6 & 4.27 & 4.05 \\
\hline 59 & -0.59491 & 0.17169 & 59. Students should know to check their email & 6 & 4.45 & 4.05 \\
\hline 60 & -1.15693 & 0.32799 & 60. Students should know how to handle themselves in a professional setting & 6 & 4.18 & 3.82 \\
\hline 61 & 1.86322 & -0.50299 & 61. Students should know their conmunity better - especially their local community - through service projects & 3 & 3.27 & 3.36 \\
\hline 62 & -1.06379 & -0.7312 & 62. Students should know what success looks like because they should have experienced some form of success by the end of their first year & 1 & 3.73 & 3.77 \\
\hline 63 & -1.27162 & -0.92784 & 63. Students should learn from their mistakes (academic or personal) and be able to move forward & 1 & 4.23 & 3.59 \\
\hline 64 & 0.64049 & 0.91975 & 64. Students in the summer bridge program should have an idea of what is expected of them before they start their fall courses & 4 & 3.68 & 3.86 \\
\hline 65 & 2.05292 & -0.12989 & 65. Students should have a better understanding of the history of campus buildings and the campus in general & 3 & 2.77 & 3.27 \\
\hline 66 & -1.10275 & -0.777 & 66. Students should be more well-rounded in the sense that they have all the tools and skills necessary to be self-sufficient & 1 & 4.05 & 4.00 \\
\hline 67 & 1.75259 & -0.94972 & 67. Students should want to stay at their institution at the end of their first year & 3 & 3.14 & 3.86 \\
\hline 68 & 0.82408 & 0.48153 & 68. Students in the summer bridge program should feel like they have a leg up or a head start compared to students who start later & 4 & 3.64 & 4.18 \\
\hline 69 & -1.36295 & -0.67933 & 69. Students should be able to stay positive despitt academic setbacks & 1 & 3.95 & 3.82 \\
\hline 70 & -1.32006 & -0.99524 & 70. Students should be prepared for anything that is thrown their way - opportunities and adverse events & 1 & 4.00 & 3.91 \\
\hline 71 & -0.16911 & -0.85468 & 71. Students should show confidence when dealing with people in positions of authority & 2 & 3.73 & 3.91 \\
\hline 72 & 1.29654 & -1.21007 & 72. Students should try enjoying clubs and/or fraternities or sororities & 3 & 3.14 & 3.95 \\
\hline 73 & -0.50844 & 1.11531 & 73. Students should know they have to find a job after college & 5 & 3.95 & 4.05 \\
\hline 74 & -1.28375 & -0.47294 & 74. Students should set their own goals & 1 & 4.09 & 3.86 \\
\hline 75 & -0.94955 & -0.69237 & 75. Students should be able to develop from a dependent person to an independent person & 1 & 4.23 & 3.91 \\
\hline 76 & -0.33175 & 1.48323 & 76. Students should be aware of the competition to get into some majors & 5 & 3.86 & 3.86 \\
\hline 77 & 0.88206 & -0.60396 & 77. Students should participate in research sessions & 3 & 3.18 & 3.45 \\
\hline 78 & -0.00634 & -1.50986 & 78. Students should know how to embrace different cultures & 2 & 3.68 & 4.00 \\
\hline 79 & -1.13916 & -1.05818 & 79. Students should know how to handle adversity, for example, tough times and challenges & 1 & 4.14 & 4.00 \\
\hline 80 & -0.88578 & -1.03046 & 80. Students should do the best they can based on their own abilities - and not compare themselves to others & 1 & 3.82 & 3.82 \\
\hline 81 & -0.51652 & 0.48043 & 81. Students should know how to present themselves professionally, for example, wearing proper attire & 6 & 3.91 & 3.59 \\
\hline 82 & -0.51652 & 0.48042 & 82. Students should know how to present themselves professionally - for example, using proper body language & 6 & 3.86 & 3.68 \\
\hline 83 & -0.79472 & -0.91485 & 83. Students should know how to self-advocate - and not be afraid to ask questions & 1 & 3.86 & 3.82 \\
\hline 84 & -0.75872 & -0.69456 & 84. Students should know how to set realistic galls & 1 & 3.95 & 3.77 \\
\hline 85 & -0.81221 & -1.20403 & 85. Students should make decisions to make themselves happy rather than making decisions to make other people happy & 1 & 4.00 & 3.77 \\
\hline 86 & -0.93571 & -0.16251 & 86. Students should discover and then build their skills & 1 & 3.95 & 3.86 \\
\hline 87 & -0.08175 & -0.5202 & 87. Students should learn how to negotiate and communicate & 2 & 3.82 & 3.95 \\
\hline 88 & 0.68245 & -1.30298 & 88. Students should know it is difficult to go through college alone & 2 & 3.59 & 3.95 \\
\hline 89 & 0.76159 & -1.45651 & 89. Students should know it i important to have friends - a social support system - to help them through college both in terms of academics and & 2 & 3.95 & 3.91 \\
\hline 90 & 0.267 & 1.35521 & 90. Students should know to take advantage of opportunities (such as internships) related to possible majors & 5 & 4.09 & 3.82 \\
\hline 91 & 1.07279 & -1.23242 & 91. Students should know it is important to realize they are not alone - they have friends, professors, support staff, etc. & 3 & 4.00 & 3.95 \\
\hline 92 & -0.5022 & -0.78752 & 92. Students should develop strategies to help themselves to de-stress & 1 & 3.68 & 3.95 \\
\hline 93 & -0.46829 & 1.5377 & 93. Students should follow a four-year plan when preparing for their careers & 5 & 3.36 & 3.59 \\
\hline 94 & -1.41967 & 0.66898 & 94. Students should know not to be over-competitive and be able to accept a setback such as someone else getting a position they wanted & 6 & 3.91 & 3.59 \\
\hline 95 & 0.31672 & 1.32655 & 95. Students should be exposed to different programs, presentations, and environments to help them decide on their ultimate major & 5 & 3.64 & 3.95 \\
\hline 96 & -0.2886 & 1.16031 & 96. Students should know what they have to do to be desirable to employers & 5 & 3.91 & 3.91 \\
\hline 97 & -0.90017 & -0.39916 & 97. Students should know how to make themselves distinct & 1 & 4.00 & 3.59 \\
\hline 98 & -1.3242 & 0.07205 & 98. Students should be able to learn the value of critical thinking & 1 & 4.18 & 3.91 \\
\hline 99 & 0.01932 & -1.12997 & 99. Students should try new things to open themselves up to new experiences & 2 & 3.95 & 3.95 \\
\hline 100 & -1.04982 & -0.59172 & 100. Students should learn how to keep themselves healthy & 1 & 4.00 & 3.64 \\
\hline
\end{tabular}




\section{Appendix H : IRB Approval Letter}

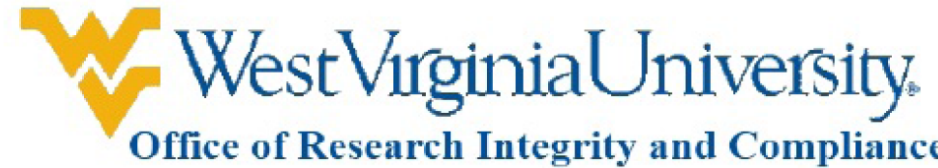

\section{Acknowledgement Letter Exempt Initial Protocol Review}

To

From

Approval Period

Subject

Protocol Number

Title
Jacob Sanwidi

WVU Office of Research Integrity and Compliance

09/23/2014 Expiration Date 09/22/2017

Acknowledgement Letter Exempt Initial Protocol Review

1404264121

The Use of Concept Mapping/Pattern Matching to Conceptualize the Desired Domain of Student Learning in the First Year of College

The above-referenced study was reviewed by the West Virginia University Institutional Review Board IRB and was granted exemption in accordance with 45 CFR 46.101.

" This research study was granted an exemption because the Research involves educational tests, survey procedures, interview procedures or observation of public behavior and (i) information obtained is recorded in such a manner that human subjects cannot be identified, directly or through identifiers linked to the subjects; and (ii) any disclosure of the human subjects responses outside the research could not reasonably place the subjects at risk of criminal or civil liability or be damaging to the subjects financial standing, employability, or reputation [45 CFR 46.101(2)]. All exemptions are only good for three years. If this research extends more than three years beyond the approved date, then the researcher will have to request another exemption. The following documents have been acknowledged for use in this study and are available in the WVU+kc system:

Documents for use in this study have been acknowledged and validated and are available in the WVUkc system in the Notes and Attachments section of your protocol.

The Office of Research Integrity and Compliance is here to provide assistance to you from the initial submission of an IRB protocol to its approval and all subsequent activity. Please feel free to contact us by phone at 304.293.7073 with any question you may have. Thank you.

WVU Office of Research Integrity and Compliance

Date: $09 / 23 / 2014$

Signed:

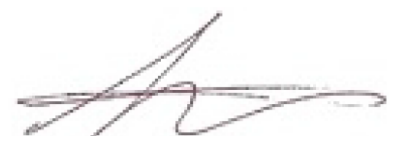


Once you begin your human subject research, the following regulations apply:

1. Any modifications to the study protocol must be reviewed and acknowledged by the IRB prior to implementation.

2. You may not use a modified form until it has been acknowledged by the IRB. 


\section{Appendix I: Excel Spreadsheet with Outcomes Distributed Between 3 and 10 Clusters}

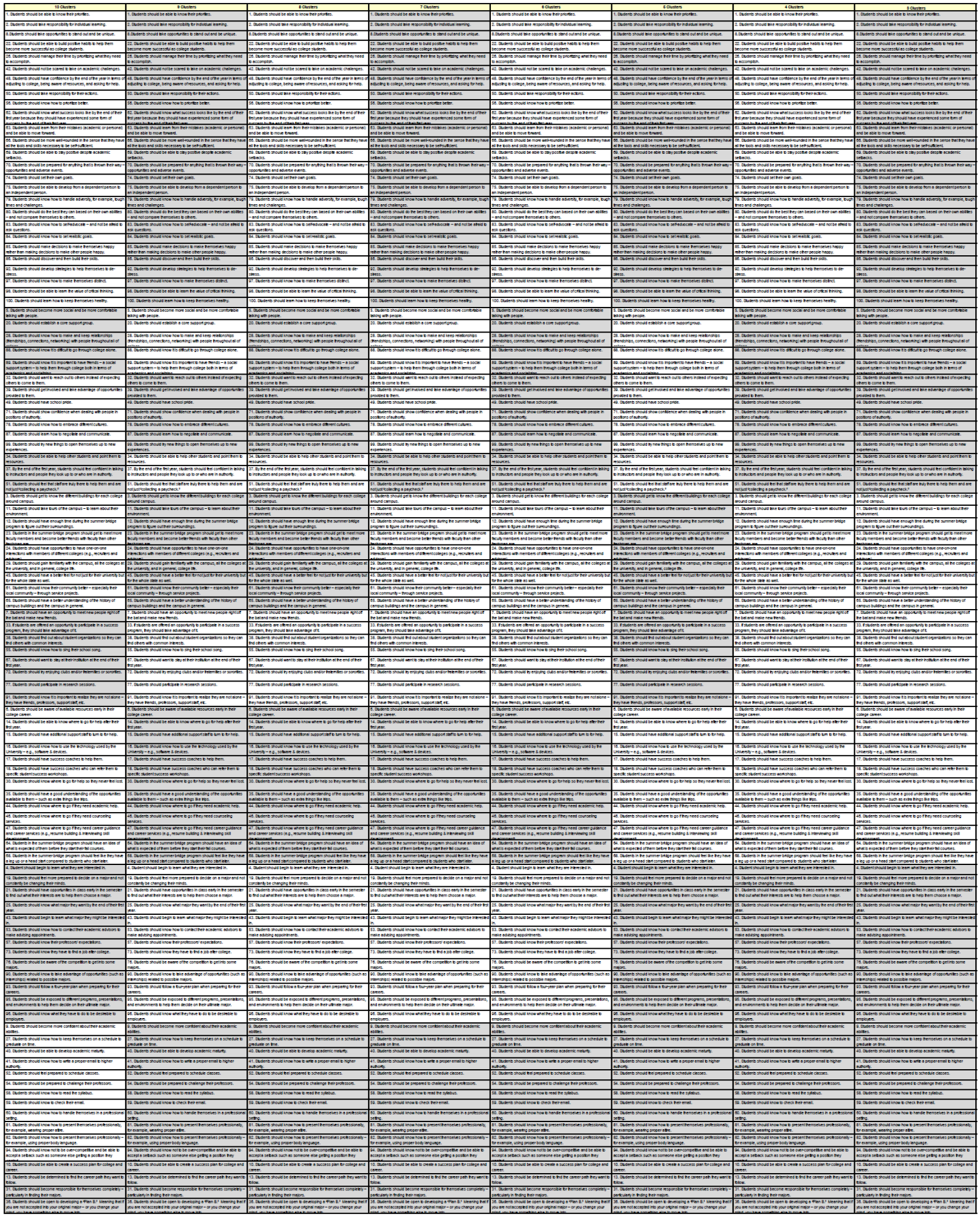




\section{Appendix J: Qualtrics Results for Importance of Each Outcome by Number of Responses}

\begin{tabular}{|c|c|c|c|c|c|c|c|c|}
\hline \multirow[t]{2}{*}{ \# } & \multirow[t]{2}{*}{ Outcome } & \multicolumn{3}{|c|}{$\begin{array}{l}\text { Notat all Somewhat Important } \\
\text { Important Important }\end{array}$} & \multicolumn{4}{|c|}{$\begin{array}{c}\text { Very Extremely } \\
\text { Important Important }\end{array}$} \\
\hline & & 1 & 2 & 3 & 4 & 5 & & \\
\hline 1 & Students should be able to know their priorities & 0 & 0 & 3 & 11 & 8 & 22 & 4.23 \\
\hline 2 & $\begin{array}{l}\text { Students should take responsibility for individual } \\
\text { learning }\end{array}$ & 0 & 0 & 3 & 9 & 10 & 22 & 4.32 \\
\hline 3 & $\begin{array}{l}\text { Students should get to know the different buildings } \\
\text { for each college around campus }\end{array}$ & 1 & 2 & 10 & 6 & 3 & 22 & 3.36 \\
\hline 4 & $\begin{array}{l}\text { Student should begin to learn what they are } \\
\text { interested in }\end{array}$ & 0 & 2 & 8 & 10 & 2 & 22 & 3.55 \\
\hline 5 & $\begin{array}{l}\text { Students should become more social and be more } \\
\text { comfortable talking with people }\end{array}$ & 0 & 2 & 5 & 10 & 5 & 22 & 3.82 \\
\hline 6 & $\begin{array}{l}\text { Students should be aware of available resources } \\
\text { early in their college career }\end{array}$ & 0 & 0 & 3 & 10 & 9 & 22 & 4.27 \\
\hline 7 & $\begin{array}{l}\text { Students should have an opportunity to meet new } \\
\text { people right off the bat and make new friends }\end{array}$ & 1 & 3 & 8 & 6 & 4 & 22 & 3.41 \\
\hline 8 & $\begin{array}{l}\text { Students should take opportunities to stand out and } \\
\text { be unique }\end{array}$ & 0 & 7 & 6 & 7 & 2 & 22 & 3.18 \\
\hline 9 & $\begin{array}{l}\text { Students should become more confident about } \\
\text { their academic abilities }\end{array}$ & 0 & 1 & 8 & 10 & 3 & 22 & 3.68 \\
\hline 10 & $\begin{array}{l}\text { Students should be able to create a success plan } \\
\text { for college and career }\end{array}$ & 0 & 2 & 3 & 11 & 6 & 22 & 3.95 \\
\hline 11 & $\begin{array}{l}\text { Students should take tours of the campus - to learn } \\
\text { about their environment }\end{array}$ & 1 & 6 & 11 & 3 & 1 & 22 & 2.86 \\
\hline 12 & $\begin{array}{l}\text { Students should have enough time during the } \\
\text { summer bridge program to figure out their } \\
\text { surroundings }\end{array}$ & 2 & 2 & 11 & 6 & 1 & 22 & 3.09 \\
\hline 13 & $\begin{array}{l}\text { Students should be determined to find the career } \\
\text { path they want to follow }\end{array}$ & 0 & 4 & 9 & 4 & 5 & 22 & 3.45 \\
\hline 14 & $\begin{array}{l}\text { Students should be able to know where to go for } \\
\text { help after their first year }\end{array}$ & 0 & 1 & 4 & 7 & 10 & 22 & 4.18 \\
\hline 15 & $\begin{array}{l}\text { Students should have additional support staff to turn } \\
\text { to for help }\end{array}$ & 0 & 1 & 9 & 9 & 3 & 22 & 3.64 \\
\hline 16 & $\begin{array}{l}\text { Students should know how to use the technology } \\
\text { used by the University - e.g., software \& devices }\end{array}$ & 0 & 2 & 8 & 7 & 5 & 22 & 3.68 \\
\hline 17 & $\begin{array}{l}\text { Students should have success coaches to help } \\
\text { them }\end{array}$ & 2 & 5 & 8 & 4 & 3 & 22 & 3.05 \\
\hline 18 & $\begin{array}{l}\text { Students should have success coaches who can } \\
\text { refer them to specific student success workshops }\end{array}$ & 1 & 5 & 9 & 3 & 4 & 22 & 3.18 \\
\hline 19 & $\begin{array}{l}\text { Students should feel more prepared to decide on a } \\
\text { major and not constantly be changing their minds }\end{array}$ & 0 & 3 & 10 & 7 & 2 & 22 & 3.36 \\
\hline 20 & $\begin{array}{l}\text { Students should establish a core support group } \\
\text { Students should have opportunities in class early in }\end{array}$ & 0 & 1 & 7 & 9 & 5 & 22 & 3.82 \\
\hline 21 & $\begin{array}{l}\text { the semester to find out what their interests are to } \\
\text { help them choose a major }\end{array}$ & 1 & 2 & 8 & 9 & 2 & 22 & 3.41 \\
\hline 22 & $\begin{array}{l}\text { Students should be able to build positive habits to } \\
\text { help them become more successful as college } \\
\text { students }\end{array}$ & 0 & 0 & 5 & 10 & 7 & 22 & 4.09 \\
\hline
\end{tabular}




\begin{tabular}{|c|c|c|c|c|c|c|c|c|}
\hline \# & Outcome & $\begin{array}{l}\text { Not at all } \\
\text { Important }\end{array}$ & $\begin{array}{l}\text { Somewhat } \\
\text { Important }\end{array}$ & Important & $\begin{array}{c}\text { Very } \\
\text { Important }\end{array}$ & $\begin{array}{l}\text { Extremely } \\
\text { Important }\end{array}$ & Total Responses & Mean \\
\hline & & 1 & 2 & 3 & 4 & 5 & & \\
\hline 23 & $\begin{array}{l}\text { Students in the summer bridge program should } \\
\text { get to meet more faculty members and become } \\
\text { better friends with faculty than other freshmen are }\end{array}$ & 0 & 3 & 10 & 6 & 3 & 22 & 3.41 \\
\hline 24 & $\begin{array}{l}\text { Students should have opportunities to have one-on- } \\
\text { one interactions with members of different colleges } \\
\text { (e.g., recruiters and advisors) }\end{array}$ & 1 & 4 & 9 & 5 & 3 & 22 & 3.23 \\
\hline 25 & $\begin{array}{l}\text { Students should know what major they want by the } \\
\text { end of their first year }\end{array}$ & 1 & 7 & 8 & 4 & 2 & 22 & 2.95 \\
\hline 26 & $\begin{array}{l}\text { Students should manage their time by prioritizing } \\
\text { what they need to accomplish }\end{array}$ & 2 & 0 & 5 & 8 & 7 & 22 & 3.82 \\
\hline 27 & $\begin{array}{l}\text { Students should know how to keep themselves on } \\
\text { a schedule to graduate on time }\end{array}$ & 0 & 0 & 8 & 9 & 5 & 22 & 3.86 \\
\hline 28 & $\begin{array}{l}\text { Students should know how to make and keep } \\
\text { relationships (friendships, connections, networking) } \\
\text { with people throughout all of college }\end{array}$ & 0 & 1 & 9 & 7 & 5 & 22 & 3.73 \\
\hline 29 & $\begin{array}{l}\text { Students should gain familiarity with the campus, } \\
\text { all the colleges at the university, and in general, } \\
\text { college life }\end{array}$ & 1 & 1 & 9 & 3 & 8 & 22 & 3.73 \\
\hline 30 & $\begin{array}{l}\text { Students should know where to go for help so they } \\
\text { never feel lost }\end{array}$ & 0 & 0 & 3 & 5 & 14 & 22 & 4.5 \\
\hline 31 & $\begin{array}{l}\text { Students should become responsible for } \\
\text { themselves completely - particularly in finding their } \\
\text { majors }\end{array}$ & 0 & 2 & 7 & 9 & 4 & 22 & 3.68 \\
\hline 32 & $\begin{array}{l}\text { Students should want to reach out to others instead } \\
\text { of expecting others to come to them } \\
\text { If students are offered an opportunity to participate }\end{array}$ & 0 & 2 & 4 & 10 & 6 & 22 & 3.91 \\
\hline 33 & $\begin{array}{l}\text { in a success program, they should take advantage } \\
\text { of it }\end{array}$ & 0 & 5 & 8 & 6 & 3 & 22 & 3.32 \\
\hline 34 & $\begin{array}{l}\text { Students should be able to help other students and } \\
\text { point them to resources }\end{array}$ & 0 & 4 & 7 & 7 & 4 & 22 & 3.5 \\
\hline 35 & $\begin{array}{l}\text { Students should have a good understanding of the } \\
\text { opportunities available to them - such as extra } \\
\text { things like trips }\end{array}$ & 2 & 5 & 6 & 5 & 4 & 22 & 3.18 \\
\hline 36 & $\begin{array}{l}\text { Students should be open to developing a "Plan B." } \\
\text { Meaning that if you are not accepted into your } \\
\text { original major - or you change your mind, you } \\
\text { have something else to move into }\end{array}$ & 0 & 2 & 7 & 5 & 8 & 22 & 3.86 \\
\hline 37 & $\begin{array}{l}\text { By the end of the first year, students should feel } \\
\text { confident in talking to instructors and people they } \\
\text { look up to or who are in authority }\end{array}$ & 0 & 2 & 4 & 11 & 5 & 22 & 3.86 \\
\hline 38 & $\begin{array}{l}\text { Students should find out about student } \\
\text { organizations so they can find others with common } \\
\text { interests }\end{array}$ & 0 & 3 & 9 & 7 & 3 & 22 & 3.45 \\
\hline 39 & $\begin{array}{l}\text { Students should get involved and take advantage } \\
\text { of opportunities provided to them }\end{array}$ & 0 & 1 & 6 & 9 & 6 & 22 & 3.91 \\
\hline 40 & $\begin{array}{l}\text { Students should be able to develop academic } \\
\text { maturity }\end{array}$ & 0 & 0 & 5 & 7 & 10 & 22 & 4.23 \\
\hline 41 & $\begin{array}{l}\text { Students should know how to write a proper email } \\
\text { to higher authority }\end{array}$ & 0 & 0 & 4 & 6 & 12 & 22 & 4.36 \\
\hline 42 & $\begin{array}{l}\text { Students should not be scared to take on academic } \\
\text { challenges }\end{array}$ & 0 & 0 & 8 & 10 & 4 & 22 & 3.82 \\
\hline
\end{tabular}




\begin{tabular}{|c|c|c|c|c|c|c|c|c|}
\hline \# & Outcome & $\begin{array}{l}\text { Not at all } \\
\text { Important }\end{array}$ & $\begin{array}{c}\text { Somewhat } \\
\text { Important }\end{array}$ & Important & $\begin{array}{c}\text { Very } \\
\text { Important }\end{array}$ & $\begin{array}{l}\text { Extremely } \\
\text { Important }\end{array}$ & Total Responses & Sean \\
\hline & & 1 & 2 & 3 & 4 & 5 & & \\
\hline 43 & $\begin{array}{l}\text { Students should begin to learn what major they } \\
\text { might be interested in }\end{array}$ & 0 & 2 & 8 & 7 & 5 & 22 & 3.68 \\
\hline 44 & $\begin{array}{l}\text { Students should know where to go if they need } \\
\text { academic help }\end{array}$ & 0 & 1 & 4 & 8 & 9 & 22 & 4.14 \\
\hline 45 & $\begin{array}{l}\text { Students should have a better feel for not just for } \\
\text { their university but for the whole state as well }\end{array}$ & 1 & 7 & 8 & 2 & 4 & 22 & 3.05 \\
\hline 46 & $\begin{array}{l}\text { Students should know where to go if they need } \\
\text { counseling services }\end{array}$ & 0 & 2 & 3 & 10 & 7 & 22 & 4 \\
\hline 47 & $\begin{array}{l}\text { Students should know where to go if they need } \\
\text { career guidance and career services (e.g., resume } \\
\text { building \& interviewing skill development) }\end{array}$ & 0 & 1 & 9 & 8 & 4 & 22 & 3.68 \\
\hline 48 & $\begin{array}{l}\text { Students should have confidence by the end of the } \\
\text { year in terms of adjusting to college, being aware } \\
\text { of resources, and asking for help }\end{array}$ & 0 & 1 & 6 & 9 & 6 & 22 & 3.91 \\
\hline 49 & Students should have school pride & 0 & 6 & 6 & 5 & 5 & 22 & 3.41 \\
\hline 50 & Students should take responsibility for their actions & 0 & 1 & 2 & 6 & 13 & 22 & 4.41 \\
\hline 51 & $\begin{array}{l}\text { Students should feel that staff are truly there to help } \\
\text { them and are not just "collecting a paycheck" }\end{array}$ & 0 & 1 & 9 & 7 & 5 & 22 & 3.73 \\
\hline 52 & Students should feel prepared to schedule classes & 0 & 1 & 8 & 6 & 7 & 22 & 3.86 \\
\hline 53 & $\begin{array}{l}\text { Students should know how to contact their } \\
\text { academic advisors to make advising appointments }\end{array}$ & 0 & 1 & 8 & 4 & 9 & 22 & 3.95 \\
\hline 54 & $\begin{array}{l}\text { Students should be prepared to challenge their } \\
\text { professors }\end{array}$ & 1 & 7 & 9 & 2 & 3 & 22 & 2.95 \\
\hline 55 & $\begin{array}{l}\text { Students should know how to sing their school } \\
\text { song }\end{array}$ & 6 & 4 & 5 & 1 & 6 & 22 & 2.86 \\
\hline 56 & Students should know how to prioritize better & 1 & 0 & 4 & 8 & 9 & 22 & 4.09 \\
\hline 57 & $\begin{array}{l}\text { Students should know their professors' } \\
\text { expectations }\end{array}$ & 0 & 0 & 7 & 7 & 8 & 22 & 4.05 \\
\hline 58 & Students should know how to read the syllabus & 0 & 0 & 4 & 8 & 10 & 22 & 4.27 \\
\hline 59 & Students should know to check their email & 0 & 0 & 2 & 8 & 12 & 22 & 4.45 \\
\hline 60 & $\begin{array}{l}\text { Students should know how to handle themselves } \\
\text { in a professional setting }\end{array}$ & 0 & 0 & 6 & 6 & 10 & 22 & 4.18 \\
\hline 61 & $\begin{array}{l}\text { Students should know their community better - } \\
\text { especially their local community - through service } \\
\text { projects }\end{array}$ & 1 & 3 & 9 & 7 & 2 & 22 & 3.27 \\
\hline 62 & $\begin{array}{l}\text { Students should know what success looks like } \\
\text { because they should have experienced some form } \\
\text { of success by the end of their first year } \\
\text { Students should learn from their mistakes }\end{array}$ & 0 & 2 & 7 & 8 & 5 & 22 & 3.73 \\
\hline 63 & $\begin{array}{l}\text { (academic or personal) and be able to move } \\
\text { forward }\end{array}$ & 0 & 0 & 5 & 7 & 10 & 22 & 4.23 \\
\hline 64 & $\begin{array}{l}\text { Students in the summer bridge program should } \\
\text { have an idea of what is expected of them before } \\
\text { they start their fall courses }\end{array}$ & 0 & 2 & 9 & 5 & 6 & 22 & 3.68 \\
\hline 65 & $\begin{array}{l}\text { Students should have a better understanding of the } \\
\text { history of campus buildings and the campus in } \\
\text { general }\end{array}$ & 3 & 7 & 7 & 2 & 3 & 22 & 2.77 \\
\hline
\end{tabular}




\begin{tabular}{|c|c|c|c|c|c|c|c|c|}
\hline \multirow[t]{2}{*}{ \# } & \multirow[t]{2}{*}{ Outcome } & $\begin{array}{l}\text { Not at all } \\
\text { Important }\end{array}$ & $\begin{array}{l}\text { Somewhat } \\
\text { Important }\end{array}$ & Important & $\begin{array}{c}\text { Very } \\
\text { Important }\end{array}$ & $\begin{array}{l}\text { Extremely } \\
\text { Important } \\
\end{array}$ & Total Responses & Mean \\
\hline & & 1 & 2 & 3 & 4 & 5 & & \\
\hline 66 & $\begin{array}{l}\text { Students should be more well-rounded in the } \\
\text { sense that they have all the tools and skills } \\
\text { necessary to be self-sufficient }\end{array}$ & 0 & 1 & 5 & 8 & 8 & 22 & 4.05 \\
\hline 67 & $\begin{array}{l}\text { Students should want to stay at their institution at } \\
\text { the end of their first year }\end{array}$ & 1 & 4 & 10 & 5 & 2 & 22 & 3.14 \\
\hline 68 & $\begin{array}{l}\text { Students in the summer bridge program should } \\
\text { feel like they have a leg up or a head start } \\
\text { compared to students who start later }\end{array}$ & 1 & 1 & 8 & 7 & 5 & 22 & 3.64 \\
\hline 69 & $\begin{array}{l}\text { Students should be able to stay positive despite } \\
\text { academic setbacks }\end{array}$ & 0 & 0 & 6 & 11 & 5 & 22 & 3.95 \\
\hline 70 & $\begin{array}{l}\text { Students should be prepared for anything that is } \\
\text { thrown their way - opportunities and adverse } \\
\text { events }\end{array}$ & 0 & 0 & 5 & 12 & 5 & 22 & 4 \\
\hline 71 & $\begin{array}{l}\text { Students should show confidence when dealing } \\
\text { with people in positions of authority }\end{array}$ & 0 & 1 & 8 & 9 & 4 & 22 & 3.73 \\
\hline 72 & $\begin{array}{l}\text { Students should try enjoying clubs and/or } \\
\text { fraternities or sororities }\end{array}$ & 2 & 4 & 9 & 3 & 4 & 22 & 3.14 \\
\hline 73 & $\begin{array}{l}\text { Students should know they have to find a job after } \\
\text { college }\end{array}$ & 0 & 1 & 6 & 8 & 7 & 22 & 3.95 \\
\hline 74 & Students should set their own goals & 0 & 1 & 5 & 7 & 9 & 22 & 4.09 \\
\hline 75 & $\begin{array}{l}\text { Students should be able to develop from a } \\
\text { dependent person to an independent person }\end{array}$ & 0 & 0 & 6 & 5 & 11 & 22 & 4.23 \\
\hline 76 & $\begin{array}{l}\text { Students should be aware of the competition to get } \\
\text { into some majors }\end{array}$ & 0 & 2 & 6 & 7 & 7 & 22 & 3.86 \\
\hline 77 & Students should participate in research sessions & 1 & 7 & 6 & 3 & 5 & 22 & 3.18 \\
\hline 78 & $\begin{array}{l}\text { Students should know how to embrace different } \\
\text { cultures }\end{array}$ & 0 & 2 & 6 & 11 & 3 & 22 & 3.68 \\
\hline 79 & $\begin{array}{l}\text { Students should know how to handle adversity, for } \\
\text { example, tough times and challenges }\end{array}$ & 0 & 0 & 5 & 9 & 8 & 22 & 4.14 \\
\hline 80 & $\begin{array}{l}\text { Students should do the best they can based on } \\
\text { their own abilities - and not compare themselves } \\
\text { to others }\end{array}$ & 1 & 1 & 6 & 7 & 7 & 22 & 3.82 \\
\hline 81 & $\begin{array}{l}\text { Students should know how to present themselves } \\
\text { professionally, for example, wearing proper attire }\end{array}$ & 1 & 0 & 5 & 10 & 6 & 22 & 3.91 \\
\hline 82 & $\begin{array}{l}\text { Students should know how to present themselves } \\
\text { professionally - for example, using proper body } \\
\text { language }\end{array}$ & 0 & 0 & 8 & 9 & 5 & 22 & 3.86 \\
\hline 83 & $\begin{array}{l}\text { Students should know how to self-advocate - and } \\
\text { not be afraid to ask questions }\end{array}$ & 0 & 0 & 7 & 11 & 4 & 22 & 3.86 \\
\hline 84 & $\begin{array}{l}\text { Students should know how to set realistic goals } \\
\text { Students should make decisions to make }\end{array}$ & 0 & 0 & 6 & 11 & 5 & 22 & 3.95 \\
\hline 85 & $\begin{array}{l}\text { themselves happy rather than making decisions to } \\
\text { make other people happy }\end{array}$ & 0 & 1 & 5 & 9 & 7 & 22 & 4 \\
\hline 86 & Students should discover and then build their skills & 0 & 1 & 5 & 10 & 6 & 22 & 3.95 \\
\hline 87 & $\begin{array}{l}\text { Students should learn how to negotiate and } \\
\text { communicate }\end{array}$ & 0 & 0 & 7 & 12 & 3 & 22 & 3.82 \\
\hline 88 & $\begin{array}{l}\text { Students should know it is difficult to go through } \\
\text { college alone }\end{array}$ & 1 & 3 & 5 & 8 & 5 & 22 & 3.59 \\
\hline
\end{tabular}




\begin{tabular}{|c|c|c|c|c|c|c|c|c|}
\hline \# & Outcome & $\begin{array}{l}\text { Not at all } \\
\text { Important }\end{array}$ & $\begin{array}{c}\text { Somewhat } \\
\text { Important }\end{array}$ & Important & $\begin{array}{c}\text { Very } \\
\text { Important }\end{array}$ & $\begin{array}{l}\text { Extremely } \\
\text { Important }\end{array}$ & Total Responses & Mean \\
\hline & & 1 & 2 & 3 & 4 & 5 & & \\
\hline & Students should know it is important to have friends & & & & & & & \\
\hline 89 & $\begin{array}{l}\text { - a social support system - to help them through } \\
\text { college both in terms of academics and socializing }\end{array}$ & 0 & 0 & 9 & 5 & 8 & 22 & 3.95 \\
\hline 90 & $\begin{array}{l}\text { Students should know to take advantage of } \\
\text { opportunities (such as internships) related to } \\
\text { possible majors }\end{array}$ & 0 & 0 & 6 & 8 & 8 & 22 & 4.09 \\
\hline 91 & $\begin{array}{l}\text { Students should know it is important to realize they } \\
\text { are not alone - they have friends, professors, } \\
\text { support staff, etc. }\end{array}$ & 0 & 0 & 7 & 8 & 7 & 22 & 4 \\
\hline 92 & $\begin{array}{l}\text { Students should develop strategies to help } \\
\text { themselves to de-stress }\end{array}$ & 1 & 0 & 8 & 9 & 4 & 22 & 3.68 \\
\hline 93 & $\begin{array}{l}\text { Students should follow a four-year plan when } \\
\text { preparing for their careers }\end{array}$ & 0 & 7 & 5 & 5 & 5 & 22 & 3.36 \\
\hline 94 & $\begin{array}{l}\text { Students should know not to be over-competitive } \\
\text { and be able to accept a setback such as someone } \\
\text { else getting a position they wanted }\end{array}$ & 0 & 2 & 5 & 8 & 7 & 22 & 3.91 \\
\hline 95 & $\begin{array}{l}\text { Students should be exposed to different programs, } \\
\text { presentations, and environments to help them } \\
\text { decide on their ultimate major }\end{array}$ & 0 & 1 & 9 & 9 & 3 & 22 & 3.64 \\
\hline 96 & $\begin{array}{l}\text { Students should know what they have to do to be } \\
\text { desirable to employers }\end{array}$ & 0 & 1 & 6 & 9 & 6 & 22 & 3.91 \\
\hline 97 & $\begin{array}{l}\text { Students should know how to make themselves } \\
\text { distinct }\end{array}$ & 0 & 0 & 6 & 10 & 6 & 22 & 4 \\
\hline 98 & $\begin{array}{l}\text { Students should be able to learn the value of critical } \\
\text { thinking }\end{array}$ & 0 & 0 & 4 & 10 & 8 & 22 & 4.18 \\
\hline 99 & $\begin{array}{l}\text { Students should try new things to open themselves } \\
\text { up to new experiences }\end{array}$ & 0 & 1 & 6 & 8 & 7 & 22 & 3.95 \\
\hline \multirow[t]{3}{*}{100} & $\begin{array}{l}\text { Students should learn how to keep themselves } \\
\text { healthy }\end{array}$ & 1 & 0 & 6 & 6 & 9 & 22 & 4 \\
\hline & & 39 & 184 & 659 & 735 & 583 & & \\
\hline & & $1.77 \%$ & $8.36 \%$ & $29.95 \%$ & $33.41 \%$ & $26.50 \%$ & & \\
\hline
\end{tabular}




\section{Appendix K: Qualtrics Results for Efficacy of Each Outcome by Number of Responses}

2. For each item, please evaluate the overall efficacy of your institution in helping students achieve that desired learning element

\begin{tabular}{|c|c|c|c|c|c|c|c|c|}
\hline \multirow{3}{*}{ \# } & \multirow{3}{*}{ Outcome } & \\
\hline & & Poor & Fair & Average & Good & Excellent & Total Responses & Mean \\
\hline & & 1 & 2 & 3 & 4 & 5 & & \\
\hline 1 & Students should be able to know their priorities & 1 & 0 & 7 & 9 & 5 & 22 & 3.77 \\
\hline 2 & $\begin{array}{l}\text { Students should take responsibility for individual } \\
\text { learning }\end{array}$ & 0 & 1 & 3 & 13 & 5 & 22 & 4 \\
\hline 3 & $\begin{array}{l}\text { Students should get to know the different buildings } \\
\text { for each college around campus }\end{array}$ & 0 & 2 & 3 & 10 & 7 & 22 & 4 \\
\hline 4 & $\begin{array}{l}\text { Student should begin to learn what they are } \\
\text { interested in }\end{array}$ & 1 & 3 & 5 & 10 & 3 & 22 & 3.5 \\
\hline 5 & $\begin{array}{l}\text { Students should become more social and be more } \\
\text { comfortable talking with people }\end{array}$ & 0 & 2 & 7 & 8 & 5 & 22 & 3.73 \\
\hline 6 & $\begin{array}{l}\text { Students should be aware of available resources } \\
\text { early in their college career }\end{array}$ & 0 & 1 & 5 & 10 & 6 & 22 & 3.95 \\
\hline 7 & $\begin{array}{l}\text { Students should have an opportunity to meet new } \\
\text { people right off the bat and make new friends }\end{array}$ & 0 & 0 & 4 & 10 & 8 & 22 & 4.18 \\
\hline 8 & $\begin{array}{l}\text { Students should take opportunities to stand out and } \\
\text { be unique }\end{array}$ & 1 & 2 & 8 & 7 & 4 & 22 & 3.5 \\
\hline 9 & $\begin{array}{l}\text { Students should become more confident about } \\
\text { their academic abilities }\end{array}$ & 0 & 3 & 6 & 9 & 4 & 22 & 3.64 \\
\hline 10 & $\begin{array}{l}\text { Students should be able to create a success plan } \\
\text { for college and career }\end{array}$ & 2 & 2 & 5 & 8 & 5 & 22 & 3.55 \\
\hline 11 & $\begin{array}{l}\text { Students should take tours of the campus - to learn } \\
\text { about their environment }\end{array}$ & 1 & 0 & 3 & 10 & 8 & 22 & 4.09 \\
\hline 12 & $\begin{array}{l}\text { Students should have enough time during the } \\
\text { summer bridge program to figure out their } \\
\text { surroundings }\end{array}$ & 1 & 2 & 3 & 10 & 6 & 22 & 3.82 \\
\hline 13 & $\begin{array}{l}\text { Students should be determined to find the career } \\
\text { path they want to follow }\end{array}$ & 0 & 2 & 9 & 7 & 4 & 22 & 3.59 \\
\hline 14 & $\begin{array}{l}\text { Students should be able to know where to go for } \\
\text { help after their first year }\end{array}$ & 0 & 1 & 5 & 11 & 5 & 22 & 3.91 \\
\hline 15 & $\begin{array}{l}\text { Students should have additional support staff to turn } \\
\text { to for help }\end{array}$ & 0 & 1 & 4 & 11 & 6 & 22 & 4 \\
\hline 16 & $\begin{array}{l}\text { Students should know how to use the technology } \\
\text { used by the University - e.g., software \& devices }\end{array}$ & 0 & 3 & 5 & 8 & 6 & 22 & 3.77 \\
\hline 17 & $\begin{array}{l}\text { Students should have success coaches to help } \\
\text { them }\end{array}$ & 0 & 3 & 2 & 12 & 5 & 22 & 3.86 \\
\hline 18 & $\begin{array}{l}\text { Students should have success coaches who can } \\
\text { refer them to specific student success workshops }\end{array}$ & 0 & 3 & 2 & 12 & 5 & 22 & 3.86 \\
\hline 19 & $\begin{array}{l}\text { Students should feel more prepared to decide on a } \\
\text { major and not constantly be changing their minds }\end{array}$ & 0 & 4 & 6 & 7 & 5 & 22 & 3.59 \\
\hline 20 & Students should establish a core support group & 1 & 3 & 6 & 7 & 5 & 22 & 3.55 \\
\hline 21 & $\begin{array}{l}\text { Students should have opportunities in class early in } \\
\text { the semester to find out what their interests are to } \\
\text { help them choose a major }\end{array}$ & 0 & 1 & 9 & 9 & 3 & 22 & 3.64 \\
\hline
\end{tabular}


\# Outcome Poor Fair Average Good Excellent Total Responses Mean

\begin{tabular}{|c|c|c|c|c|c|c|c|c|}
\hline & & 1 & 2 & 3 & 4 & 5 & & \\
\hline 23 & $\begin{array}{l}\text { Students in the summer bridge program should } \\
\text { get to meet more faculty members and become } \\
\text { better friends with faculty than other freshmen are }\end{array}$ & 1 & 1 & 3 & 11 & 6 & 22 & 3.91 \\
\hline 24 & $\begin{array}{l}\text { Students should have opportunities to have one-on- } \\
\text { one interactions with members of different colleges } \\
\text { (e.g., recruiters and advisors) }\end{array}$ & 1 & 1 & 5 & 9 & 6 & 22 & 3.82 \\
\hline 25 & $\begin{array}{l}\text { Students should know what major they want by the } \\
\text { end of their first year }\end{array}$ & 0 & 4 & 6 & 11 & 1 & 22 & 3.41 \\
\hline 26 & $\begin{array}{l}\text { Students should manage their time by prioritizing } \\
\text { what they need to accomplish }\end{array}$ & 0 & 1 & 5 & 8 & 8 & 22 & 4.05 \\
\hline 27 & $\begin{array}{l}\text { Students should know how to keep themselves on } \\
\text { a schedule to graduate on time }\end{array}$ & 0 & 1 & 4 & 11 & 6 & 22 & 4 \\
\hline 28 & $\begin{array}{l}\text { Students should know how to make and keep } \\
\text { relationships (friendships, connections, networking) } \\
\text { with people throughout all of college }\end{array}$ & 0 & 1 & 8 & 7 & 6 & 22 & 3.82 \\
\hline 29 & $\begin{array}{l}\text { Students should gain familiarity with the campus, } \\
\text { all the colleges at the university, and in general, } \\
\text { college life }\end{array}$ & 0 & 0 & 6 & 10 & 6 & 22 & 4 \\
\hline 30 & $\begin{array}{l}\text { Students should know where to go for help so they } \\
\text { never feel lost }\end{array}$ & 0 & 2 & 5 & 9 & 6 & 22 & 3.86 \\
\hline 31 & $\begin{array}{l}\text { Students should become responsible for } \\
\text { themselves completely - particularly in finding their } \\
\text { majors }\end{array}$ & 0 & 2 & 9 & 11 & 0 & 22 & 3.41 \\
\hline 32 & $\begin{array}{l}\text { Students should want to reach out to others instead } \\
\text { of expecting others to come to them }\end{array}$ & 0 & 4 & 7 & 8 & 3 & 22 & 3.45 \\
\hline 33 & $\begin{array}{l}\text { If students are offered an opportunity to participate } \\
\text { in a success program, they should take advantage } \\
\text { of it }\end{array}$ & 1 & 3 & 4 & 9 & 5 & 22 & 3.64 \\
\hline 34 & $\begin{array}{l}\text { Students should be able to help other students and } \\
\text { point them to resources }\end{array}$ & 0 & 2 & 5 & 10 & 5 & 22 & 3.82 \\
\hline 35 & $\begin{array}{l}\text { Students should have a good understanding of the } \\
\text { opportunities available to them - such as extra } \\
\text { things like trips }\end{array}$ & 0 & 1 & 5 & 10 & 6 & 22 & 3.95 \\
\hline 36 & $\begin{array}{l}\text { Students should be open to developing a "Plan B." } \\
\text { Meaning that if you are not accepted into your } \\
\text { original major - or you change your mind, you } \\
\text { have something else to move into }\end{array}$ & 1 & 0 & 8 & 6 & 7 & 22 & 3.82 \\
\hline 37 & $\begin{array}{l}\text { By the end of the first year, students should feel } \\
\text { confident in talking to instructors and people they } \\
\text { look up to or who are in authority }\end{array}$ & 0 & 0 & 8 & 6 & 8 & 22 & 4 \\
\hline 38 & $\begin{array}{l}\text { Students should find out about student } \\
\text { organizations so they can find others with common } \\
\text { interests }\end{array}$ & 1 & 2 & 6 & 8 & 5 & 22 & 3.64 \\
\hline 39 & $\begin{array}{l}\text { Students should get involved and take advantage } \\
\text { of opportunities provided to them }\end{array}$ & 0 & 0 & 8 & 7 & 7 & 22 & 3.95 \\
\hline 40 & $\begin{array}{l}\text { Students should be able to develop academic } \\
\text { maturity }\end{array}$ & 0 & 0 & 11 & 5 & 6 & 22 & 3.77 \\
\hline 41 & $\begin{array}{l}\text { Students should know how to write a proper email } \\
\text { to higher authority }\end{array}$ & 0 & 1 & 5 & 11 & 5 & 22 & 3.91 \\
\hline
\end{tabular}




\begin{tabular}{|c|c|c|c|c|c|c|c|c|}
\hline \multirow{2}{*}{ \# } & \multirow{2}{*}{ Outcome } & \multirow{2}{*}{$\begin{array}{c}\text { Poor } \\
1\end{array}$} & \multirow{2}{*}{$\begin{array}{c}\text { Fair } \\
2\end{array}$} & \multirow{2}{*}{$\frac{\text { Average }}{3}$} & \multirow{2}{*}{$\begin{array}{c}\text { Good } \\
4\end{array}$} & \multicolumn{3}{|c|}{ Excellent Total Responses Mean } \\
\hline & & & & & & 5 & & \\
\hline 42 & $\begin{array}{l}\text { Students should not be scared to take on academic } \\
\text { challenges }\end{array}$ & 0 & 0 & 9 & 6 & 7 & 22 & 3.91 \\
\hline 43 & $\begin{array}{l}\text { Students should begin to learn what major they } \\
\text { might be interested in }\end{array}$ & 0 & 1 & 4 & 10 & 7 & 22 & 4.05 \\
\hline 44 & $\begin{array}{l}\text { Students should know where to go if they need } \\
\text { academic help }\end{array}$ & 0 & 0 & 5 & 8 & 9 & 22 & 4.18 \\
\hline 45 & $\begin{array}{l}\text { Students should have a better feel for not just for } \\
\text { their university but for the whole state as well }\end{array}$ & 2 & 2 & 5 & 7 & 6 & 22 & 3.59 \\
\hline 46 & $\begin{array}{l}\text { Students should know where to go if they need } \\
\text { counseling services }\end{array}$ & 2 & 1 & 4 & 8 & 7 & 22 & 3.77 \\
\hline 47 & $\begin{array}{l}\text { Students should know where to go if they need } \\
\text { career guidance and career services (e.g., resume } \\
\text { building \& interviewing skill development) }\end{array}$ & 0 & 1 & 4 & 12 & 5 & 22 & 3.95 \\
\hline 48 & $\begin{array}{l}\text { Students should have confidence by the end of the } \\
\text { year in terms of adjusting to college, being aware } \\
\text { of resources, and asking for help }\end{array}$ & 0 & 0 & 5 & 10 & 7 & 22 & 4.09 \\
\hline 49 & Students should have school pride & 0 & 0 & 3 & 8 & 11 & 22 & 4.36 \\
\hline 50 & Students should take responsibility for their actions & 1 & 2 & 5 & 6 & 8 & 22 & 3.82 \\
\hline 51 & $\begin{array}{l}\text { Students should feel that staff are truly there to help } \\
\text { them and are not just "collecting a paycheck" }\end{array}$ & 0 & 2 & 6 & 10 & 4 & 22 & 3.73 \\
\hline 52 & Students should feel prepared to schedule classes & 0 & 2 & 7 & 4 & 9 & 22 & 3.91 \\
\hline 53 & $\begin{array}{l}\text { Students should know how to contact their } \\
\text { academic advisors to make advising appointments }\end{array}$ & 1 & 0 & 4 & 9 & 8 & 22 & 4.05 \\
\hline 54 & $\begin{array}{l}\text { Students should be prepared to challenge their } \\
\text { professors }\end{array}$ & 1 & 2 & 9 & 6 & 4 & 22 & 3.45 \\
\hline 55 & $\begin{array}{l}\text { Students should know how to sing their school } \\
\text { song }\end{array}$ & 2 & 1 & 4 & 7 & 8 & 22 & 3.82 \\
\hline 56 & Students should know how to prioritze better & 0 & 1 & 8 & 4 & 9 & 22 & 3.95 \\
\hline 57 & $\begin{array}{l}\text { Students should know their professors' } \\
\text { expectations }\end{array}$ & 0 & 0 & 8 & 9 & 5 & 22 & 3.86 \\
\hline 58 & Students should know how to read the syllabus & 0 & 1 & 6 & 6 & 9 & 22 & 4.05 \\
\hline 59 & Students should know to check their email & 0 & 2 & 4 & 7 & 9 & 22 & 4.05 \\
\hline 60 & $\begin{array}{l}\text { Students should know how to handle themselves } \\
\text { in a professional setting }\end{array}$ & 1 & 1 & 5 & 9 & 6 & 22 & 3.82 \\
\hline 61 & $\begin{array}{l}\text { Students should know their community better - } \\
\text { especially their local community - through service } \\
\text { projects }\end{array}$ & 1 & 3 & 8 & 7 & 3 & 22 & 3.36 \\
\hline 62 & $\begin{array}{l}\text { Students should know what success looks like } \\
\text { because they should have experienced some form } \\
\text { of success by the end of their first year } \\
\text { Students should learn from their mistakes }\end{array}$ & 0 & 2 & 6 & 9 & 5 & 22 & 3.77 \\
\hline 63 & $\begin{array}{l}\text { (academic or personal) and be able to move } \\
\text { forward }\end{array}$ & 0 & 3 & 7 & 8 & 4 & 22 & 3.59 \\
\hline 64 & $\begin{array}{l}\text { Students in the summer bridge program should } \\
\text { have an idea of what is expected of them before } \\
\text { they start their fall courses }\end{array}$ & 0 & 2 & 5 & 9 & 6 & 22 & 3.86 \\
\hline
\end{tabular}


\# Outcome

65 history of campus buildings and the campus in general

Students should be more well-rounded in the

66 sense that they have all the tools and skills necessary to be self-sufficient

Students should want to stay at their institution at the end of their first year

Students in the summer bridge program should

68 feel like they have a leg up or a head start compared to students who start later

69 Students should be able to stay positive despite academic setbacks

Students should be prepared for anything that is

70 thrown their way - opportunities and adverse events

Students should show confidence when dealing

with people in positions of authority

72

Students should try enjoying clubs and/or

fraternities or sororities

73 Students should know they have to find a job after college

74 Students should set their own goals

Students should be able to develop from a dependent person to an independent person

Poor Fair Average Good Excellent Total Responses Mean

$\begin{array}{lllllll}1 & 2 & 3 & 4 & 5 & & \\ 4 & 2 & 5 & 6 & 5 & 22 & 3.27\end{array}$

Students should be aware of the competition to get into some majors

77 Students should participate in research sessions

Students should know how to embrace different cultures

Students should know how to handle adversity, for example, tough times and challenges

$\begin{array}{lllllll}0 & 1 & 8 & 3 & 10 & 22 & 4 \\ 0 & 3 & 2 & 12 & 5 & 22 & 3.86\end{array}$

Students should do the best they can based on

80 their own abilities - and not compare themselves to others

Students should know how to present themselves professionally, for example, wearing proper attire Students should know how to present themselves

82 professionally - for example, using proper body language

83 Students should know how to self-advocate - and not be afraid to ask questions

84 Students should know how to set realistic goals Students should make decisions to make

85 themselves happy rather than making decisions to make other people happy

\begin{tabular}{|c|c|c|c|c|c|c|}
\hline 0 & 1 & 5 & 5 & 11 & 22 & 4.18 \\
\hline 0 & 3 & 4 & 9 & 6 & 22 & 3.82 \\
\hline 0 & 1 & 7 & 7 & 7 & 22 & 3.91 \\
\hline 0 & 1 & 7 & 7 & 7 & 22 & 3.91 \\
\hline 0 & 2 & 3 & 11 & 6 & 22 & 3.95 \\
\hline 0 & 0 & 8 & 5 & 9 & 22 & 4.05 \\
\hline 0 & 1 & 8 & 6 & 7 & 22 & 3.86 \\
\hline 1 & 0 & 8 & 4 & 9 & 22 & 3.91 \\
\hline 0 & 1 & 7 & 8 & 6 & 22 & 3.86 \\
\hline 1 & 3 & 6 & 9 & 3 & 22 & 3.45 \\
\hline 0 & 2 & 3 & 10 & 7 & 22 & 4 \\
\hline 0 & 0 & 6 & 10 & 6 & 22 & 4 \\
\hline 1 & 0 & 9 & 4 & 8 & 22 & 3.82 \\
\hline 0 & 6 & 4 & 5 & 7 & 22 & 3.59 \\
\hline 0 & 4 & 5 & 7 & 6 & 22 & 3.68 \\
\hline 1 & 1 & 4 & 11 & 5 & 22 & 3.82 \\
\hline 0 & 4 & 4 & 7 & 7 & 22 & 3.77 \\
\hline 0 & 1 & 9 & 6 & 6 & 22 & 3.77 \\
\hline 0 & 1 & 7 & 8 & 6 & 22 & 3.86 \\
\hline
\end{tabular}




\begin{tabular}{|c|c|c|c|c|c|c|c|c|}
\hline \multirow{3}{*}{ \# } & \multirow{3}{*}{ Outcome } & & & & & & & \\
\hline & & Poor & Fair & Average & Good & Excellent & Total Responses & Mean \\
\hline & & 1 & 2 & 3 & 4 & 5 & & \\
\hline 87 & $\begin{array}{l}\text { Students should learn how to negotiate and } \\
\text { communicate }\end{array}$ & 0 & 1 & 8 & 4 & 9 & 22 & 3.95 \\
\hline 88 & $\begin{array}{l}\text { Students should know it is difficult to go through } \\
\text { college alone }\end{array}$ & 0 & 0 & 7 & 9 & 6 & 22 & 3.95 \\
\hline 89 & $\begin{array}{l}\text { Students should know it is important to have friends } \\
\text { - a social support system - to help them through } \\
\text { college both in terms of academics and socializing }\end{array}$ & 0 & 0 & 7 & 10 & 5 & 22 & 3.91 \\
\hline 90 & $\begin{array}{l}\text { Students should know to take advantage of } \\
\text { opportunities (such as internships) related to } \\
\text { possible majors }\end{array}$ & 0 & 1 & 7 & 9 & 5 & 22 & 3.82 \\
\hline 91 & $\begin{array}{l}\text { Students should know it is important to realize they } \\
\text { are not alone - they have friends, professors, } \\
\text { support staff, etc. }\end{array}$ & 0 & 1 & 5 & 10 & 6 & 22 & 3.95 \\
\hline 92 & $\begin{array}{l}\text { Students should develop strategies to help } \\
\text { themselves to de-stress }\end{array}$ & 0 & 2 & 4 & 9 & 7 & 22 & 3.95 \\
\hline 93 & $\begin{array}{l}\text { Students should follow a four-year plan when } \\
\text { preparing for their careers }\end{array}$ & 2 & 0 & 9 & 5 & 6 & 22 & 3.59 \\
\hline 94 & $\begin{array}{l}\text { Students should know not to be over-competitive } \\
\text { and be able to accept a setback such as someone } \\
\text { else getting a position they wanted }\end{array}$ & 0 & 3 & 8 & 6 & 5 & 22 & 3.59 \\
\hline 95 & $\begin{array}{l}\text { Students should be exposed to different programs, } \\
\text { presentations, and environments to help them } \\
\text { decide on their ultimate major }\end{array}$ & 0 & 0 & 8 & 7 & 7 & 22 & 3.95 \\
\hline 96 & $\begin{array}{l}\text { Students should know what they have to do to be } \\
\text { desirable to employers }\end{array}$ & 0 & 1 & 5 & 11 & 5 & 22 & 3.91 \\
\hline 97 & $\begin{array}{l}\text { Students should know how to make themselves } \\
\text { distinct }\end{array}$ & 0 & 2 & 10 & 5 & 5 & 22 & 3.59 \\
\hline 98 & $\begin{array}{l}\text { Students should be able to learn the value of critical } \\
\text { thinking }\end{array}$ & 1 & 1 & 4 & 9 & 7 & 22 & 3.91 \\
\hline 99 & $\begin{array}{l}\text { Students should try new things to open themselves } \\
\text { up to new experiences }\end{array}$ & 0 & 0 & 7 & 9 & 6 & 22 & 3.95 \\
\hline 100 & $\begin{array}{l}\text { Students should learn how to keep themselves } \\
\text { healthy }\end{array}$ & 0 & 1 & 11 & 5 & 5 & 22 & 3.64 \\
\hline & & 00 & 100 & 597 & & & & \\
\hline & & $1.64 \%$ & $6.40 \%$ & $26.95 \%$ & $37.23 \%$ & $27.55 \%$ & & \\
\hline
\end{tabular}

